\title{
Economic development and de-carbonization paths: Micro and macro perspectives from Indonesia
}

\author{
Dissertation \\ zur Erlangung des wirtschaftswissenschaftlichen Doktorgrades \\ der Wirtschaftswissenschaftlichen Fakultät der Universität Göttingen
}

vorgelegt von

Mohammad Iqbal Irfany

aus Bogor, Indonesien

Göttingen, 2014 
$\begin{array}{ll}\text { Erstgutachter } & \text { : Prof. Stephan Klasen, PhD } \\ \text { Zweitgutachter } & \text { : Jun.-Prof. Dr. Jann Lay } \\ \text { Drittprüfer } & \text { : Prof. Dr. Bernhard Brümmer }\end{array}$

Tag der mündlichen Prüfung: 14.11.2014 


\section{Summary}

The three essays of this dissertation associate topics on economic development and climate change. All essays discuss the general topic on how to link rising income level and environmental trade-offs, focusing on $\mathrm{CO}_{2}$ emissions as the main source of greenhouse gas. The research offers insight on major drivers and distributions of $\mathrm{CO}_{2}$ emissions as well as how economic growth, energy use and emissions interact.

The first essay measures household carbon footprints from their consumption decision, using Indonesia as an example. It analyzes the pattern, determinants, and decomposition of growing household emissions. This study found that fuel-light and transportation sectors are the most intensive emitters in Indonesia and found a significant disparity of household carbon emissions. It also found that rising income level is the main determinant of the household emission. The decomposition of emissions growth suggests that growing emission between 2005 and 2009 are primarily attributed to the rise in household affluence.

Household distribution may have direct implication in mitigating climate change as any emission reduction policy has more pronounce in a more equal society than in an unequal one. The second essay examines how unequal the households in their emission levels and decomposes emission inequality based on emission sources. Results found that there is an increasing inequality among households and greater portion of emission inequality is contributed by energy-transportation household consumption item.

The third essay investigates the causality nexus between emissions, energy use and economic development along with urbanization and investment employing a number of time series analyses for the Indonesian case. This study indicates the direction of Granger-causality running from output and energy consumption to emissions but not in the opposite direction from emission to output, suggesting the possibility of reducing emission without impeding growth. Energy use could take 
a role as an intervening variable linking output and emissions. Urbanization and capital formation could be carbon-neutral if the country in question has an appropriate urbanization and energy policy dealing with climate change mitigation.

Each essay contributes to the literature on how economic activities (from rising consumption) causes rising emissions as one of main externalities of human development. In the opposite direction, environmental degradation (and/or its mitigating strategies) could also impede further development of human well being. Appropriate policies to stimulate consumption towards less emission intensive expenditures could be implemented although it might be very difficult particularly in developing countries which are struggling with energy efficiency, carbon intensive energy system, insufficient green infrastructures, urban management and public transport systems, as well as high (and not well targeted) fuel subsidies. Those issues could then have substantial relevance not only to Indonesia as a developing economy but also to global debates on how to decarbonize development paths. 


\section{Zusammenfassung}

Die drei Essays dieser Dissertation verbinden Themen der wirtschaftlichen Entwicklung und des Klimawandels. Alle Essays erörtern die allgemeine Frage wie steigende Einkommen und Austauschbeziehungen in Umweltfragen verbunden werden können und konzentrieren sich dabei auf $\mathrm{CO}_{2}$ Emissionen als Hauptverursacher von Treibhausgasen. Die Forschungsarbeit beleuchtet die wesentlichen Treiber und Verteilungswege von $\mathrm{CO}_{2}$ Emissionen und zeigt wie wirtschaftliches Wachstum, Energieverbrauch und Emissionen interagieren.

Im ersten Essay wird am Beispiel Indonesiens der ökologische Fußabdruck von Haushalten durch ihre Konsumentscheidung aufgezeigt. Es werden Muster, Determinanten und die Aufschlüsselung der steigenden Emissionen der Haushalte analysiert. Die Arbeit konnte zeigen, dass die Sektoren mit Leichtöl und im Transportwesen die intensivsten Emittenten in Indonesien sind und ein signifikantes Ungleichgewicht der Karbon-Emissionen zwischen Haushalten besteht. Sie konnte zudem darlegen, dass ein steigendes Einkommen die wichtigste Determinante der Haushaltsemissionen sind. Die Aufschlüsselung des Emissionswachstums legt nahe, dass die steigenden Emissionen zwischen 2005 und 2009 hauptsächlich auf den steigenden Wohlstand der Haushalte zurückzuführen sind.

Eine gerechtere Haushaltsverteilung besitzt -wie jedes Emissionsreduzierungskonzept- einen größeren Effekt zur Abschwächung des Klimawandels in einer Gesellschaft mit weniger Ungleichheit als in einer Gesellschaft mit verstärkter Ungleichheit. Im zweiten Essay wurde die Ungleichheit von Haushalts-Emissionen und die Aufschlüsselung der Emissionsungleichheiten in ihre Ursachen untersucht.. Die Studie zeigt einerseits eine steigende Ungleichheit unter den untersuchten Haushalten als auch dass Energie-Transport hauptsächlich für höhere Emissionsungleichheit verantwortlich ist. 
Der dritte Essay untersucht kausale Zusammenhänge zwischen Emissionen, Energieverbrauch und wirtschaftliche Entwicklung gemeinsam mit Urbanisierung und Investitionen im Falle von Indonesien unter Verwendung von Zeitreihenanalyse. Diese Studie zeigt eine Granger-Kausalität von Output und Energieverbrauch hin zu Emissionen, aber nicht in die entgegengesetzte Richtung von Emissionen zu Output. Dies weist darauf hin die Möglichkeit Emissionen zu reduzieren ohne Wachstum zu hemmen. Damit könnte Energieverbrauch die hauptsächlich verändernde Variable zwischen Output und Emissionen sein. Urbanisierung und Kapitalformation können $\mathrm{CO}_{2}$ neutral sein, wenn das betreffende Land nachhaltige städtische Entwicklung, grüne Investitionen und Energieeffizienz zur Entschärfung des Klimawandels fördert.

Jeder dieser Essays trägt zu der Literatur dazu bei, wie ökonomische Aktivitäten (wie steigender Konsum) steigende Emissionen - eine der wichtigsten Externalitäten menschlicher Entwicklung - bedingen. Andersherum könnte Umweltzerstörung (und/oder entschärfende Maßnahmen) weitere Entwicklung menschlichen Wohlbefindens erschweren. Passende Politikmaßnahmen, der Konsum in Richtung von weniger emissionsintensiven Ausgaben stimulieren, könnten implementiert werden. Aber insbesondere in Entwicklungsländern, die mit Energieeffizienz $\left(\mathrm{CO}_{2}\right.$ intensive Energiesysteme), ungenügend grünen Infrastrukturen, Städteplanung, öffentlichem Nahverkehr und hohen (und ungünstig gezielte) Treibstoffsubventionen zu kämpfen haben, könnte dies schwierig werden. Diese Themen könnten dann nicht nur für Indonesien als entwickelnde Ökonomie sondern auch bei globalen Debatten dazu beitragen, wie Entwicklungspfade weniger kohlenstoffintensiv gestaltet werden können und damit substantielle Bedeutung erlangen. 


\section{Acknowledgements}

I am grateful to the assistance from a number of people. First and foremost, I owe the greatest intellectual debt to my supervisor, Prof. Stephan Klasen, PhD, for the guidance, encouragement, patience, and giving me opportunities during the course of my PhD research. His support, trust, and understanding have kept me strong until the end of my dissertation. I cannot imagine a better and more intelligent supervision than him. Special gratitude is also extended to Jun-Prof. Jann Lay as the second supervisor for his valuable comments including at the project meetings and presentations. I further wish to express my sincere thanks to Prof. Bernhard Brümmer for volunteering to be my third supervisor and his quick insights during discussions.

I must also express my special thanks to Experts I Erasmus Mundus for the $\mathrm{PhD}$ grant, without their funding this research would not have been possible. I would also like to thank to the Göttinger Graduiertenschule Gesellschaftswissenschaften (GGG), which provided a further assistance during the last months of my dissertation.

I would like to thank my colleagues in the project of "Low Carbon Development Paths" (EntDekEn), Dr. Nicole Grunewald, Moises Neil Serino, and Sebastian Renner. With them I presented the preliminary findings in various international conferences, seminars, workshops, and expert meetings. My appreciation also goes to the member of the project on "Long-term Land Use, Poverty Dynamics and Emission Trade-offs in Sulawesi and Jambi" (CRC 990, C04).

I would like to extend my sincere thanks to Dr. Felicitas Nowak-Lehmann Danzinger, who has helped me with the econometric analysis. I would also like to acknowledge to all members of the Chair of Development Economics, especially Syamsul H. Pasaribu, Bumi Camara, Deniey A. Purwanto, Junaid Ahmed, Rivayani, Dewi Nur Asih, Radjius Idzalika, among others for valuable discussions during $\mathrm{PhD}$ courses towards the final day of dissertation, to the students and IT assistants who have supported me with academic, technical and administrative works. To Jennifer Phillips, I am grateful for her excellent English proofreading.

Furthermore, I would like to express a big thanks to all people who directly and indirectly supported me with writing this doctoral thesis as well as living in Göttingen and numerous people who I cannot explicitly mention here.

Back home, this work is attributed to my beloved mother $\mathrm{Hj}$. Iyah Sulasiah, for her love and praying, and to the big family of Nurul Hidayah and Uqon Bulqoeny descendants. Finally, my work and life in Göttingen would not have been written without the encouragement, spirit, practical supports and happiness from my small family: Rosa Samrotul Fauzah, and our sweetest children, Salwa and Haqqi. This is dedicated to all of you. 


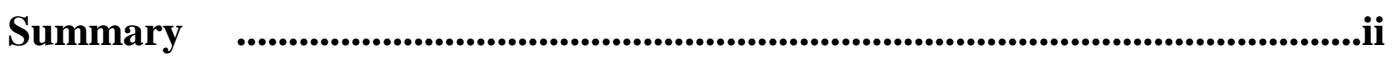

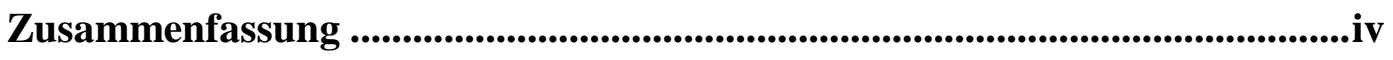

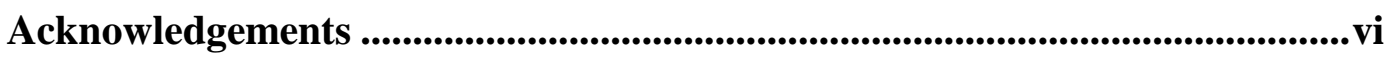

Table of Contents ...........................................................................................................vii

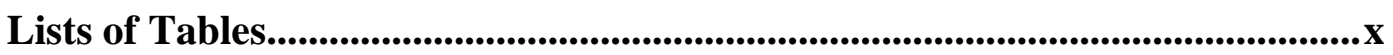

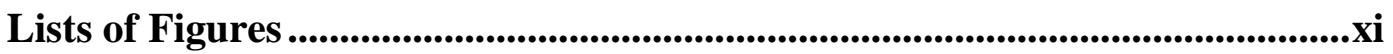

Lists of Abbreviations...........................................................................................xii

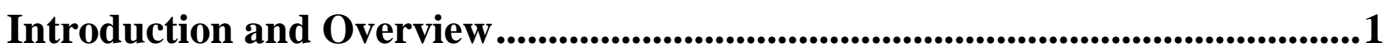

Chapter 1 : Affluence and emission trade-offs: evidence from Indonesian household carbon footprint ...........................................................7

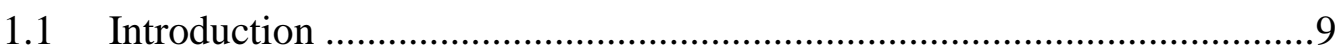

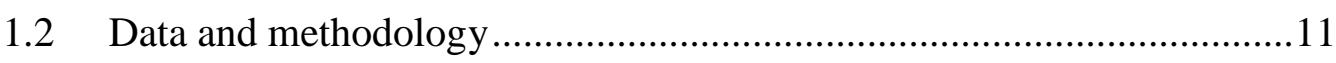

1.2.1 Measuring emission intensities and deriving the household carbon

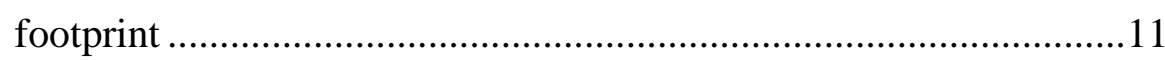

1.2.2 Drivers of the household carbon footprint.....................................15

1.2.3 Decomposing the changes in the carbon footprint ........................17

1.2.4 Expenditure elasticites of emission .............................................18

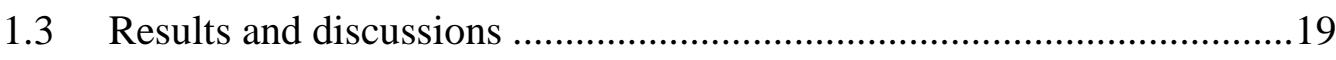

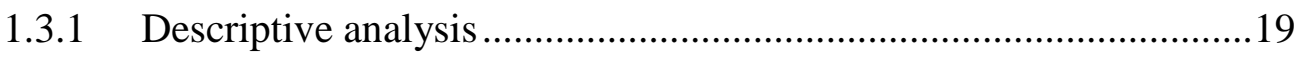

1.3.2 Drivers of household carbon footprint.........................................26

1.3.3 The decomposition analysis of emission growth.............................30

1.3.4 Expenditure elasticities of emission .............................................31

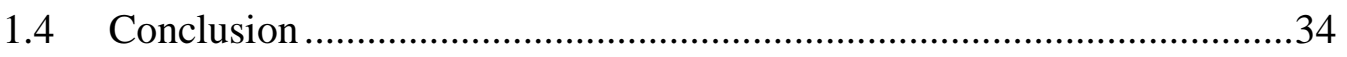


Chapter 2 : Inequality in emissions: Evidence from Indonesian households ..................................................................................................337

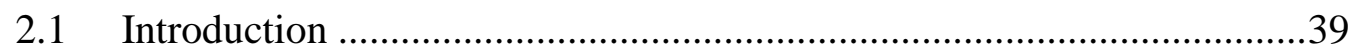

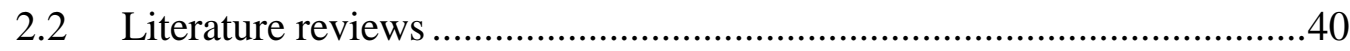

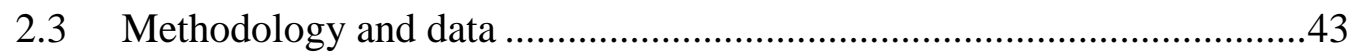

2.3.1 Basic measures of emission inequality ........................................43

2.3.2 Emission concentration index vs. expenditure Gini .......................44

2.3.3 Inequality decomposition into emission sources ...........................45

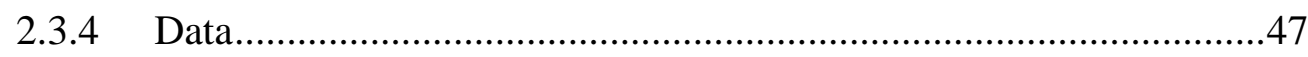

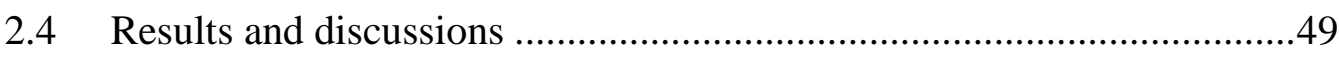

2.4.1 Household characteristics and emission share...............................49

2.4.2 Emission inequality measure by household characteristics..............51

2.4.3 Emission inequality and its relationship with the expenditure

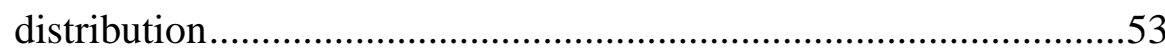

2.4.4 Decomposition and simulation of $\mathrm{CO}_{2}$ inequality by emission

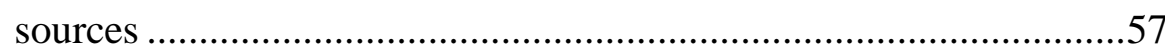

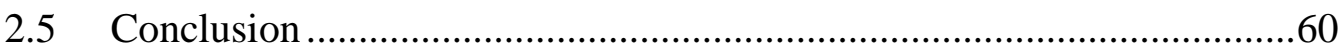

\section{Chapter 3 : Examining causality between economic development, energy} consumption, and emissions in Indonesia ..................................63

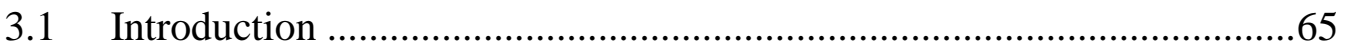

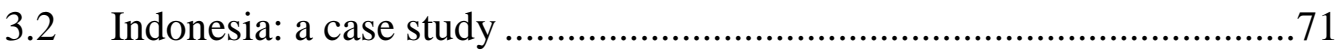

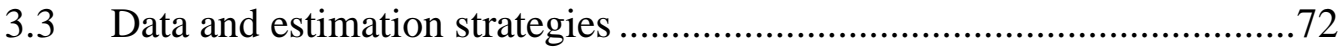

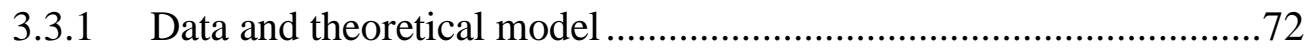

3.3.2 Tests for univariate integration, multivariate cointegration, and

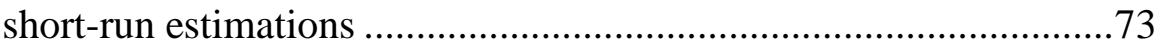

3.3.3 Long-run estimation and long-run Granger-causality: DOLS..........76 
3.3.4 Extended short-run analysis: Augmented-VAR estimation .77

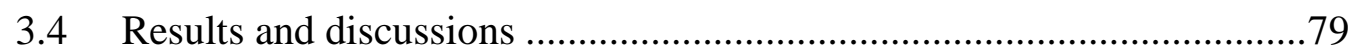

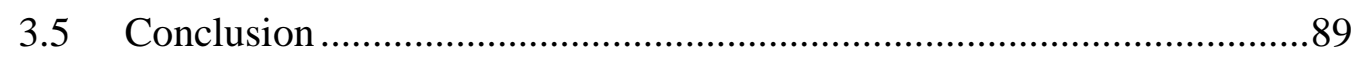

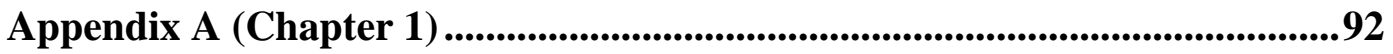

Appendix B (Chapter 2) .........................................................................................113

Appendix C (Chapter 3) ...........................................................................117

Bibliography .............................................................................................................................128 


\section{Lists of Tables}

Table 1.1 Estimate private consumption: Susenas vs. National Account (Rp)...21

Table $1.2 \mathrm{CO}_{2}$ intensity of economic sectors: top 10 and bottom $10 \ldots \ldots \ldots \ldots \ldots \ldots . . .22$

Table 1.3 The determinants of household carbon footprint, 2005-2009............27

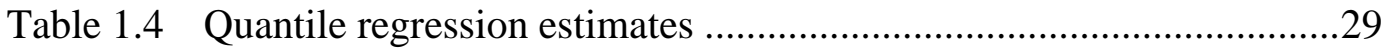

Table 1.5 Expenditure elasticities of emission....................................................32

Table 1.6 Share of $\mathrm{CO}_{2}$ emission and changes once total expenditure

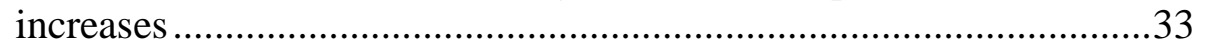

Table 2.1 Per capita emission and emission share .............................................50

Table 2.2 Per capita emission vs. per capita expenditure: contribution

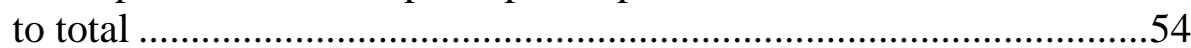

Table 2.3 Concentration of $\mathrm{CO}_{2}$ emissions vs. expenditure Gini........................55

Table 2.4 Gini decomposition by emission sources.........................................57

Table 2.5 Gini decomposition by per capita expenditure category .....................58

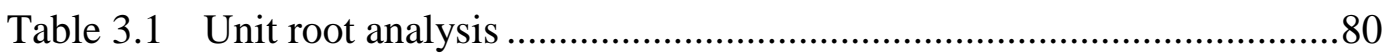

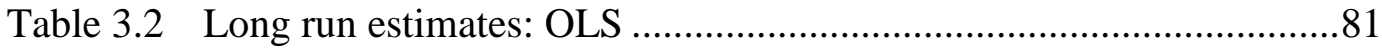

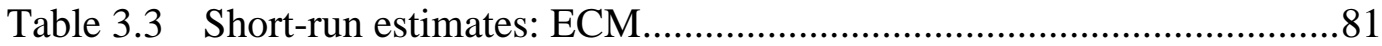

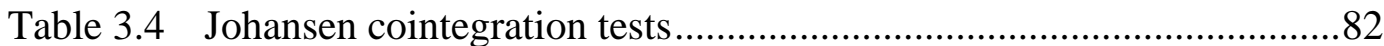

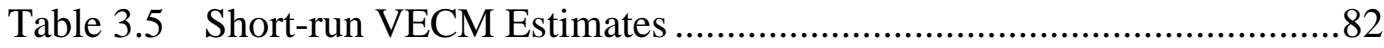

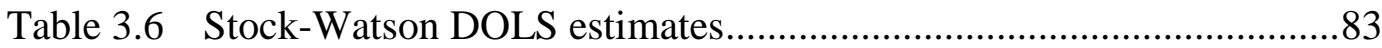

Table 3.7 Error correction term and long-run Granger causality........................84

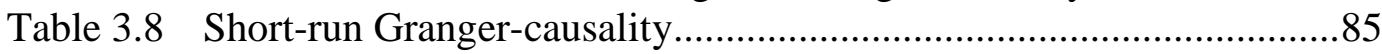




\section{Lists of Figures}

Figure 1.1 Emission Analysis - Expenditure Approach....................................13

Figure 1.2 Expenditure share per consumption category................................20

Figure 1.3 Emissions in Expenditure Subgroup (2005 and 2009) ....................23

Figure 1.4 Carbon footprint by household affluence quintile, education attainment, and region (2005 and 2009) ........................................24

Figure 1.5 Emission shares to expenditure shares by quintile

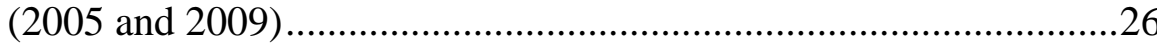

Figure 1.6 Decomposition of $\mathrm{CO}_{2}$ emission growth ......................................30

Figure 2.1 Per capita emission by affluence quintile (2005 and 2009).............49

Figure 2.2 Emission inequality measures across quintiles............................52

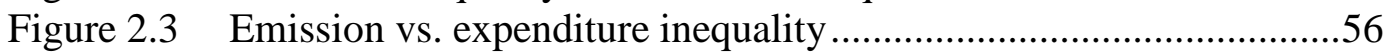

Figure 2.4 Sources of inequality: emission vs. expenditure ............................59

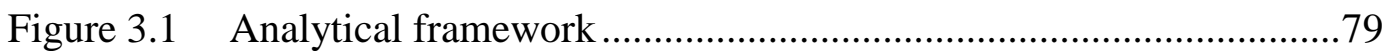

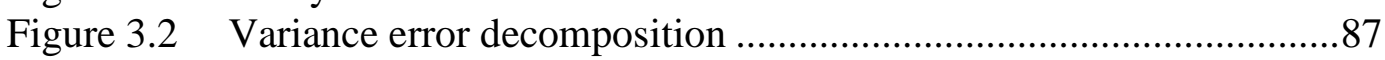

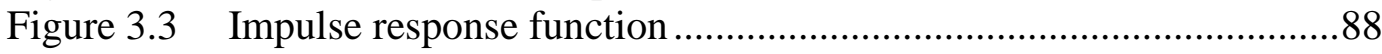




\section{Lists of Abbreviations}

\begin{tabular}{|c|c|}
\hline $\mathrm{ADF}$ & Augmented Dickey-Fuller \\
\hline AIC & Akaike information criterion \\
\hline BPS & Badan Pusat Statistik (the Indonesian Central Board of Statistics) \\
\hline $\mathrm{CO}_{2}$ & Carbon dioxide \\
\hline CUSUM & Cumulative sum \\
\hline CUSUMSQ & Cumulative sum square \\
\hline DLNCO2CP & First difference in logarithm of per capita $\mathrm{CO}_{2}$ emissions \\
\hline DLNECP & First difference in logarithm of per capita energy use \\
\hline DOLS & Dynamic ordinary least squares \\
\hline ECM & Error correction model \\
\hline $\mathrm{EKC}$ & Environmental Kuznets Curve \\
\hline Exp. & Expenditure \\
\hline GDP & Gross Domestic Product \\
\hline GHG & Green house gases \\
\hline GTAP & Global Trade Analysis Project \\
\hline GTAP-E & Global Trade Analysis Project - Environmental account \\
\hline $\mathrm{HH}$ & Household \\
\hline HHSize & Household size \\
\hline HQ & Hannan-Quinn information criterion \\
\hline IEA & International Energy Agency \\
\hline $\mathrm{IO}$ & Input output \\
\hline IRF & Impulse response function \\
\hline $\mathrm{kg}$ & Kilogram \\
\hline LMDI & Logarithmic mean divisia index \\
\hline $\mathrm{LNCO} 2 \mathrm{CP}$ & Natural logarithm of per capita $\mathrm{CO}_{2}$ emissions \\
\hline LNECP & Natural logarithm of per capita energy use \\
\hline LNK & Natural logarithm of capital formation \\
\hline LNU & Natural logarithm of urban population \\
\hline LNYCP & Natural logarithm of per capita output \\
\hline LR & Log likelihood criterion \\
\hline Obs. & Observations \\
\hline OECD & Organisation for Economic Co-operation and Development \\
\hline OLS & Ordinary least square \\
\hline OPEC & Organization of the Petroleum Exporting Countries \\
\hline $\mathrm{Rp}$ & Rupiah (the official currency of Indonesia) \\
\hline $\mathrm{SC}$ & Schwarz criterion \\
\hline
\end{tabular}

Susenas Survey Sosial Ekonomi Nasional (National Socioeconomic Survey) 
UK

UN

UNFCCC

US

USD

VAR

VECM

VED

WDI
The United Kingdom

The United Nation

United Nations Framework Convention on Climate Change The United States

The United States Dollar

Vector auto regressive model

Vector auto correction model

Variance error decomposition

World Development Indicators 


\section{Introduction and Overview}

"Green is a process, not a status. We need to think of 'green' as a verb, not an adjective." (Daniel Goleman) ${ }^{1}$

The environmental trade-off of development is one of the pressing challenges of the global world, particularly since the industrial revolution. While income growth is a reflection of rising welfare and one of main dimensions of human development, reducing environmental damage is problematic as it could be associated with hampering economic growth and long-run welfare. Formulating a roadmap towards a low carbon economy that cuts the climate-change trade-off without impeding economic growth is one of biggest tasks both in academic discourses and in practices.

Green house gas (GHG) emissions, of which $81 \%$ was $\mathrm{CO}_{2}$ emissions in 2009 (UNFCCC, 2010), are regulated based on its country of production (e.g. WDI reports from World Bank, 2012). However, though they are produced in one country they are often consumed elsewhere. Consumers thus partially contribute to the emissions. Given this fact, apart from the production side, the demand side analysis of growth and emission trade-offs is also important in order to account for the real emissions' contribution and to analyze the drivers of rising emissions that are important in climate change mitigations.

Numerous studies (e.g. Wier et al., 2001; Kok et al., 2006; Tukker and Jansen, 2006; Hertwich and Peters, 2009) fall into this nexus, especially in measuring GHG emissions from household consumption. While relatively abundant investigations have been done for developed countries (e.g. Kenny and Gray, 2009; Girod and de Haan, 2010; Murthy et al., 1997; Parikh et al., 1997), less research has been done regarding developing countries. Hypothetically, increasing

\footnotetext{
1 "Ecological Intelligence: How Knowing the Hidden Impacts of What We Buy Can Change Everything" (New York: Broadway Books, 2009; available at goo.gl/dnjmwV. Accessed: September 2014).
} 
standards of living is accompanied by changes in consumption patterns that then cause higher $\mathrm{CO}_{2}$ emissions from burning fossil fuels (oil, gas, and coal) for household activities, transportation, and other energy-related expenditures. In other words, socio-economic development has been closely related to energy consumption, as it is an important element in the transition from traditional to modern economy (Schäfer, 2005; Kok et al., 2006). While transitions from traditional to modern sources of energy are intended to improve efficiency, such improvements are also compensated by higher energy requirements that are closely related to lifestyle changes (Pachauri, 2004; Pachauri and Jiang, 2008).

As witnessed in macro level (cross-country) studies, similar empirical evidence can be found in the differences between consumption-related household carbon footprints. Such studies typically indicated the significant heterogeneity of household carbon emissions based on their characteristics. For instance, in the UK case, Druckman and Jackson (2009) found that carbon footprints differ widely between the richest subgroups (called 'prospering suburbs'), which have almost two-thirds of total $\mathrm{CO}_{2}$ emissions, and the poorest group (called 'constrained by circumstances'). Other similar studies such as Wier et al. (2001) investigating Danish households, Kerkhof and Moll (2009) in the UK, the Netherlands, Sweden, and Norway; Bin and Dowlatabadi (2005) and Weber and Matthews (2008) in the US case; found that household emissions widely differ depending on different characteristics, and that income has been found to be the single most important determinant of rising household carbon footprints (Murthy et al., 1997; Parikh et al., 1997; Weber and Matthews, 2008). For developing economies, studies done for households in China (e.g. Pachauri and Jiang, 2008), India (Parikh et al., 1997; Pachauri, 2004; Lenzen et al., 2006), and Brazil (Lenzen et al., 2006), also find remarkable heterogeneity within those countries.

Apart from the lifestyle and consumption changes which are likely to raise $\mathrm{CO}_{2}$ emissions as households become more affluent, for some developing countries, including Indonesia, the method of energy production (renewable energy sources) as well as green infrastructures and technology (including energy subsidy regimes) may also play a role in widening the emission disparities across 
household groups. The differences in carbon footprint between household groups in developing countries even tend to be more obvious than in richer countries, as Pachauri (2004) found in the Indian case. Taking fuel subsidies as an example for the Indonesian case, the inappropriate subsidy allocation allows for increasing households' incomes (ability to consume) to easily translate (both directly and indirectly) into consuming high carbon intensive expenditure items provided by the subsidies. The study of emission and income inequality within household groups and the emission inequality decomposition based on expenditure/emission source is also fruitful. The main idea is to capture how much the level and distribution of household affluence and the consumption of emission intensive items affect overall emission inequality.

Last but not least, the above household level analysis should be reconciled with the historical macro perspective of how the income-emissions relationships were developed. Apart from the comparison, one of central ideas deals with how the uni-direction causality assumption does not satisfy the evidence, rather it is necessary to look at the Environmental Kuznets Curve (EKC) hypothesis in examining the growth-emissions relationship (e.g. Coondoo and Dinda, 2002; Dinda and Coondoo, 2006; Soytas et al., 2007; Zhang and Cheng, 2009; Tiwari, 2011). Among the main debates in this discourse is that the uni-directional causality assumption could be over-simplistic, given the fact that emissions may affect both consumers' wellbeing as well as income creation leading to further consumption and output. Another point of interest is that the conventional assumption does not distinctively highlight the dynamic process of change, which is also essential in the context of growth-emissions relationships. Hence, it is valuable to employ causality tests to determine the relationship direction between income and emissions using two or more series of variables. For the policy perspective, understanding this causality will allow us to know whether efforts to reduce emissions can further impede economic growth.

Addressing those issues will allow us to identify the determinants, distribution, and (direction of) causality in the growth-emission relationship, which may have great relevance to Indonesian and global debates on reducing the carbon intensity 
of development paths, both for the methodological and policy perspective. From the analytical perspective, this research could allow us to understand the factors, contributors to, and distribution of emissions from the in-depth micro level analysis as well as contribute to further research on green growth. From a policy perspective, it could allow us to examine, monitor, and formulate appropriate lowcarbon development policy interventions.

As briefly mentioned, this thesis consists of three chapters that cover research on the determinants of the rising household carbon footprint, patterns and sources of inequality in the micro level analysis, and a macro level analysis of the direction of causality (mainly) between economic growth and emissions.

Chapter 1, titled Affluence and emission trade-offs: Evidence from the Indonesian household carbon footprint, analyzes the pattern and the determinants of the growing household carbon footprint in Indonesia. To measure the household emissions, it combines the national input-output GTAP's emission database to generate sectoral $\mathrm{CO}_{2}$ emission intensities and matched these intensities with two waves of national expenditure surveys from 2005 and 2009. We then use this household $\mathrm{CO}_{2}$ emissions level information for investigating the drivers of the rise in emissions from the micro perspective. Comparing $\mathrm{CO}_{2}$ intensities, the results show that the 'fuel-light' and transportation sectors are the most intensive emitters in Indonesia. We also found a significant difference of household carbon emissions when comparing between affluence level, region, and education. The regression analysis suggests that income is the main determinant of the household carbon footprint. Although other household characteristics determine the variation in emissions, it is shown that varying affluence levels differ significantly in terms of their carbon footprint. The decomposition analysis confirms that changes in emissions are primarily due to the income effect. The analysis of expenditure elasticities suggests that the rise in household emissions is mainly caused by a general volume increase in overall household consumption, and not by shifting the share of expenditure amongst the consumption baskets.

Chapter 2, titled Inequality in emissions: evidence from Indonesian households, using the same generated database as Chapter 1, investigates the 
distribution in per capita $\mathrm{CO}_{2}$ emissions by employing various measures of inequality and then comparing the differences between the emission and expenditure inequality indices. It also decomposes emission inequality based on household affluence level, socio-demographic characteristics as well as sources of emissions to assess the patterns and drivers of inequality. First, disaggregating emission inequality into any particular within group inequality based on different household characteristics assumes that different characteristics would have different within-inequality measures in emissions. Second, decomposing inequality by emission sources aims to measure the contribution of emission shares and to study the marginal effects of changes in different emission sources on the change in overall emission inequality. Results from the first case show that as per capita expenditure increases, within inequality in emissions tends to decline until the middle quintiles where it then increases in expenditure level and worsens emission inequality until the richest households. Results from the decomposition of inequality suggest that energy-transportation is the dominant contributor to overall emission inequality.

\section{Chapter 3, titled Examining causality between economic development, energy} consumption, and emissions in Indonesia, is a macro level and multivariate time series analysis that investigates the causality nexus between emissions, energy use and economic performance along with urbanization and capital formation (investment activity). It employs various time-series econometric techniques ranging from single equation ECM, VECM, and DOLS to investigating the presence and direction of long-run causality between the three variables. When adding urbanization and capital formation, we employ a modified (augmented) VAR as suggested by Toda and Yamamoto (1995) given the different order of integrations among variables. Various cointegration analyses reveal consistent findings suggesting long-run causality amongst variables. We also find that the direction of long-run Granger-causality is running from output and energy consumption to emission but not in the opposite direction from emission to output in the long-run, suggesting the possibility of reducing emissions without impeding growth. In the short-run, the Toda-Yamamoto approach generally suggests similar indication of uni-directional Granger causality running from output to emission 
but not in the opposite direction, indicating that clean growth is also possible in the short-run. The empirical evidence of a uni-directional causality from urbanization and capital formation to energy uses but not from urbanization to emission indicates that urbanization and capital formation will increase energy use but could be carbon-neutral if the country in question has a sustainable urban management and energy system. Results also show that the greater variations in emissions in the longer period are mainly due to Indonesia's rising economic performance.

Each essay contributes to the literature on green growth and provides a basis for substantial investigations using Indonesia as an example. The essays might have a significant relevance not only to Indonesia itself but also to global debates on how to de-carbonize development paths and how to make development compatible with environmental sustainability.

For future research, these studies recommend using different approaches, as well as utilizing other emission sources (production and land use changes). Incorporating other possible relevant (or country/regional specific) variables as control variables could also be fruitful on how to analyze the link between economic development and emission both from a micro and macro level analysis. 
Chapter 1: Affluence and emission trade-offs: evidence from Indonesian household carbon footprint 


\title{
Affluence and emission trade-offs: evidence from Indonesian household carbon footprint
}

\begin{abstract}
This study estimates the Indonesian household emissions that are attributed from their expenditures in 2005 and 2009 to analyze the pattern, distribution, and drivers of the household carbon footprint. Employing Input Output-EmissionExpenditure analysis, we found that fuel-light and transportation are the two most intensive emitting expenditure categories in Indonesia, and found a significant difference in household carbon emissions between different affluence levels, regions, and education levels. We also found that the income level is the main determinant of household emissions. The decomposition analysis confirms that changes in emissions are mainly due to the income effect between the two periods, while expenditure elasticities analysis suggests that the rise in household emissions is mainly caused by the overall volume rise in total household expenditure, and not by shifting consumption shares amongst consumption baskets.
\end{abstract}

Keywords: carbon footprint, household, Indonesia 


\subsection{Introduction}

Climate change is one of the pressing challenges of the world, including Indonesia. In this emerging economy, the middle-income group has been growing and consuming more goods and services, causing households to directly and indirectly contribute to the rising emissions. However, quick glances at the literature on household carbon footprint show that most analyses were conducted in the developed countries compared to developing countries (e.g. Kenny and Gray (2009), Girod and de Haan (2010), Parikh et al. (1997), Murthy et al. (1997)). With that in regard, this study will fill in that gap by estimating the average household carbon footprint of Indonesia as one of the emerging economies.

In order to calculate the environmental consequences of household activities, Lenzen (1998a) analyses energy and green house gas (GHG) in the case of Australian households. It was found that the direct expenditure of fuels and electricity represent of about 30\% (17\%) of the overall energy expenditure (the overall GHG expenditure), the remainder of which was indirectly spent on nonenergy commodities. Bin and Dowlatabadi (2005), using the US Consumer Lifecycle Approach to energy use and associated $\mathrm{CO}_{2}$ emissions, estimates that more than $80 \%$ of the energy used and the $\mathrm{CO}_{2}$ emitted in the US are a consequence of consumer demands and their supporting activities. Kenny and Gray (2009) show that the total $\mathrm{CO}_{2}$ emissions of Irish households are associated with home energy usage (42\%), transportation (35\%), air travel and other fuel intensive leisure activities (21\%). Moreover, using the Swiss household expenditure database, Girod and de Haan (2010) found that the most important consumption categories are living, transportation, and foods, which together account for almost $70 \%$ of overall GHG emissions.

Apart from just emissions measurement, there are several studies that investigate the determinants of the household carbon footprint using various methods. Taking an example of a cross-country perspective, Lenzen et al. (2006) focused on the investigation of the Environmental Kuznets Curve (EKC) hypothesis, which 
proposes an inverted U-shaped relationship between per capita output and environmental degradation, at the household level. However, their findings do not support the EKC hypothesis. They argue that household energy use monotonically rise due to rising consumption and show that no turning point is observed.

Household emission patterns may differ due to differences in household characteristics, including their incomes. Income portfolios and levels as well as the related patterns of consumption and production are considered as the important determinants. Findings show that income is the main driver of carbon footprints (Murthy et al., 1997, Parikh et al., 1997; Li and Wang, 2010). For instance, Parikh et al. (1997), for the Indian case analyzed expenditure patterns by income groups as well as what the $\mathrm{CO}_{2}$ consequences were. Their approach is based on an input-output (IO) analysis, which uses an expenditure database examining the direct and indirect $\mathrm{CO}_{2}$ emissions from household expenditure items. They found that carbon emissions were attributed to private consumption (of about 62\%), direct household consumption (12\%), and the remaining to indirect consumption of intermediates. It is also indicated that the rich have a more carbon-intensive lifestyle than the poor. Apart from income, numerous studies found that household characteristics also matter as driver of their emissions, such as household size, education, age of household head, and other demographic factors (e.g. Li and Wang, 2011, Wier et al., 2001). Additionally, another study from Pachauri and Spreng (2009) also suggest household energy requirements, increasing emission intensity in food and agricultural sectors are among other drivers.

This study attempts to answer the following issues. First, what are the characteristics of $\mathrm{CO}_{2}$ emissions of households in Indonesia? How do they differ in terms of affluence and other household characteristics? Second, what are the main determinants of the growing carbon footprint in a fast growing emerging country, and which consumption categories are the most carbon intensive? Third, how will carbon emissions develop over time when household incomes increase?

Our findings can be summarized as follows. We found that fuel-light and transportation expenditures are the two most carbon intensive items. This study 
also indicates the variations of household carbon footprint in terms of their affluence level as well as other household characteristics such as urbanity and educational attainment. Household income (proxied by expenditure) is found as the main driver of the household carbon footprint, which is confirmed by the decomposition of emission growth between 2005 and 2009 suggesting that rising emissions are mainly attributed to the income effect. The expenditure elasticity of emissions proposes that the surging increase in household carbon footprint is mainly due to the overall volume rise in expenditure, and not to the shifting consumption shares of the consumption basket.

\subsection{Data and methodology}

We use numerous databases including sectoral emissions from the Global Trade Analysis Project-Environmental Account (GTAP-E), the Indonesian Input Output (IO) table, and the Indonesian household expenditure survey (Susenas) from the 2005 and 2009 database. The GTAP-E includes $\mathrm{CO}_{2}$ emissions from fossil fuels combustion (coal, oil, gas, petroleum products) and cement production, but does not include emissions from land use change, which is also important for the Indonesian case (PEACE, 2007). We combine the IO analysis with GTAP-E and Susenas to calculate the indirect and direct carbon emissions of households. This approach is appropriate to analyze the environmental impact with respect to different household characteristics (Kok et al., 2006). Expenditure amounts on consumption items in Susenas are multiplied with the corresponding value of the emission intensity. Each consumption item in the expenditure survey is categorized into a specific economic sector.

\subsubsection{Measuring emission intensities and deriving the household carbon footprint}

This study only focuses on $\mathrm{CO}_{2}$ emissions since it represents the largest share of GHG emissions (UNFCCC, 2010) ${ }^{2}$. To estimate an Indonesian household's

\footnotetext{
${ }^{2}$ Also, the emissions associated with land use changes cannot easily be attributed to households particularly since much of the land use change is associated with cash crop production for exports (such as palm oil, rubber, or cocoa).
} 
carbon footprint, we follow Lenzen (1998)'s approach, which computed carbon embedded in an Australian household's final consumption. We basically trace the $\mathrm{CO}_{2}$ emitted by the final consumption element back to its intermediates and factor both the direct and indirect emissions that occur from household expenditure. Applying the expenditure approach, Figure 1.1 shows how $\mathrm{CO}_{2}$ intensities of goods and services in a given economy can be traced using IO analysis. ${ }^{3}$

In the first step, $\mathrm{CO}_{2}$ intensities of each Indonesian IO sector (in the local currency unit, Rp) were estimated. We assume the Single Region Model, which suggests that emissions of both imported and domestic products are not estimated differently assuming that they are produced by the same technology. One can argue that products in the developed world are produced more efficiently and may have lower emission intensities. On the other hand, imports require transport that might increase emissions. However such issues are beyond the scope of this study ${ }^{4}$. In this study, the $\mathrm{CO}_{2}$ emission intensities were derived using the Leontif inverse of the IO table multiplied by the carbon intensities derived from GTAP.

\footnotetext{
${ }^{3}$ There are three available methods in accounting the environmental load of GHG emissions released by household consumption which are primarily from IO analysis, including the basic approach, the expenditure approach and the process approach (Kok et al., 2006). First, 'the basic approach' is a pure top-down approach as it simply utilizes national accounts to calculate energy requirements (emissions). One particular drawback of this approach is that it does not consider the possibility that the price of energy may vary between sectors. Second, 'the expenditure approach' combines IO-energy/emission account with the expenditure database. Here, the consumption database is more disaggregated as it is taken from household expenditure surveys instead of the consumption database from the IO table. Third, the 'process or hybrid approach' combines the IOenergy/emission account with process analysis, which proposes that lifecycle process of any product (consumption item) is denoted in physical terms (e.g. energy use per unit materials or energy use per transport distance, etc.). Although it could be more accurate as it avoids truncation errors, this process is more time consuming. In this study, the expenditure approach is utilized since we will use a national household expenditure database.

${ }^{4}$ There is also another version of input-output table called World IO Data (http://www.wiod.org) that has a set of synchronized use and supply tables, along with international trade database. However the dataset are quite aggregated with just only consists 38 industrial sectors as well as final household consumption sector. This study does not employ it partly to allow more flexibility to construct emission intensities. In this regard, the fact that the Indonesian IO table has 175 sectors allows us to have the more disaggregated sectoral emission intensities to be matched with consumption items in Susenas.
} 


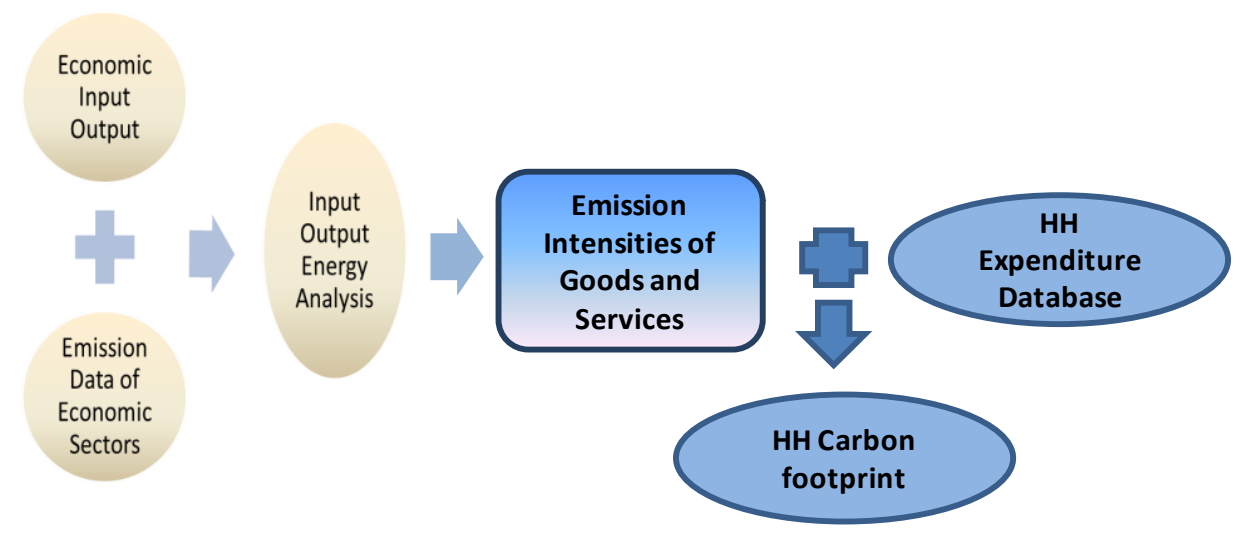

Figure 1.1 Emission Analysis - Expenditure Approach

Source: modified from Kok et al. (2006).

In the second step, the $\mathrm{CO}_{2}$ emission intensities of each economic sector were matched to their household expenditure category. We refer to the Susenas questionnaire and GTAP sector classification (Huff et al., 2000) to match these sectors. Consumption expenditures from Susenas are then multiplied to the derived $\mathrm{CO}_{2}$ emission intensity, and then by summing them up we get the household carbon footprint ${ }^{5}$.

As the Single Region Model assumes that the domestic energy and environmental technologies used in production are the same as abroad, we just calculate emissions from direct and indirect $\mathrm{CO}_{2}$ emissions from final demand of industrial sectors. First, the direct $\mathrm{CO}_{2}$ emission intensities from final demand, $\mathrm{CO}_{2}^{\mathrm{fd}}$, are expressed by the following:

$\mathrm{CO}_{2}^{\mathrm{fd}}=\mathrm{c}^{\prime} \mathrm{E}^{\mathrm{fd}} \mathrm{y}$

where c', $E^{\mathrm{fd}}$, and y represent the inverse of the emissions coefficient vector, the matrix of energy use, and the vector of final demand.

\footnotetext{
${ }^{5}$ The overview of data matching scheme of the IO sectors with the household expenditure categories via the GTAP energy intensity is outlined as follows. There are 175 economic sectors in Indonesia, which were mapped using the GTAP sectors and aggregated into 57 sectors (Huff et al., 2010). The data on household expenditure is rather disaggregated, consisting of around 340 expenditure categories.
} 
Second, the indirect emissions, $\mathrm{CO}_{2}$ ind, can be divided into three sources of emissions: (a) from domestic production of domestic final demand; (b) from imported intermediates; (c) from imported products for domestic final demand (excluding exports). Then, the sectoral $\mathrm{CO}_{2}$ emission intensity can be estimated by multiplying each sector's final demand, $y$, the transposed emissions coefficients, $c^{\prime}$, the matrix of industrial energy use, $E^{\text {ind }}$, and with the domestic Leontief inverse $(\mathrm{I}-\mathrm{A})^{-1}$, as follows:

$$
\begin{aligned}
\mathrm{CO}_{2}^{\text {ind }}= & \mathrm{c}^{\prime} \mathrm{E}^{\text {ind }}\left[(\mathrm{I}-\mathrm{A})^{-1} \mathrm{y}_{\neq \exp }+\left(\left(\mathrm{I}-\mathrm{A}_{\mathrm{tot}}\right)^{-1}-(\mathrm{I}-\mathrm{A})^{-1}\right) \mathrm{y}_{\neq \exp }+\right. \\
& \left.\left(\mathrm{I}-\mathrm{A}_{\mathrm{tot}}\right)^{-1} \mathrm{y}_{\text {imp }_{\neq \exp }}\right]
\end{aligned}
$$

where $A_{\text {tot }}=\mathrm{A}+\mathrm{A}_{\mathrm{imp}}$, and $\mathrm{y}_{\mathrm{tot}}=\mathrm{y}+\mathrm{y}_{\mathrm{imp}}$.

$\mathrm{y}_{\neq \exp }$ and I represent domestic final demand and identity matrix, while A indicates the matrix of technical coefficients that reflects the intermediates' contribution to one unit of final output.

Hence the direct and indirect $\mathrm{CO}_{2}$ emission intensities can be calculated as follows:

$$
\begin{aligned}
\mathrm{CO}_{2}= & \mathrm{CO}_{2}^{\mathrm{fd}}+\mathrm{CO}_{2}^{\text {ind }} \\
\mathrm{CO}_{2}= & \mathrm{c}^{\prime}\left\{\mathrm{E}^{\mathrm{fd}} \mathrm{y}+\mathrm{E}^{\mathrm{ind}}\left[(\mathrm{I}-\mathrm{A})^{-1} \mathrm{y}_{\neq \exp }+\left(\left(\mathrm{I}-\mathrm{A}_{\mathrm{tot}}\right)^{-1}-(\mathrm{I}-\mathrm{A})^{-1}\right) \mathrm{y}_{\neq \exp }+\right.\right. \\
& \left.\left.\left(\mathrm{I}-\mathrm{A}_{\text {tot }}\right)^{-1} \mathrm{y}_{\mathrm{imp} \neq \exp }\right]\right\}
\end{aligned}
$$

Finally, the above carbon intensities (in $\mathrm{kg} \mathrm{CO}_{2} / \mathrm{Rp}$ ) of each sector are multiplied with the household consumption recorded from Susenas (in Rp) for the respective category and then the products from all categories are summed up for each household. The carbon footprint $\mathrm{CO}_{2}{ }^{\text {hh }}$ (in $\mathrm{kg}$ of $\mathrm{CO}_{2}$ ) for each household is calculated by the following equation:

$\mathrm{CO}_{2}{ }^{\mathrm{hh}}{ }_{\mathrm{i}}=\sum_{\mathrm{i}}^{\mathrm{j}}\left(\mathrm{CO}_{2 \mathrm{j}} * \operatorname{Exp}_{\mathrm{ij}}\right)$

where $\mathrm{i}$ and $\mathrm{j}$ denote household and expenditure item, respectively. 


\subsubsection{Drivers of the household carbon footprint}

This section will investigate the emission implications, household characteristics and their consumption decisions. The linkage between the expenditure choices and the carbon footprints will be determined from the carbon intensity of particular items consumed in Indonesia. From the list of consumption items in Susenas, we will analyze the determinants of particular carbon-intensive consumption preference, including choices related to household operations such as fuel-light and transportation. The empirical analysis is postulated as follows.

$\operatorname{lnCO}{ }_{2}^{\mathrm{hh}}{ }_{\mathrm{i}}=\alpha+\beta_{1} \ln \mathrm{EXP}_{\mathrm{i}}+\beta_{2} \mathrm{X}_{\mathrm{i}}+\varepsilon_{\mathrm{i}}$

The ordinary least square (OLS) method will first be employed to regress the log of household carbon footprint $\mathrm{CO}_{2}{ }^{\text {hh }}$ on $\log$ of household expenditure, $\operatorname{lnEXP}$, as a proxy for income, and a range of control variables $\mathrm{X}$, including region, household members, education, gender and age of household head. To apprehend the nonlinearity effect on household emissions, a squared term for the expenditure, household size, and age will be incorporated as well.

As we derived $\mathrm{CO}_{2}$ emissions from expenditure, one can argue that our expenditure variable could have high correlation with $\mathrm{CO}_{2}$ computed emissions by construction. Dealing with this issue, we can proxy expenditure with expenditure quintile dummies ${ }^{6}, \mathrm{Q}$, then regression (1.6) could be split into two stages, as follows:

$\operatorname{lnCO}{ }_{2}^{\text {hh }}=\alpha+\beta_{\mathrm{q}} \sum_{\mathrm{q}=1}^{5} \mathrm{Q}_{\mathrm{qi}}+\varepsilon_{\mathrm{i}}$

and

$\varepsilon_{\mathrm{i}}=\alpha+\beta_{1} \mathrm{X}_{\mathrm{i}}+\gamma_{\mathrm{i}}$

where $\varepsilon_{\mathrm{i}}$ is the residual from the regression (1.7).

In other words, we regress emissions on the expenditure quintiles in (1.7) then regressing its residuals on other control variables (i.e. household characteristics

\footnotetext{
${ }^{6}$ Household affluence quintiles are constructed based on per capita expenditure.
} 
excluding expenditure) in (1.8). This approach could reveal the true effect of characteristics of households on their emissions. Of particular objectives are to understand the drivers of the heterogeneity of the household emissions, and to identify possible policy implications to reduce emissions without compromising the well-being of households.

In addition, we will also apply quantile regressions in the analysis to account for the possibility that the household emissions distribution is highly skewed. In this case, compare with the OLS regression, the quantile regression could be more robust to outliers partly given the assumption that it does not assume that the variables are normally distributed. Another reason is that we will be allowed to analysis the effect of the right-hand side variables on the location and the scale parameters in the model. Technically, while OLS minimizes the residuals sum of squared, $\sum \mathrm{e}_{\mathrm{i}}^{2}$, the quantile regression minimizes the sum that gives penalties of about $(1-q)|e i|$ for over-prediction and of about q|ei| for underprediction (Cameron and Trivedi, 2010).

Our analysis assumes that the impact of income and control variables for lower carbon emitting households is different from the households with a high carbon footprint. With this in regard, the quintile regression estimates the effect of a oneunit expenditure change on a particular quintile $\mathrm{q}$ of our dependent variable (household emissions). Technically, by linear programming, the qth quintile regression minimizes over $\beta \mathrm{q}$ :

$\mathrm{Q}\left(\beta_{\mathrm{q}}\right)=\sum_{\mathrm{i}: \mathrm{y} \geq \mathrm{x}^{\prime} \beta}^{\mathrm{N}} \mathrm{q}\left|\mathrm{y}_{\mathrm{i}}-\mathrm{x}_{\beta}^{\prime}\right|+\sum_{\mathrm{i}: \mathrm{y} \leq \mathrm{x}^{\prime} \beta}^{\mathrm{N}}(1-\mathrm{q})\left|\mathrm{y}_{\mathrm{i}}-\mathrm{x}_{\beta}^{\prime}\right|$.

We can choose $\mathrm{q}(0<\mathrm{q}<1)$ that uniquely estimates the value of $\beta$. Suppose choosing $\mathrm{q}=0.9$, instead of $\mathrm{q}=0.1$, indicates that more weight is to be assigned on the estimation for observations with $y_{i} \geq x_{i}^{\prime} \beta_{q}$. 


\subsubsection{Decomposing the changes in the carbon footprint}

Another important issue in comparing household emission changes from two periods is determining what the drivers are of these changes. If one considers emissions to be an output of the process, we could argue that it is a product of driving forces. One approach is given by Kaya (1990) who provides an intuitive approach to the interpretation of the historical trend of $\mathrm{CO}_{2}$ emissions. This method, which is widely known as the Kaya Identity, suggests that the total emissions level can be found by calculating the changes in four inputs, i.e. population size, per capita income, energy use per unit of GDP, and $\mathrm{CO}_{2}$ emissions per unit of energy used. Using this decomposition technique, we can then directly link $\mathrm{CO}_{2}$ emission levels to the population effect, and level of economic affluence (measured by per capita expenditure), carbon emission intensity (per energy use) and energy intensity (per output) ${ }^{7}$. Finally we can find the main driving forces of changes in emission levels in the periods observed.

In macro analysis, the Kaya Identity suggests that $\mathrm{CO}_{2}$ emission levels are the product of: (i) the carbon intensity of the energy supply, (ii) the energy intensity of the economic activity, (iii) the economic per capita output, and population. However, since we do not have the data for energy intensities, in our analysis the Kaya Identity is modified as follows:

$\mathrm{CO}_{2}=\mathrm{HHsize}_{\mathrm{i}} * \frac{\mathrm{EXP}_{\mathrm{i}}}{\mathrm{HHSize}_{\mathrm{i}}} * \frac{\mathrm{CO}_{2}}{\operatorname{EXP}_{\mathrm{i}}}$

where the household $\mathrm{CO}_{2}$ emissions level is a function of household size, HHsize, per capita expenditure, EXP/HHsize, and emission intensity, $\mathrm{CO}_{2} / \mathrm{EXP}$.

In other words, we set up an emission equation to calculate and decompose the growth of $\mathrm{CO}_{2}$ emissions into the population effect, per capita expenditure effect (Rp/capita), and carbon intensity effects $\left(\mathrm{CO}_{2} / \mathrm{Rp}\right)$, and express the result as a percentage of the base line $\mathrm{CO}_{2}$ emissions level. Following Ang (2005), our decomposition will be employed using the Logarithmic Mean Divisia Index

\footnotetext{
${ }^{7}$ In terms of policy, the $\mathrm{CO}_{2}$ intensity of output generally focuses on the promotion of low (or zero) carbon sources of energy.
} 
(LMDI), which has several advantages apart from it being consistent in aggregation, it also gives a perfect decomposition as the results will not contain unexplained residuals. The LMDI approach is modified (1.10) to construct the following formula:

$\Delta \mathrm{CO} 2_{\mathrm{i}}=\mathrm{C}^{\mathrm{T}}-\mathrm{C}^{0}=\Delta \mathrm{CO} 2_{\mathrm{HHsize}}+\Delta \mathrm{CO} 2_{\frac{\mathrm{EXP}}{\mathrm{HHsize}}}+\Delta \mathrm{CO} 2_{\frac{\mathrm{CO} 2}{\mathrm{EXP}}}$

where

$\Delta \mathrm{CO} 2_{\mathrm{HHsize}}=\sum_{\mathrm{i}} \frac{\mathrm{C}_{\mathrm{i}}^{\mathrm{T}}-\mathrm{C}_{\mathrm{i}}^{0}}{\ln \mathrm{C}_{\mathrm{i}}^{\mathrm{T}}-\ln \mathrm{C}_{\mathrm{i}}^{0}} \ln \left(\frac{\mathrm{HHsize}_{\mathrm{i}}^{\mathrm{T}}}{\mathrm{HHsize}_{\mathrm{i}}^{0}}\right)$

$\Delta \mathrm{CO} 2_{\text {EXP } / \text { HHSize }}=\sum_{i} \frac{C_{i}^{\mathrm{T}}-C_{i}^{0}}{\ln C_{i}^{\mathrm{T}}-\ln C_{i}^{0}} \ln \left(\frac{\left(\frac{\text { EXP }}{\text { HHsize }}\right)_{i}^{\mathrm{T}}}{\left(\frac{\text { EXP }}{\text { HHsize }}\right)_{i}^{0}}\right)$

$\Delta \mathrm{CO} 2_{\mathrm{CO} 2 / \mathrm{EXP}}=\sum_{\mathrm{i}} \frac{\mathrm{C}_{\mathrm{i}}^{\mathrm{T}}-\mathrm{C}_{\mathrm{i}}^{0}}{\operatorname{lnc} \mathrm{C}_{\mathrm{i}}^{\mathrm{T}}-\ln \mathrm{C}_{\mathrm{i}}^{0}} \ln \left(\frac{\left(\frac{\mathrm{CO} 2}{\mathrm{EXP}}\right)_{\mathrm{i}}^{\mathrm{T}}}{\left(\frac{\mathrm{CO} 2}{\mathrm{EXP}}\right)_{\mathrm{i}}^{0}}\right)$

where $\Delta \mathrm{CO} 2_{\mathrm{HHsize}}, \Delta \mathrm{CO} 2_{\mathrm{EXP} / \mathrm{HHSize}}$, and $\Delta \mathrm{CO} 2_{\mathrm{CO} 2 / \mathrm{EXP}}$ represent changes in $\mathrm{CO}_{2}$ emissions because of population, expenditure, and the carbon intensity effect, respectively.

\subsubsection{Expenditure elasticites of emission}

The demand analysis is generally utilized to measure the change in demand for any particular good due to the change in income. This demand function is originated from the consumers' utility maximization equation, which depends on the prices of goods and individuals' income (Deaton and Muellbauer, 1980). We modify this demand theory by replacing the demand for goods with $\mathrm{CO}_{2}$ emissions given the consumption of the respective goods. By applying this, we can analyze the responsiveness of $\mathrm{CO}_{2}$ emissions of any household consumption category to a change in household income, which is proxied by household expenditure.

As suggested by the conventional Engel curves, we should include price as one of the independent variables. However, since there is no price data in Susenas, we will estimate the expenditure elasticites of emission without using prices, meaning that the response of $\mathrm{CO}_{2}$ emissions will only be dependent on the expenditure 
amount and socio-economic level of the households. We will estimate the following model:

$s C O 2_{i j}=\beta_{0}+\beta_{1_{i j}} \ln \operatorname{EXP}_{i}+\beta_{2_{i j}} X_{i}+\varepsilon_{i j}$

where $\mathrm{sCO} 2_{\mathrm{ij}}$ represents the share of $\mathrm{CO}_{2}$ emissions of $\mathrm{j}$-th consumption category to total $\mathrm{CO}_{2}$ emissions by the $\mathrm{i}$-th household, $\operatorname{lnEXP} \mathrm{P}_{\mathrm{i}}$ is the natural logarithm of household i expenditure. $\mathrm{X}_{\mathrm{i}}$ represents a vector of household characteristics and $\varepsilon_{\mathrm{ij}}$ is error terms ${ }^{8}$.

\subsection{Results and discussions}

\subsubsection{Descriptive analysis}

Susenas 2005 and 2009 consist of a large data on household expenditures of more than 257,000 and 291,753 Indonesian households, respectively ${ }^{9}$. Figure 1.2 provides an overview on the allocation of household expenditure in 2005 and 2009. In general expenditure increased by $72.27 \%$ (nominal) and $24.83 \%$ (deflated). We also indicate that the large differences of the expenditure share between households living in urban and rural areas. Compared to urban households, households in rural areas have unsurprisingly a larger expenditure share on foods and a much smaller share on services, recreations, rents and taxes. In general, comparing two surveys we find that food expenditure declined as expected. Moreover, the shares of telecommunication, transportation, health,

\footnotetext{
${ }^{8}$ One might argue that there is a potential endogeneity problem due to the fact that our $\mathrm{CO}_{2}$ emissions are derived from expenditure. We could apply the instrumental variables estimation using (for instance) the households' asset index as an instrument for household expenditure. However, due to data limitation this is beyond of our scope of study.

${ }^{9}$ For both surveys, the consumption is disaggregated to around 300 consumption items. In 2005 (and 2009), about $62.57 \%(64.64 \%)$ of households were located in rural areas. About $12.12 \%$ $(13.61 \%)$ of households were headed by a woman. The households consisted of about 4.08 (3.96) members which $81.36 \%(83.30 \%)$ of them had a maximum 5 household members. On average, household heads' years of schooling was 6.1 (6.49) years. The annual household expenditure equaled to $\mathrm{Rp} 11.90$ million (Rp 20.50 million). Urban households spent about Rp 16.50 million/year ( $R p 27.70$ million/year) compare to $R p 9.13$ million/year (Rp 16.60 million/year) in urban area.
} 
education, and taxes have been increasing both in the rural and urban areas. The share of beverage goods has been increasing in urban areas as oppose to in rural areas where it has been decreasing. In contrast, the share of income that has been spent on housing and durable expenditures has been increasing for households in rural areas as oppose to household in urban areas where it has indeed been decreasing.

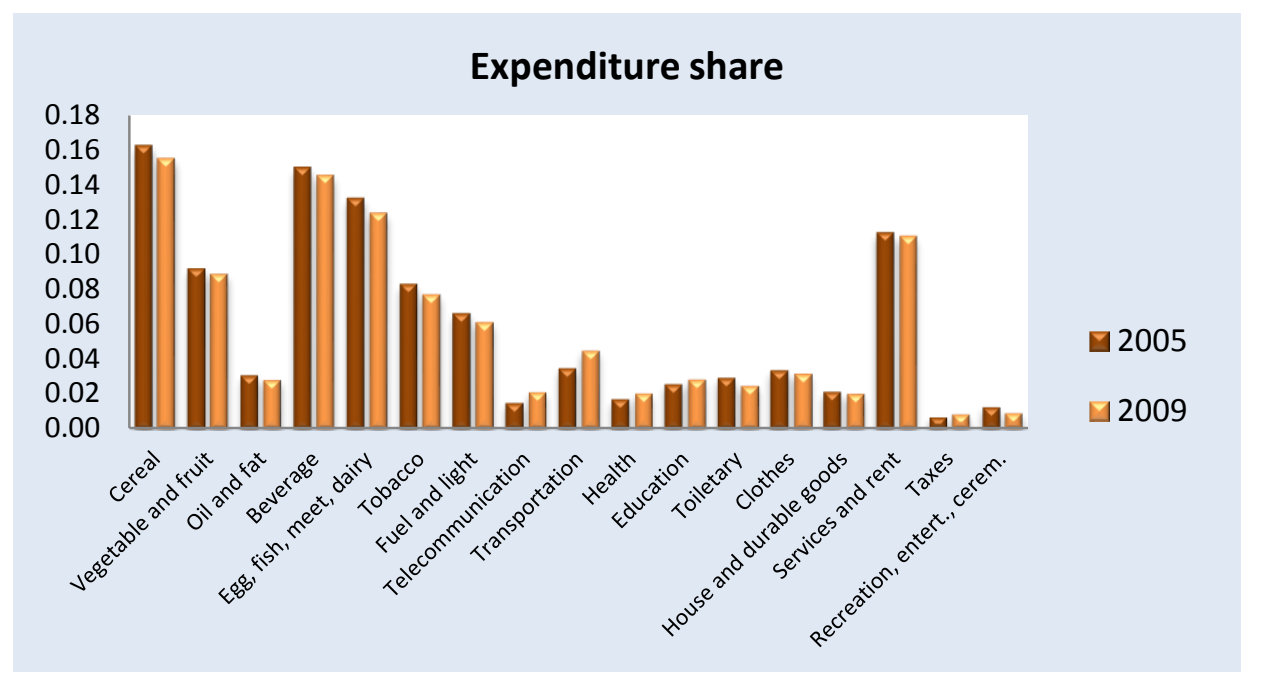

Figure 1.2 Expenditure share per consumption category

Source: Author's computation based on Susenas (2005 and 2009)

Before we begin the computation of the carbon footprint, it is very important to point out the coverage of Susenas compared to the private consumption database based on the macro perspective. If we compare the two databases, we indicate that the expenditure computation from Susenas will be significantly less than the national account (this underestimation measure can be also found in other studies e.g. Yusuf, 2006; Mishra, 2009). The deviation between the two measures is partly because of the computations in the national accounts that were constructed from the supply side's economy while Susenas expenditures were taken from representative sample surveys. In addition, national accounts also include the consumption by non-households.

Table 1.1 portrays the calculations of household expenditure using the national account and Susenas. Given the difference in the measurements from Susenas, 
which accounted for around $42-49 \%$ of the national account measurements, we scaled up the computation of household emissions by dividing household consumption by the percentage of Susenas to total expenditure based on national accounts when we computed the carbon emissions (Mishra, 2009). However, the fact that the aggregate from Susenas expenditures falls short from the national account (including in our calculation with the scaled up household emissions) would not imply anything about the distribution of the expenditures across households hence that we assume that the discrepancy between expenditure items are more or less at the same amount across households.

Table 1.1 Estimate private consumption: Susenas vs. National Account (Rp)

\begin{tabular}{cccc}
\hline Year & Susenas & National Accounts & $\begin{array}{c}\text { Percentage of Susenas } \\
\text { to National Accounts }\end{array}$ \\
\hline 1996 & 210,507 & 460,297 & 45.73 \\
1999 & 499,435 & $1,051,483$ & 47.50 \\
2002 & 760,003 & $1,557,099$ & 48.81 \\
2005 & 983,032 & $2,167,979$ & 45.34 \\
2009 & $1,695,220$ & $4,031,541$ & 42.05 \\
\hline
\end{tabular}

Source: Author's computation based on the monthly household expenditure (Susenas, BPS) and the monthly private (household) consumption (WDI, World Bank), various series.

In the next step, by incorporating the Indonesia input-output table and GTAP's energy use matrix, we extract the $\mathrm{CO}_{2}$ emission intensity level of the 175 economic sectors ${ }^{10}$. The $\mathrm{CO}_{2}$ emission intensity is measured in terms of kilotons per million rupiah (or gram $\mathrm{CO}_{2} / \mathrm{Rp}$ ), which captures the amount of $\mathrm{CO}_{2}$ released from the production of goods and services in the Indonesian economy. Table 1.2 presents the 10 most and least $\mathrm{CO}_{2}$ intensive sectors. It can be seen that sectors that emit $\mathrm{CO}_{2}$ intensively including: electricity, gas, cement, non-metallic minerals, glasses and their products, ceramics and clay products. In addition to those electric and manufacturing sectors, all transportation services are also very carbon intensive.

In contrast, the least $\mathrm{CO}_{2}$ intensive sectors in Indonesia are associated with agricultural crops sectors, including fiber crops, grains, sweet potato, fruits, and

\footnotetext{
${ }^{10}$ We follow Huff et al. (2000) using concordance matrix between GTAP's emission data and all IO sectors.
} 
beans. These figures reflect the fact that these products do not use much energy in production compared to manufacturing and transportation sectors ${ }^{11}$. In addition to the agricultural sectors, service sectors also have a lower $\mathrm{CO}_{2}$ intensity, which include such industries as film and distribution services, building and land rent. In general, agricultural related activities emit less $\mathrm{CO}_{2}$ compared to manufacturing sectors.

Table $1.2 \mathrm{CO}_{2}$ intensity of economic sectors: top 10 and bottom 10

\begin{tabular}{clc}
\hline Number on list & Sectors & gram $\mathbf{C O}_{2} / \mathbf{R p}$ \\
\hline Top 10 & & \\
1 & Electricity and gas & 1.04962 \\
2 & Cement & 0.44619 \\
3 & Other items of non-metallic materials & 0.39552 \\
4 & Glass and glass products & 0.38542 \\
5 & Ceramics and building materials from clay & 0.37331 \\
6 & Ceramics and items made of clay & 0.36825 \\
7 & Air transport services & 0.20421 \\
8 & Railway services & 0.17156 \\
9 & Marine transportation services & 0.16338 \\
10 & River and lake transport services & 0.16153
\end{tabular}

Bottom 10

\begin{tabular}{lll}
10 & Other nuts & 0.00380 \\
9 & Other animal products & 0.00374 \\
8 & Soybean & 0.00287 \\
7 & Cassava & 0.00280 \\
6 & Vegetables & 0.00266 \\
5 & Beans & 0.00218 \\
4 & Fruits & 0.00185 \\
3 & Sweet potato & 0.00102 \\
2 & Grains and other foodstuffs & 0.00078 \\
1 & Fiber crops & 0.00031 \\
\hline
\end{tabular}

Source: Author's computation based on IO 2005 and GTAP-E 2005. Note: For more detail sectors, see Appendix Table A.1.

The derived $\mathrm{CO}_{2}$ emission intensities were then matched with the consumption categories in the Susenas 2005 and 2009. There are around 340 consumption items in the expenditure survey and this was aggregated to represent the major household expenditures. Figure 1.3 shows the average $\mathrm{CO}_{2}$ emissions (in $\mathrm{kg}$ ) from major expenditure categories. It is observed that $\mathrm{CO}_{2}$ emissions vary based on the consumption item. The lowest $\mathrm{CO}_{2}$ emissions were observed from the consumption of cereals, medical services, telecommunication services and recreation. On the other hand, the highest $\mathrm{CO}_{2}$ emissions were observed from the consumption of transportation as well as fuel and light.

${ }^{11}$ But note that emissions from land use change are not considered here. 
From 2005 to 2009, emissions from fuel-light expenditures accounted for 1,688 $\mathrm{kg}$ to $2,768 \mathrm{~kg}$, growing about $19 \%$ (real). Meanwhile, emissions from transportation, the second highest emission source, account for $183 \mathrm{~kg}$ to $401 \mathrm{~kg}$ (real growth of about 59\%). Emissions from food related expenditures grew (real) around $30 \%$. We also indicate that health, transportation, tax and redistribution are among the fastest growing emission sources (around 50\%).

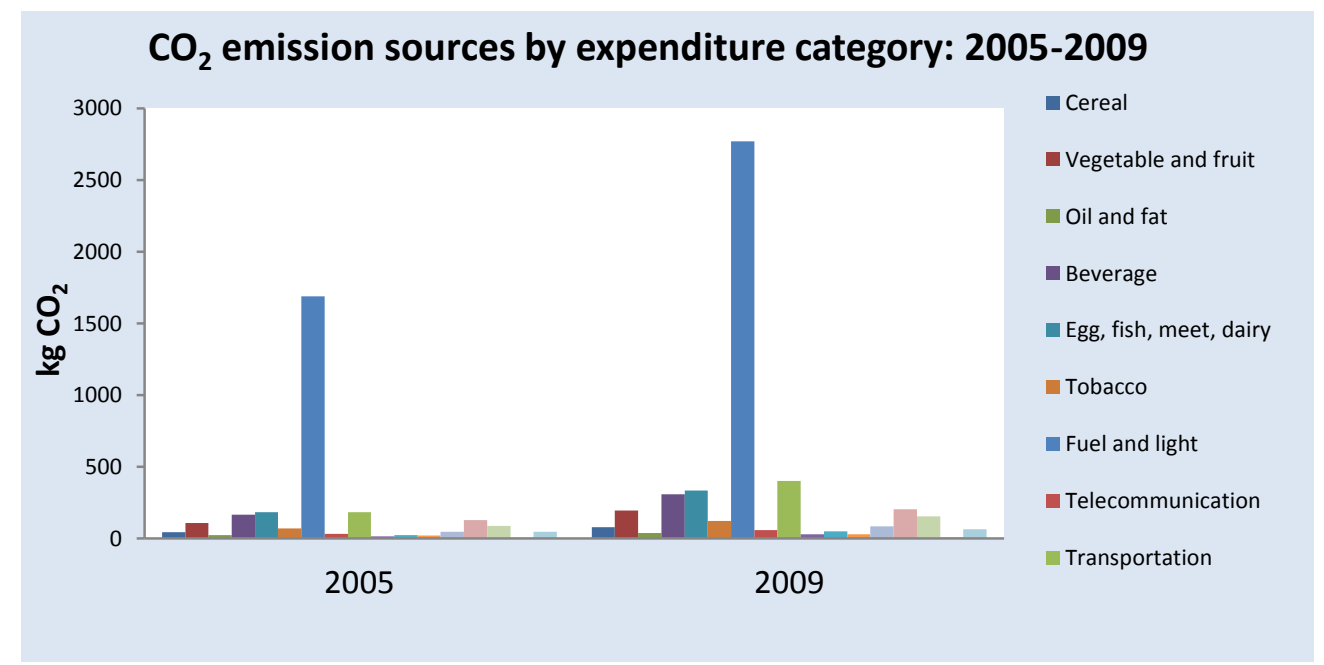

Figure 1.3 Emissions in Expenditure Subgroup (2005 and 2009)

Source: Author's computation based on Susenas 2005-2009, IO 2005, GTAP-E 2005

The disaggregation of the $\mathrm{CO}_{2}$ emissions into regions and income levels is presented in Figure 1.4. It is found the large differences in $\mathrm{CO}_{2}$ emissions with respect to household affluence level. Moreover, we found a variation in the carbon emission levels of households of different educational attainments. In more detail, the household emissions from the $5^{\text {th }}$ affluence quintile is 4.6 times higher than the household emissions from the lowest quintile, and still about 2.6 times as high as the level from households in the third quintile (middle income group) ${ }^{12}$.

\footnotetext{
${ }^{12}$ In per capita emission terms, the richest quintile households emit about 6.9 times as the lowest quintile, and about 3.1 times as the 3rd quintile (Appendix Table A.4).
} 


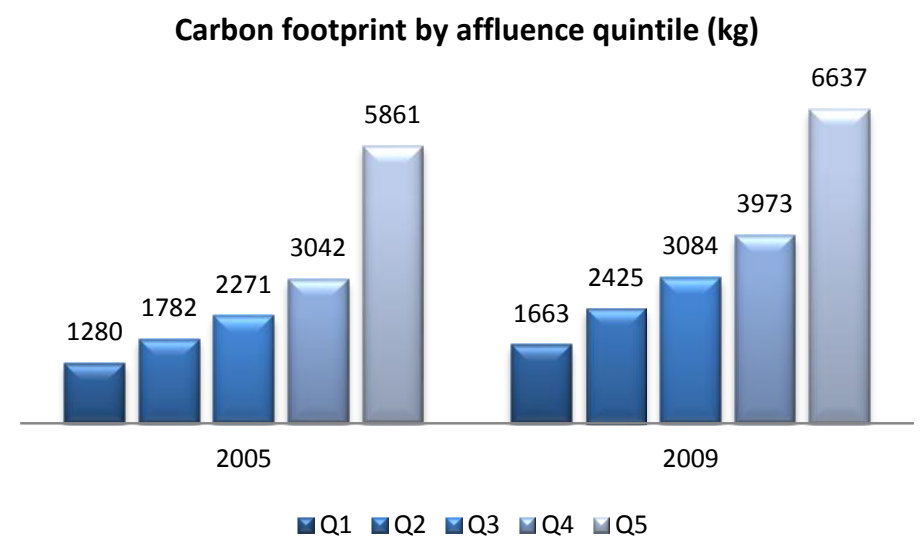

Carbon footprint by education (kg)

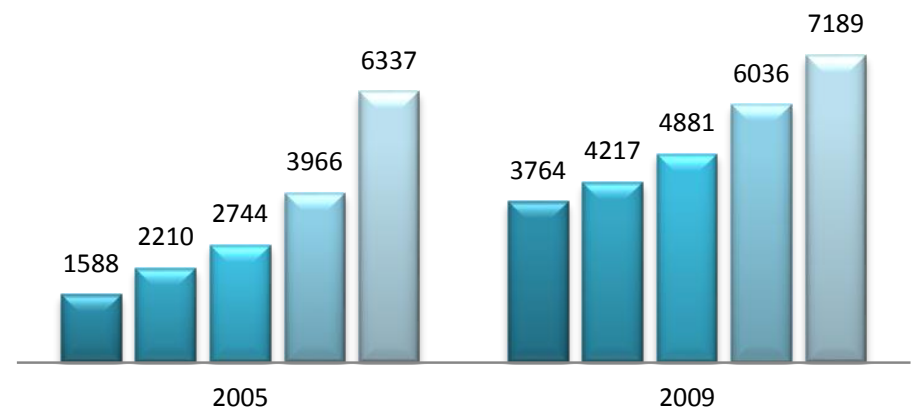

$\square$ Did not grad $\square$ Elementary $\square$ Secondary $\square$ High school $\square$ At least college

\section{Carbon footprint by region (kg)}

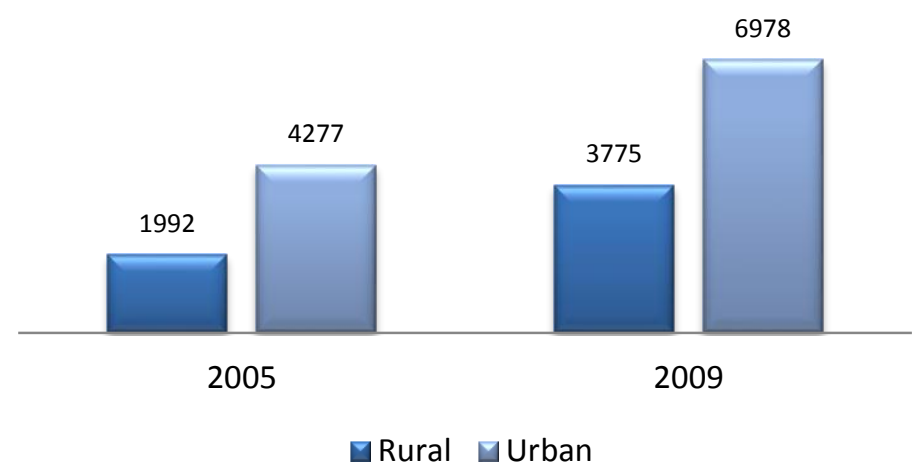

Figure 1.4 Carbon footprint by household affluence quintile, education attainment, and region (2005 and 2009)

Source: Author's computation based on Susenas 2005-2009, IO 2005, GTAP-E 2005

Looking at change from 2005 to 2009 , we indicate that overall emissions grew on average from 2.8 tons in 2005 to 3.5 tons in 2009 (expenditure deflated, $2005=$ 
$100)^{13}$. In 2005 households in the poorest quintile emitted of about 1.3 tons of carbon emissions (to 1.6 tons in 2009) while emissions from the richest households were about 5.8 tons (6.6 tons). The pattern of emissions with respect to educational attainment also has a similar story as the affluence quintile given that education could mirror income level, although the differences between are not as not as steep as affluence level. Last, based on location, both surveys indicated that the urban household emissions are about twice the amount of rural households. Rural households emit almost 2 tons in 2005 (3.8 tons in 2009), while urban households emit of about 4.3 tons ( 7 tons).

Comparing emission shares to expenditure shares (Figure 1.5), we indicate that the emission shares are somewhat lower than expenditure shares from the first to the third quintile. In contrast, $\mathrm{CO}_{2}$ emission shares of households in the top two quintiles are higher than their emission shares. This picture indicates that affluent households in the top two quintiles have a more carbon intensive lifestyle than households in the first three quintiles. It also means that $\mathrm{CO}_{2}$ emissions inequality is slightly larger than the expenditure inequality (See Chapter 2 for more detailed analysis).

\footnotetext{
13 On per capita term, the average per capita $\mathrm{CO}_{2}$ emissions were about 0.70 tons (2005) and 0.90 tons (2009). Estimated per capita $\mathrm{CO}_{2}$ emissions in Indonesia from IEA (2013) were about 1.48 tons (2005) and 1.61 tons (2009). Our calculation is relatively lower than the estimation provided by IEA (2013) partly because our focus is only on household consumption (around 340 items in Susenas) and not on all economic activities.
} 

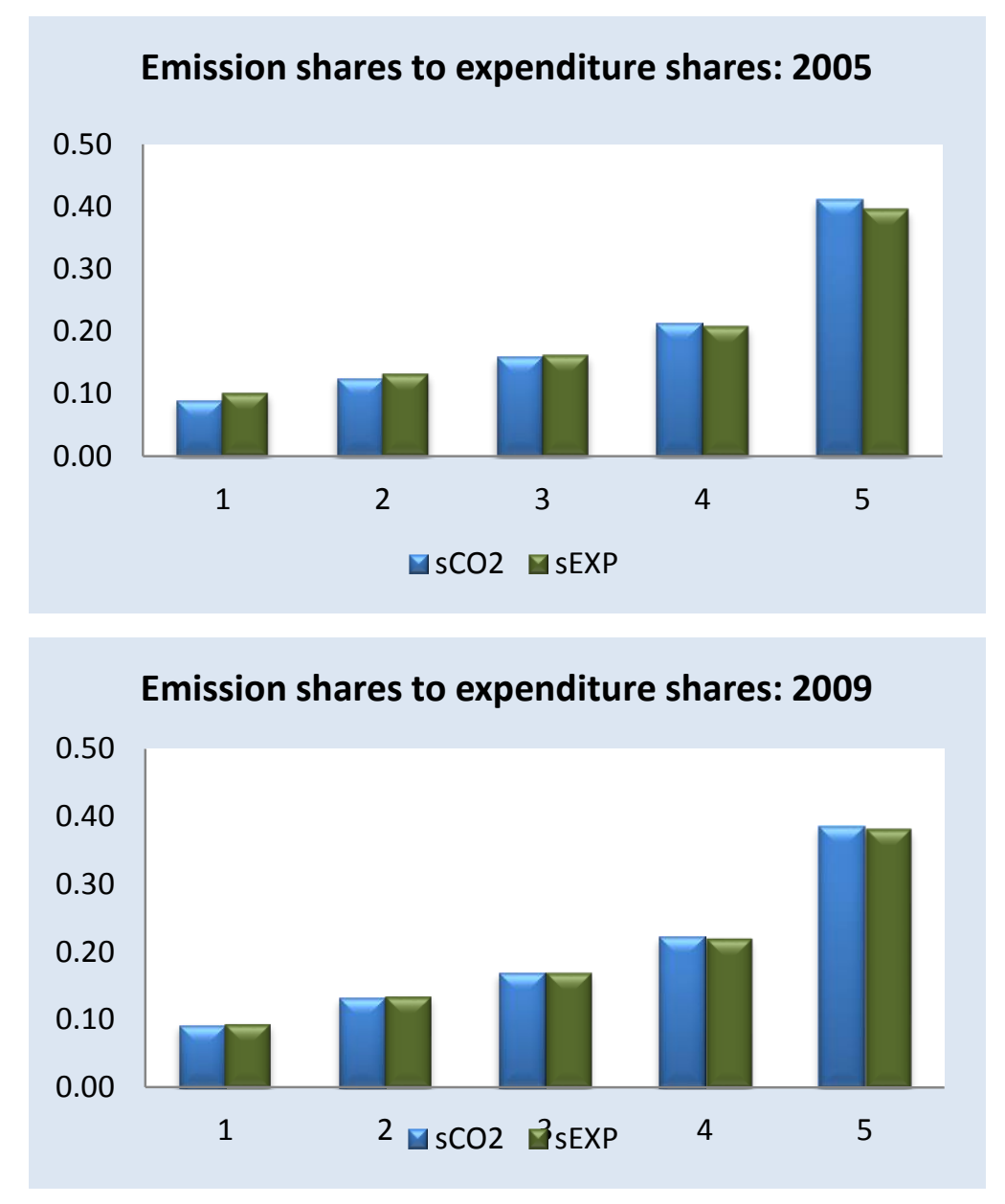

Figure 1.5 Emission shares to expenditure shares by quintile (2005 and 2009) Source: Author's computation based on Susenas 2005-2009, IO 2005, GTAP-E 2005

\subsubsection{Drivers of household carbon footprint}

The regression analysis of the determinants of household emissions is presented in Table 1.3. Various model specifications were employed to analyze the drivers of the variation in $\mathrm{CO}_{2}$ emissions. In Regression I and II, we regress the log of household emissions with log household expenditure and other control variables, including dummies for different household characteristics. In the third regression, we regress the carbon footprint with only income quintiles. Regression IV, V and VI use the residuals from the Regression III as the dependent variable and household characteristics as control variables. 
Table 1.3 The determinants of household carbon footprint, 2005-2009

\begin{tabular}{|c|c|c|c|c|c|c|}
\hline & $\mathbf{I}$ & II & III & $\begin{array}{c}\text { IV } \\
\text { Dep var: } \\
\text { Residuals III }\end{array}$ & $\begin{array}{c}\text { VI } \\
\text { Dep var: } \\
\text { Residuals III }\end{array}$ & $\begin{array}{c}\text { VI } \\
\text { Dep var: } \\
\text { Residuals III }\end{array}$ \\
\hline $\ln \exp$ & $1.045^{* * *} *$ & $1.029 * * *$ & & & & \\
\hline $\ln \exp ^{\wedge} 2$ & $-0.002 * * *$ & $-0.001 * *$ & & & & \\
\hline \multicolumn{7}{|l|}{ Expenditure quintile } \\
\hline 2 & & & $0.351 * * *$ & & & \\
\hline 3 & & & $0.579 * * *$ & & & \\
\hline 4 & & & $0.825^{* * *} *$ & & & \\
\hline 5 & & & $1.251^{* * *}$ & & & \\
\hline hhsize & $0.004 * * *$ & $0.036^{* * *}$ & & $0.345^{* * *}$ & $0.494 * * *$ & \\
\hline hhsizesq & $-0.001 * * *$ & $-0.008 * * *$ & & $-0.019 * * *$ & $-0.050^{* * * *}$ & \\
\hline hhsizecub & & $4.12 \mathrm{E}-04 * * *$ & & & $0.002 * * *$ & \\
\hline age & $0.005 * * *$ & $0.013 * * *$ & & $0.008 * * *$ & $0.011 * * *$ & \\
\hline agesq & $-3.47 \mathrm{E}-05^{* * *}$ & $-1.98 \mathrm{E}-04 * * *$ & & $-5.77 \mathrm{E}-05^{*} * *$ & $-1.19 \mathrm{E}-04 * * *$ & \\
\hline agecub & & $1.05 \mathrm{E}-06^{* * *}$ & & & $4.12 \mathrm{E}-07 * * *$ & \\
\hline \multicolumn{7}{|l|}{ HH size (\#) } \\
\hline 2 & & & & & & $0.424 * * *$ \\
\hline 3 & & & & & & $0.700 * * *$ \\
\hline 4 & & & & & & $0.903 * * *$ \\
\hline 5 & & & & & & $1.054 * * *$ \\
\hline 6 & & & & & & $1.176 * * *$ \\
\hline $7+$ & & & & & & $1.325 * * *$ \\
\hline \multicolumn{7}{|l|}{ HH-head age } \\
\hline $25-44$ & & & & & & $0.081 * * *$ \\
\hline $44-64$ & & & & & & $0.133 * * *$ \\
\hline $65+$ & & & & & & $0.148 * * *$ \\
\hline Urbanity & $0.108 * * *$ & $0.109 * * *$ & & $0.240 * * *$ & $0.240 * * *$ & $0.242 * * *$ \\
\hline \multicolumn{7}{|l|}{ Education } \\
\hline Elementary & $0.020 * * *$ & $0.020 * * *$ & & $0.076^{* * * *}$ & $0.073 * * *$ & $0.069 * * *$ \\
\hline Secondary & $0.039 * * *$ & $0.039 * * *$ & & $0.125^{* * * *}$ & $0.121 * * *$ & $0.115^{* * *}$ \\
\hline High school & $0.068 * * *$ & $0.067 * * *$ & & $0.200 * * *$ & $0.196 * * *$ & $0.191 * * *$ \\
\hline At least college & $0.068 * * *$ & $0.068 * * *$ & & $0.298 * * *$ & $0.299 * * *$ & $0.298 * * *$ \\
\hline Married HH-head & $0.044 * * *$ & $0.037 * * *$ & & $0.055^{* * *} *$ & $0.027 * * *$ & $0.010 * * *$ \\
\hline Female HH-head & $0.053 * * *$ & $0.052 * * *$ & & $0.036^{* * * *}$ & $0.031 * * *$ & $0.030 * * *$ \\
\hline Survey year 2009 & $0.067 * * *$ & $0.067 * * *$ & $0.625^{* * *}$ & $0.019 * * *$ & $0.018 * * *$ & $0.019 * * *$ \\
\hline _cons & $-9.139 * * *$ & $-9.158 * * *$ & $6.833 * * *$ & $-1.512 * * *$ & $-1.730 * * *$ & $-1.145 * * *$ \\
\hline Number of observations & 549,659 & 549,659 & 549,659 & 549,659 & 549,659 & 549,659 \\
\hline $\mathrm{R}^{2}$ & 0.828 & 0.828 & 0.505 & 0.417 & 0.422 & 0.420 \\
\hline $\begin{array}{l}\text { Including province } \\
\text { dummy }\end{array}$ & Yes & Yes & Yes & Yes & Yes & Yes \\
\hline
\end{tabular}

Source: Author's estimation. Note: In Regression I, II and III, the dependent variable is log of total household carbon footprint, while in Regression IV-VI, the dependent variable is residual from Regression III. * $(* * * * *)$ indicates significance at the ten (five, one) percent level.

From Regressions I and II, we find that all independent variables are statistically significant. In addition, expenditure has a nonlinear effect on the $\mathrm{CO}_{2}$ emissions. This implies an inverted U-shaped pattern of the carbon footprint with respect to expenditure ${ }^{14}$. In other words, rising affluence leads to increasing $\mathrm{CO}_{2}$ emissions, ceteris paribus, and turns to decline as household expenditure rises even farther. Furthermore, we also indicate that the larger the number of household members, the greater the age (of the household head), if the gender (of household head) was female, and if the region was an urban area, the more carbon was emitted. Moreover, the number of household members and age of the household head both have non-linear relationships with the carbon footprint. It is noticeable that survey

\footnotetext{
${ }^{14}$ The negative expenditure squared coefficient indicates an emissions decline after reaching a turning point. However, the calculated turning point is far beyond our sample, indicating there is still a progressively rising emissions with respect to rising affluence.
} 
year dummy is still positive even though we already controlled for expenditure, indicating that apart from being affluence-driven, there has been other things that have pushed up emissions by $6.7 \%$ between two surveys controlling for other things.

In the Regression III, we regress household emissions with household affluence quintiles, which divide household into 5 equal parts by sorting the per capita expenditure out from lowest to highest. It is observed that households in the higher quintiles have a larger carbon footprint and the coefficients are statistically significant. Moving from the first to the second quintile increases the household emissions by $35 \%$ whereas moving from the first to the richest quintile increases household emissions by $125 \%$.

We then utilize the residual from the Regression III as the dependent variable of Regression IV, V, and VI, and household characteristics as control variables. The idea is to drop the income interventions which would then reveal the effect of certain household characteristics on their emissions without compromising their well-beings. As indicated, it is not surprising that the coefficients of household characteristics (the control variables) are statistically significant and consistent with the previous specifications. In other words, household characteristics are among determinants of the household carbon footprint. Moreover, we include dummies for all of the provinces in all regressions. The estimated coefficients for all control variables with and without dummies do not change significantly. However, from the province fixed effects regression we indicate that the emissions of provinces in Java and Bali, Kalimantan Timur, Kalimantan Selatan, Sulawesi Selatan and Sulawesi Tenggara, were higher than the amount in other provinces $^{15}$.

Table 1.4 presents quantile regression estimates using $\mathrm{q}=0.1 ; 0.25 ; 0.50 ; 0.75$; and 0.90. Apart from its advantages that quantile regression fits prediction over quintile that avoid sensitivity of the outliers with can dominate the regression if we just employ OLS, it will also estimate an equation expressing a quintile of

\footnotetext{
15 The detailed estimations of the dummy coefficients are presented in Appendix Table A.9.
} 
conditional distribution as well as allow as to investigate the effects of the independent variables to differ over quintiles. In our case, this might be sensible since that household affluence effect might have different effect for any different household groups.

Table 1.4 Quantile regression estimates ${ }^{16}$

\begin{tabular}{|c|c|c|c|c|c|c|c|c|c|c|c|c|}
\hline & \multicolumn{2}{|l|}{ OLS } & \multicolumn{2}{|l|}{$Q(0.1)$} & \multicolumn{2}{|l|}{$Q(0.25)$} & \multicolumn{2}{|c|}{$Q(0.50)$} & \multicolumn{2}{|c|}{$Q(0.75)$} & \multicolumn{2}{|l|}{$Q(0.90)$} \\
\hline & coef & se & coef & se & coef & se & coef & se & coef & se & coef & se \\
\hline $\ln \exp$ & $1.045^{* * *}$ & 0.024 & $1.967 * * *$ & 0.039 & $1.525^{* * *}$ & 0.030 & $0.908 * * *$ & 0.025 & $0.358 * * *$ & 0.025 & $0.180^{* * *}$ & 0.033 \\
\hline lnexpsq & $-0.002 * * *$ & 0.001 & $-0.028 * * *$ & 0.001 & $-0.016 * * *$ & 0.001 & $0.001 *$ & 0.001 & 0.017 *** & 0.001 & $0.021 * * *$ & 0.001 \\
\hline hhsize & $0.004 * * *$ & 0.001 & $0.067 * * *$ & 0.005 & $0.061 * * *$ & 0.003 & $0.051^{* * *}$ & 0.003 & $0.037 * * *$ & 0.002 & $0.025^{* * *}$ & 0.003 \\
\hline hhsizesq & $-0.001 * * *$ & 0.000 & $-0.014 * * *$ & 0.001 & $-0.013 * * *$ & 0.001 & $-0.012 * * *$ & 0.000 & $-0.009 * * *$ & 0.000 & $-0.007 * * *$ & 0.001 \\
\hline hhsizecub & & & $0.001 * * *$ & 0.000 & $0.001 * * *$ & 0.000 & $0.001 * * *$ & 0.000 & $4.78 \mathrm{E}-04$ & 0.000 & $0.000^{* * *}$ & 0.000 \\
\hline age & $0.005^{* * *}$ & 0.000 & $0.022 * * *$ & 0.001 & $0.022 * * *$ & 0.001 & $0.021^{* * *}$ & 0.001 & $0.017 * * *$ & 0.001 & $0.014 * * * *$ & 0.001 \\
\hline agesq & $-3.47 \mathrm{E}-05^{* * *}$ & 0.000 & $-3.35 \mathrm{E}-04 * * *$ & 0.000 & $-3.40 \mathrm{E}-04 * * *$ & 0.000 & $-3.22 \mathrm{E}-04 * * *$ & 0.000 & $-0.000 * * *$ & 0.000 & $-1.86 \mathrm{E}-04 * * *$ & 0.000 \\
\hline agecub & & & $1.78 \mathrm{E}-06^{* * * *}$ & 0.000 & $1.81 \mathrm{E}-06^{* * *}$ & 0.000 & $1.70 \mathrm{E}-06 * * *$ & $=0.0001$ & $1.27 \mathrm{E}-06 * * *$ & 0.000 & $8.63 \mathrm{E}-07^{* * *}$ & 0.000 \\
\hline Urbanity & $0.108^{* * *}$ & 0.001 & $0.210 * * *$ & 0.002 & $0.207 * * *$ & 0.001 & $0.177 * * *$ & 0.001 & $0.143 * * *$ & 0.001 & $0.122 * * *$ & 0.002 \\
\hline Married HH-head & $0.044 * * *$ & 0.002 & $0.048 * * *$ & 0.004 & $0.053 * * *$ & 0.003 & $0.052 * * *$ & 0.003 & $0.045^{* * *}$ & 0.002 & $0.033^{* * *}$ & 0.003 \\
\hline Female HH-head & $0.053^{* * *}$ & 0.002 & $0.055^{* * *}$ & 0.004 & $0.055 * * *$ & 0.003 & $0.050 * * *$ & 0.003 & $0.044 * * *$ & 0.003 & $0.031 * * *$ & 0.003 \\
\hline Elementary school & $0.020^{* * *}$ & 0.002 & $0.044 * * *$ & 0.003 & $0.029 * * *$ & 0.002 & $0.018 * * *$ & 0.002 & $0.014 * * *$ & 0.002 & $0.005^{*}$ & 0.003 \\
\hline Secondary school & 0.039 *** & 0.002 & $0.051 * * *$ & 0.004 & $0.032 * * *$ & 0.003 & $0.019 * * *$ & 0.002 & $0.014 * * *$ & 0.002 & 0.004 & 0.003 \\
\hline High school & $0.068^{* * *}$ & 0.002 & $0.081 * * *$ & 0.004 & $0.062 * * *$ & 0.003 & $0.047 * * *$ & 0.002 & $0.039 * * *$ & 0.002 & $0.029 * * *$ & 0.003 \\
\hline At least college & $0.068^{* * *}$ & 0.002 & $0.086^{* * *}$ & 0.005 & $0.074 * * *$ & 0.004 & $0.065^{* * *}$ & 0.003 & $0.057 * * *$ & 0.003 & $0.042^{* * *} *$ & 0.004 \\
\hline Survey year 2009 & 0.067 *** & 0.001 & $0.045^{* * *}$ & 0.002 & $0.047 * * *$ & 0.001 & $0.048 * * *$ & 0.001 & $0.061 * * *$ & 0.001 & $0.079 * * *$ & 0.002 \\
\hline cons & $-9.139 * * *$ & 0.197 & $-17.869 * * *$ & 0.324 & $-13.654 * * *$ & 0.246 & $-7.905 * * *$ & 0.207 & $-2.702 * * *$ & 0.208 & $-0.716 * * *$ & 0.268 \\
\hline \#Obs & 549,659 & & 549,659 & & 549,659 & & 549,659 & & 549,659 & & 549,659 & \\
\hline (pseudo) $R^{2}$ & 0.828 & & 0.5538 & & 0.55893 & & 0.5639 & & 0.5732 & & 0.576 & \\
\hline
\end{tabular}

Source: Author's estimation. Note: ${ }^{*}(* *, * *)$ indicates significance at the ten (five, one) percent level.

We found that those households who have less emissions seem have higher expenditure elasticites to emit of about 1.52 (at $25 \%$ quantile), the magnitudes are then lower to 0.91 (at median quantile), and to 0.36 (at $75 \%$ quantile) and 0.18 (at $90 \%$ quantile). In other words, low emitter household groups seem to be more responsive to emit and then its effect decreases for those with higher emissions. Meanwhile, household with high carbon footprint have an expenditure elasticites to emit lower than one, indicating they might pass a saturation point that allows them to have rising consumption to become less-carbon intensive. Finally, similar to the OLS estimation, here we also indicate that other household characteristics also matter as the determinants of household carbon footprint ${ }^{17}$.

\footnotetext{
${ }^{16}$ Quantile regression estimates without expenditure square are presented in Appendix Table A.10.

${ }^{17} \mathrm{We}$ also found the estimated coefficients of squared expenditure are no longer negative for $\mathrm{q}=0.50 ; 0.75 ; 0.90$, that could indicate the convex relationship of income-emissions of higher emitters. However, this convexity does not seem quite strong.
} 


\subsubsection{The decomposition analysis of emission growth}

Figure 1.6 presents the decomposition of the growth of household $\mathrm{CO}_{2}$ emissions from 2005 to 2009. From the perspective of contributors to $\mathrm{CO}_{2}$ emissions growth, we can clearly show that rising expenditures is the largest contributor to the rise in $\mathrm{CO}_{2}$ emissions in all quintiles. This rise in expenditures has the largest effect in the lowest quintile, which means that rising the per capita expenditure of households in this quintile will more greatly increase $\mathrm{CO}_{2}$ emissions than the same rise in per capita expenditures of household in the upper quintiles would. Moving to affluent households, the expenditure effect then decrease gradually, but the effects in all quintiles remain positive.

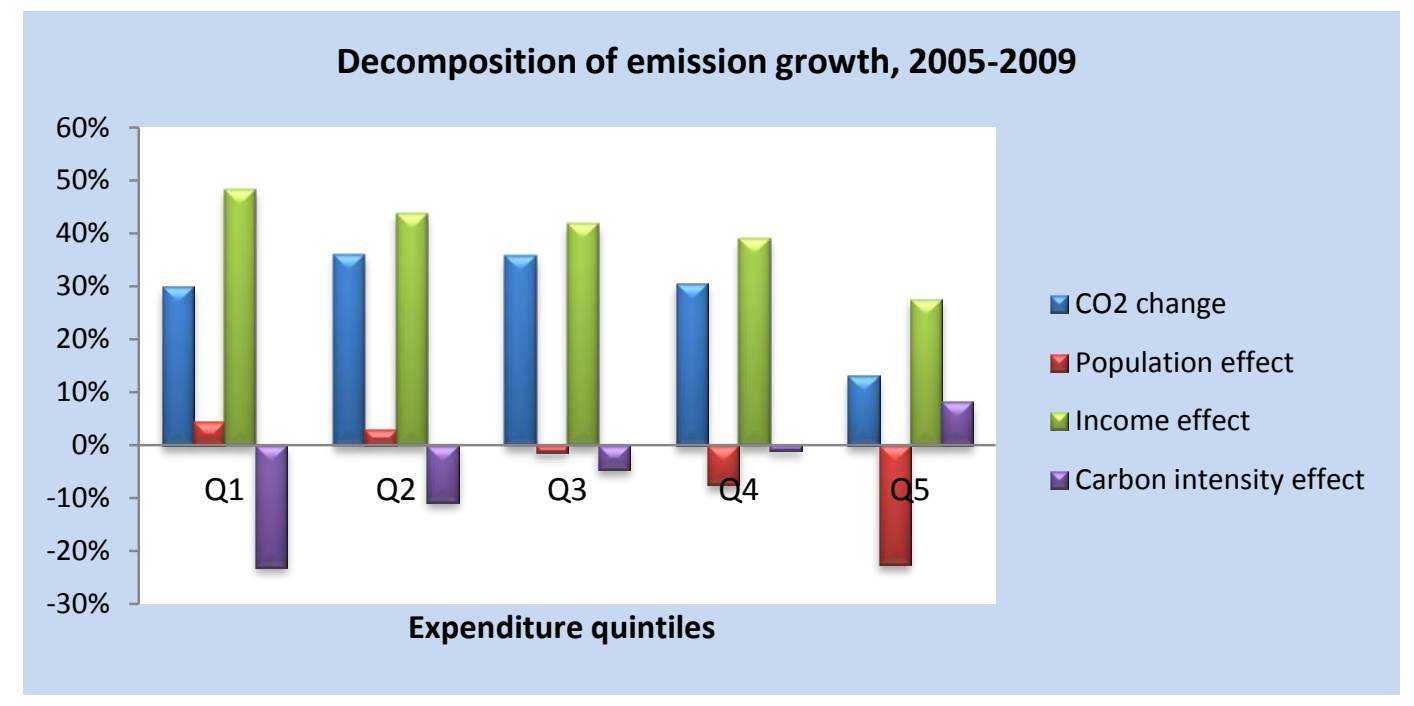

Figure 1.6 Decomposition of $\mathrm{CO} 2$ emission growth ${ }^{18}$

Source: Author's computation based on Susenas 2005-2009, IO 2005, GTAP-E 2005

Moreover, moving from the lowest to highest household, we can clearly identify that the population effect has a decreasing pattern, which has a positive effect on the first two quintiles, and has a negative effect on the third to the highest quintile. Finally, the $\mathrm{CO}_{2}$ intensity effect (measure as $\mathrm{kg} \mathrm{CO}_{2} / \mathrm{Rp}$ ) has the largest negative contribution to $\mathrm{CO}_{2}$ emissions risings in the lowest quintile. This effect has a negative sign from the first until third quintile and has a positive sign in the highest quintile.

\footnotetext{
${ }^{18}$ Note: $\mathrm{CO}_{2}$ emissions and total expenditure are deflated.
} 
From the quintile perspective, it can be seen that the rise in $\mathrm{CO}_{2}$ emissions between 2005 and 2009 in the first and second quintiles is mostly a result of the positive income (expenditure) effect, followed by the (negative) $\mathrm{CO}_{2}$ intensity effect and the positive population effect. In the third and fourth quintiles, the rise of $\mathrm{CO}_{2}$ emissions is a result of the positive effect of rising expenditures, but the effect is not as strong as it was in the first two quintiles. They are also affected by the negative contribution from carbon intensity and population effect. In the richest quintile, the expenditure effect is not as strong as it was in the lower quintiles, however it is still the largest contributor to the change in household emissions. This effect was strengthened by the carbon intensity effect that only had a positive contribution in this quintile, but was weakened by the larger negative population effect. Increase in energy expenditure share (mainly transportation) to overall consumption in 2009 is considered as the driving factor of this positive carbon intensity effect among the richest household group (or falling in the lower income groups ${ }^{19}$. To sum up, the richer households have lower emissions growth because their population (household size) effect has fallen, but this is partly offset by choosing carbon intensive goods due to rising affluence.

\subsubsection{Expenditure elasticities of emission}

Due to the fact that expenditure is the most important driver of the household carbon footprint, we conduct an analysis of expenditure elasticities of $\mathrm{CO}_{2}$ emissions that measure the responsiveness of $\mathrm{CO}_{2}$ emissions (as a share of total household emissions) to a change in expenditure. There are some important issues to be taken into consideration for our analysis. First, dealing with the potential endogeneity problem, one could have a valid instrument for total expenditures, say for the instance asset index, and employ the instrument in a two-stage least squares procedure. However, our database unfortunately does not provide sufficient candidates as valid instruments for total expenditure, as we do not have sufficient data on assets in Susenas. Second, in addition to the national estimation,

\footnotetext{
${ }^{19}$ See for instance Appendix Table A.8.
} 
we will also analyze expenditure elasticities for both rural and urban areas, as well as computing expenditure elasticities by household quintiles.

As the demand theory suggests, the negative coefficient of expenditure elasticities accounts for a decreasing share of any particular expenditure group due to rising affluence, and vice versa. Our results on expenditure elasticities on $\mathrm{CO}_{2}$ emissions generally have the same direction as the conventional Engle curve. Table $\mathbf{1 . 5}$ reveals some important findings. We found that inferior goods, such as vegetables and cereals, have negative signs that mean that rising expenditure will reduce their share of $\mathrm{CO}_{2}$ emissions of these consumption categories. In the opposite direction, luxury goods such as health expenditures, housing, durable goods, transportation, services and rent have positive value, meaning that the rising of household affluence tends to contribute a higher share of $\mathrm{CO}_{2}$ emissions to the total household emissions. Specifically, the transportation expenditure is carbon intensive that a $1 \%$ increase of household expenditure will increase the share of $\mathrm{CO}_{2}$ emissions from transportation by about $0.03 \%$ (both in 2005 and 2009). Fuel and light consumption, another carbon intensive category, has a negative elasticity, which means a $1 \%$ increase in household income will reduce the share of $\mathrm{CO}_{2}$ emissions from these consumption items by about $0.07 \%$ in $2005(008 \%$ in 2009).

Table 1.5 Expenditure elasticities of emission

\begin{tabular}{lrrrrrr}
\hline & \multicolumn{2}{c}{ Overall observation } & \multicolumn{2}{c}{ Urban } \\
\cline { 2 - 6 } Share of $\mathrm{CO}_{2}$ emission & $\mathbf{2 0 0 5}$ & $\mathbf{2 0 0 9}$ & $\mathbf{2 0 0 5}$ & $\mathbf{2 0 0 9}$ & $\mathbf{2 0 0 5}$ & $\mathbf{2 0 0 9}$ \\
\hline Cereal & -0.0169 & -0.0095 & -0.0185 & -0.0076 & -0.0080 & -0.0052 \\
Vegetable and fruit & -0.0088 & -0.0066 & -0.0084 & -0.0060 & -0.0095 & -0.0074 \\
Oil and fat & -0.0044 & -0.0029 & -0.0054 & -0.0032 & -0.0033 & -0.0024 \\
Beverage & 0.0045 & -0.0006 & 0.0070 & 0.0023 & 0.0021 & -0.0048 \\
Egg, fish, meat, dairy & 0.0033 & 0.0143 & 0.0074 & 0.0159 & -0.0011 & 0.0122 \\
Tobacco & 0.0023 & 0.0046 & 0.0048 & 0.0089 & -0.0005 & -0.0011 \\
Fuel and light & -0.0686 & -0.0916 & -0.0740 & -0.1045 & -0.0639 & -0.0741 \\
Telecommunication & 0.0065 & 0.0068 & 0.0041 & 0.0064 & 0.0091 & 0.0073 \\
Transportation & 0.0277 & 0.0334 & 0.0304 & 0.0379 & 0.0250 & 0.0272 \\
Health & 0.0022 & 0.0021 & 0.0023 & 0.0019 & 0.0021 & 0.0024 \\
Education & -0.0011 & 0.0047 & -0.0004 & 0.0045 & -0.0019 & 0.0048 \\
Toiletry & -0.0012 & -0.0007 & -0.0014 & -0.0008 & -0.0009 & -0.0007 \\
Clothes & 0.0000 & 0.0024 & 0.0003 & 0.0031 & -0.0003 & 0.0013 \\
House and durable goods & 0.0349 & 0.0263 & 0.0391 & 0.0282 & 0.0306 & 0.0240 \\
Services and rent & 0.0087 & 0.0077 & 0.0045 & 0.0056 & 0.0136 & 0.0105 \\
Taxes & 0.0007 & 0.0010 & 0.0005 & 0.0008 & 0.0009 & 0.0012 \\
Recreation, ceremony & 0.0071 & 0.0057 & 0.0079 & 0.0066 & 0.0062 & 0.0047 \\
\hline Souryyyyyyy
\end{tabular}

Source: Author's estimation ( $\left.s C O 2_{i j}=\beta_{0}+\beta_{1_{i j}} \ln E X P_{i}+\beta_{2_{i j}} X_{i}+\varepsilon_{i j}\right)$. Note: all estimated coefficients are significant at one percent level, estimations for different quintiles are mentioned in Appendix Table A.12. 
Conducting a simulation of a $10 \%$ increase in income (Table 1.6), we indicate that some of the priorities of households, if they were more affluent, would be to have more housing and durable goods, transportation, and services and rents. For instance, in the hypothetical case where a household has double the total expenditure, i.e. a rise of about $100 \%$, the $\mathrm{CO}_{2}$ emissions for consuming durable goods and transportation increase by $3.4 \%$ and $2.7 \%$, respectively ${ }^{20}$.

\section{Table 1.6 Share of $\mathrm{CO}_{2}$ emission and changes once total expenditure increases}

\begin{tabular}{|c|c|c|c|c|c|c|}
\hline \multirow[t]{2}{*}{$\begin{array}{l}\text { Emissions from consumption } \\
\text { category }\end{array}$} & \multicolumn{2}{|c|}{$\begin{array}{c}\text { Share from overall } \\
\text { emission }(\%) \text { before } \\
\text { expenditure rise } \\
\end{array}$} & \multicolumn{2}{|c|}{$\begin{array}{c}\text { Change in share }(\%) \\
\text { once } 10 \% \\
\text { expenditure increase }\end{array}$} & \multicolumn{2}{|c|}{$\begin{array}{c}\text { Emission share }(\%) \\
\text { after expenditure } \\
\text { rise }\end{array}$} \\
\hline & 2005 & 2009 & 2005 & 2009 & 2005 & 2009 \\
\hline Cereals & 2.468 & 2.317 & -0.169 & -0.095 & 2.299 & 2.222 \\
\hline Vegetables and fruits & 4.956 & 4.855 & -0.088 & -0.066 & 4.867 & 4.789 \\
\hline Oil and fat & 1.108 & 1.003 & -0.044 & -0.029 & 1.064 & 0.974 \\
\hline Beverage & 6.545 & 6.801 & 0.045 & -0.006 & 6.590 & 6.794 \\
\hline Egg, fish, meat, dairy & 7.603 & 7.290 & 0.033 & 0.143 & 7.636 & 7.433 \\
\hline Tobacco & 3.249 & 3.052 & 0.023 & 0.046 & 3.272 & 3.098 \\
\hline Fuel and light & 57.330 & 55.927 & -0.686 & -0.916 & 56.644 & 55.011 \\
\hline Telecommunication & 0.572 & 0.903 & 0.065 & 0.068 & 0.637 & 0.971 \\
\hline Transportation & 5.028 & 7.011 & 0.277 & 0.334 & 5.305 & 7.345 \\
\hline Health & 0.466 & 0.579 & 0.022 & 0.021 & 0.488 & 0.600 \\
\hline Education & 0.702 & 0.893 & -0.011 & 0.047 & 0.691 & 0.940 \\
\hline Toiletry & 0.759 & 0.672 & -0.012 & -0.007 & 0.747 & 0.664 \\
\hline Clothes & 1.862 & 1.826 & 0.000 & 0.024 & 1.862 & 1.849 \\
\hline House and durable goods & 2.837 & 2.683 & 0.349 & 0.263 & 3.186 & 2.946 \\
\hline Services and rent & 2.833 & 2.880 & 0.087 & 0.077 & 2.920 & 2.957 \\
\hline Taxes & 0.089 & 0.117 & 0.007 & 0.010 & 0.096 & 0.126 \\
\hline Recreation, ceremony & 1.593 & 1.194 & 0.071 & 0.057 & 1.664 & 1.252 \\
\hline
\end{tabular}

Source: Author's estimation

Last but not least, most of the estimated expenditure elasticities coefficients are generally very small, but generally the directions of these expenditure elasticities to $\mathrm{CO}_{2}$ emissions have the same signs as the conventional Engle curve. However, they have different sensitivities due to the different $\mathrm{CO}_{2}$ intensities of the consumption categories. The small size of the expenditure elasticites indicates that the household emission change can mainly be attributed to a general volume increase in overall expenditure, and not by shifting the expenditure shares within the consumption basket. These findings support the previous results on the decomposition of emission growth that suggests that the emission growth is mainly due to rising income (expenditure) level.

\footnotetext{
${ }^{20}$ However, it is noticeable that there could be a different response to expenditure rises in different household characteristics. See for instance the expenditure elasticites to emission share by household affluence quintile can be shown in Appendix Table A.13.
} 


\subsection{Conclusion}

The objectives of this study are to analyze the household carbon footprint pattern in Indonesia and to analyze the determinants of the growing carbon footprint in this emerging economy. Of particular relevance is identifying possible trade-offs between increasing incomes (which are in line with poverty reduction) and the carbon intensive behavioral choices of households from the consumption side as in the transition economy, household consumption (particularly associated with energy expenditures) is an important element. This study combines national inputoutput, and the GTAP emission database to compute $\mathrm{CO}_{2}$ emission intensities for all input output sectors in Indonesia. These intensities were then matched with two waves of national expenditure surveys from 2005 and 2009 to calculate the carbon footprint for every household in the surveys. We further use this household $\mathrm{CO}_{2}$ emissions information in investigating the drivers of the rise in emissions from a micro-cross sectional perspective.

Comparing $\mathrm{CO}_{2}$ intensities, the results show that the fuel-light and transportation consumption categories are the two most $\mathrm{CO}_{2}$ intensive emitting sectors in Indonesia. These expenditures are also the main sources of overall household emission. In contrast, food or agriculture-related expenditures post the lowest $\mathrm{CO}_{2}$ intensities as well as carbon emission levels. In terms of numbers, we found that there was an increase of households' carbon footprint from 2005 to 2009 by about $72.36 \%$ (or $24.90 \%$ if we deflate $\mathrm{CO}_{2}$ and expenditure). Dividing households into per capita expenditure quintiles, we showed emission disparities between household quintiles as the richest household emit almost 5 and 3 times compare to the first and third quintile ( 7 and 3 times based on per capita emission terms). In addition, we found there is a significant difference of household carbon emissions between different income levels, regions, and education levels.

To understand the drivers of the variations in the household carbon footprint, we apply various regressions of household $\mathrm{CO}_{2}$ emissions on household characteristics such as income, education, region, household population, and gender and age of the household head. We found that rising household 
expenditures is the main determinant of rising household emissions. It is clearly shown that varying income levels differ significantly in terms of their carbon footprint. Other household characteristics also contribute to the variation in emission levels. Urbanity, large household size, more educated, older and female household head, as well as households in Java provinces, all have a higher profile of $\mathrm{CO}_{2}$ emissions. Quantile regression indicates that low emitter household have stronger magnitude to emit as income increasing, while household with high carbon footprint have an income elasticites to emit lower than one, indicating that they might have passed a saturation point allowing their rising expenditure towards less-carbon intensive. Last but not least, the results of the decomposition analyses also show that changes in household emission levels are due primarily to the income (expenditure) effect, between household levels and over the two periods. The expenditure elasticities analysis suggested that the rise in household emissions is mainly caused by general increases in overall household expenditure, and not by shifts in the consumption basket.

Back to the EKC hypothesis that proposes the income-environmental degradation relationship depends the scale, composition and technology effects (see Grossman and Krueger, 1995; Torras and Boyce, 1998), from the micro perspective, on the one hand our findings indicate that growing household affluence is remarkably compensated by higher emissions (the scale effect). On the other hand, we indicated little evidence of a transformation in behavioral choices of the households towards sustainable consumption patterns, although there is evidence of declining emission intensity as income rises.

Finally, our study could motivate some possible policy implications. As Indonesian per capita income grows, the future emissions will undeniably rise but there would be potential way outs that the household emissions could grow more slowly. In this regard, transformation towards less carbon-intensive consumption would play a role. This issue might be reinforced by a number of supporting policies such as developing energy efficiency, low-carbon energy system, green technology and infrastructures including sustainable transport system, along with a gradual (well-targeting) reduction of fuel subsidies. Taking those strategies 
together would allow rising affluence could be translated towards consumption patterns that might minimize the scale of the emission trade-offs of development and thus promote low-carbon development paths. All of the above issues could have significant relevance to Indonesian as well as to global debates on how to reduce the carbon intensity of development paths. 
Chapter 2 : Inequality in emissions: Evidence from Indonesian households 


\title{
Inequality in emissions: Evidence from Indonesian households
}

\begin{abstract}
Although the literature on emission inequality is abundant, this study will differentiate itself by focusing on emission inequalities at the household level. We further separate measures on emission inequality based on household characteristics as well as decompose it into sources of emission. The results show that as per capita expenditure increases, within-group emission inequality tends to decline until the middle-income group but then further increases in expenditure level and worsens emission inequality until the richest household group. The decomposition of inequality based on emission sources suggests that energytransportation dominantly contributes of the overall emission inequality.
\end{abstract}

Keywords: carbon footprint, household, inequality, Indonesia 


\subsection{Introduction}

Human activity is one the leading contributors to the rise in global emissions, particularly since the industrial revolution. The idea of the relationship between economic development and environmental degradation is suggested by the Environmental Kuznets Curve (EKC) hypothesis, which proposes that in the early stage of development environmental degradation surges until reaching its peak, then a further increase in economic affluence would lead to a decline in environmental degradation. For that reason, the investigation of the driving forces as well as the evolution of $\mathrm{CO}_{2}$ emission levels are important and thus have been becoming of great interest to both research and policy perspectives.

However, different levels and patterns of development in countries or groups of economic actors lead to a disparity in the figures of environmental degradation. Of particular relevance is the fact that the inequality in emissions across countries (or regions) is enormously huge. For instance, the World Bank (2013) reports that in the 1980s developing countries in East Asia emitted only 1.27 tons of $\mathrm{CO}_{2}$ per capita compared to the European countries that emitted about 5.75 tons/capita. In 2009 however there was a huge change in the emission disparity as the $\mathrm{CO}_{2}$ emission per capita in East Asia jumped to 4.59 tons while Europe increased to just around 7.22 tons of $\mathrm{CO}_{2}$ emissions.

More importantly, many studies, such as Heil and Wodon (1997) and ClarkeSather et al. (2011), proclaim that the inequality in emissions between developed and developing countries has been one of the huge challenges hampering the process of forging international agreements towards reducing green house gas (GHG) emissions. One particular reason for this is that developed countries believe that restraining their emissions will disrupt their economy. Conversely, developing and emerging economies argue that their growth should not be limited by any climate mitigation policies, as their historical levels of carbon emissions have been lower (Heil and Wodon 1997; Duro and Padilla, 2006). These contradictory arguments challenge the mitigation of global climate policies. 
Notwithstanding the fact that the emission inequality problem is somewhat global or regional, it could be also relevant to investigate the issue at the micro level across households within country. Given this, this study tries to measure the $\mathrm{CO}_{2}$ inequality and its decomposition from the household/micro perspective that could be valuable in the discourse on climate change. The measure and degree of inequality in $\mathrm{CO}_{2}$ emissions across households show what degree of "responsibility" of emitters and emission sources from the household perspective within a country.

Some particular motivations of this study are: to discover whether the apparent stability in household (cross-sectional) emissions could coincide with the unequal expenditure distribution, as well as to investigate the drivers of its distributions. Similar to the emission inequality in the macro analysis concerning household distribution, we apply several measures of inequality to synthesize the amount of inequality at the household level. In addition to determining the level of inequality, we will also disaggregate and decompose inequality into subgroups of observations as well as into sources of emission. Among the major reasons to decompose household emission inequality are: (i) allowing us to identify whether the change in emission inequality is fueled by a reduction in the emission gap between household affluence, or whether its difference is due to the homogeneity of households' lifestyles within the same group; (ii) allowing us to understand which subgroups (and source of emissions) dominantly contribute to the overall emission inequality. Finally, regarding the comparison between expenditure and emissions, we analyze the inequality measures as well as decomposition of the two variables into the drivers and sources of such inequality.

\subsection{Literature reviews}

A number of studies have been conducted to investigate emission inequalities that are mainly focusing on the international (e.g. Heil and Wodon, 1997; Hedenus and Azar, 2005; Padilla and Serrano, 2006; Cantore and Padilla, 2010) as well as the regional level (e.g. Alcantara and Duro, 2004; Padilla and Duro, 2013; Clarke- 
Sather et al., 2011). In general, these studies have taken into account the characteristics of the emission distribution and have dealt with the arrangement in international and national emissions inequality.

In an international context, Heil and Wodon (1997) analyze the $\mathrm{CO}_{2}$ emissions inequality between poor and rich countries. Employing the Gini index, results found that the inequality in GHG emissions remained high during the period 1960-1990 and the between group component accounted for half of the per capita emissions inequality. Padilla and Serrano (2006) applied conventional applications of inequality to measure $\mathrm{CO}_{2}$ emissions inequality, and employ the Theil index decomposition to investigate the contribution of four income country groups to the overall inequality in $\mathrm{CO}_{2}$ emissions. They found that while the overall $\mathrm{CO}_{2}$ emissions inequality lessens over time, the low-income countries experience an increase in inequality. Employing the concentration indices of emissions (cross country emission inequality ordered by increasing value of income, which was proposed by Kakwani et al. (1997)), they found it has diminished less than the conventional measure in emission inequality. Duro and Padilla (2006) decompose the Theil index of emissions by using Kaya factors to find what contribution the factors had on per capita $\mathrm{CO}_{2}$ emissions, $\mathrm{CO}_{2}$ intensity, energy intensity and per capita income. They found that the $\mathrm{CO}_{2}$ emissions inequality was mainly attributed to the difference in per capita income levels. Recently, an investigation of the international inequalities in ecological footprint was conducted by Duro and Teixidó-Figueras (2013), that primarily suggested that the global emission inequality was largely explained by "between groups" inequalities rather than the "within group" component.

From the regional context, a study on the energy intensities inequality among OECD countries by Alcantara and Duro (2004) revealed that the decline in energy intensities differences was mainly due to "between-group component inequalities" rather than "within group inequalities". Similarly, Padilla and Duro (2013), who only focused on the European Union case, employed the same method of decomposing emission inequality of using the Kaya factor. They found that per capita output is the most important factor of emission inequality. In other words, 
evidence from the European Union is consistent with the global context. Furthermore, there was a significant decline in emission inequality, which is primarily due to the declining contribution of energy intensity inequality and the reduction of output inequality between country groups.

In the case of the provincial level analysis, Clarke-Sather et al. (2011) primarily intend to investigate whether the Chinese provincial-level of $\mathrm{CO}_{2}$ inequality mirrors the international pattern. They found that global evidence of $\mathrm{CO}_{2}$ emission inequality was not reflected in the provincial context, as the contribution of the "within group inequality" (i.e. intraregional inequality) was larger than the "between group" inequality component. This means that the variations of $\mathrm{CO}_{2}$ emissions between regions in China are lower than the variation within any particular provinces.

Therefore this study could fill the gaps in analyzing inequality in emission and its decomposition from the household level perspective. As mentioned, although the above problem is global, it is also relevant to investigate it in local context. In that sense, a cross-country study on household-level emission inequality and how it relates to income is relevant. Specifically, the contributions of this study are as follows: (i) disaggregated household-level study on $\mathrm{CO}_{2}$ emissions in a developing country using Indonesia as example, to understand the patterns of emission inequality from the micro level perspective; (ii) a study on the main contributors (drivers) of $\mathrm{CO}_{2}$ emissions inequality at the household-level ${ }^{21}$; (iii) investigation on the internal dynamics of emission inequality at the household level, which remains an understudied dimension in mitigating climate change.

\footnotetext{
${ }^{21}$ Overall, it is hypothesized that if emission is more unequal than income, one could suggest that (richer) households should have more carbon intensive lifestyle. It is also hypothesized that if households are ordered based on income and under this circumtance emission inequality is dominated by between-group component; then the income is considered as important driver of emission inequality. This is also comparable with the case households are ordered based on nonincome characteristics. For instance, in the case that most inequality is between group component (if households are ranked based on their income) and an opposite findings if they are ranked based on non-income characteristics; one could suggest that income has a strong influence on emission inequality. Finally, the decomposition of emission inequality by income source hypothesizes that apart from individual emission source inequality, overall emission inequality should be largely attributed to any emission (income) source that highly dominates to overall emission, and/or which highly correlated to overall emission inequality.
} 


\subsection{Methodology and data}

\subsubsection{Basic measures of emission inequality}

Imagine we have a distribution of emissions, $e=\left(e_{1}, e_{2}, e_{3}, \ldots, e_{N}\right)$, for $\mathrm{N}$ individuals which has the mean $\mu=\frac{1}{N} \sum_{i=1}^{N} e_{i}$. For this distribution, emission inequality can be defined as a $\mathrm{I}(\mathrm{e})$ function which determines how unequal this emission distribution is. Several methods are commonly applied to measure inequality, each of which possesses their own benefits and drawbacks. This study will utilize the Gini and the Theil index, which will be applied to find the level of inequality in the emission and expenditure distributions.

One of the most popular inequality measures, the Gini coefficient, is defined as the area between the absolute equality line and the Lorenz curve. It is easily and readily understandable as it has a value from 0 (means perfect equality) to 1 (means perfect inequality). We calculate the household Gini coefficient of household emissions using the following formula:

$\mathrm{G}(\mathrm{c})=\left(\frac{2 \sum_{\mathrm{i}=1}^{\mathrm{N}} \mathrm{i} * \mathrm{c}_{\mathrm{i}}}{\mathrm{N} \sum_{\mathrm{i}=1}^{\mathrm{N}} \mathrm{c}_{\mathrm{i}}}\right)-\left(\frac{\mathrm{N}+1}{\mathrm{~N}}\right)$

$\mathrm{N}$ and $\mathrm{c}_{\mathrm{i}}$ refer to the total number of households (observations) and per capita emissions, respectively.

The Theil index measures a weighted entropy index and can be fully decomposable into subgroups of observations or other factors. This decomposability is beneficial as it allows us to study the composition of the index by factors or sources. This index can be calculated using the following formula:

$\mathrm{T}(\mathrm{c})=\sum_{\mathrm{i}=1}^{\mathrm{N}} \mathrm{p}_{\mathrm{i}} \ln \left(\frac{\overline{\mathrm{c}}}{\mathrm{c}_{\mathrm{i}}}\right)$

where $\mathrm{p}_{\mathrm{i}}$ is the proportion of individual $\mathrm{i}$ to the overall individuals in the (group) sample, $\overline{\mathrm{c}}$ is the mean of per capita emissions. As mentioned, if our overall number of observations is divided into several groups (in our case, per capita expenditure quintiles, regions, educational attainment, number of household 
members, gender and age of household head), the overall emission inequality can be expressed as a sum of two terms called the 'within group inequality', T(c) $)_{\mathrm{w}}$, and the 'between group inequality', $\mathrm{T}(\mathrm{c})_{\mathrm{b}}$, as follows:

$\mathrm{T}(\mathrm{c})=\mathrm{T}(\mathrm{c})_{\mathrm{w}}+\mathrm{T}(\mathrm{c})_{\mathrm{b}}$

The within-group inequality measures how much per capita emission inequality is due to the variations between the individuals in each of these groups, while the between group inequality quantifies to what extent emission inequality is due to the differences in the average emission amount of each subgroup. Equation (2.3) can be re-expressed as follows:

$\mathrm{T}(\mathrm{c})=\sum_{\mathrm{g}=1}^{\mathrm{G}} \mathrm{p}_{\mathrm{g}} \mathrm{T}(\mathrm{c})_{\mathrm{g}}+\sum_{\mathrm{g}=1}^{\mathrm{G}} \mathrm{p}_{\mathrm{g}} \ln \left(\frac{\overline{\mathrm{c}}}{\mathrm{c}_{\mathrm{g}}}\right)$

The first term, which represents the within group inequality, is a weighted sum of subgroup inequality values, while the latter term indicates the between group component of inequality. $\mathrm{p}_{\mathrm{g}}$ is the household proportion in group $\mathrm{g}, \mathrm{T}(\mathrm{c})_{\mathrm{g}}$ represents the internal Theil coefficient of household emission in group $g$, and $\mathrm{c}_{\mathrm{g}}$ denotes the household emission in group $\mathrm{g}$.

\subsubsection{Emission concentration index vs. expenditure Gini}

Intuitively, we can directly compare the amount of emission inequality to the amount of expenditure inequality just comparing their Gini indices. However, one particular drawback of direct comparison is a different ranking criterion since the emissions Gini index is basically computed using the ranks of individuals based on their emissions, while the expenditure Gini index is constructed using the ranks of households based on their expenditure rank. To solve this, we can apply another index, modified from Kakwani et al. (1997), which basically compares the concentration of emissions and expenditure using the same rank ordering based on expenditure. In other words, this can be regarded as emissions inequality conditional on expenditure. Among the previous studies that employed this similar method were Padilla and Serrano (2006) and Cantore and Padilla (2010). 
We basically calculate the Kakwani index by subtracting the household expenditure Gini, G(Exp) from the quasi-Gini index of $\mathrm{CO}_{2}$ emissions, $\mathrm{qG}(\mathrm{c})$, as follows.

$\mathrm{G}(\operatorname{Exp})_{\mathrm{i}}=\left[\frac{2 \sum_{\mathrm{i}=1}^{\mathrm{N}} \mathrm{i} \cdot \operatorname{Exp}_{\mathrm{i}}}{\mathrm{N} \sum_{\mathrm{i}=1}^{\mathrm{N}} \operatorname{Exp}_{\mathrm{i}}}\right]-\sum_{\mathrm{i}=1}^{\mathrm{N}}$ i. $\mathrm{c}_{\mathrm{i}}$

where $\operatorname{Exp}_{\mathrm{i}}$ is expenditure of $\mathrm{i}$-th individual (which were ordered by their per capita expenditure).

$q G(c)=\left[\frac{2 \sum_{i=1}^{\mathrm{N}} \mathrm{i}_{\mathrm{i}} \mathrm{c}_{\mathrm{i}}}{\mathrm{N} \sum_{\mathrm{i}=1}^{\mathrm{N}} \mathrm{c}_{\mathrm{i}}}\right]-\left(\frac{\mathrm{N}+1}{\mathrm{~N}}\right)$

where $c_{i}$ refers to the emissions of the $\mathrm{i}$-th individual, but ordered by per capita expenditure. The Kakwani index is then computed by the following formula:

$K=q G(c)-G(\operatorname{Exp})_{i}$

which measures the difference between the concentration of household emissions and household expenditure inequality. A positive number of $\mathrm{K}$ indicates that $\mathrm{CO}_{2}$ emissions are more concentrated along the expenditure distribution (less equally distributed than expenditure), and vice versa.

\subsubsection{Inequality decomposition into emission sources}

Although the Gini index cannot be decomposed into 'between' and 'within' group, we can decompose this index into sources of emissions using the application suggested by Lerman and Yitzhaki (1985) and Stark et al. (1986), employing the following steps. We initially need to divide the overall amount of emissions by the number of households and then rank the households from the lowest to the highest emitter. Then we compute the Gini index of the overall emission, $\mathrm{G}(\mathrm{c})$, using another expression as follows:

$\mathrm{G}(\mathrm{c})=\frac{2}{\mathrm{~N} \mu} \operatorname{Cov}(\mathrm{c}, \mathrm{r})$ 
where $\mathrm{c}$ is the per capita $\mathrm{CO}_{2}$ emissions, $\mu$ is the mean of per capita $\mathrm{CO}_{2}$ emissions for all $\mathrm{N}$ observations (in $\mathrm{kg}$ of $\mathrm{CO}_{2}$ ) from all emission sources, and $\mathrm{r}$ is the rank of the individual according to their emissions.

Modifying (2.8), the Gini index of the i-th source of emissions, G(c) $)_{i}$, can be computed as follows:

$\mathrm{G}(\mathrm{c})_{\mathrm{i}}=\frac{2}{\mathrm{~N} \mu_{\mathrm{i}}} \operatorname{Cov}\left(\mathrm{c}_{\mathrm{i}}, \mathrm{r}_{\mathrm{i}}\right)$

where $c_{i}$ is the per capita emission amount in that particular expenditure category, $\mu_{i}$ is the average per capita emission amount of the $i$-th emission source, and $r_{i}$ denotes the corresponding rank of the individual in that emissions source.

The overall Gini index of the overall per capita $\mathrm{CO}_{2}$ emission amount can be derived from the above individual Gini index of emission source, as follows:

$\mathrm{G}(\mathrm{c})=\sum_{\mathrm{i}} \mathrm{S}_{\mathrm{i}} \mathrm{R}_{\mathrm{i}} \mathrm{G}(\mathrm{c})_{\mathrm{i}}$

where $S_{i}=\frac{\mu_{i}}{\mu}$ is the share of a particular emission source in overall emissions, $\mathrm{R}_{\mathrm{i}}=\frac{\operatorname{Cov}\left(\mathrm{y}_{\mathrm{i}}, \mathrm{r}\right)}{\operatorname{Cov}\left(\mathrm{y}_{\mathrm{i}}, \mathrm{r}_{\mathrm{i}}\right)}$, is the rank correlation ratio of the covariance between the amount of emissions from a particular emission source and the overall emission rank $\left(\operatorname{Cov}\left(y_{i}, r\right)\right)$ to the covariance between the amount of emissions in that particular source and the emission source rank, $\operatorname{Cov}\left(\mathrm{y}_{\mathrm{i}}, \mathrm{r}_{\mathrm{i}}\right)$.

Therefore, we can then estimate what effect a small change has in a particular inequality has on the total inequality given the equation (10), which shows that the overall emission inequality is a product of the three terms, including (i) the share of the average emission amount of a particular source has in total emissions, $S_{i}$, (ii) the correlation between the $i$-th emission source and its rank in overall emission, $\mathrm{R}_{\mathrm{i}}$, and (iii) the emission source Gini, $\mathrm{G}(\mathrm{c})_{\mathrm{i}}$.

In addition, we can measure what marginal effect of a percentage change in the emission source has on the total emission inequality. This will allow us to calculate what kind of an effect a marginal change in a particular emission source 
will have on overall emission inequality. We modified the method proposed by Lerman and Yitzhaki (1985) and Stark et al. (1986). Suppose we have an exogenous change in $\mathrm{i}$ emission source by a factor, say $\mathrm{h}$, such that $\mathrm{c}_{\mathrm{i}}(\mathrm{h})=$ $(1+h) c_{i}$, we can then capture the change as:

$\frac{\partial \mathrm{G}(\mathrm{c})}{\partial \mathrm{h}}=\mathrm{S}_{\mathrm{i}}\left[\mathrm{R}_{\mathrm{i}} \mathrm{G}(\mathrm{c})_{\mathrm{i}}-\mathrm{G}(\mathrm{c})\right]$

Dividing (2.11) by $\mathrm{G}(\mathrm{c})$ yields the following formula:

$\frac{\frac{\partial G(c)}{\partial h}}{G(c)}=\frac{\left.S_{i} R_{i} G(c)\right)_{i}}{G(c)}-S_{i}$

which implies that the relative effect (change) of a percentage in i emission source to the total inequality equals the relative contribution of $i$ emission source to the overall emission inequality minus the relative share of emissions from source $i$ in the total emission amount.

\subsubsection{Data}

As described in more detail in Chapter 1, we use the data on carbon emission from the Global Trade Analysis Project-Environmental Account (GTAP-E), which contains $\mathrm{CO}_{2}$ emissions from energy and cement production but does not include emissions from land-use change, which is also an important factor for the Indonesian case. These emissions are then incorporated with the Indonesian InputOutput (IO) table, and the Indonesian household expenditure survey (Susenas) from the 2005 and 2009 survey. This method is convenient for describing and explaining the environmental impact of different household types (Kok et al., 2006).

We combine the IO analysis with GTAP-E to calculate the cumulative sectoral carbon intensities, which account for the direct and indirect emissions of any particular economic sectors. Expenditure amounts on consumption items in Susenas are multiplied with the corresponding emission intensity from the IO- 
GTAP computation. Then by summing the $\mathrm{CO}_{2}$ emissions from any particular consumption category we get the household carbon footprint.

Technically, the total households' $\mathrm{CO}_{2}$ emissions can be computed by summing up the direct $\left(\mathrm{c}_{\mathrm{dir}}\right)$ and indirect $\left(\mathrm{c}_{\mathrm{ind}}\right)$ emissions, as follows:

$\mathrm{c}_{\mathrm{hh}}=\mathrm{c}_{\mathrm{dir}}+\mathrm{c}_{\mathrm{ind}}$

while the direct emissions consist of domestic energy consumption and transport, the indirect emissions account for emissions embodied in the consumption related to household operations, food expenditures, service-oriented goods and other expenditure items. The indirect emissions are calculated by tracing the emissions of a certain household expenditure item down to its intermediates in the IO table, employing the methods of IO analysis in estimating the embodied carbon emissions (e.g. Parikh, et al., 1997; Lenzen, 1998; Bin and Dowlatabadi, 2005; Kok et al., 2006). The sectoral $\mathrm{CO}_{2}$ emission intensities, $\mathrm{EI}_{\mathrm{j}}$, can be computed by utilizing the following formula:

$E I_{j}=e^{\prime}(I-A)^{-1} y$

$\mathrm{EI}_{\mathrm{j}}$ is the carbon intensity of each economic sector in the IO table, e is a vector of carbon coefficients taken from the GTAP (Lee, 2008). A is the technical coefficients, while $(\mathrm{I}-\mathrm{A})^{-1}$ is widely known as the Leontief inverse; $\mathrm{y}$ is the vector of final demand for commodities. We then match $\mathrm{j}$ carbon intensity (2.14) with the i consumption categories taken from household expenditure as follows:

$c_{\text {ind }}=\sum E_{j} \cdot \operatorname{Exp}_{\mathrm{i}}$

We found that the average Indonesian carbon footprint ${ }^{22}$ in 2005 were $698 \mathrm{~kg}$ $\mathrm{CO}_{2} /$ capita and increased to $898 \mathrm{~kg} \mathrm{CO} /$ capita in 2009 (expenditure deflated, $2005=1)^{23}$. When disaggregating across expenditure quintiles, there is a huge disparity in emissions across affluence quintiles (Figure 2.1), which indicates that there are large differences between the household carbon footprints across

${ }^{22}$ The $\mathrm{CO}_{2}$ emissions are scaled up to national account expenditure.

${ }^{23}$ Per capita emission is about $1,239 \mathrm{~kg}$ (without deflated expenditure). 
different household affluence level. For instance, the per capita emission amount of the richest quintile is almost seven times as high as the carbon footprint of the poorest quintile, and still about three times as high as the level of the third quintile (middle affluence group). Considering such large differences of household emissions, it is then sensible to analyze emission inequality of different household affluence as can be explained further in the following sections.

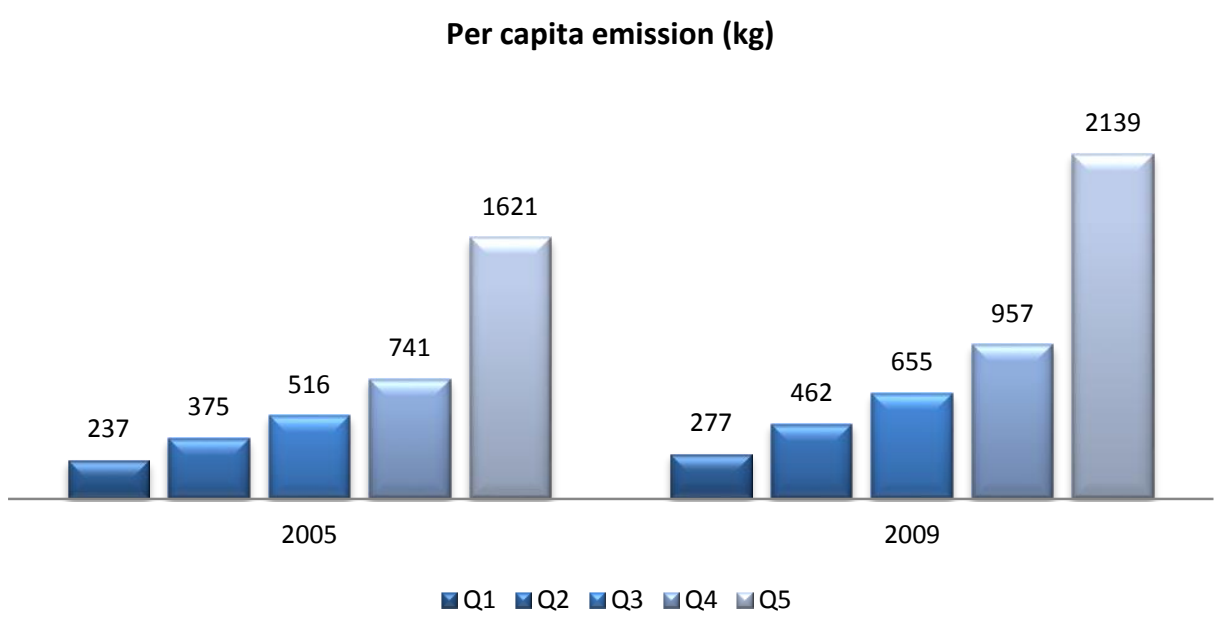

Figure 2.1 Per capita emission by affluence quintile (2005 and 2009)

Source: Author's computation based on Susenas 2005-2006, IO 2005, GTAP-E 2005

\subsection{Results and discussions}

\subsubsection{Household characteristics and emission share}

We begin with providing a simple measure of inequality by computing the share of per capita emission from the overall figures, as shown in Table 2.1. First, by classifying observations into five quintiles based on per capita expenditure, it is clearly shown that the average per capita emission contribution increased in line with the rise in expenditures. In the 2005 survey, the richest quintile contributed about $46 \%$ of total emissions (48\% in 2009) compared to the fourth quintile at $21 \%(21 \%)$, the third quintile at about $15 \%(15 \%)$, the second quintile at about $11 \%(10 \%)$, and the poorest quintile at about $7 \%(6 \%)$. In other words, the individuals from the richest household emit more than 7 times ( 8 times) the 
amount that the first and the second quintile emit. In general, these figures clearly suggest similar patterns of the share of emissions among household groups in both surveys.

Table 2.1 Per capita emission and emission share

\begin{tabular}{|c|c|c|c|c|c|c|}
\hline & \multicolumn{2}{|c|}{$\begin{array}{l}\text { Mean of per capita } \\
\text { emission }\left(\mathrm{kg} \mathrm{CO} \mathrm{CO}_{2}\right)\end{array}$} & \multicolumn{2}{|c|}{$\begin{array}{l}\text { Share of per capita } \\
\text { emission ( \% of total } \\
\text { emission) }\end{array}$} & \multicolumn{2}{|c|}{$\begin{array}{c}\text { Share of obs. (\% of total } \\
\text { obs.) }\end{array}$} \\
\hline & 2005 & 2009 & 2005 & 2009 & 2005 & 2009 \\
\hline \multicolumn{7}{|l|}{ Affluence } \\
\hline Poorest & 237 & 382 & 6.80 & 6.17 & 20 & 20 \\
\hline $2^{\text {nd }}$ & 375 & 638 & 10.75 & 10.29 & 20 & 20 \\
\hline Middle & 516 & 904 & 14.77 & 14.59 & 20 & 20 \\
\hline $3^{\text {rd }}$ & 741 & 1,321 & 21.24 & 21.32 & 20 & 20 \\
\hline Richest & 1,621 & 2,952 & 46.44 & 47.64 & 20 & 20 \\
\hline \multicolumn{7}{|l|}{ Location } \\
\hline Rural & 489 & 952 & 31.81 & 35.03 & 62.52 & 64.72 \\
\hline Urban & 1,047 & 1,766 & 68.19 & 64.97 & 37.48 & 35.28 \\
\hline \multicolumn{7}{|l|}{ Education } \\
\hline Did not grad & 570 & 1,113 & 13.01 & 16.32 & 19.06 & 17.51 \\
\hline Elementary & 577 & 1,114 & 13.17 & 16.34 & 43.34 & 41.91 \\
\hline Secondary & 680 & 1,191 & 15.52 & 17.46 & 16.69 & 16.62 \\
\hline High school & 940 & 1,468 & 21.45 & 21.52 & 16.62 & 17.98 \\
\hline At least college & 1,615 & 1,934 & 36.85 & 28.36 & 4.30 & 5.98 \\
\hline \multicolumn{7}{|l|}{$\begin{array}{l}\text { If } \mathrm{s} / \mathrm{he} \text { is member of } \mathrm{x} \\
\text { persons } \mathrm{HH}\end{array}$} \\
\hline 1 & 1,408 & 4,767 & 24.51 & 38.28 & 1.31 & 1.53 \\
\hline 2 & 1,035 & 2,336 & 18.02 & 18.76 & 5.98 & 6.79 \\
\hline 3 & 830 & 1,589 & 14.45 & 12.76 & 15.91 & 17.03 \\
\hline 4 & 733 & 1,242 & 12.76 & 9.97 & 24.55 & 25.03 \\
\hline 5 & 656 & 1,010 & 11.42 & 8.11 & 21.04 & 20.83 \\
\hline 6 & 581 & 850 & 10.11 & 6.83 & 14.4 & 13.57 \\
\hline $7+$ & 501 & 659 & 8.73 & 5.29 & 16.81 & 15.21 \\
\hline \multicolumn{7}{|l|}{ Gender } \\
\hline Male & 706 & 1,213 & 50.59 & 48.95 & 50.23 & 50.13 \\
\hline Female & 690 & 1,265 & 49.41 & 51.05 & 49.77 & 49.87 \\
\hline \multicolumn{7}{|l|}{ Age } \\
\hline$<30$ & 656 & 1,129 & 22.47 & 20.45 & 59.44 & 55.44 \\
\hline $30-44$ & 736 & 1,262 & 25.18 & 22.85 & 20.21 & 22.1 \\
\hline $45-64$ & 796 & 1,424 & 27.26 & 25.79 & 15.83 & 17.31 \\
\hline $65+$ & 733 & 1,706 & 25.09 & 30.90 & 4.52 & 5.15 \\
\hline $\begin{array}{l}\text { Per capita emission } \\
\text { (number of obs.) }\end{array}$ & 698 & 1,239 & & & $1,052,091$ & $1,155,566$ \\
\hline
\end{tabular}

Comparing locations, in both surveys we can see that the per capita emission of urban households is more than double the amount of those who are living in rural areas. The contribution of urban households to overall emissions in 2005 was about $68 \%$ then decreased to $65 \%$. Meanwhile the per capita emission of rural households had a slight increase in their contribution to total emissions.

Classifying observations according to educational attainment, the figure has a similar pattern to the affluence classification. The contribution of 'at least college' graduates was higher than lower educational attainments. Someone who had 'at 
least college' contributed about $38 \%$ in 2005 (27\% in 2009), compared to elementary school graduate at about $13 \%$ (16\%). Comparing the two years, we can see there was an increasing pattern in the share of emissions from 'did not graduate' to 'high school graduate', while 'at least college graduate' group has a decreasing emission share pattern.

Comparing emissions according to the number of household members, there have been decreasing patterns of per capita emission share from those who are a member of a small family to those who are a member of a large family. If s/he has 2 household members, for instance, per capita emission is about 18\% (19\%) compared to the share of per capita emission from an individual of 6 household members, which contribute of about $10 \%(7 \%)$ to overall emissions.

Comparing gender of household head, the emission share of those who are headed by a female is slightly lower than male-headed households. However, comparing between the two surveys, there was a slight increase in the emission contribution of female household heads, so the contribution to $\mathrm{CO}_{2}$ emissions of female and male headed households are slightly more equal in 2009. Finally, when categorizing households by the age of the household head, we not-surprisingly found that there is an 'inverted U-shape' of the emission share of households, as the share increased until the age of 64 and then lowered after 65 years of age.

\subsubsection{Emission inequality measure by household characteristics}

This section will analyze the disparity in emissions among households through employing the Gini and Theil indices. Classifying observations by their affluence, the conditional Gini coefficient indicates that both in 2005 and 2009 the emission inequality within quintiles has a U-shaped pattern when moving from the lowest to the highest expenditure quintiles (Appendix Table B.2). The poorest and the richest household groups are more unequal in their emission inequality than the middle income quintile (Figure 2.2). This implies that an increase in affluence at lower end of distribution has an equalizing effect on emission while at the upper end of the distribution an increase in income leads to a worsening carbon footprint 
inequality. The middle income groups are more homogenous in term of emission distribution. Of particular reason of this lower inequality within the middle income quintiles is due to the boundaries of those quintiles. Meanwhile, among all quintiles, the richest household group is the most unequal group in their emissions, which is expected due to their greater variations in lifestyle that the richest household group have a large range of expenditures (luxury effect). Comparing the two surveys, similar expenditure inequality, overall emission inequality in 2009 is higher than in 2005 (Appendix Table B.2). This means that rising household emission level overtime is still driven by rising emission among richer households. Furthermore, looking at the within and between inequality component, we indicate that overall emission inequality is largely attributed by the between group inequality component.

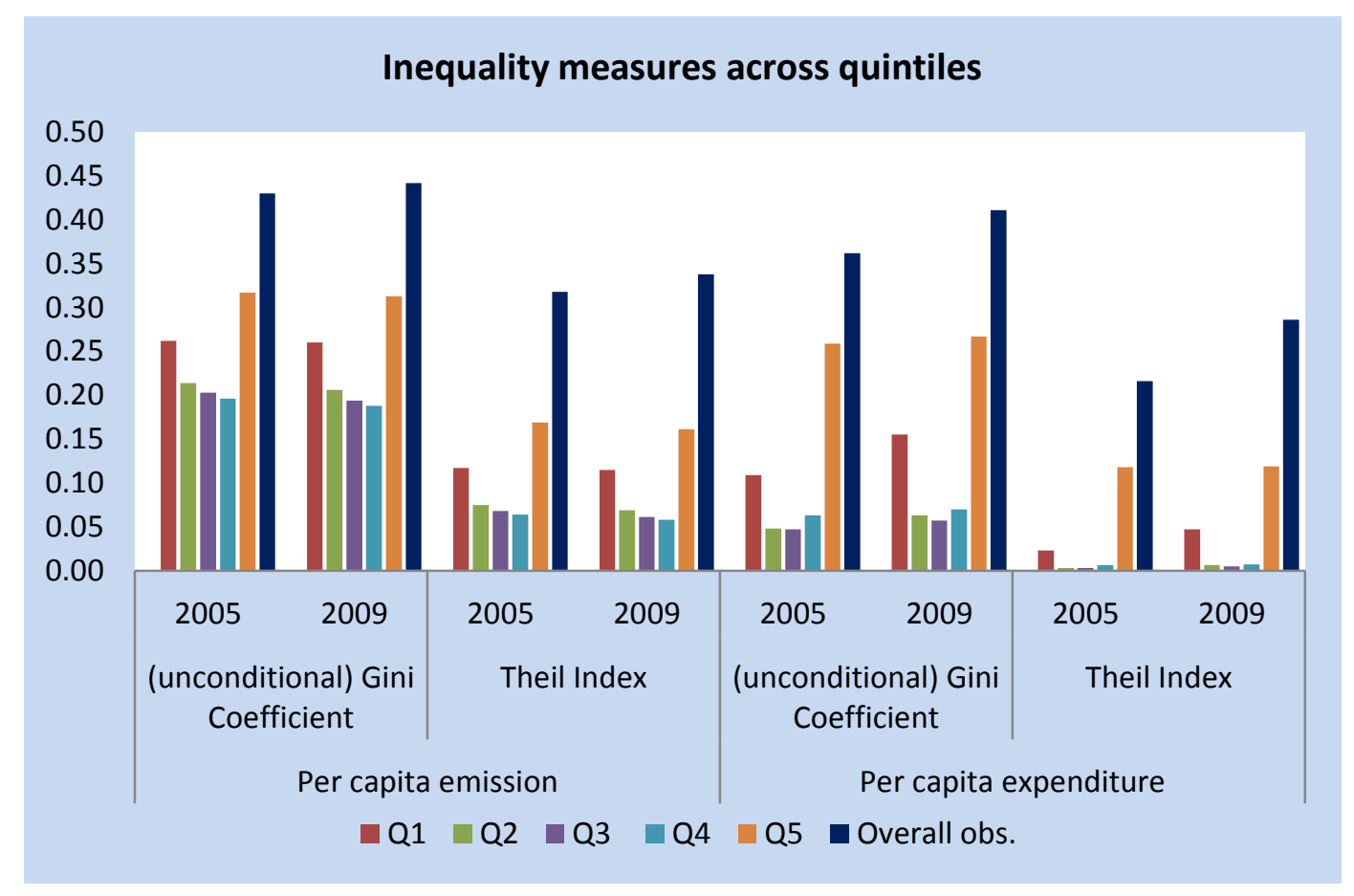

Figure 2.2 Emission inequality measures across quintiles

Source: Author's estimation

Based on location, we indicate that urban household group is slightly more unequal than rural household in both the 2005 and 2009 surveys. We also indicate that the inequality is mostly due to within-group inequality (Appendix Table B.2). One possible explanation is that urban household seems to have wide range 
of expenditure (source of emissions) that leads to make higher emission inequality measure than rural households. Based on educational attainment, we found that the most unequal group is observed amongst households headed with someone who has 'at least college graduate'. Apart from decreasing inequality pattern from without formal education to elementary school graduate, there is an increasing pattern of inequality with respect to higher educational attainment. In addition, the Theil index decomposition indicates that the emission inequality is dominantly attributed to the within group component. The above figures could hint that formal education attainment does not likely change the consumption preferences towards less carbon intensive expenditure items. The more educated a household becomes, the greater the income attained and the more that is spent on carbon intensive consumption items.

Classifying observations based on the number of household members, we observe an U-shape pattern of emission inequality moving from the least to the biggest household size (Appendix Table B.2). There is a decreasing pattern of per capita emission inequality from group of one family member to three members, and it increase from 4 household member groups to the largest household size. A possible explanation could be that it is related to the sharing of resources (energy use) among household members. If a small household generally has a higher per capita energy use, then the emission inequality could be higher. In larger sized households, resources could be shared, thus lowering per capita energy use that would cause emission inequality to decrease. Finally, from the gender classification, we found that in both surveys the male-headed households were more unequal than the female-headed households. We also found an increasing pattern of emission inequality based on the age of the household head. Younger household heads have a lower emission inequality.

\subsubsection{Emission inequality and its relationship with the expenditure distribution}

We compare the inequality distribution of per capita emissions to the inequality distribution of per capita expenditure instead of solely analyzing the emission 
inequality itself. Comparing both figures allows us to evaluate whether the emission distribution is more or less equal than the expenditure distribution. This section compares the computation of emission inequality with the same measure and rank as the expenditure inequality. Table 2.2 shows a descriptive analysis of the per capita emission contribution of all of the household affluence levels from both surveys.

In the 2005 survey, the richest quintile is responsible for about $46 \%$ (45\% in 2009) of total emissions compared to the fourth quintile that contributes about $21 \%(21 \%)$, the middle affluence group contributes about $15 \%(15 \%)$, the $2^{\text {nd }}$ quintile about $11 \%(12 \%)$, and the poorest group contributes about $7 \%(8 \%)$. In other words, the richest group emits (in per capita terms) more than 7 times (8 times in 2009) the amount of the poorest household. Similarly, the pattern of the per capita expenditure shares (to total expenditure) is comparable to the emissions. In 2005 the most affluent household quintile emitted about $48 \%$ of total emissions compared to the poorest household group at 6\%. Finally, comparing the expenditure shares, in both surveys the emission shares were generally higher than the expenditure shares in the two richest groups, which is opposite from the three lowest quintiles. In other words, the emissions are more concentrated relative to the expenditure in the top two quintiles than the lower quintiles. It also means that in 2005 the emission inequality is larger than the expenditure inequality. In 2009, it appears the reverse figure that expenditure is slightly more unequal than emission.

Table 2.2 Per capita emission vs. per capita expenditure: contribution to total

\begin{tabular}{lcccc}
\hline & \multicolumn{2}{c}{$\mathbf{2 0 0 5}$} & \multicolumn{2}{c}{$\mathbf{2 0 0 9}$} \\
\cline { 2 - 5 } & $\begin{array}{c}\text { Per capita } \\
\text { emission }\end{array}$ & $\begin{array}{c}\text { Per capita } \\
\text { expenditure }\end{array}$ & $\begin{array}{c}\text { Per capita } \\
\text { emission }\end{array}$ & $\begin{array}{c}\text { Per capita } \\
\text { expenditure }\end{array}$ \\
\hline Poorest & 6.80 & 7.75 & 6.17 & 5.98 \\
$2^{\text {nd }}$ & 10.75 & 11.51 & 10.29 & 10.30 \\
Middle & 14.77 & 15.20 & 14.59 & 14.64 \\
$4^{\text {th }}$ & 21.24 & 20.98 & 21.32 & 21.26 \\
Richest & 46.44 & 44.56 & 47.64 & 47.83 \\
\hline Gini index & 0.430 & 0.362 & 0.442 & 0.411 \\
Theil index & 0.318 & 0.216 & 0.338 & 0.286 \\
\hline
\end{tabular}

Source: Author's calculation 
In addition to the application of the 'conventional' Gini index, we can also measure emissions inequality by employing the concentration index of $\mathrm{CO}_{2}$ emissions, which is modified from Kakwani et al. (1997). This method basically measures the inequality in emissions by employing the Gini index, but we ranked household $\mathrm{CO}_{2}$ emissions in the distribution according to their expenditures, which is widely called quasi-Gini or the concentration index. We then compared this emission concentration index with the expenditure Gini index. The Kakwani index measures to what extent the distribution of emissions is greater than the distribution of expenditure. It also measures what degree of rich households emit than poor households. Applying this index, we can measure the level of 'regressivity' or 'progressivity' of the emission distribution across observed subgroups (Padilla and Serrano, 2006).

Table 2.3 Concentration of $\mathrm{CO}_{2}$ emissions vs. expenditure Gini

\begin{tabular}{lcccccccr}
\hline & $\begin{array}{c}\text { Unconditional Gini } \\
\text { index of per capita } \\
\text { emissions } \\
(\mathbf{A})\end{array}$ & $\begin{array}{c}\text { Quasi Gini Index } \\
\text { of per capita } \\
\text { emissions } \\
\text { (B) }\end{array}$ & $\begin{array}{c}\text { Gini index of per } \\
\text { capita expenditure } \\
\text { (C) }\end{array}$ & \multicolumn{2}{c}{$\begin{array}{c}\text { Kakwani Index } \\
\text { (D = B-C) }\end{array}$} \\
\cline { 2 - 9 } & $\mathbf{2 0 0 5}$ & $\mathbf{2 0 0 9}$ & $\mathbf{2 0 0 5}$ & $\mathbf{2 0 0 9}$ & $\mathbf{2 0 0 5}$ & $\mathbf{2 0 0 9}$ & $\mathbf{2 0 0 5}$ & $\mathbf{2 0 0 9}$ \\
\hline Poorest & 0.262 & 0.260 & 0.129 & 0.142 & 0.109 & 0.155 & $\mathbf{0 . 0 2 0}$ & $\mathbf{- 0 . 0 1 3}$ \\
$2^{\text {nd }}$ & 0.214 & 0.206 & 0.056 & 0.063 & 0.048 & 0.063 & $\mathbf{0 . 0 0 8}$ & $\mathbf{0 . 0 0 0}$ \\
Middle & 0.203 & 0.194 & 0.053 & 0.059 & 0.047 & 0.057 & $\mathbf{0 . 0 0 6}$ & $\mathbf{0 . 0 0 2}$ \\
$4^{\text {th }}$ & 0.196 & 0.188 & 0.070 & 0.071 & 0.063 & 0.070 & $\mathbf{0 . 0 0 7}$ & $\mathbf{0 . 0 0 1}$ \\
Richest & 0.317 & 0.313 & 0.257 & 0.264 & 0.259 & 0.267 & $\mathbf{- 0 . 0 0 1}$ & $\mathbf{- 0 . 0 0 3}$ \\
\hline Overall & 0.430 & 0.442 & 0.390 & 0.409 & 0.362 & 0.411 & $\mathbf{0 . 0 2 8}$ & $\mathbf{- 0 . 0 0 2}$ \\
\hline Source
\end{tabular}

Source: Author's computation. Note: Quasi Gini Index is based on Concentration Index of $\mathrm{CO}_{2}$ emissions, i.e. Gini index of $\mathrm{CO}_{2}$ emissions ranked by household expenditure (Kakwani et al.,1997).

Table 2.3 portrays the concentration index of per capita emissions versus the Gini index of per capita expenditure. Overall, emissions are similarly unequally distributed as expenditure. Comparing two years for the overall households surveys in 2005 and 2009 tell a different story. In 2005, the overall Kakwani index had positive sign, which indicates that $\mathrm{CO}_{2}$ emission inequality surpasses income inequality. In contrast, the Kakwani index of the 2009 survey has a negative value (but the sign is quite small), which indicates that the $\mathrm{CO}_{2}$ emission distribution conditional on expenditure is slightly less concentrated than the expenditure distribution. From 2005 to 2009, results also show that rising 
emission inequality is lower than rising emission inequality, indicating that unequalizing emission inequality seems less pronounced than un-equalizing income.
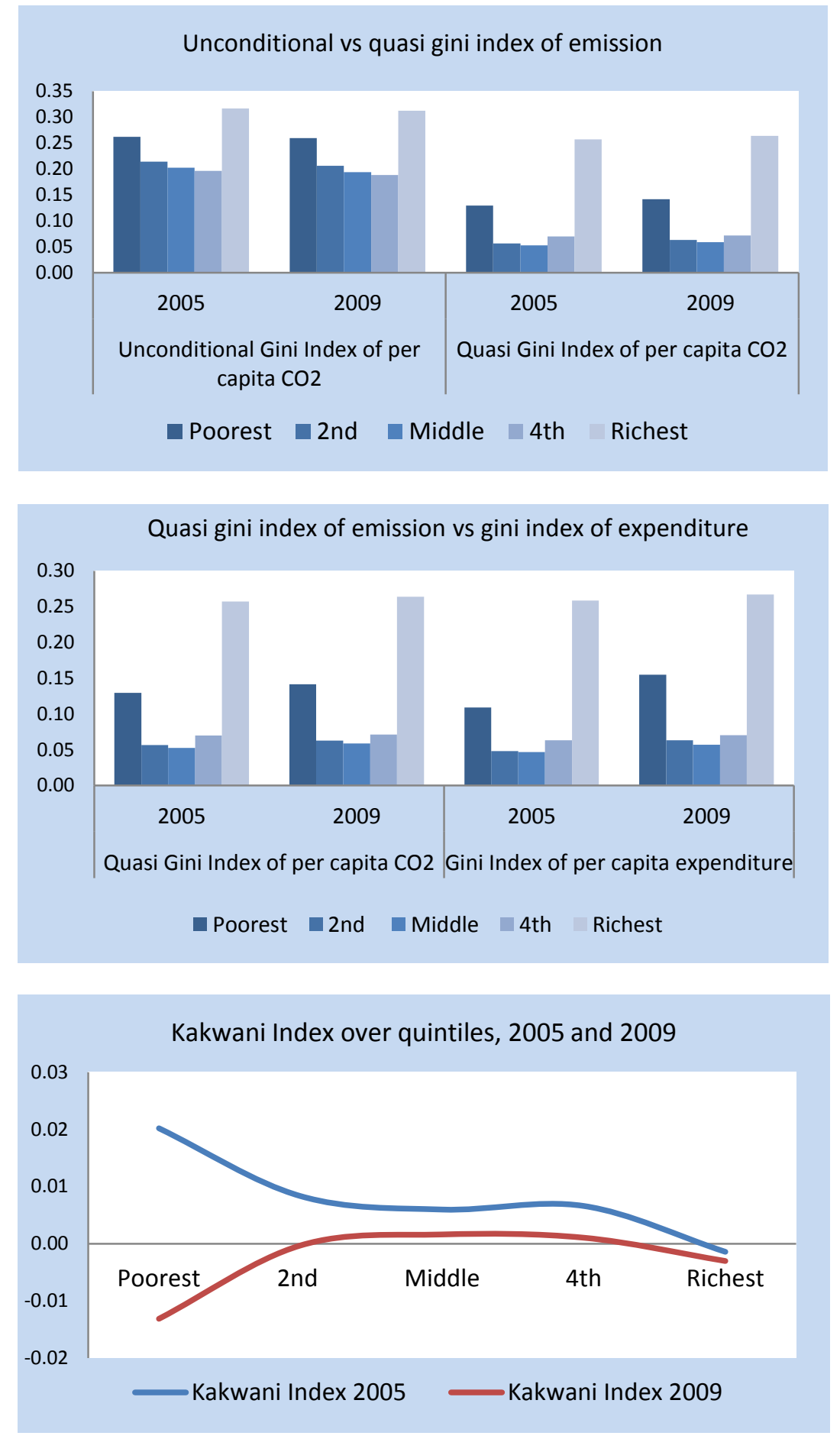

Figure 2.3 Emission vs. expenditure inequality

Source: Author's computation 


\subsubsection{Decomposition and simulation of $\mathrm{CO}_{2}$ inequality by emission sources}

This section provides the decomposition of emission inequality into emission sources (expenditure categories) to determine how they contributed to changing the inequality in emissions as well to see the drivers/contributors of such inequalities and to see the marginal effects of a percentage change in emission sources that will determine the overall emission inequality. It is noticeable from Table 2.4 that fuel-light contributes of about 59\% in 2005 (56\% in 2009) to overall emissions, followed by transportation, which accounts for $6-8 \%$ of the overall emissions. This clearly suggests that these two emission sources (expenditure groups) enormously contributed to the overall emission level. In addition, fuel and light and transportation are highly correlated to total emissions of about $95-96 \%$ and $77-79 \%$, respectively. Therefore, changing people's preferences of them could mainly contribute to the behavior of overall emissions. This also means that the distribution of household emissions can be largely traced from the composition of household consumption of these two carbon intensive categories.

Table 2.4 Gini decomposition by emission sources

\begin{tabular}{|c|c|c|c|c|c|c|c|c|c|c|}
\hline \multirow[t]{2}{*}{ Emission source } & \multicolumn{2}{|c|}{$\begin{array}{c}\text { Share of emission } \\
\text { source }(S k)\end{array}$} & \multicolumn{2}{|c|}{$\begin{array}{l}\text { Gini of emission } \\
\text { sourcea }(G k)\end{array}$} & \multicolumn{2}{|c|}{$\begin{array}{c}\text { Correlation to } \\
\text { total emissions } \\
(R k)\end{array}$} & \multicolumn{2}{|c|}{$\begin{array}{l}\text { Share } \\
=\frac{S_{k} G_{k} R_{k}}{G}\end{array}$} & \multicolumn{2}{|c|}{$\begin{array}{l}\% \text { change } \\
=\frac{S_{k} G_{k} R_{k}}{G}-S_{k}\end{array}$} \\
\hline & 2005 & 2009 & 2005 & 2009 & 2005 & 2009 & 2005 & 2009 & 2005 & 2009 \\
\hline Cereal & 0.015 & 0.016 & 0.261 & 0.379 & 0.013 & 0.403 & 0.000 & 0.005 & -0.015 & -0.010 \\
\hline Vegetable and fruit & 0.038 & 0.040 & 0.381 & 0.434 & 0.637 & 0.711 & 0.021 & 0.028 & -0.016 & -0.012 \\
\hline Oil and fat & 0.007 & 0.007 & 0.343 & 0.402 & 0.379 & 0.547 & 0.002 & 0.004 & -0.005 & -0.004 \\
\hline Beverage & 0.058 & 0.063 & 0.509 & 0.551 & 0.733 & 0.736 & 0.050 & 0.058 & -0.008 & -0.005 \\
\hline Egg, fish, meat, dairy & 0.064 & 0.068 & 0.487 & 0.551 & 0.610 & 0.707 & 0.044 & 0.060 & -0.020 & -0.008 \\
\hline Tobacco & 0.024 & 0.025 & 0.578 & 0.623 & 0.314 & 0.448 & 0.010 & 0.016 & -0.014 & -0.009 \\
\hline Fuel and light & 0.593 & 0.564 & 0.469 & 0.468 & 0.956 & 0.951 & 0.618 & 0.568 & 0.025 & 0.004 \\
\hline Telecommunication & 0.011 & 0.012 & 0.882 & 0.736 & 0.844 & 0.795 & 0.018 & 0.016 & 0.008 & 0.004 \\
\hline Transportation & 0.064 & 0.082 & 0.721 & 0.659 & 0.771 & 0.790 & 0.083 & 0.096 & 0.019 & 0.015 \\
\hline Health & 0.005 & 0.006 & 0.757 & 0.774 & 0.582 & 0.599 & 0.005 & 0.006 & 0.000 & 0.000 \\
\hline Education & 0.008 & 0.010 & 0.783 & 0.775 & 0.575 & 0.623 & 0.008 & 0.011 & 0.000 & 0.001 \\
\hline Toiletry & 0.007 & 0.006 & 0.460 & 0.474 & 0.737 & 0.769 & 0.005 & 0.005 & -0.001 & -0.001 \\
\hline Clothes & 0.016 & 0.017 & 0.509 & 0.532 & 0.627 & 0.708 & 0.012 & 0.014 & -0.004 & -0.003 \\
\hline House and durable goods & 0.045 & 0.042 & 0.881 & 0.889 & 0.760 & 0.753 & 0.069 & 0.063 & 0.025 & 0.022 \\
\hline Services and rent & 0.030 & 0.031 & 0.634 & 0.635 & 0.789 & 0.786 & 0.035 & 0.035 & 0.005 & 0.004 \\
\hline Taxes & 0.001 & 0.002 & 0.844 & 0.817 & 0.754 & 0.753 & 0.002 & 0.002 & 0.001 & 0.001 \\
\hline Recreation, ceremony & 0.016 & 0.013 & 0.854 & 0.904 & 0.523 & 0.544 & 0.017 & 0.014 & 0.001 & 0.002 \\
\hline Per capita $\mathrm{CO}_{2}$ & & & 0.430 & 0.442 & & & & & & \\
\hline
\end{tabular}

Applying the modified methods of Lerman and Yitzhaki (1985) and Stark et al. (1986), we compute the decomposition of the Gini coefficient, which allows us to estimate the marginal effects of each of the consumption categories on the overall emission inequality. A positive (negative) marginal effect indicates that an 
increase in any emission source leads to un-equalizing (equalizing) total household emissions, ceteris paribus. We found that from the household crosssectional analysis, it is noticeable that a $1 \%$ increase in the emissions of fuel-light leads to an increase the total emission inequality to about $0.25 \%$ in $2005(0.04 \%$ in 2009). In other words, a rise in the share of emissions from this category will increase the overall emission inequality (i.e. the distribution of $\mathrm{CO}_{2}$ emissions become more unequal). In contrast, an increase in emissions from cereals will have an equalizing effect of emissions.

In terms of direction, we found that emissions from food, toiletry, and clothesrelated expenditures have an equalizing effect on the distribution of overall emission inequality. On the other hand, an increase in emissions from fuel-light, transportation and services will have a worsening effect on emission inequality. This finding is consistent with the fact that as income rises; the food-related expenditure share decreases, causing people to spend more on durables and services. When households become affluent, they tend to consume more energy, services and durables goods, which leads to an increase in the inequality level of emissions from these sources, contributing to more unequal emissions (particularly in the richest group).

Table 2.5 Gini decomposition by per capita expenditure category

\begin{tabular}{|c|c|c|c|c|c|c|c|c|c|c|}
\hline \multirow{2}{*}{ Expenditure category } & \multicolumn{2}{|c|}{$\begin{array}{c}\text { Share of } \\
\text { expenditure }(S k)\end{array}$} & \multicolumn{2}{|c|}{$\begin{array}{c}\text { Gini of } \\
\text { expenditure } \\
\text { category }(G k)\end{array}$} & \multicolumn{2}{|c|}{$\begin{array}{c}\text { Correlation to } \\
\text { total expenditure } \\
(R k)\end{array}$} & \multicolumn{2}{|c|}{ Share $=\frac{S_{k} G_{k} R_{k}}{G}$} & \multicolumn{2}{|c|}{$\begin{array}{l}\text { \%Change } \\
=\frac{S_{k} G_{k} R_{k}}{G}-S_{k}\end{array}$} \\
\hline & 2005 & 2009 & 2005 & 2009 & 2005 & 2009 & 2005 & 2009 & 2005 & 2009 \\
\hline Cereal & 0.126 & 0.123 & 0.255 & 0.376 & 0.247 & 0.588 & 0.022 & 0.066 & -0.104 & -0.057 \\
\hline Vegetable and fruit & 0.082 & 0.079 & 0.379 & 0.432 & 0.712 & 0.771 & 0.061 & 0.064 & -0.021 & -0.015 \\
\hline Oil and fat & 0.025 & 0.023 & 0.343 & 0.402 & 0.520 & 0.650 & 0.012 & 0.015 & -0.013 & -0.008 \\
\hline Beverage & 0.146 & 0.142 & 0.451 & 0.499 & 0.816 & 0.818 & 0.148 & 0.141 & 0.002 & -0.001 \\
\hline Egg, fish, meat, dairy & 0.132 & 0.126 & 0.452 & 0.513 & 0.768 & 0.805 & 0.126 & 0.127 & -0.006 & 4.0E-04 \\
\hline Tobacco & 0.077 & 0.073 & 0.576 & 0.622 & 0.468 & 0.569 & 0.057 & 0.063 & -0.020 & -0.010 \\
\hline Fuel and light & 0.064 & 0.057 & 0.469 & 0.468 & 0.769 & 0.785 & 0.064 & 0.051 & 0.000 & -0.006 \\
\hline Telecommunication & 0.028 & 0.029 & 0.882 & 0.736 & 0.853 & 0.812 & 0.058 & 0.042 & 0.030 & 0.013 \\
\hline Transportation & 0.046 & 0.054 & 0.721 & 0.659 & 0.757 & 0.785 & 0.069 & 0.068 & 0.023 & 0.014 \\
\hline Health & 0.020 & 0.024 & 0.759 & 0.775 & 0.653 & 0.665 & 0.027 & 0.030 & 0.007 & 0.006 \\
\hline Education & 0.032 & 0.035 & 0.783 & 0.775 & 0.545 & 0.684 & 0.037 & 0.045 & 0.006 & 0.010 \\
\hline Toiletry & 0.028 & 0.024 & 0.460 & 0.474 & 0.735 & 0.794 & 0.026 & 0.022 & -0.002 & -0.002 \\
\hline Clothes & 0.034 & 0.032 & 0.509 & 0.532 & 0.664 & 0.766 & 0.031 & 0.032 & -0.002 & $-3.0 \mathrm{E}-04$ \\
\hline House and durable goods & 0.036 & 0.031 & 0.881 & 0.889 & 0.778 & 0.745 & 0.068 & 0.050 & 0.032 & 0.019 \\
\hline Services and rent & 0.134 & 0.127 & 0.614 & 0.604 & 0.856 & 0.841 & 0.194 & 0.157 & 0.060 & 0.030 \\
\hline Taxes & 0.010 & 0.011 & 0.822 & 0.792 & 0.760 & 0.757 & 0.017 & 0.017 & 0.007 & 0.005 \\
\hline Recreation, ceremony & 0.015 & 0.011 & 0.854 & 0.904 & 0.563 & 0.559 & 0.020 & 0.013 & 0.005 & 0.002 \\
\hline Per capita expenditure & & & 0.362 & 0.411 & & & & & & \\
\hline
\end{tabular}

It is also fruitful to compare the figure of the emission inequality decomposition with the inequality decomposition of expenditure sources as shown in Table $\mathbf{2 . 5}$. 
Here we indicate that fuel-light expenditures no longer have a large contribution to overall expenditure inequality (only about $6 \%$ ). The biggest portion is services, beverage and egg-fish-dairy products.

We further aggregate the emission source and expenditure sources as shown in Table 2.4 and Table 2.5 into four major emission (expenditure) categories, namely food, energy and transportation, housing operation and durables, and services ${ }^{24}$. We then compute the same application to get a deeper understanding of the sources of inequality in emissions and expenditure. The results are summarized in Figure 2.4.

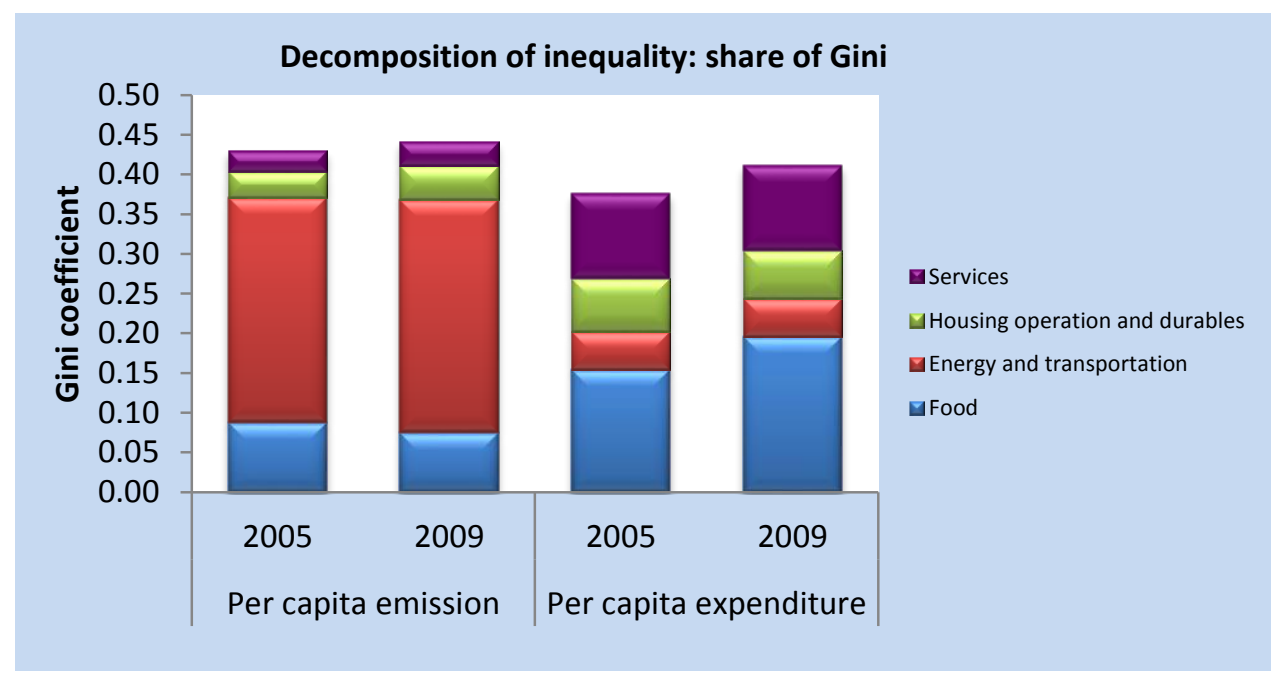

Figure 2.4 Sources of inequality: emission vs. expenditure

Source: Author's computation based on share of Gini

We indicate that there was an increase in the emission and expenditure inequality measure from 2005 to 2009 . However, we observed a different story about the contributors to the inequalities in emissions and expenditure. For the emission inequality contributors, it is noticeable that in both years, energy-transport is responsible for more than two-thirds of the overall emission inequality, followed by services and household operations, so if we get rid of the disparity in the energy-transport emissions, then the overall emission inequality will reduce by the

\footnotetext{
24"Food" refers to emissions from cereals, vegetables and fruits, oil and fats, eggs fish, meat and dairy, and tobacco; "Energy and transportation" captures the emissions from fuel-light and transportation; "Housing operations and durables" represents emissions from house operation and durables, toiletry, and telecommunication; "Services" represents emissions from health, education, services sectors and rent, tax and redistribution, and recreation and ceremony.
} 
same amount. For expenditure inequality, we found that the main contributors to inequality are food (mainly beverages) and services.

\subsection{Conclusion}

This study investigates the dispersion in per capita $\mathrm{CO}_{2}$ emissions by employing various measures of inequality and then comparing the differences between the emission and expenditure inequality indices. We also decompose emission inequality based on household affluences, socio-demographic factors as well as sources of emissions to assess the patterns and drivers of inequality. Disaggregating emission inequality into any particular within-group inequality based on different household characteristics assumes that different characteristics would have different within-inequality measure in emissions. And decomposing inequality by emission sources aims to measure the contribution of emission shares and to study the marginal effects of changes in different emission sources to the change in overall emission inequality.

We found that as household affluence increases, emission inequality tends to decline until the middle household affluence group, but then increases and worsens emission inequality until the richest group, which is the most unequal group in terms of the within group inequality measure of emissions. This evidence could hint that the variation in consumption preferences (lifestyle), particularly toward emission-intensive items, determines overall emission inequality. As the inequality measure based on household affluence, the emission inequality figure based on educational attainment has a similar pattern. Classifying observation according to the number of household members, we observe an U-shaped pattern of inequality figures from the smallest to the largest household size group. Based on location, the per capita emissions in urban areas are observed to be more unequal than the figure from rural households. Based on gender, we found that the group of male-headed households is more equal than the female-headed group. Based on the age of household head, we found younger household head groups have a lower emission inequality. In addition, dividing observation based on their affluence, we found a dominant contribution of "between group" component of 
inequality compare to between-group component. However, classifying based on non-expenditure characteristics, we found that "within-group inequality" dominates overall inequality.

The decomposition analysis of inequality based on emission sources suggests that in both years, energy-transport emissions were responsible for more than twothirds of the overall emission inequality. It is then noticeable that the change in overall emissions can be reflected by dominant contribution of energy-related emission source and to some extent attributed to a rise in the share of emissions from services, durable goods and luxury. The decomposition of the emission and expenditure inequality suggests a different story about the contributors to inequalities in emission and expenditure. While the largest contributor to emission inequality is energy-transport (followed by services and household operations), food (mainly beverages) and services are the largest contributors to the expenditure inequality.

Although there are only a limited number of empirical studies related to household emissions inequality, we could compare this study to international (cross-country), national and regional perspectives to investigate whether our household level analysis mirrors the results from more macro perspectives. One piece of evidence suggests that emission inequality is dominantly explained by the between-affluence component, which is reasonably consistent with Clarke-Sather et al. (2011) for a provincial-level analysis in China. Other studies (e.g. Padilla and Serrano, 2006; Levy et al., 2009; Duro and Padilla, 2006) report that inequality between groups of different income levels largely explains the overall emission inequality. Our findings then suggest that the level of affluence dominates the emission inequality, although non-income characteristics might also contribute to the overall emission inequality.

Finally, the improvements in the standard of living of poor households may initially promote a declining the emission inequality, as indicated by the decomposition of inequality across affluence quintiles. Yet a balanced development has to be sought out as growth in the higher quintiles, particularly the two richest quintiles will then push emission inequality wider. Therefore, 
rising environmental awareness from the demand side could be taken in line with providing households with greener consumption items, green infrastructure, and sustainable (public) transport system. A carbon tax could be also introduced in line with a gradual reduction (and better targeting of) fossil fuel subsidies. Another important strategy in reducing emission inequality is the effort towards the improvement of energy and carbon efficiency allowing households, at any level of affluence, to consume carbon-efficient consumption items that will not merely reduce the emission level but also reduce the emission inequality. 
Chapter 3 : Examining causality between economic development, energy consumption, and emissions in Indonesia 


\title{
Examining causality between economic development, energy consumption, and emissions in Indonesia
}

\begin{abstract}
This chapter investigates the causality nexus between emissions, energy use and economic performance along with urbanization and capital formation (investment activity) taking Indonesia as a case study, employing single equation ECM, VECM, DOLS, and the augmented-VAR approach to investigate the presence and direction of long-run and short-run causality amongst variables. We found the direction of long-run causality running from output and energy consumption to emissions but not in opposite direction from emissions to output and energy consumption, suggesting the possibility of reducing emissions without impeding growth. The short-run augmented-VAR approach found similar evidence of a unidirectional Granger causality running from output to emissions but not in the opposite direction, indicating that green growth could be also possible in the short run. Urbanization and capital formation will unsurprisingly increase energy consumption but could be carbon-neutral if energy efficiency, sustainable urban development and green investment are promoted. Results also indicate that the greater variations of emissions in the longer period are mainly due to rising economic performance.
\end{abstract}

Keywords: economic growth, emission, energy use, causality 


\subsection{Introduction}

Over the last two decades Indonesia has come a long way in its socio-economic development with relatively fast and stable economic growth. Although there was a deep recession during the Asian economic crisis at the end of 1990s, since that period the economy emerged significantly growing at about $5-7 \%$ per year. The pace did not change even with the recent global crisis in 2008; while the United States and European Union countries have been experiencing a recession, Indonesia has been growing above the country averages. The Indonesian government even has set for itself the ambitious target of becoming one of the ten largest economies in the world by 2025 with an expected per capita income of USD 14,250-15,500 (Ministry of National Planning, 2011).

However, the figures of environmental damage have also amplified as a consequence of the fast growing economy in the last decades. Among emerging economies, this country is one of main contributors of world $\mathrm{CO}_{2}$ emissions as well as one of the most accelerating contributors to global emissions (EDGAR, 2011) $)^{25}$. Along with deforestation, industrial based economic growth and rising middle-income class consumption are what lead to this rising $\mathrm{CO}_{2}$ emissions profile. The growing trend of $\mathrm{CO}_{2}$ emissions generates debatable issues, particularly for Indonesia. One of central questions is whether Indonesia can push growth without causing environmental degradation, or whether this country can implement emission reduction without impeding growth. To address these issues, this study will examine the econometric relationships between output, emissions and socio-economic development, including rising urbanization and investment.

Recent studies investigated the relationship between GHG emissions (mainly $\mathrm{CO}_{2}$ emissions) and socio-economic development, ranging from cross or panel studies (e.g. Selden and Song, 1994; Dinda and Coondoo, 2006; Coondoo and Dinda, 2002; Baek et al., 2008; Bernard et al., 2011; Choi et al., 2010; Martinez-Zarzoso and Maroutti, 2011) to more specific national/regional analyses (e.g. Zaman, 2010; Zhang and Cheng, 2009; Tiwari, 2011; Akbostanci et al., 2009; Nasir and

\footnotetext{
${ }^{25}$ See Appendix Table C.12.
} 
Rehman, 2011). As for the determinants of environmental degradation, Shafik (1994) differentiates them into structural and policy drivers; which are as follows: (1) endowment, such as location and climate; (2) income, reflecting the production structure, private consumption patterns, and urbanization; (3) other exogenous factors such as technology in particular; and (4) policies, reflecting public decisions related to environmental public goods.

One of the central issues in the literature on development and the environment (climate change) is a question regarding the relationship between $\mathrm{CO}_{2}$ emissions, economic growth, and energy use. A quick glance at the literature shows that there are at least three nexuses for the relationships of the three variables, which are as follows. The first nexus basically focuses on income and energy use that proposes as the economy grows, energy consumption increases as one of the important elements in making growth possible. In this line of research, a number of studies (e.g. Kraft and Kraft, 1978; Masih and Masih, 1996, 1997; Narayan et al., 2008) generally measure the existence and direction of causality between economic growth and energy consumption. In the US case, Kraft and Kraft (1978), for instance, found the evidence of an income to energy use unidirectional Granger-causality. Moreover, Masih and Masih (1996) and Narayan et al. (2008) investigated this income-energy use causality using countries panel data, but they found that in some cases the causality is ambiguous.

The second nexus deals with the examination of the impact of economic growth on environmental degradation. One of most popular arguments is the hypothesis of the Environmental Kuznets Curve (EKC) that suggests an inverted U-shape relationship between economic performance and environmental degradation (e.g. Selden and Song, 1993; Grossman and Krueger, 1995; Stern, 2004; Dinda and Coondoo, 2006; Akbostanci et al., 2009; Martinez-Zarzoso and Maroutti, 2011; Nasir and Rehman, 2011). However, it is found that their results, whether employing cross-country or single country data, differ substantially and are to some extent inconclusive. For instance, Grossman and Krueger (1995), employing the reduced-form relationship between per capita income and a number of environmental indicators including emissions, indicated no evidence that steady 
environmental degradation correlates with economic performance, but for most environmental indicators, a growing economy reasonably causes an initial stage of environmental decline. Selden and Song (1993), which investigate the EKC for four air pollutants, found that per capita emission of all emission sources reveal an inverted-U relationships pattern with respect to per capita output, suggesting that the emissions will decrease in the long-run.

However, numerous studies suggest that the discussion on EKC is inadequate. For instance, Coondoo and Dinda (2002) and Dinda and Coondoo (2006) propose that there are at least two arguments on this matter. First, the EKC assumption of unidirectional causality from income to emissions could be over-simplistic as environment (less emission) might affect further consumers' wellbeing as well as future income ${ }^{26}$. Second, more importantly, it just assumes the immediacy in causality, i.e. change in one variable would instantly cause change in other variables. In other words, it does not distinctively highlight the dynamic process of change, which is essential in the EKC relationships.

To get a better understanding of the interplay between income and emissions, Coondoo and Dinda (2002) and Dinda and Coondoo (2006) utilize the intertemporal choice model'. Suppose an economy has $\mathrm{E}(\mathrm{t}), \mathrm{K}(\mathrm{t})$, and $\mathrm{C}(\mathrm{t})$ that indicate environment, capital stock, and consumption at time t, and assume there is $\theta(t)$ $(0<\theta(t)<1)$ portion of $\mathrm{K}$ is used for production and the remaining $1-\theta(\mathrm{t})$ of its fraction is allocated for environmental upgrading. Assume there is $\gamma(\gamma>0)$ of pollution rate (in our case, emission per output), then the infinite time horizon 'inter-temporal choice' could be identified by the following:

$\operatorname{Max} W=\int_{0}^{\infty} e^{-\rho t} U(C(t), E(t)) d t$

which would be subject to the accumulation constraints related to the physical capital formation, $\dot{\mathrm{K}}=\mathrm{f}(\theta \mathrm{K}(\mathrm{t}), \mathrm{E}(\mathrm{t}))-\mathrm{C}(\mathrm{t})$, and accumulation constraints related to the net environmental change from production as well as upgrading the

${ }^{26}$ It is suggested that emission can affect consumers' wellbeing since it is considered as excludable public goods, and can affect income creations by being virtual input to generate further output (Dinda and Coondoo, 2006). 
environment, $\dot{E}=g((1-\theta) K(t), E(t))-\gamma f(\theta K(t), E(t))$. In this case, $\rho(>0)$ is the discount rate while $\mathrm{f}(\cdot)$ and $\mathrm{g}(\cdot)$ represent the production and environmental upgrading functions, respectively. Considering $\mathrm{K}(\mathrm{t})$ and $\mathrm{E}(\mathrm{t})$ as state variables while $\mathrm{C}(\mathrm{t})$ and $\theta$ as control variables, the above problem has optimal condition which can be expressed as follows:

$\alpha(\mathrm{t}) \frac{\dot{\mathrm{C}}(\mathrm{t})}{\mathrm{C}(\mathrm{t})}+\beta(\mathrm{t}) \frac{\dot{\mathrm{E}}(\mathrm{t})}{\mathrm{E}(\mathrm{t})}-\phi(\mathrm{t})=0$

where $\alpha(t)=\frac{C(t) U_{C C}}{U_{C}}, \beta(t)=\frac{E(t) U_{C E}}{U_{C}}$, and $\phi(t)=\left(-\frac{f_{K} g_{K}}{g_{K}+\gamma f_{K}}+\rho\right)$

$\mathrm{U}_{\mathrm{C}}, \mathrm{U}_{\mathrm{CC}}, \mathrm{U}_{\mathrm{CE}}$ are the $1^{\text {st }}$ - and $2^{\text {nd }}$ - order partial derivatives of $\mathrm{U}(\cdot)$, while $\mathrm{f}_{\mathrm{K}}$ and $\mathrm{g}_{\mathrm{K}}$ represent the $1^{\text {st }}$-order derivative of $f(\cdot)$ and $g(\cdot)$ with respect to $K$, respectively.

The above conditions propose that the time paths of income (C), and emission (E) should be interdependent, indicating that there would generally exist two-way causality between output and emission. Meanwhile, if we suppose a case where $\mathrm{U}_{\mathrm{CC}}=0$ but $\mathrm{U}_{\mathrm{CE}} \neq 0$, then an autonomously selected path of income (C) suggests that the emission time path $(\mathrm{E})$ will be driven by the optimality condition. Since $\mathrm{E}$ is driven by $\mathrm{C}$ (autonomous), we can say to have the case of the income to emission uni-directional causality. Last, for the case where $\mathrm{U}_{\mathrm{CC}}=0$ but $\mathrm{U}_{\mathrm{CE}}=0$, the time path of $\mathrm{C}$ is driven conditional upon the autonomously selected time path of $\mathrm{E}$, indicating the emission to income uni-directional causality.

To determine the direction of causality, it is possible to employ a (time-series) econometric causality test to observe the direction of causality between income and emission. The Granger-causality test is one of the widely known applications to test the presence of such statistical feedback effects between (at least) the two series of variables in the system.

In the empirical analysis, Coondoo and Dinda (2002) analyze the incomeemission causality for different groups of countries using the Granger causality test. They found that contrary to developed countries (North America and Western Europe in their study case), which have causality running from emission to 
income, developing countries in Latin America and Oceania show an income to emission uni-directional causality. For Asia and Africa, they found the causality to be bi-directional. Similarly, Dinda and Coondoo (2006), analyze the direction of the income-emission causality by applying a cointegration analysis, Granger causality, and an ECM. They found a bi-directional causal relationship between the two variables for several regions such as Africa, America, Europe, and the whole world.

The third strand of the literature combines the first two nexuses in a single framework, which examines the causality between emissions, energy use, and output. The main idea of this nexus is partly to avoid omitted variable bias problems by modelling income, energy use, and emissions in separate models. A quick glance of the literature showed these studies are mostly conducted for single countries. Zhang and Cheng (2009), Jalil and Mahmud (2009), Tiwari (2011) are among contributors to this group of literature.

In addition to just three variables, numerous studies also add other control variables into the system. For instance, Choi et al. (2010) investigate the relationships between $\mathrm{CO}_{2}$ emissions, output and openness for three countries including China (representing emerging markets), South Korea (representing newly industrialized countries), and Japan (representing developed countries). Employing the VECM for the data from 1971 to 2006, the findings show that there is no uniform evidence of the environmental effects due to economic growth and openness for all countries. The estimated EKC shows different patterns due to differences in national characteristics ${ }^{27}$.

From a policy perspective, this study will also replicate the above investigations by using the case of Indonesia, following the single-country analysis, such as the US case (Soytas et al., 2007), China (Zhang and Cheng, 2009), and India (Tiwari, 2011), which generally links emission, energy use, and economic growth. Soytas et al. (2007), employing the Granger-causality method and including labor and gross fixed capital formation in the model, generally found that although energy

${ }^{27}$ In terms of curve patterns, China has an N-shaped while Japan has a U-shaped. For the relationships between $\mathrm{CO}_{2}$ emissions and openness, Korea and Japan show inverted Ushaped, while China has a U-shaped. 
consumption Granger-causes emissions, income does not Granger cause emissions in the US in the long run. They later propose that economic growth by itself could not become a solution to environmental degradation. For the Chinese case, Zhang and Cheng (2009), also using the Granger causality method but including capital and urban population in the system, found a uni-directional causality running from income to energy consumption and an income to energy use uni-directional causality in the long run. As their findings indicate that neither emissions nor energy use leads to economic growth, they propose that the Chinese government could pursue long-run conservative emissions reduction and energy policies without impeding economic growth. For the Indian case, by applying VECM-Granger causality and the VAR Dolado-Lütkepohl's approach the authors found that emissions Granger-cause output, but energy use does not. In the opposite direction, GDP does not Granger-cause emission, while energy consumption does. Emissions Granger-cause energy use but GDP does not Granger-cause emissions. Their findings suggest that India may choose an energy conservation strategy in line with efficient energy utilization.

Specifically, the objectives of this study are as follows. First we will examine the existence and direction of long-run and short-run causality between economic growth, energy consumption and $\mathrm{CO}_{2}$ emissions employing several recent time series analyses. We further ask whether urbanization, investment (gross-fixed capital formation), and other possible control variables matter. Second, what is the reaction of variables (particularly $\mathrm{CO}_{2}$ emissions) overtime in response to some external shocks (economic growth, energy consumption, urbanization, and investment). Third, we measure the contributions of each variable overtime to other variables as well as how much of any variable can be explained by exogenous shocks to the other variables in the system.

Therefore, the novelties of this study are as follows. First, we will employ a multivariate analysis, which combines the two nexuses of growth-environment and growth-energy into a single model (e.g. Soytas et al., 2007; Zhang and Cheng, 2009; Tiwari, 2011). Second, in terms of the methodological aspect, this study employs various time series applications ranging from the single equation Engle- 
Granger cointegration to Dynamic OLS, Vector Error Correction Estimation, and 'modified' VAR, to partly deal with data properties as well as to employ robustness checks, which will be explained in more detail in the methodology section. Third, this study could fill a gap in the previous literatures by using time series data for the single country of Indonesia (e.g. Saboori and Soleymani, 2011, and Shahbaz et al., 2012)) as we add other possible control variables including urbanization (e.g. Hossain, 2011; Martinez-Zarzoso and Maruotti, 2011), and capital formation (e.g. Soytas et al., 2007; Zhang and Cheng, 2009). Moreover, a single-country time series analysis (Indonesia for this case) may identify a relationship amongst variables and allow us to examine the impact of development conditions (urbanization, capital stock, environmental policies), and other exogenous factors through time. The study conducted for Indonesia using national time-series data would represent a country case study to the literature as well as provide helpful information for policy implications in the sense that it identifies the specific tendencies for that country.

The rest of this paper will be organized as follows. Section 3.2 will provide an overview of Indonesia as a case study. Data, model and estimation strategies will be explained in Section 3.3 followed by Section 3.4, which provides the empirical results and discussions. The final part provides conclusions and possible policy implications.

\subsection{Indonesia: a case study}

Among several interesting features on why Indonesia is an interesting country to analyze due to the economic, demographic, as well as the country's energy policies. First, regarding the overall macroeconomic stance, this country has experienced an economic crisis in 1997-1998 but since then per capita GDP has returned to growth, and has been rising despite the global financial crisis of 2008 . Domestic consumption is the main driver of the economy; which roughly accounted for about $56.7 \%$ of GDP in 2010, followed by investment (32.2\%), and government consumption $(9.1 \%)$. In terms of international trade, Indonesian 
exports depend on natural resource products (mainly gas, crude coal, crude palm oil), which accounted for about $50 \%$ of overall exports (BPS, 2010).

Second, looking at the oil and gas sectors, as the total oil production cannot meet rising consumption, Indonesia has been a net importing country since 2004 and has left the Organization of Petroleum Exporting Countries (OPEC) in 2008. Moreover, this country has been struggling with a huge subsidy on energy (fuels and electricity), which accounted for about 22.9\% of the 2012 overall budget (Ministry of Finance, 2012). In addition, it has caused high opportunity cost and was poorly targeted as $80 \%$ of the fuel subsidies only benefited the highest income quintile (Ministry of Energy and Mineral Resources, 2012).

Third, the challenges in GDP composition and energy subsidies are then strengthened by the demographic development. According to the official census (BPS, 2010), from 240 million population based on 2010 census, $58 \%$ of them are living in Java and Bali (which just account for around 6\% of all Indonesian land area). Massive urbanization has been also another challenge. The urban population accounts for about 44\% (2010) of the total population, double the figure in the 1980s. The expected growth rate of urbanization from 2010 to 2015 is around $1.7 \%$ annually, which is higher than the $1.03 \%$ population growth rate. In addition, the recent report of the median age of the total population is 28.5 years, meaning there is a demographic bonus since $17.1 \%$ and $42.2 \%$ of population is around 15-24 and 25-54 year old, respectively.

\subsection{Data and estimation strategies}

\subsubsection{Data and theoretical model}

We use annual data from 1971 to 2010 of $\mathrm{CO}_{2}$ emissions (in $\mathrm{kg}$ per capita), real per capita GDP (in constant 2000 USD), energy consumption (in $\mathrm{kg}$ oil equivalent per capita), urban population, and capital formation. All data are taken from 
World Development Indicators (WDI) ${ }^{28}$. Historical data are shown in Appendix

\section{Figure C.1.}

We utilize several estimation techniques to analyze the long-run and short-run causality between emission, energy consumption and economic development. First we employ a log linear specification to measure long-run causality between emission, energy consumption and output using OLS estimates as benchmark. The long-run causality can be expressed as follows:

$\mathrm{LNCO}_{2 \mathrm{CP}_{\mathrm{t}}}=\alpha_{0}+\alpha_{1} \mathrm{LNECP}_{\mathrm{t}}+\alpha_{2} \mathrm{LNYCP}_{\mathrm{t}}+\varepsilon_{\mathrm{t}}$,

where $\mathrm{LNCO}_{2} \mathrm{CP}_{\mathrm{t}}, \mathrm{LNECP}_{\mathrm{t}}$, and $\mathrm{LNYCP}_{\mathrm{t}}$ represent per capita $\mathrm{CO}_{2}$ emission, per capita energy use, and per capita output (all in natural logarithm), respectively. $\varepsilon_{\mathrm{t}}$ is the error term assumed to be iid $\left(0, \sigma^{2}\right)$. We also implement adequately modified equations utilizing LNECP and LNYCP as the dependent variables.

\subsubsection{Tests for univariate integration, multivariate cointegration, and short-run estimations}

Before the examination of long-run causality, we follow common practice in time series econometric analysis since classical OLS regression properties only hold when the variables are integrated at level, I(0), or stationary. In most cases however economic variables are just integrated in the first difference, I(1), or higher, hence they do not satisfy classical assumptions. The first step is to determine the order of integration of each series of variables. We employ the standard technique Augmented Dickey-Fuller (ADF) (Dickey and Fuller, 1979), and Phillip-Perron (PP) (Phillips and Perron, 1988) unit root tests on individual

\footnotetext{
${ }^{28}$ The WDI basically reports the per capita $\mathrm{CO}_{2}$ emissions from Carbon Dioxide Information Analysis Center (CDIAC) that calculates $\mathrm{CO}_{2}$ emissions from the burning of fossil fuels and the manufacture of cement. They also include $\mathrm{CO}_{2}$ produced during consumption of solid, liquid, and gas fuels and gas flaring (http://cdiac.ornl.gov/). The data of energy of the WDI are taken from International Energy Agency (IEA) Statistics that accounts use of primary energy before transformation to other end-use fuels, which equals to indigenous production plus imports and stock changes, minus exports and fuels supplied for international transport (http://www.iea.org/stats/index.asp).
} 
series in levels, first differences, second differences. The null hypothesis is that the series contains a unit root (non-stationary).

Variables do not satisfy the OLS assumption when they are integrated of order 1 or higher, but if an error correction mechanisms or a long-run relationship exists, we can interpret the OLS estimation as the long-run relationship. In this case, the variables are supposed to be cointegrated and OLS estimation of these cointegrated variables may be super-consistent.

Numerous methods are commonly applied to examine the presence of cointegration. We first apply the Engle-Granger cointegration method (Granger, 1986; Hendry, 1986; Engle and Granger, 1987). This test basically argues that two or more variables are cointegrated (they reveal long-run equilibrium relationship) if they share common trends (Masih and Masih, 1996). Granger (1986, 1988) argues that if two variables are cointegrated, one can rule out the non-causality. Given this, there should exist causality, in the Granger sense, being either unidirectional or bidirectional ${ }^{29}$.

Technically, this approach suggests conducting a unit root analysis to the OLS residuals of the supposed long-run model to detect the presence of cointegration. If residuals are stationary or integrated at level, $\mathrm{I}(0)$, the model is considered to be cointegrated and there should be a valid long-run relationship between variables which rules out the possibility of the estimated relationship being spurious. In order to do so, we can utilize the ADF test to check the unit root properties of residuals. The null hypothesis is that residuals have unit roots (non stationary). The ADF test of Engle-Granger cointegration test follows the McKinnon critical value.

However the OLS approach in the Engle-Granger technique could have certain problems related to the parameter bias and endogeneity of regressors. In this regard, the estimated parameter could be biased particularly in the presence of dynamic effects and small samples. In addition, if we analyze more than two

\footnotetext{
${ }^{29}$ The Granger causality aims to determine whether one time series variable forecast another, the causality in the Granger sense is then considered as 'predictive causality' since it is just reflected by predicting the future values of a (time series) variable utilizing the historical values of another (time series) variable (Granger, 1969; Geweke, 1984).
} 
regressors, it is possible that we have more than one cointegrating relationship due to the endogeneity of the regressors. These issues motivate us to employ an alternative procedure developed by Johansen and Juselius (1990, 1992), which could improve the single equation cointegration in several ways: (1) the presence of more than one cointegrating vector is not excluded a priori but it is even incorporated in the testing procedure; (2) the Johansen-Juselius approach assumes the regressors to be endogenous, thus it relaxes the assumption of one direction causality; (3) it provides a powerful set of tests, which allow us to identify the number of cointegrating vectors as well as the possibility of evaluating the effect of various restrictions. Technically, the Johansen approach tries to identify the rank of $\Pi$ matrix in the following equation:

$\Delta \mathrm{X}_{\mathrm{t}}=\partial+\sum_{\mathrm{i}=1}^{\mathrm{k}-1} \Gamma_{\mathrm{i}} \Delta \mathrm{X}_{\mathrm{t}-\mathrm{i}}+\Pi \Delta \mathrm{X}_{\mathrm{t}-\mathrm{k}}+\mathcal{E}_{\mathrm{i}}$

where $\mathrm{X}_{\mathrm{t}}$ represents a vector of $\mathrm{m}$ variables, $\Gamma$, $\Pi$ represent coefficient matrices, $\Delta$ represents difference operator, $\mathrm{k}$ is the lag length and $\partial$ is constant.

To examine the number of cointegrating vectors (rank of $\Pi, r$ ), we should first estimate the parameters of the matrix $\Pi$ to get the associated eigenvalues. Zero rank of $\Pi$ means that no stationary linear combination can be identified. Meanwhile if rank of matrix is more than zero, there would be $r$ possible stationary linear combination(s) so that $\Pi$ could be decomposed into $\Pi=\alpha \beta^{\prime}, \alpha$ and $\beta$ have $\mathrm{m} \times \mathrm{r}$ dimensions. $\alpha$ contains the coefficient of adjustment, and $\beta$ comprises the coefficient of the $r$ distinct cointegrating vectors that make $\beta^{\prime} X_{t}$ stationary albeit $\mathrm{X}_{\mathrm{t}}$ is non-stationary.

Given that variables are cointegrated, Engle and Granger (1987) claim the presence of a corresponding error correction terms, ECT, which captures that apart from changes in the other explanatory variables, the dependent variables change as a function of the level of disequilibrium in the cointegrating relationship. We first follow the Johansen-Juselius method (Johansen and Juselius, 1990, 1992) to estimate the vector error correction specification. For the emission (lnCO2P), the VECM is expressed as follows: 


$$
\begin{aligned}
& \Delta \mathrm{LNCO}^{2} \mathrm{CP}_{\mathrm{t}}=\sum_{\mathrm{j}}^{\mathrm{J}} \varphi_{\mathrm{j}} \Delta \mathrm{LNCO} 2 \mathrm{CP}_{\mathrm{t}-\mathrm{j}}+\sum_{\mathrm{j}=1}^{\mathrm{J}} \phi_{\mathrm{j}} \Delta \mathrm{LNECP}_{\mathrm{t}-\mathrm{j}}+\sum_{\mathrm{j}=1}^{\mathrm{J}} \phi_{\mathrm{j}} \Delta \mathrm{LNYCP}_{\mathrm{t}-\mathrm{j}}+ \\
& \alpha\left(\text { LNCO2P }_{\mathrm{t}-1}+\beta_{1} \text { LNECP }_{\mathrm{t}-1}+\beta_{2} \mathrm{LNYCP}_{\mathrm{t}-1}\right)+\mathrm{E}_{\mathrm{t}}
\end{aligned}
$$

We implement the same procedure with energy use (LNECP) and output (LNYCP) as dependent variables. Intuitively, we can interpret when variables are cointegrated, and then the short-run deviations from the long-run equilibrium will feed back on the changes in dependent variables so as to force the movement towards the long-run equilibrium.

\subsubsection{Long-run estimation and long-run Granger-causality: DOLS}

Thomas (1993) discussed that theory typically has nothing to say about short-term relationships. Hence it is important to estimate long-run coefficients in the system. Apart from the Johansen-Juselius procedure that is a maximum likelihood approach, we also employ an alternative approach, namely dynamic OLS (DOLS) as proposed by Stock and Watson (1993), which has certain advantages over OLS procedures since it remedies sources of OLS bias from small samples and dynamic sources. It also has an advantage over maximum likelihood given the possibility in the Johansen-Juselius approach (full information technique) that estimation in one equation could be affected by other estimation's misspecification in the VAR system. In contrast, the DOLS approach is fairly robust since it removes the endogeneity of the regressors by the inclusion of lead(s) and $\operatorname{lag}(\mathrm{s})$ of the first difference of all regressors. Moreover, it can be free from serial correlation of errors by using the generalized least square (GLS) procedure. The standard error of DOLS estimation follows Newey and West (1987). It has also another benefit since it has the same asymptotic optimality properties as the distribution of Johansen technique. Technically, modifying Masih and Masih (1996) and Saikkonen (1991), the DOLS model can be expressed as follow:

$$
\begin{aligned}
& \operatorname{lnCO} 2 \mathrm{CP}_{\mathrm{t}}=\mathrm{c}_{0}+\mathrm{c}_{1} \operatorname{lnECP_{\mathrm {t}}}+\mathrm{c}_{2} \ln \mathrm{YCP}_{\mathrm{t}}+\sum_{\mathrm{i}=-\mathrm{p}}^{\mathrm{i}=+\mathrm{p}} \Phi_{\mathrm{i}} \Delta \operatorname{lnECP_{\mathrm {t}-\mathrm {i}}}+\sum_{\mathrm{i}=-\mathrm{p}}^{\mathrm{i}=+\mathrm{p}} \Psi_{\mathrm{i}} \Delta \\
& \operatorname{lnYCP} \mathrm{P}_{\mathrm{t}-\mathrm{i}}+\varepsilon_{\mathrm{t}}
\end{aligned}
$$


where $\mathrm{p}$ represents lead(s) and $\operatorname{lag}(\mathrm{s})$ of all regressors, accounting for possible endogeneity of regressors and serial correlation. We implement the same procedure with LNECP and output LNYCP as dependent variables. Suppose that LNCO2CP is I(1) and LNECP and LNYCP are I(1) and cointegrated, then the DOLS estimates can be obtained.

When variables are cointegrated, we could then estimate the direction of causality between all variables by conducting Granger-causality through estimating the following ECM:

$$
\begin{aligned}
\Delta \mathrm{LNCO}^{-C_{\mathrm{t}}}= & \sum_{\mathrm{j}}^{\mathrm{J}} \theta_{\mathrm{j}} \Delta \mathrm{LNCO} \mathrm{CP}_{\mathrm{t}-\mathrm{j}}+\sum_{\mathrm{j}}^{\mathrm{J}} \phi_{\mathrm{j}} \Delta \mathrm{LNECP}_{\mathrm{t}-\mathrm{j}}+\sum_{\mathrm{j}}^{\mathrm{J}} \varphi_{\mathrm{j}} \Delta \mathrm{LNYCP}_{\mathrm{t}-\mathrm{j}}+ \\
& \lambda \mathrm{ECT}_{\mathrm{t}-1}+u_{t}
\end{aligned}
$$

ECT that is derived from lagged residuals of DOLS estimation (3.6). A negative and significant $\lambda$ reveals the presence of long-run Granger causality from the regressors to the dependent variables.

\subsubsection{Extended short-run analysis: Augmented-VAR estimation}

Finally, when adding other variables into the VAR system, namely urbanization and capital formation, we employ a modified (lag-augmented) VAR as proposed by Toda and Yamamoto (1995). Some of the central reasons for applying this method are related to flexibility regarding the possibility to implement this technique for variables with different orders of integration (Toda and Yamamoto, 1995). There are several steps included in conducting this estimation technique. First, measuring the order of integration of all variables (called d). Second, determining the optimum lag length criteria of the original VAR model (called p) employing Akaike information criterion (AIC), Schwarz information criterion (SBC), and the sequential modified lag length statistic (LR), all test at the 5\% critical value. Third, estimating the modified (lag-augmented) VAR model by augmenting original $\operatorname{VAR}(\mathrm{p})$ to $\operatorname{VAR}(\mathrm{p}+\mathrm{d})$ through the following formula:

$\mathrm{V}_{\mathrm{t}}=\delta_{0}+\delta_{1} \mathrm{~V}_{\mathrm{t}-1}+\delta_{2} \mathrm{~V}_{\mathrm{t}-2}+\cdots+\delta_{\mathrm{p}} \mathrm{V}_{\mathrm{t}-\mathrm{p}}+\delta_{\mathrm{p}+\mathrm{d}} \mathrm{V}_{\mathrm{t}-\mathrm{p}-\mathrm{d}}+\varepsilon_{\mathrm{t}}$ 
where $\mathrm{V}$ is vector of variables, $\delta_{0}$ is vector of constant, $\delta_{\mathrm{p}}$ is coefficient matrix, and $\varepsilon_{\mathrm{t}}$ is white noise residuals (Toda and Yamamoto, 1995; Soytas et al., 2007; Zhang and Cheng, 2009; Tiwari, 2011). Fourth, having checked the robustness (via diagnostic tests) of the augmented VAR(p+d), a Wald test is employed on the first $\mathrm{p}$ parameters instead of on all parameters in the augmented $\operatorname{VAR}(\mathrm{p}+\mathrm{d})$ model, and the statistics follows an asymptotic $\chi^{2}$ distribution with $\mathrm{p}$ degrees of freedom (Toda and Yamamoto, 1995), where the null hypothesis is that the row $\mathrm{i}$, column $\mathrm{j}$ element in $\delta_{\mathrm{k}}$ equals zero for $\mathrm{k}=1,2 \ldots, \mathrm{p}$. The rejection of the null hypothesis indicates that the $j_{\text {th }}$ element of $V_{t}$ does Granger-cause the $i_{\text {th }}$ element of $V_{t}$, and vice versa.

In addition to the modified Granger Causality, we also estimate our model employing two well-known innovations, namely variance error decomposition (VED) and impulse response function (IRF). The VED investigates how change in a variable (shown as variance error) that is determined by other variables and to see the strength of each variable in explaining other variables in the longer period. The IRF examines how and for how long variables respond to innovations in other variables overtime. In other words, it traces out the responsiveness of the dependent variables to shocks to each of other explanatory variables overtime (Enders, 2009). 


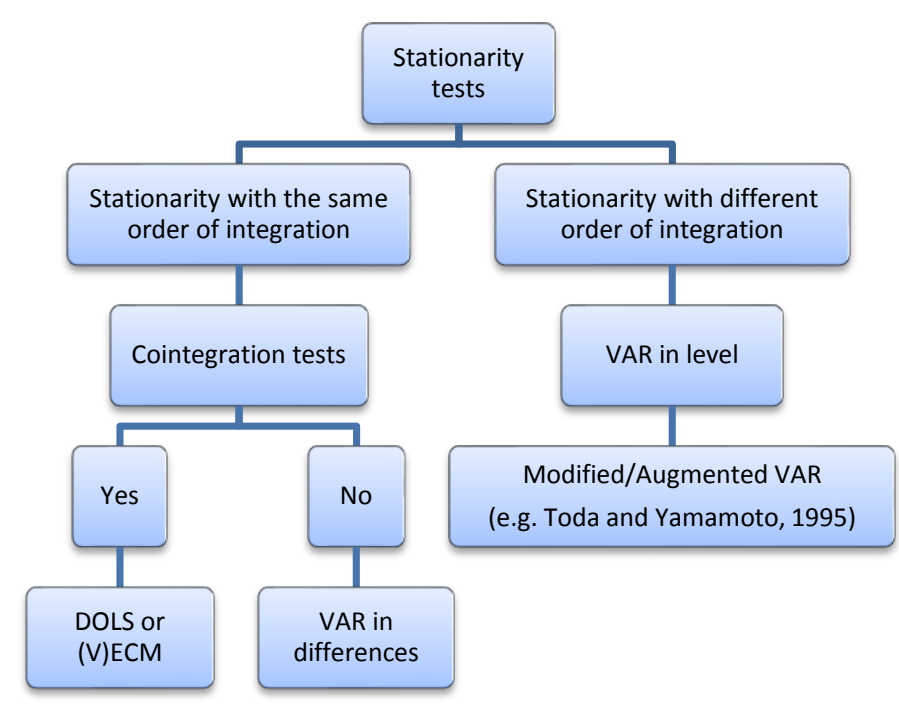

Figure 3.1 Analytical framework

Source: adapted from Engle and Granger (1987), Johansen and Juselius (1990, 1992), Stock and Watson (1993), Toda and Yamamoto (1995), Enders (2009).

Figure 3.1 summarizes our analytical framework that has been explained before. First we figure out the order of integration of each series of variables by means stationarity tests. If the variables have the same order of $I(d)$, it is possible to employ tests of cointegration such as Engle-Granger's method or JohansenJuselius procedure. The presence of cointegration allows us to estimate series variables using single-equation (or vector) ECM to estimate long-run and shortrun coefficients. Once the variables cannot pass the cointegation test, a VAR system could be estimated in first difference although it only captures short-run analysis. Second, the case variables have different orders of integration I(d) leads us to conduct VAR in levels. One way of doing VAR in levels is, as proposed by Toda-Yamamoto's approach, by augmenting the original VAR(p) with a maximum order of integration of variables in the system.

\subsection{Results and discussions}

The preliminary stage in time series data is the test of the existence of unit roots, which assesses the order of integration of each variable. The ADF and PP tests are summarized in Table 3.1. In general, we found that LNCO2CP, LNYCP, and 
LNECP are integrated at first difference, I(1), while urban population (LNU) and capital formation are integrated at $\mathrm{I}(2)$ and $\mathrm{I}(0)$, respectively. To sum up, the unit root analysis indicates that the integration orders of all variables do not appear to be exceeding $\mathrm{I}(2)$.

Table 3.1 Unit root analysis

\begin{tabular}{|c|c|c|c|c|}
\hline \multirow[b]{2}{*}{ Variables } & \multicolumn{2}{|c|}{ ADF test statistic } & \multicolumn{2}{|c|}{ PP (adjusted) test statistic } \\
\hline & Constant & Constant and trend & Constant & Constant and trend \\
\hline \multicolumn{5}{|l|}{ Level, I(0) } \\
\hline LNCO2CP & $-2.72 *$ & -1.61 & $-2.87 *$ & -1.87 \\
\hline LNECP & -1.49 & -2.11 & -1.49 & -2.11 \\
\hline LNYCP & -1.42 & -2.13 & -1.33 & -1.98 \\
\hline LNU & 2.20 & 0.63 & 4.10 & 3.48 \\
\hline LNK & $-2.92 *$ & $3.47 * *$ & $-5.25 * * *$ & $-3.97 * *$ \\
\hline \multicolumn{5}{|c|}{ First difference, $I(1)$} \\
\hline $\mathrm{D}(\mathrm{LNCO} 2 \mathrm{CP})$ & $-5.11 * * *$ & $-5.73 * * *$ & $-5.11 * * *$ & $-5.72 * * *$ \\
\hline $\mathrm{D}(\mathrm{LNECP})$ & $-7.40 * * *$ & $-7.37 * * *$ & $-7.25 * * *$ & $-7.24 * * *$ \\
\hline $\mathrm{D}(\mathrm{LNYCP})$ & $-4.53 * * *$ & $-4.57 * * *$ & $-4.53 * * *$ & $-4.58 * * *$ \\
\hline $\mathrm{D}(\mathrm{LNU})$ & -0.19 & 1.98 & -0.03 & -1.89 \\
\hline \multicolumn{5}{|c|}{$2^{\text {nd }}$ difference, I(2) } \\
\hline $\mathrm{D}(\mathrm{LNU}, 2)$ & $-6.35^{* * * *}$ & $-6.50 * * *$ & $-6.37 * * *$ & $-7.11 * * *$ \\
\hline
\end{tabular}

Source: Author's estimation. Note: $*(* *, * * *)$ indicates significance at the ten (five, one) percent level. For the ADF test, the lag length is based on the AIC.

In the first step, we estimate the long-run causality by applying the Engle-Granger cointegration and single equation error correction model (ECM) for the three main variables including emission, energy use, and income. We first estimate emissions as the function of energy use and income as presented in Table 3.2. We then conduct the ADF unit root test for the residuals of this estimation to examine the presence of a long-run relationship between three variables (presented in Appendix Table C.3). As the residual is integrated at I(0), it is clearly suggested there is a cointegration between emission, energy use, and income. Hence we can interpret the OLS parameter estimates as long-run coefficients.

Table 3.2 presents simple OLS estimations that regress emission on energy use and output. Estimating output as a function of both energy use and output, we found that the long-run elasticity of energy consumption and income on emission are about 0.68 and 0.71 respectively. However, estimating the emission function without energy use found a higher elasticity of income at about 1.43 , while estimating emission as a function of energy use found that energy use elasticity to be about 1.34. All long-run elasticities have the predicted signs and are significant. Engle-Granger short-run estimates can be seen in Table 3.3. The 
model passes all diagnostic tests (normality, serial correlation, and heteroskedasticity). We found that the ECT coefficient is about -0.25 , suggesting that the speed of adjustment of the disequilibrium (to long-run equilibrium) is about $25 \%$ annually. From the short-run estimates, although output does not have a significant short-run impact, it does have a significant impact in the long-run.

Table 3.2 Long run estimates: OLS

\begin{tabular}{lcccccc}
\hline & \multicolumn{6}{c}{ Dep. Variable: LNCO2CP } \\
\cline { 2 - 7 } \multicolumn{1}{c}{ Variable } & \multicolumn{2}{c}{ A } & \multicolumn{2}{c}{ B } & \multicolumn{2}{c}{ C } \\
\cline { 2 - 7 } & Coef. & $\begin{array}{c}\text { Std. } \\
\text { Error }\end{array}$ & Coef. & $\begin{array}{c}\text { Std. } \\
\text { Error }\end{array}$ & Coef. & $\begin{array}{c}\text { Std. } \\
\text { Error }\end{array}$ \\
\hline LNECP & $0.6799^{* * *}$ & 0.1106 & $1.3397^{* * *}$ & 0.0278 & & \\
LNYCP & $0.7123^{* * *}$ & 0.1174 & & & $1.4222^{* * *}$ & 0.0297 \\
$\mathrm{C}$ & $-1.9978^{* * *}$ & 0.1522 & $-1.4273^{* * *}$ & 0.1668 & $-2.4341^{* * *}$ & 0.1889 \\
\hline $\mathrm{R}^{2}$ & 0.9919 & & 0.9839 & & 0.9837 & \\
Adjusted $\mathrm{R}^{2}$ & 0.9915 & & 0.9835 & & 0.9832 & \\
\hline
\end{tabular}

Source: Author's estimation. Note: $*(* *, * * *)$ indicates significance at the ten (five, one) percent level.

Table 3.3 Short-run estimates: ECM

\begin{tabular}{lcc}
\hline & Dependent variable: & D(LNCO2CP) \\
\hline Variable & Coefficient & Std. Error \\
\hline ECT(-1) & $-0.2536^{* * *}$ & 0.1049 \\
$\mathrm{D}($ LNECP) & $0.3749^{* * *}$ & 0.0828 \\
$\mathrm{D}(\mathrm{LNYCP})$ & 0.2168 & 0.1664 \\
$\mathrm{C}$ & $0.0315^{* * *}$ & 0.0086 \\
\hline $\mathrm{R}^{2}$ & 0.4523 & \\
Adjusted $\mathrm{R}^{2}$ & 0.4053 & \\
\hline Source Aut & &
\end{tabular}

Source: Author's estimation. Note: ECT(-1) indicates lagged of residual of Table 3.2 panel A. Note: $*(* *, * * *)$ indicates significance at the ten (five, one) percent level.

We later compare these single-equation estimation results with other cointegration estimations including Johansen-Juselius procedure and DOLS estimation when variables are cointegrated. The Johansen-Juselius approach suggests the presence of one cointegrating equation since we can reject the null hypothesis of no cointegrating equation at the $5 \%$ critical value, both employing trace statistic and maximum eigenvalue (Table 3.4). Given this, we can then conduct the VECMmaximum likelihood estimation of the cointegrating vector. Estimating the complete model, the results show consistent signs of long-run elasticity of energy use and income of about 0.06 and 1.18, respectively (Appendix C.5). It is important to note that the estimation results are quite different from the single equation Engle-Granger (complete model, Table 3.2 column A), given that the 
VECM approach treats all variables in a full system (not a partial system), which are dependent on each other. The higher value of income elasticities is however relatively similar to the single equation model without energy use. In short-run analysis, which is the focus of our analysis, it is found that the speed of adjustment of the disequilibrium to long-run equilibrium is about $21.2 \%$ annually, which is also close to the single equation estimation (Table 3.3).

Table 3.4 Johansen cointegration tests

\begin{tabular}{ccccccccc}
\hline \multicolumn{2}{c}{$\begin{array}{c}\text { No. of cointegrating } \\
\text { equations }\end{array}$} & & \multicolumn{3}{c}{ Trace } & \multicolumn{4}{c}{ Maximum eigenvalue } \\
\cline { 5 - 8 } Ho & \multirow{2}{*}{ H1 } & Eigenvalue & $\begin{array}{c}\text { Trace } \\
\text { statistic }\end{array}$ & $\begin{array}{c}\mathbf{5 \%} \\
\text { Critical } \\
\text { Value }\end{array}$ & Prob. & $\begin{array}{c}\text { Max } \\
\text { Eigen } \\
\text { Statistic }\end{array}$ & $\begin{array}{c}\mathbf{5 \%} \\
\text { Critical } \\
\text { Value }\end{array}$ & Prob. \\
\hline None * & At most 1 & 0.463304 & 43.17964 & 35.19275 & 0.0056 & 23.64826 & 22.29962 & 0.0322 \\
At most 1 & At most 2 & 0.317050 & 19.53138 & 20.26184 & 0.0628 & 14.49070 & 15.89210 & 0.0819 \\
At most 2 & At most 3 & 0.124228 & 5.040685 & 9.164546 & 0.2790 & 5.040685 & 9.164546 & 0.2790 \\
\hline
\end{tabular}

Source: Author's estimation. Note: Note: ECT(-1) indicates lagged of residual of Table 2a panel

A. * $(* *, * * *)$ indicates significance at the ten (five, one) percent level.

Table 3.5 Short-run VECM Estimates

\begin{tabular}{lccc}
\hline Short-run Estimates & & & \\
\hline Error Correction: & $\mathrm{D}(\mathrm{LNCO} 2 \mathrm{CP})$ & $\mathrm{D}(\mathrm{LNECP})$ & $\mathrm{D}(\mathrm{LNYCP})$ \\
\hline ECT(-1) & -0.212939 & -0.047260 & -0.081293 \\
& $(0.04869)$ & $(0.08498)$ & $(0.04420)$ \\
& {$[-4.37378]$} & {$[-0.55614]$} & {$[-1.83929]$} \\
$\mathrm{D}(\mathrm{LNCO} 2 \mathrm{CP}(-1))$ & 0.045064 & 0.397083 & 0.114930 \\
& $(0.18556)$ & $(0.32388)$ & $(0.16845)$ \\
& {$[0.24286]$} & {$[1.22601]$} & {$[0.68227]$} \\
D(LNECP(-1)) & 0.028818 & -0.319227 & -0.006377 \\
& $(0.11288)$ & $(0.19703)$ & $(0.10248)$ \\
& {$[0.25529]$} & {$[-1.62018]$} & {$[-0.06223]$} \\
D(LNYCP(-1)) & -0.064884 & 0.280332 & 0.246254 \\
& $(0.21950)$ & $(0.38313)$ & $(0.19927)$ \\
& {$[-0.29560]$} & {$[0.73168]$} & {$[1.23579]$} \\
\hline
\end{tabular}

Source: Author's estimation. Note: Adjustment sample: 1973-2010.

Standard errors and t-statistics are in () and [].

The Stock-Watson's DOLS estimates are presented in Table 3.6. We include up to $\mathrm{j}=+/-2$ lags and leads as we use an annual database. The standard errors are following Newey and West (1987). Consistent with the ECM estimates, we found that the expected and significant long-run elasticity of energy use and income are about 0.74 and 0.64 (using a complete model). Estimating the emission equation without energy use as an independent variable, we found that the elasticity of 
income is 1.42, which is similar to the previous estimation (Appendix Table C.7). This suggests that energy use is a key intervening variable linking income to emission. In terms of the serial correlation of the residual, heteroskedasticy, nonnormality of residuals, and functional misspecifications, our DOLS estimates are robust to various departures from the OLS regression, and passed stability tests ${ }^{30}$.

Table 3.6 Stock-Watson DOLS estimates

\begin{tabular}{|c|c|c|c|c|c|c|c|c|c|}
\hline \multirow{2}{*}{ Variable } & \multicolumn{3}{|c|}{$\begin{array}{c}\text { Dependent Variable: } \\
\text { LNCO2CP }\end{array}$} & \multicolumn{3}{|c|}{$\begin{array}{c}\text { Dependent Variable: } \\
\text { LNECP }\end{array}$} & \multicolumn{3}{|c|}{$\begin{array}{c}\text { Dependent Variable: } \\
\text { LNYCP }\end{array}$} \\
\hline & Coef. & $\begin{array}{l}\text { Std. } \\
\text { Error }\end{array}$ & Prob. & Coef. & $\begin{array}{l}\text { Std. } \\
\text { Error }\end{array}$ & Prob. & Coef. & $\begin{array}{c}\text { Std. } \\
\text { Error }\end{array}$ & Prob. \\
\hline $\bar{C}$ & $-1.956 * * *$ & 0.245 & 0.000 & $2.406 * * *$ & 0.391 & 0.000 & 0.737 & 0.730 & 0.324 \\
\hline $\mathrm{LNCO} 2 \mathrm{CP}$ & & & & $0.628 * * *$ & 0.153 & 0.001 & 0.340 & 0.308 & 0.281 \\
\hline LNECP & $0.746 * *$ & 0.263 & 0.010 & & & & 0.543 & 0.448 & 0.239 \\
\hline LNYCP & $0.647 * *$ & 0.266 & 0.024 & -0.053 & 0.203 & 0.797 & & & \\
\hline $\mathrm{D}(\mathrm{LNCO} 2 \mathrm{CP})$ & & & & -0.020 & 0.195 & 0.919 & 0.430 & 0.424 & 0.322 \\
\hline $\mathrm{D}(\mathrm{LNCO} 2 \mathrm{CP}(-1))$ & & & & -0.014 & 0.169 & 0.934 & 0.687 & 0.447 & 0.139 \\
\hline D(LNCO2CP(-2)) & & & & -0.031 & 0.182 & 0.866 & 0.289 & 0.329 & 0.390 \\
\hline $\mathrm{D}(\mathrm{LNCO} 2 \mathrm{CP}(1))$ & & & & 0.102 & 0.242 & 0.678 & $0.876^{* *}$ & 0.364 & 0.025 \\
\hline $\mathrm{D}(\mathrm{LNCO} 2 \mathrm{CP}(2))$ & & & & 0.073 & 0.261 & 0.782 & $0.925^{* * * *}$ & 0.322 & 0.009 \\
\hline $\mathrm{D}(\mathrm{LNECP})$ & -0.013 & 0.187 & 0.945 & & & & -0.500 & 0.319 & 0.132 \\
\hline $\mathrm{D}(\operatorname{LNECP}(-1))$ & -0.111 & 0.184 & 0.555 & & & & -0.471 & 0.298 & 0.129 \\
\hline $\mathrm{D}(\operatorname{LNECP}(-2))$ & -0.051 & 0.118 & 0.670 & & & & -0.139 & 0.202 & 0.498 \\
\hline $\mathrm{D}(\mathrm{LNECP}(1))$ & 0.272 & 0.261 & 0.309 & & & & -0.187 & 0.194 & 0.346 \\
\hline $\mathrm{D}(\mathrm{LNECP}(2))$ & 0.199 & 0.141 & 0.173 & & & & -0.236 & 0.156 & 0.143 \\
\hline D(LNYCP) & $-0.490 * *$ & 0.205 & 0.026 & & & & & & \\
\hline $\mathrm{D}(\mathrm{LNYCP}(-1))$ & $-0.400 *$ & 0.215 & 0.077 & & & & & & \\
\hline D(LNYCP(-2)) & -0.202 & 0.182 & 0.279 & & & & & & \\
\hline D(LNYCP(1)) & 0.115 & 0.189 & 0.548 & & & & & & \\
\hline $\mathrm{D}(\mathrm{LNYCP}(2))$ & 0.177 & 0.117 & 0.145 & & & & & & \\
\hline D(LNYCP) & & & & 0.213 & 0.221 & 0.346 & & & \\
\hline D(LNYCP(-1)) & & & & $0.224 *$ & 0.113 & 0.059 & & & \\
\hline D(LNYCP(-2)) & & & & -0.083 & 0.191 & 0.667 & & & \\
\hline D(LNYCP(1)) & & & & -0.010 & 0.110 & 0.927 & & & \\
\hline $\mathrm{D}(\mathrm{LNYCP}(2))$ & & & & -0.055 & 0.108 & 0.616 & & & \\
\hline $\mathrm{R}^{2}$ & 0.995 & & & 0.987 & & & 0.988 & & \\
\hline Adjusted $\mathrm{R}^{2}$ & 0.993 & & & 0.980 & & & 0.981 & & \\
\hline
\end{tabular}

Source: Author's estimation. Note: ${ }^{*}(* *, * * *)$ indicates significance at the ten (five, one) percent level.

Having the evidence of cointegration among variables, it is also important to investigate the presence and the direction of long-run Granger-causality using DOLS. Highlighted findings, which focus on ECT estimates, are presented in Table 3.7. First, from the emission equation, as we found a negative and significant ECT(-1), we could argue that both energy use and output have a longrun impact due to Granger-causality on emission. Second, from the energy use equation, as ECT(-1) is not significant, we cannot find any evidence that both emissions and output Granger-cause energy consumption in the long-run. Third, from the output equation, findings do not show any evidence of the long-run Granger-causality, neither from emission nor energy use to output. To sum up,

\footnotetext{
${ }^{30}$ CUSUM and CUSUMSQ stability test
} 
there is in general only evidence of uni-directional causality running from output to emissions as well as from energy use to emissions. These findings could send the message that energy use and output tend to increase emission and in the opposite direction the effort to reduce emission could be achieved without impeding growth.

Table 3.7 Error correction term and long-run Granger causality

\begin{tabular}{|c|c|c|c|c|c|c|c|c|c|}
\hline \multirow[b]{2}{*}{ Variable } & \multicolumn{3}{|c|}{$\begin{array}{c}\text { Dependent Variable: } \\
\text { D(LNCO2CP })\end{array}$} & \multicolumn{3}{|c|}{$\begin{array}{c}\text { Dependent Variable: } \\
\text { D(LNECP) }\end{array}$} & \multicolumn{3}{|c|}{$\begin{array}{c}\text { Dependent Variable: } \\
\text { D(LNYCP })\end{array}$} \\
\hline & Coef. & $\begin{array}{r}\text { Std. } \\
\text { Error }\end{array}$ & Prob. & Coef. & $\begin{array}{r}\text { Std. } \\
\text { Error }\end{array}$ & Prob. & Coef. & $\begin{array}{r}\text { Std. } \\
\text { Error }\end{array}$ & Prob. \\
\hline $\mathrm{C}$ & $0.024 * *$ & 0.011 & 0.047 & 0.013 & 0.017 & 0.453 & $0.028 * *$ & 0.011 & 0.014 \\
\hline $\mathrm{D}(\mathrm{LNCO} 2 \mathrm{CP}(-1))$ & $0.354 *$ & 0.204 & 0.094 & $0.577^{*}$ & 0.284 & 0.052 & 0.069 & 0.093 & 0.460 \\
\hline $\mathrm{D}(\mathrm{LNCO} 2 \mathrm{CP}(-2))$ & $0.218 * *$ & 0.097 & 0.034 & 0.167 & 0.274 & 0.547 & -0.108 & 0.088 & 0.230 \\
\hline $\mathrm{D}(\operatorname{LNECP}(-1))$ & -0.207 & 0.126 & 0.114 & $-0.449 * * *$ & 0.158 & 0.009 & -0.033 & 0.133 & 0.804 \\
\hline $\mathrm{D}(\mathrm{LNECP}(-2))$ & -0.097 & 0.110 & 0.384 & -0.084 & 0.269 & 0.758 & 0.055 & 0.034 & 0.119 \\
\hline $\mathrm{D}(\mathrm{LNYCP}(-1))$ & -0.028 & 0.187 & 0.883 & 0.375 & 0.285 & 0.199 & 0.336 & 0.190 & 0.089 \\
\hline $\mathrm{D}(\mathrm{LNYCP}(-2))$ & $0.251 * *$ & 0.098 & 0.017 & -0.138 & 0.202 & 0.500 & -0.022 & 0.081 & 0.791 \\
\hline ECT $(-1)$ & $-0.420 * *$ & 0.196 & 0.041 & 0.315 & 0.526 & 0.554 & -0.131 & 0.225 & 0.565 \\
\hline $\mathrm{R}^{2}$ & 0.162 & & & 0.113 & & & 0.107 & & \\
\hline Adjusted $\mathrm{R}^{2}$ & -0.055 & & & -0.117 & & & -0.124 & & \\
\hline F-statistic & 0.747 & & & 0.489 & & & 0.464 & & \\
\hline Prob(F-statistic) & 0.635 & & & 0.834 & & & 0.852 & & \\
\hline
\end{tabular}

Source: Author's estimation. Note: $*(* *, * * *)$ indicates significance at the ten (five, one) percent level.

Finally, we extend our analysis by incorporating other variables into the system, namely urban population and capital formation to investigate the causality in the short-run. By including these two variables, all series do not have the same order of integration; Toda and Yamamoto (1995) is among the appropriate procedures to estimate the model for both the Granger causality test as well as innovation accounting. Lag length of VAR suggested that based on LR, AIC, and HQ criteria, the maximum lag is about 3, while only SC suggests 1 lag (Appendix Table C.9). Then we have to decide how much maximum VAR(p+d) should be employed following the Toda-Yamamoto approach. Having the maximum order of integrations among variables being $2(\mathrm{~d}=2)$, and the majority of lags of original VAR proposed 3 as the optimum lag $(\mathrm{p}=3)$, we can then augment our model to $\operatorname{VAR}(\mathrm{p}+\mathrm{d})$ to $\operatorname{VAR}(5)$. In addition, choosing this $\operatorname{VAR}(5)$, with $\mathrm{V}_{\mathrm{t}}=$ $\left(\mathrm{LNCO}_{2} \mathrm{CP}_{\mathrm{t}}, \mathrm{LNECP}_{\mathrm{t}}, \mathrm{LNYCP}_{\mathrm{t}}, \mathrm{LNK}_{\mathrm{t}}, \mathrm{LNU}_{\mathrm{t}}\right)^{\prime}$, also passes the stability tests. 
Table 3.8 Short-run Granger-causality

\begin{tabular}{|c|c|c|c|c|c|}
\hline \multicolumn{3}{|c|}{ Dependent variable: LNCO2CP } & \multicolumn{3}{|c|}{ Dependent variable: $\mathrm{LNU}$} \\
\hline Excluded & $\chi^{2}$ & Prob. & Excluded & $\chi^{2}$ & Prob. \\
\hline LNYCP & $9.843953 *$ & 0.0798 & $\mathrm{LNCO} 2 \mathrm{CP}$ & 5.262322 & 0.3847 \\
\hline LNECP & $13.15049^{* *}$ & 0.0220 & LNYCP & 1.150363 & 0.9495 \\
\hline LNU & 4.547104 & 0.4736 & LNECP & 4.411578 & 0.4918 \\
\hline LNK & 5.863166 & 0.3198 & LNK & 2.878113 & 0.7188 \\
\hline All & $52.03977 * * *$ & 0.0001 & All & $43.37403^{* * *}$ & 0.0018 \\
\hline \multicolumn{3}{|c|}{ Dependent variable: LNYCP } & \multicolumn{3}{|c|}{ Dependent variable: $\mathrm{LNK}$} \\
\hline Excluded & $\chi^{2}$ & Prob. & Excluded & $\chi^{2}$ & Prob. \\
\hline LNCO2CP & 7.099016 & 0.2134 & $\mathrm{LNCO} 2 \mathrm{CP}$ & 8.479434 & 0.1317 \\
\hline LNECP & $9.245992 *$ & 0.0996 & LNYCP & 7.439830 & 0.1899 \\
\hline LNU & 4.463491 & 0.4848 & LNECP & $9.397698 *$ & 0.0942 \\
\hline LNK & 9.148862 & 0.1033 & LNU & 7.581426 & 0.1809 \\
\hline All & 18.58177 & 0.5491 & All & 26.27474 & 0.1569 \\
\hline \multicolumn{6}{|c|}{ Dependent variable: LNECP } \\
\hline Excluded & $\chi^{2}$ & Prob. & & & \\
\hline $\mathrm{LNCO} 2 \mathrm{CP}$ & $18.77003 * * *$ & 0.0021 & & & \\
\hline LNYCP & 1.350570 & 0.9296 & & & \\
\hline LNU & $13.05599 * *$ & 0.0229 & & & \\
\hline LNK & $17.01388 * * *$ & 0.0045 & & & \\
\hline All & $73.43952 * * *$ & 0.0000 & & & \\
\hline
\end{tabular}

Source: Author's estimation. Note: Granger-causality is based on block exogeneity Wald test. $*(* *, * * *)$ indicates significance at the ten (five, one) percent level.

The estimation of the (short-run) Granger causality test highlights some particular findings as summarized in Table 3.8. We focus on the direction of causality from output, energy use, urbanization and capital stock to emissions. First, there is a short-run output to emission uni-directional Granger causality ${ }^{31}$, but not from the opposite direction. This indicates that while economic growth will increase emissions but the effort to reduce emission could be fulfilled without impeding economic growth.

Second, we indicate the evidence of energy use-emission bi-directional short-run causality $^{32}$. Likewise, this finding suggests that energy can cause rising emission, but effort to reduce emission will impede energy use. For policy perspective, this could send a message to develop low-carbon energy systems such as by intensifying renewable energy uses so as to reduce emissions without harming energy use, which is needed for a growing economy.

Finally, urbanization and capital stock have the same direction of causality to emissions. There is uni-directional causality running from urbanization and

\footnotetext{
${ }^{31}$ At the $10 \%$ significance level

${ }^{32}$ From energy use to emissions at the $5 \%$ significance level, and from emissions to energy use at $1 \%$ significance level.
} 
capital formation to energy use ${ }^{33}$, and more importantly no causality from the urbanization and capital formation to emissions. These findings indicate that both concentrations in urban areas (as a consequence of urbanization) as well as rising investment tend to increase energy use but does not directly trigger rising emissions. Both urbanization and investment could be carbon 'neutral' such as by promoting low-carbon urban development strategies and sustainable investment and energy policies for economic activities.

In addition to the causality analysis among the series, it is also noteworthy to conduct innovation simulations in the VAR system. In this regard, we employ VED to examine what the contributions of other variables overtime are, and the IRF to measure how and for how long variables respond to innovations in other variables overtime. The results, which are presented in Figure $\mathbf{3 . 2}^{\mathbf{3 4}}$, can be highlighted as follows. First, variation of emission (LNCO2CP) is initially explained by itself, but the contribution of energy consumption (LNECP), output (LNYCP) and urban population (LNU) significantly increases in the longer period, which was started by the higher contribution of energy consumption from the second period, and urban population from the third period. In the last period of simulation, LNYCP, and LNECP are the two largest contributors to LNCO2CP.

Second, the major variation of LNECP was initially explained by LNCO2CP (64\%), but the contribution of LNECP, LNYCP and LNU then increased overtime. This finding confirmed the fact that energy production consists mostly from non-renewable (mainly fossil fuel) resources that have higher carbon intensity (Appendix Figure C.2). In the end of the simulation, LNCO2CP still dominantly contributes to the variation of LNECP, followed by LNYCP. Third, more interestingly, the variation of LNYCP is initially contributed by LNECP $(63 \%)$ but its contribution is decreasing. The contribution of LNCO2CP to LNYCP increases in the longer period and is then relatively constant in the longer period.

\footnotetext{
${ }^{33}$ At the 5\% significance level.

${ }^{34}$ Numerical presentation of the VED is presented in Appendix Table C.10.
} 

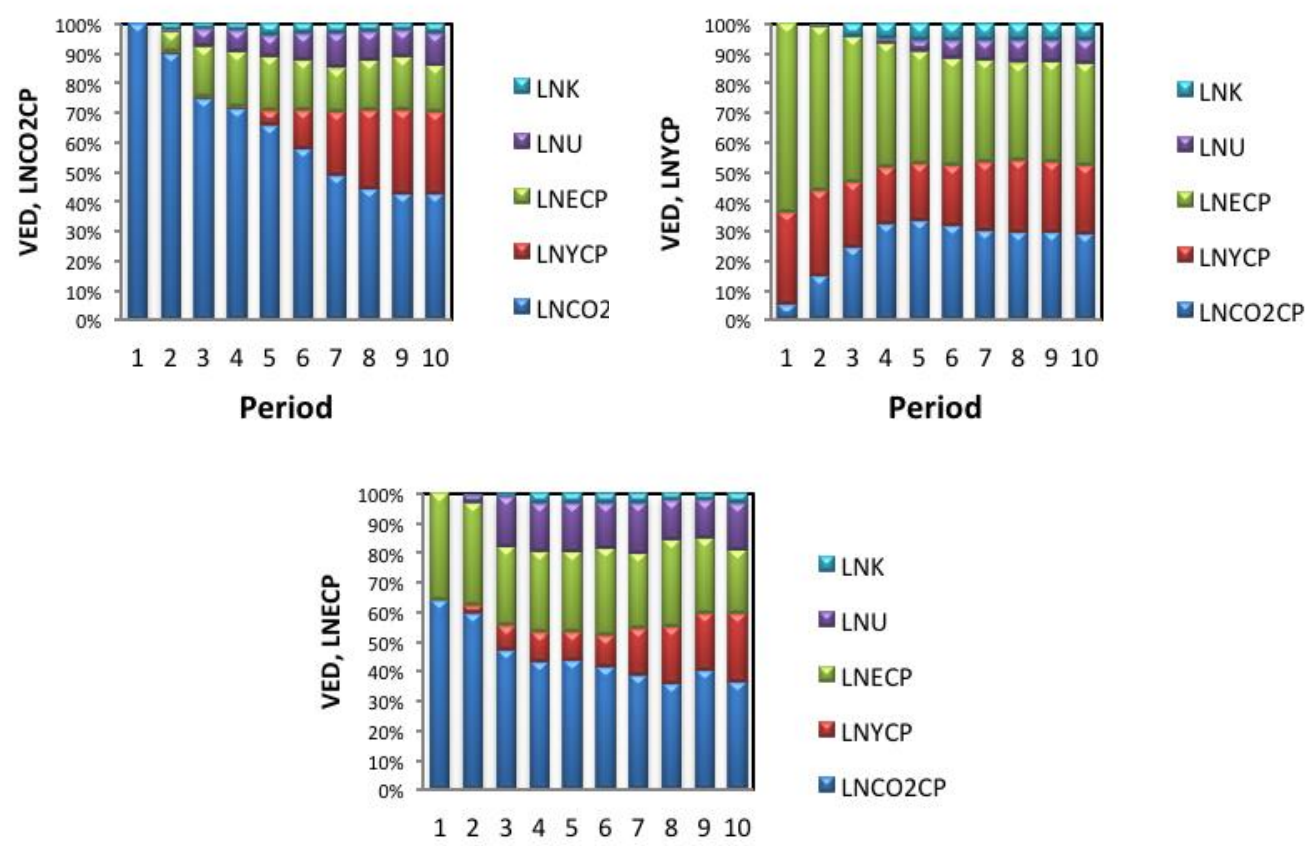

Period

Figure 3.2 Variance error decomposition

Source: Author's estimation

Finally, we conduct a simulation to analyze the response of any variable to any exogenous shock in the system. In order to do so, we utilize IRF which investigates how a shock to one variable affects other variables, as well as how long the effect lasts in the short-run. In other words, IRF allows us to investigate how variables react to a shock in another variable, whether the shock initially occurs and whether it persists in the longer time period, and whether it evaporates quickly or slowly.

Our main findings are summarized in Figure $3.3^{35}$. First, the response of LNCO2CP to the innovations of other variables as follows: (i) the response of LNCO2CP to LNECP is minor in the initial period, then has a negative sign in the second and $6^{\text {th }}$ period but has generally has positive impact in simulation period; (ii) the initial impact of LNYCP to $\mathrm{LNCO} 2 \mathrm{CP}$ is initially low and persists with

\footnotetext{
${ }^{35}$ Numerical presentation can be seen in Appendix Table C.11.
} 
positive signs from the third period on; (iii) LNU has a low initial impact on LNCO2CP, and although it has negative impact until the $4^{\text {th }}$ period it has a minor positive effect in the longer period; (iv) consistent with the previous VED analysis, the response of $\mathrm{LNCO} 2 \mathrm{CP}$ to capital formation (LNK) is minor over the simulation period.
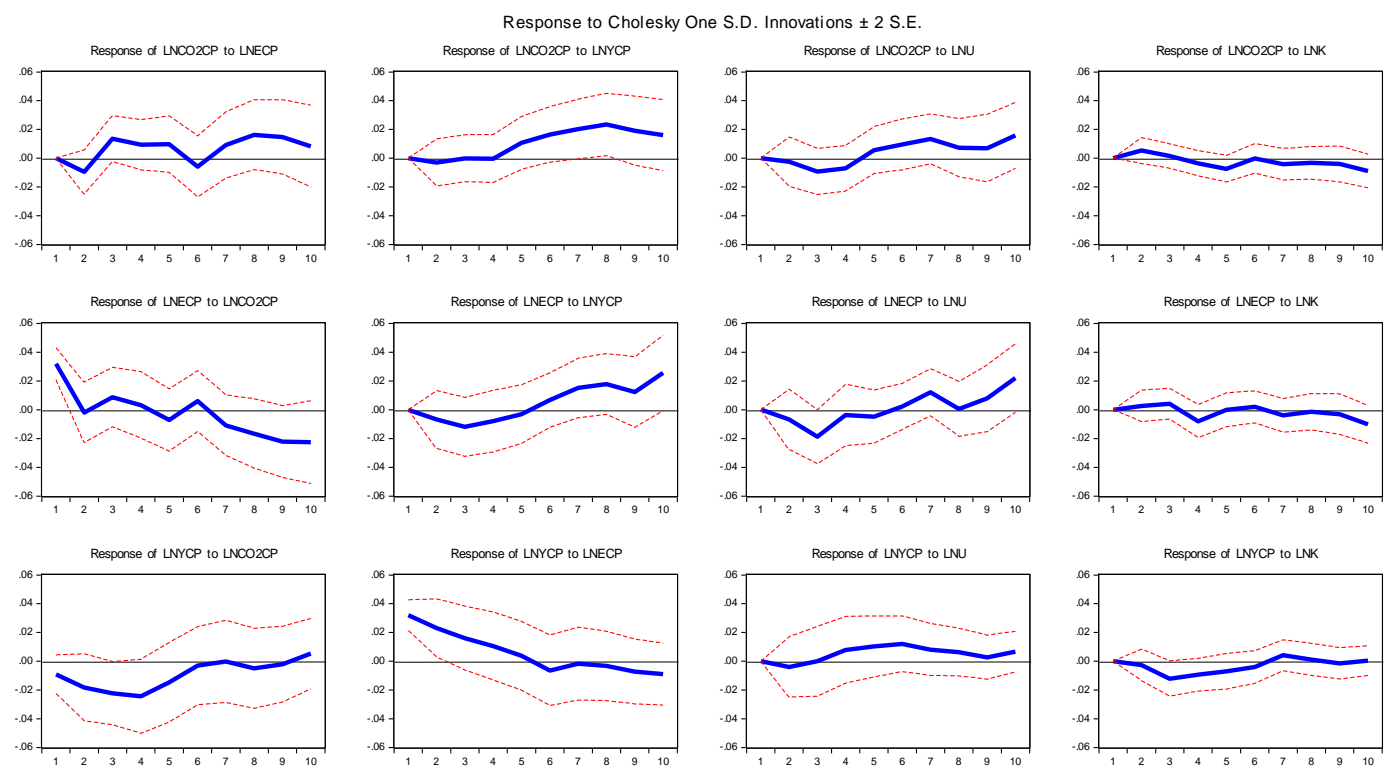

Figure 3.3 Impulse response function

Source: Author's estimation

Second, the responses of LNECP to the innovations in other variables can be highlighted as follows: (i) there is a minor initial impact of LNYCP to LNECP, and although there was a decreasing impact but generally has positive impact the longer period; (ii) The response of LNECP to the innovation of $\mathrm{LNCO} 2 \mathrm{CP}$ is positive in the initial period, and it gradually decreases in the longer period; (iii) LNU has a minor initial impact to LNECP, decreased until the $3^{\text {rd }}$ period, and then increased with small positive impact after that period; (iv) although there were some fluctuations, the response of $\mathrm{LNCO} 2 \mathrm{CP}$ to $\mathrm{LNK}$ is generally minor over the simulations period.

Third, responses of LNYCP to the innovations of other variables are as follows. (i) The impact of LNCO2CP to LNYCP is initially negative and vanished in the longer period of simulation; (ii) The initial impact of LNECP to LNYCP is 
positive and lessening in the longer period, (iii) similar to the previous evidence on LNCO2CP; LNU and LNK steadily have a low impact on LNYCP.

To sum up, the IRF analysis shows although there are fluctuations of reactions of any variable to a shock in another variables, it seems that only shocks of output to energy use and emissions that could persist in the longer period of simulations.

\subsection{Conclusion}

This study analyses the three causality nexuses between emissions, energy use and economic performance along with urbanization and investment (capital formation), for the case of Indonesia. Employing the Engle-Granger cointegration procedure, we found evidence of long-run causality amongst variables. Employing the complete model, the long-run elasticities of energy use and income to emissions are about 0.68 and 0.71 (1.34 and 1.43 if using separate model) respectively. The speed of adjustment is about $25 \%$, which is also confirmed by the Johansen-Juselius procedure of about $21 \%$. The Stock-Watson DOLS longrun estimates are quite consistent at about 0.74 for energy use and 0.64 for output. Similarly, estimating the emission equation without energy use, we found longrun causality of output to emissions to be about 1.42, suggesting that energy use could be a key intervening variable linking income to emission. More importantly, we do find evidence that energy use and output Granger-cause emissions, but not in the opposite direction, suggesting that while by nature output (and energy use) will foster emissions, there is the possibility to implement emission reduction strategies without impeding growth.

When adding urbanization and capital formation, we employ augmented-VAR procedures to measure the short-run Granger-causality. Similarly, in the short-run, we found a uni-directional Granger causality running from output to emission, which suggests the possibility of implementing green growth development in Indonesia. Bi-directional causality between energy use and $\mathrm{CO}_{2}$ emission indicates that rising energy consumption (which is mainly derived from fossil and non-renewable energy sources), will increase emissions indicating that any effort 
that aims to reduce emissions will impede energy use. This suggests that, among other strategies, the energy policy should pursue an alternative strategy toward intensifying renewable energy sources.

With respect to urbanization and capital formation we found an uni-directional causality of both variables to energy consumption, implying that the population concentration in urban area as well as investment will surge energy use and importantly there is no evidence of causality existing running from urbanization investment to rising $\mathrm{CO}_{2}$ emissions. These findings suggest that urbanization and investment would be reasonably 'carbon neutral' if sustainable low-carbon urban development and investment strategies are promoted.

The VED analysis reveals that the contribution of energy use, output and urbanization to the variation in $\mathrm{CO}_{2}$ emissions considerably increased in the longer periods. The IRF analysis also supports these findings, which suggests that the response of emission to output increases and could persist in the longer period. Furthermore, most of the variation in energy use is initially explained by $\mathrm{CO}_{2}$ emissions, however the contribution of output and urbanization increase over the remaining periods of the simulation. Regarding the variation of output, the contribution of energy use and emission explaining the variation in output is relatively constant. Finally, urbanization could have significant contribution on energy use (and then on emissions), but in the longer period, appropriate lowcarbon urban development strategies could moderate it.

For the policy standpoint, those findings motivate the promotion of sustainable energy system as a way out to decouple economic development with emission trade-offs. Specifically, for the Indonesian case, the policies that could be applied such as improving energy efficiency (consuming less energy to provide the same service), developing renewable energy (replacing current high dependency on fossil fuels), the provision of green infrastructures, supporting investment in environmentally friendly technologies, promoting sustainable urban development and transport systems, and gradual reduction (and well-targeted) energy subsidies. For further research, the above findings can contribute empirical evidence of inter-temporal links in $\mathrm{CO}_{2}$ emissions, energy use, and the economic growth 
nexus, including urbanization and investment. Although only utilizing Indonesia as an example, this could also be relevant to other emerging economies, which could have similar characteristics. For future study, it would be fruitful to incorporate more relevant variables into the analysis if econometrically feasible. Potential variables could be education, renewable energy production and consumption, domestic oil price (ratio to international price), trade openness, financial development, among other potential candidates. Due to data availability and methodological issues, such additional variables are beyond this study and left for further investigations. 
Appendix A (Chapter 1) 
Table A.1. $\mathrm{CO}_{2}$ Emission Intensity (gram $\mathrm{CO}_{2} / \mathrm{Rp}$ ), domestic technology, domestic emission

\begin{tabular}{|c|c|c|}
\hline IO code & Sectors & $\mathrm{CO}_{2}$ intensity \\
\hline 1 & Paddy & 0.006820 \\
\hline 2 & Corn & 0.004500 \\
\hline 3 & Cassava & 0.002800 \\
\hline 4 & Sweet potato & 0.001020 \\
\hline 5 & Other tubers & 0.024600 \\
\hline 6 & Bean & 0.002180 \\
\hline 7 & Soybean & 0.002860 \\
\hline 8 & Other nuts & 0.003790 \\
\hline 9 & Vegetables & 0.002660 \\
\hline 10 & Fruits & 0.001850 \\
\hline 11 & Grains and other foodstuffs & 0.000780 \\
\hline 12 & Rubber & 0.007480 \\
\hline 13 & Cane & 0.021460 \\
\hline 14 & Coconut & 0.019640 \\
\hline 15 & Palm & 0.025310 \\
\hline 16 & Fiber crops & 0.000310 \\
\hline 17 & Tobacco & 0.038470 \\
\hline 18 & Coffee & 0.029880 \\
\hline 19 & Tea & 0.029950 \\
\hline 20 & Clove & 0.028100 \\
\hline 21 & Cocoa & 0.025890 \\
\hline 22 & Cashew nuts & 0.026000 \\
\hline 23 & Other plantation crops & 0.033320 \\
\hline 24 & Other agricultural products & 0.029300 \\
\hline 25 & Livestock and their products except fresh milk & 0.005670 \\
\hline 26 & Fresh milk & 0.023430 \\
\hline 27 & Poultry and their products & 0.009140 \\
\hline 28 & Other animal products & 0.003740 \\
\hline 29 & Timber & 0.028400 \\
\hline 30 & Other forest products & 0.028310 \\
\hline 31 & Marine fish and other marine products & 0.046800 \\
\hline 32 & The inland fish and products & 0.045190 \\
\hline 33 & Shrimp & 0.046910 \\
\hline 34 & Agricultural services & 0.032950 \\
\hline 35 & Coal & 0.008320 \\
\hline 36 & Petroleum & 0.008160 \\
\hline 37 & Natural gas and geothermal & 0.081440 \\
\hline 38 & Tin ore & 0.028600 \\
\hline 39 & Nickel ore & 0.025250 \\
\hline 40 & Seeds of bauxite & 0.043390 \\
\hline 41 & Copper seed & 0.030620 \\
\hline 42 & Gold ore & 0.031790 \\
\hline 43 & Silver ore & 0.039280 \\
\hline 44 & Iron & 0.027290 \\
\hline 45 & Other metallic minerals & 0.024600 \\
\hline 46 & Nonmetallic mineral mining products & 0.034900 \\
\hline 47 & Coarse salt & 0.030480 \\
\hline 48 & Excavation of all types of goods & 0.033690 \\
\hline 49 & Meat, offal and the like & 0.006420 \\
\hline 50 & Processed and preserved meat & 0.026770 \\
\hline 51 & Food and beverages made from milk & 0.013140 \\
\hline 52 & Fruits and vegetables are processed and preserved & 0.093870 \\
\hline 53 & Dried fish and salted fish & 0.023870 \\
\hline 54 & Processed and preserved fish & 0.025020 \\
\hline 55 & Copra & 0.019600 \\
\hline 56 & Animal and vegetable oils & 0.009260 \\
\hline 57 & Rice & 0.004670 \\
\hline 58 & Wheat flour & 0.010970 \\
\hline 59 & Other flours & 0.012080 \\
\hline 60 & Bread, biscuits and the like & 0.015100 \\
\hline 61 & Noodles, macaroni and the like & 0.014640 \\
\hline 62 & Sugar & 0.010110 \\
\hline 63 & Peeling grains & 0.019800 \\
\hline 64 & Chocolate and sugar confectionery & 0.012800 \\
\hline 65 & Ground and peeling coffee & 0.015140 \\
\hline 66 & Processed tea & 0.029010 \\
\hline 67 & Soybean processing results & 0.013100 \\
\hline 68 & Other food & 0.014480 \\
\hline 69 & Animal feed & 0.018200 \\
\hline 70 & Alcoholic beverages & 0.025000 \\
\hline 71 & Non alcoholic beverages & 0.023500 \\
\hline 72 & Processed Tobacco & 0.034640 \\
\hline 73 & Cigarette & 0.020450 \\
\hline 74 & Cotton & 0.076400 \\
\hline 75 & Thread & 0.082420 \\
\hline
\end{tabular}


Textiles

0.072660

Textiles products unless clothes $\quad 0.054530$

Knitted goods $\quad 0.033800$

Rugs, rope and other textiles

0.026400

0.037070

Equate skin and processed

Leather products

Footwear

0.020030

0.021260

0.036540

0.030980

Plywood etc

0.030480

0.019920

0.022480

0.013320

0.053740

0.066100

0.060060

0.071730

0.012060

0.023240

0.031640

0.023960

0.037870

0.021070

0.023610

0.023290

0.020070

0.019500

0.110930

0.128280

0.011870

0.037650

0.027660

0.031330

0.368250

0.385420

0.373310

0.446190

0.395520

0.138910

0.133080

0.024030

0.051320

0.052470

0.054190

0.068670

0.069270

0.020000

0.006760

0.015840

0.020130

0.020680

0.020910

0.026940

0.020140

0.013680

0.041400

0.013010

0.016270

0.028900

0.008260

0.050580

0.097850

0.108740

0.091770

0.100440

1.049620

0.152200

$\begin{array}{ll}\text { Residential and non residential buildings } & 0.039490 \\ \text { Agricultural infrastructure } & 0.045890 \\ \text { Roads, bridges and ports } & 0.041360\end{array}$

$\begin{array}{ll}\text { Residential and non residential buildings } & 0.039490 \\ \text { Agricultural infrastructure } & 0.045890 \\ \text { Roads, bridges and ports } & 0.041360\end{array}$

$\begin{array}{ll}\text { Residential and non residential buildings } & 0.039490 \\ \text { Agricultural infrastructure } & 0.045890 \\ \text { Roads, bridges and ports } & 0.041360\end{array}$

Building and installations, electricity, gas and water supply and 0.030220

communication

0.033460

0.028160

0.015450

0.013600

0.171560

0.111490

0.163380

River and lake transport services $\quad 0.161530$

Marine transportation services

Air transport services

0.204210 


\begin{tabular}{lll}
157 & Transport support services & 0.107950 \\
158 & Communication services & 0.015180 \\
159 & Bank & 0.014460 \\
160 & Other financial institutions & 0.014820 \\
161 & Insurance and pension funds & 0.012100 \\
162 & Building and land rent & 0.005080 \\
163 & Corporate services & 0.020050 \\
164 & General government services & 0.025900 \\
165 & Government educational services & 0.023290 \\
166 & Government health services & 0.016340 \\
167 & Other government services (entertainment, recreation and culture) & 0.018760 \\
168 & Private education services & 0.019120 \\
169 & Private health services & 0.015720 \\
170 & Other community services & 0.016430 \\
171 & Film and distribution services of private & 0.006330 \\
172 & Entertainment services, recreation and culture of private & 0.020130 \\
173 & Overhaul services & 0.023410 \\
174 & Personal and household services & 0.018980 \\
175 & Goods and services not included elsewhere & 0.039860 \\
\hline Source: & Author's computation based on GTAP-E and IO 2005.
\end{tabular}


A.2a. GTAP sectors

\begin{tabular}{|c|c|c|}
\hline No. & Code & Description \\
\hline 1 & pdr & Paddy rice \\
\hline 2 & wht & Wheat \\
\hline 3 & gro & Cereal grains nec \\
\hline 4 & $\mathrm{~V} f$ & Vegetables, fruits, nuts \\
\hline 5 & osd & Oilseeds \\
\hline 6 & c_b & Sugar cane, sugar beet \\
\hline 7 & $\overline{\mathrm{pfb}}$ & Plant-based fibers \\
\hline 8 & ocr & Crops nec \\
\hline 9 & ctl & Bovine cattle, sheep and goats, horses \\
\hline 10 & oap & Animal products nec \\
\hline 11 & rmk & Raw milk \\
\hline 12 & wol & Wool, silk-worm cocoons \\
\hline 19 & $\mathrm{cmt}$ & Bovine cattle, sheep and goat, horse meat products \\
\hline 20 & omt & Meat products nec \\
\hline 21 & vol & Vegetable oils and fats \\
\hline 22 & mil & Dairy products \\
\hline 23 & pcr & Processed rice \\
\hline 24 & sgr & Sugar \\
\hline 25 & ofd & Food products nec \\
\hline 26 & b_t & Beverages and tobacco products \\
\hline 15 & $\mathrm{col}$ & Coal \\
\hline 16 & oil & Oil \\
\hline 17 & gas & Gas \\
\hline 32 & p_c & Petroleum, coal products \\
\hline 43 & ely & Electricity \\
\hline 44 & $\mathrm{gdt}$ & Gas manufacture, distribution \\
\hline 13 & for & Forestry \\
\hline 14 & fsh & Fishing \\
\hline 18 & omn & Minerals nec \\
\hline 27 & tex & Textiles \\
\hline 28 & wap & Wearing apparel \\
\hline 29 & lea & Leather products \\
\hline 30 & lum & Wood products \\
\hline 31 & ppp & Paper products, publishing \\
\hline 33 & crp & Chemical, rubber, plastic products \\
\hline 34 & $\mathrm{nmm}$ & Mineral products nec \\
\hline 35 & i_s & Ferrous metals \\
\hline 36 & $\mathrm{nfm}$ & Metals nec \\
\hline 37 & fmp & Metal products \\
\hline 38 & mvh & Motor vehicles and parts \\
\hline 39 & otn & Transport equipment nec \\
\hline 40 & ele & Electronic equipment \\
\hline 41 & ome & Machinery and equipment nec \\
\hline 42 & omf & Manufactures nec \\
\hline 45 & wtr & Water \\
\hline 46 & cns & Construction \\
\hline 47 & $\operatorname{trd}$ & Trade \\
\hline 48 & otp & Transport nec \\
\hline 49 & wtp & Water transport \\
\hline 50 & atp & Air transport \\
\hline 51 & $\mathrm{cmn}$ & Communication \\
\hline 52 & ofi & Financial services nec \\
\hline 53 & isr & Insurance \\
\hline 54 & obs & Business services nec \\
\hline 55 & ros & Recreational and other services \\
\hline 56 & osg & Public administration and defense, education, health \\
\hline 57 & dwe & Dwellings \\
\hline
\end{tabular}

Source: Huff, McDougall, Walmsley (2000). Contributing Input-Output Tables to the GTAP Data Base. GTAP Technical Paper No. 1 Release 4.2 January 2000. 


\section{A.2b. GTAP sectors: detailed description}

\begin{tabular}{|c|c|c|c|}
\hline No. & Code & Code & Description \\
\hline \multirow[t]{2}{*}{1} & $\mathrm{pdr}$ & 113 & Rice, not husked \\
\hline & & 114 & Husked rice \\
\hline 2 & wht & 111 & Wheat and meslin \\
\hline \multirow[t]{4}{*}{3} & gro & 112 & Maize (corn) \\
\hline & & 115 & Barley \\
\hline & & 116 & Rye, oats \\
\hline & & 119 & Other cereals \\
\hline \multirow[t]{2}{*}{4} & v_f & 12 & Vegetables \\
\hline & & 13 & Fruit and nuts \\
\hline 5 & osd & 14 & Oil seeds and oleaginous fruit \\
\hline 6 & c_b & 18 & Plants used for sugar manufacturing \\
\hline 7 & $\mathrm{pfb}$ & 192 & Raw vegetable materials used in textiles \\
\hline \multirow[t]{7}{*}{8} & ocr & 15 & Live plants; cut flowers and flower buds; flower seeds and fruit seeds; vegetable seeds \\
\hline & & 16 & Beverage and spice crops \\
\hline & & 17 & Unmanufactured tobacco \\
\hline & & 191 & $\begin{array}{l}\text { Cereal straw and husks, unprepared, whether or not chopped, ground, pressed or in the form of } \\
\text { pellets; swedes, mangolds, fodder roots, hay, lucerne (alfalfa), clover, sainfoin, forage kale, } \\
\text { lupines, vetches and similar forage products, whether or not in the form of pellets }\end{array}$ \\
\hline & & 193 & $\begin{array}{l}\text { Plants and parts of plants used primarily in perfumery, in pharmacy, or for insecticidal, } \\
\text { fungicidal or similar purposes }\end{array}$ \\
\hline & & 194 & Sugar beet seed and seeds of forage plants \\
\hline & & 199 & Other raw vegetable materials \\
\hline \multirow[t]{2}{*}{9} & ctl & 211 & Bovine cattle, sheep and goats, horses, asses, mules, and hinnies, live \\
\hline & & 299 & Bovine semen \\
\hline \multirow[t]{7}{*}{10} & oap & 212 & Swine, poultry and other animals, live \\
\hline & & 292 & Eggs, in shell, fresh, preserved or cooked \\
\hline & & 293 & Natural honey \\
\hline & & 294 & $\begin{array}{l}\text { Snails, live, fresh, chilled, frozen, dried, } \\
\text { salted or in brine, except sea snails; frogs' } \\
\text { legs, fresh, chilled or frozen }\end{array}$ \\
\hline & & 295 & Edible products of animal origin n.e.c. \\
\hline & & 297 & Hides, skins and furskins, raw \\
\hline & & 298 & Insect waxes and spermaceti, whether or not refined or coloured \\
\hline 11 & $\mathrm{rmk}$ & 291 & Raw milk \\
\hline 12 & wol & 296 & Raw animal materials used in textile \\
\hline 13 & for & 3 & Forestry, logging and related service activities \\
\hline \multirow[t]{8}{*}{19} & $\mathrm{cmt}$ & 21111 & Meat of bovine animals, fresh or chilled \\
\hline & & 21112 & Meat of bovine animals, frozen \\
\hline & & 21115 & Meat of sheep, fresh or chilled \\
\hline & & 21116 & Meat of sheep, frozen \\
\hline & & 21117 & Meat of goats, fresh, chilled or frozen \\
\hline & & 21118 & Meat of horses, asses, mules or hinnies, fresh, chilled or frozen \\
\hline & & 21119 & $\begin{array}{l}\text { Edible offal of bovine animals, swine, sheep, goats, horses, asses, mules or hinnies, fresh, chilled } \\
\text { or frozen }\end{array}$ \\
\hline & & 2161 & Fats of bovine animals, sheep, goats, pigs and poultry, raw or rendered; wool grease \\
\hline \multirow[t]{6}{*}{20} & omt & 21113 & Meat of swine, fresh or chilled \\
\hline & & 21114 & Meat of swine, frozen \\
\hline & & 2112 & Meat and edible offal, fresh, chilled or frozen, n.e.c. \\
\hline & & 2113 & Preserves and preparations of meat, meat offal or blood \\
\hline & & 2114 & Flours, meals and pellets of meat or meat offal, inedible; greaves \\
\hline & & 2162 & $\begin{array}{l}\text { Animal oils and fats, crude and refined, except fats of bovine animals, sheep, goats, pigs and } \\
\text { poultry }\end{array}$ \\
\hline \multirow[t]{8}{*}{21} & vol & 2163 & $\begin{array}{l}\text { Soya-bean, ground-nut, olive, sunflower-seed, safflower, cotton-seed rape, colza and mustard } \\
\text { oil, crude }\end{array}$ \\
\hline & & 2164 & Palm, coconut, palm kernel, babassu and linseed oil, crude \\
\hline & & 2165 & $\begin{array}{l}\text { Soya-bean, ground-nut, olive, sunflower-seed, safflower, cotton-seed, rape, colza and mustard } \\
\text { oil and their fractions, refined but not chemically modified; other oils obtained solely from } \\
\text { olives and sesame oil, and their fractions, whether or not refined, but not chemically modified }\end{array}$ \\
\hline & & 2166 & Maize (corn) oil and its fractions, not chemically modified \\
\hline & & 2167 & $\begin{array}{l}\text { Palm, coconut, palm kernel, babassu and linseed oil and their fractions, refined but not } \\
\text { chemically modified; castor, tung and jojoba oil and fixed vegetable fats and oils (except maize } \\
\text { oil) and their fractions n.e.c., whether or not refined, but not chemically modified }\end{array}$ \\
\hline & & 2168 & Margarine and similar preparations \\
\hline & & 2169 & $\begin{array}{l}\text { Animal or vegetable fats and oils and their fractions, partly or wholly hydrogenated, inter- } \\
\text { esterified, re-esterified or elaidinised, } \\
\text { whether or not refined, but not further prepared }\end{array}$ \\
\hline & & 217 & Cotton linters \\
\hline
\end{tabular}


218 Oil-cake and other solid residues resulting from the extraction of vegetable fats or oils; flours and meals of oil seeds or oleaginous fruits, except those of mustard; vegetable waxes, except triglycerides; degras; residues resulting from the treatment of fatty substances or animal or vegetable waxes

Rice, semi- or wholly milled

Sugar

212 Prepared and preserved fish

213 Prepared and preserved vegetables

214 Fruit juices and vegetable juices

215 Prepared and preserved fruit and nuts

2311 Wheat or meslin flour

2312 Cereal flours other than of wheat or meslin

2313 Groats, meal and pellets of wheat

2314 Cereal groats, meal and pellets n.e.c.

2315 Other cereal grain products (including corn flakes)

2317 Other vegetable flours and meals

Mixes and doughs for the preparation of bakers' wares

232 Starches and starch products; sugars and syrups n.e.c.

233 Preparations used in animal feeding

234 Bakery products

236 Cocoa, chocolate and sugar confectionery

237 Macaroni, noodles, couscous and similar farinaceous products

239 Food products n.e.c.

Beverages

\section{Tobacco products}

5 Hunting, trapping and game propagation including related service activities

5 Fishing, operation of fish hatcheries and fish farms; service activities incidental to fishing

101 Mining and agglomeration of hard coal

102 Mining and agglomeration of lignite

103 Mining and agglomeration of peat

111 Extraction of crude petroleum and natural gas

112 Service activities incidental to oil and gas extraction excluding surveying (part)

111 Extraction of crude petroleum and natural gas

112 Service activities incidental to oil and gas extraction excluding surveying (part)

12 Mining of uranium and thorium ores

13 Mining of metal ores

14 Other mining and quarrying

17 Manufacture of textiles

243 Manufacture of man-made fibres

18 Manufacture of wearing apparel; dressing and dyeing of fur

19 Tanning and dressing of leather; manufacture of luggage, handbags, saddlery, harness and footwear

20 Manufacture of wood and of products of wood and cork, except furniture; manufacture of articles of straw and plaiting materials

21 Manufacture of paper and paper products

22 Publishing, printing and reproduction of record media

231 Manufacture of coke oven products

232 Manufacture of refined petroleum products

233 Processing of nuclear fuel

241 Manufacture of basic chemicals

242 Manufacture of other chemical products

25 Manufacture of rubber and plastics products

26 Manufacture of other non-metallic mineral products

271 Manufacture of basic iron and steel

2731 Casting of iron and steel

272 Manufacture of basic precious and non-ferrous metals

2732 Casting of non-ferrous metals

28 Manufacture of fabricated metal products, except machinery and equipment

34 Manufacture of motor vehicles, trailers and semi- trailers

35 Manufacture of other transport equipment

30 Manufacture of office, accounting and computing machinery

32 Manufacture of radio, television and communication equipment and apparatus

29 Manufacture of machinery and equipment n.e.c.

31 Manufacture of electrical machinery and apparatus n.e.c.

33 Manufacture of medical, precision and optical instruments, watches and clocks

36 Manufacturing n.e.c.

37 Recycling

401 Production, collection and distribution of electricity

402 Manufacture of gas; distribution of gaseous fuels through mains

403 Steam and hot water supply 


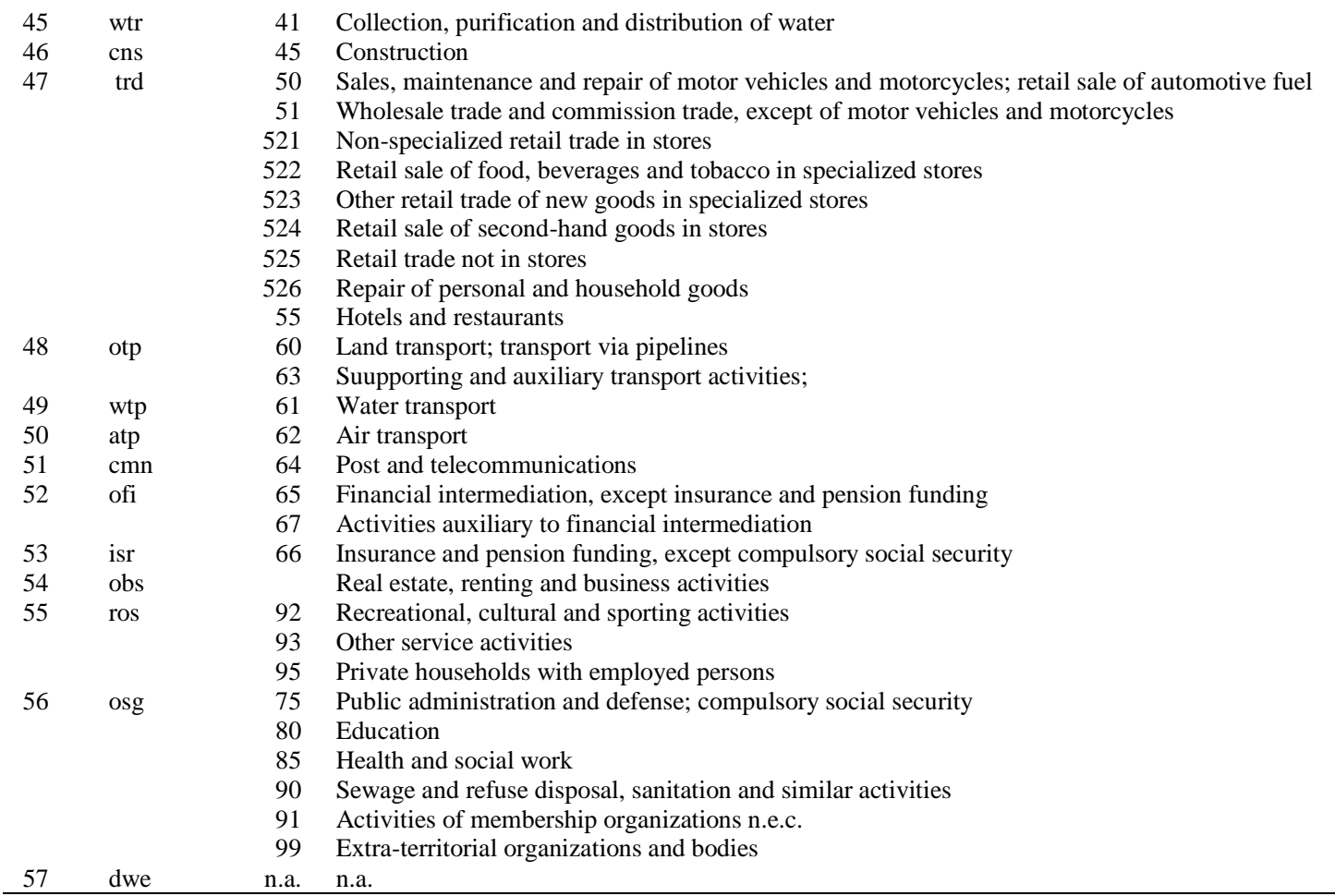

Source: Huff, McDougall, Walmsley (2000). Contributing Input-Output Tables to the GTAP Data Base. GTAP Technical Paper No. 1 Release 4.2 January 2000.

Note: GTAP A5GSC2 sectors defined by reference to the ISIC. 
Table A.3. Expenditure category: description

\begin{tabular}{ll}
\hline & Description \\
\hline Cereal & Rice, grains, and cereals \\
Vegetable and fruit & Vegetable and fruit \\
Oil and fat & Oil and fat ingredients \\
Beverage & Drink material, season, noodles, chips, alcohol drink \\
Egg, fish, meat, and dairy & Egg, fish, meat, dairy products \\
Tobacco & Tobacco \\
Fuel and light & Electricity bill, fuel \\
Telecommunication & Telephone bill, other telecommunication \\
Transportation & Transportation cost \\
Health & Health costs, health insurance \\
Education & Education costs \\
Toiletry & Soap, cosmetic, etc \\
Clothes & Clothes \\
House and durable goods & House and durable goods \\
Services and rent & Services \\
Taxes & Taxes, retribution, other taxes \\
Recreation, entertainment, ceremony & Recreation, entertainment, ceremony \\
\hline Source: Author's computation, based on GTAP-E, Indonesian Input Output and Susenas 2005 and \\
2009.
\end{tabular}


Table A.4. Descriptive analysis by income quintiles: 2005 and 2009

\begin{tabular}{|c|c|c|c|c|c|c|}
\hline 2005 & Q1 & $\mathbf{Q 2}$ & Q3 & Q4 & Q5 & Overall \\
\hline Total household expenditure (Rp 000) & 4,264 & 6,804 & 9,131 & 12,600 & 26,600 & 11,900 \\
\hline Per capita expenditure $(\operatorname{Rp} 000)$ & 846 & 1,564 & 2,283 & 3,396 & 8,036 & 2,917 \\
\hline $\mathrm{CO}_{2}$ emissions $(\mathrm{kg})$ & 1,280 & 1,782 & 2,271 & 3,042 & 5,861 & 2,847 \\
\hline Per capita $\mathrm{CO}_{2}$ emission $(\mathrm{kg})$ & 254 & 410 & 568 & 820 & 1,771 & 698 \\
\hline Household size (persons) & 5.04 & 4.35 & 4.00 & 3.71 & 3.31 & 4.08 \\
\hline No. of observations & 51,582 & 51,581 & 51,581 & 51,581 & 51,581 & 257,906 \\
\hline 2009 & Q1 & Q2 & Q3 & Q4 & Q5 & Overall \\
\hline Total household expenditure (Rp 000), deflated & 6,775 & 10,145 & 12,899 & 16,594 & 27,899 & 14,855 \\
\hline Per capita expenditure (Rp 000), deflated & 1,293 & 2,275 & 3,265 & 4,782 & 10,410 & 3,751 \\
\hline $\mathrm{CO}_{2}$ emissions $(\mathrm{kg})$ & 1,663 & 2,425 & 3,084 & 3,973 & 6,637 & 3,556 \\
\hline Per capita $\mathrm{CO}_{2}$ emission $(\mathrm{kg})$ & 317 & 544 & 781 & 1,145 & 2,476 & 898 \\
\hline Household size (persons) & 5.24 & 4.46 & 3.95 & 3.47 & 2.68 & 3.96 \\
\hline No. of observations & 58,351 & 58,351 & 58,351 & 51,850 & 51,850 & 291,753 \\
\hline
\end{tabular}

Source: Author's computation, based on GTAP-E, Indonesian Input Output and Susenas 2005 and 2009.

Note: Quintile classification is based on household per-capita expenditure distribution. Quintile 1 refers to the poorest quintile. Expenditure in 2009 is deflated $(2005=100)$ 
Table A.5. Consumption category

\begin{tabular}{|c|c|c|c|c|c|c|c|c|}
\hline \multirow[t]{2}{*}{ Group of expenditure } & \multicolumn{3}{|c|}{ Nominal (Rp) } & \multicolumn{3}{|c|}{$\begin{array}{c}\text { CPI deflated (Rp) } \\
(2005=100)\end{array}$} & \multicolumn{2}{|c|}{$\begin{array}{c}\text { Expenditure } \\
\text { share }(\%)\end{array}$} \\
\hline & 2005 & 2009 & $\begin{array}{c}\text { Growth } \\
(\%)\end{array}$ & 2005 & 2009 & $\begin{array}{c}\text { Growth } \\
(\%)\end{array}$ & 2005 & 2009 \\
\hline Cereal & $1,932,727$ & $3,178,787$ & 64.47 & $1,932,727$ & $2,303,469$ & 19.18 & 16.24 & 15.51 \\
\hline Vegetable and fruit & $1,095,324$ & $1,822,202$ & 66.36 & $1,095,324$ & $1,320,436$ & 20.55 & 9.20 & 8.89 \\
\hline Oil and fat & 366,246 & 576,454 & 57.40 & 366,246 & 417,720 & 14.05 & 3.08 & 2.81 \\
\hline Beverage & $1,784,393$ & $2,980,696$ & 67.04 & $1,784,393$ & $2,159,925$ & 21.05 & 14.99 & 14.54 \\
\hline Egg, fish, meat, dairy & $1,572,178$ & $2,538,249$ & 61.45 & $1,572,178$ & $1,839,311$ & 16.99 & 13.21 & 12.38 \\
\hline Tobacco & 987,676 & $1,582,001$ & 60.17 & 987,676 & $1,146,378$ & 16.07 & 8.30 & 7.72 \\
\hline Fuel and light & 788,083 & $1,255,051$ & 59.25 & 788,084 & 909,457 & 15.40 & 6.62 & 6.12 \\
\hline Telecommunication & 178,571 & 433,491 & 142.75 & 178,571 & 314,124 & 75.91 & 1.50 & 2.11 \\
\hline Transportation & 415,262 & 922,775 & 122.21 & 415,262 & 668,677 & 61.03 & 3.49 & 4.50 \\
\hline Health & 204,061 & 421,968 & 106.78 & 204,061 & 305,774 & 49.84 & 1.71 & 2.06 \\
\hline Education & 306,425 & 581,749 & 89.85 & 306,425 & 421,557 & 37.57 & 2.58 & 2.84 \\
\hline Toiletry & 349,539 & 510,649 & 46.09 & 349,539 & 370,035 & 5.86 & 2.94 & 2.49 \\
\hline Clothes & 401,673 & 650,842 & 62.03 & 401,673 & 471,625 & 17.42 & 3.38 & 3.17 \\
\hline House and durable goods & 255,414 & 413,278 & 61.81 & 255,415 & 299,477 & 17.25 & 2.15 & 2.02 \\
\hline Services and rent & $1,339,935$ & $2,268,360$ & 69.29 & $1,339,935$ & $1,643,739$ & 22.67 & 11.26 & 11.07 \\
\hline Taxes & 80,531 & 172,592 & 114.32 & 80,531 & 125,066 & 55.30 & 0.68 & 0.84 \\
\hline Recreation, entertainment, ceremony & 148,476 & 190,859 & 28.55 & 148,476 & 138,304 & -6.85 & 1.25 & 0.93 \\
\hline
\end{tabular}

Source: Author's computation, based on GTAP-E, Indonesian Input Output and Susenas 2005 and 2009.

Table A.6. Expenditure: share to total expenditure (\%)

\begin{tabular}{|c|c|c|c|c|c|c|}
\hline \multirow{2}{*}{ Group of expenditure } & \multicolumn{3}{|c|}{2005} & \multicolumn{3}{|c|}{2009} \\
\hline & National & Rural & Urban & National & Rural & Urban \\
\hline Cereal & 16.24 & 19.68 & 10.49 & 15.51 & 18.67 & 9.72 \\
\hline Vegetable and fruit & 9.20 & 9.72 & 8.34 & 8.89 & 9.37 & 8.01 \\
\hline Oil and fat & 3.08 & 3.51 & 2.35 & 2.81 & 3.21 & 2.09 \\
\hline Beverage & 14.99 & 14.32 & 16.12 & 14.54 & 13.62 & 16.23 \\
\hline Egg, fish, meat, dairy & 13.21 & 13.44 & 12.83 & 12.38 & 12.60 & 11.98 \\
\hline Tobacco & 8.30 & 9.08 & 6.99 & 7.72 & 8.42 & 6.42 \\
\hline Fuel and light & 6.62 & 6.08 & 7.54 & 6.12 & 5.87 & 6.58 \\
\hline Telecommunication & 1.50 & 0.55 & 3.09 & 2.11 & 1.53 & 3.18 \\
\hline Transportation & 3.49 & 2.64 & 4.91 & 4.50 & 3.86 & 5.68 \\
\hline Health & 1.71 & 1.61 & 1.89 & 2.06 & 1.89 & 2.36 \\
\hline Education & 2.58 & 1.93 & 3.65 & 2.84 & 2.41 & 3.62 \\
\hline Toiletry & 2.94 & 2.84 & 3.11 & 2.49 & 2.46 & 2.54 \\
\hline Clothes & 3.38 & 3.42 & 3.31 & 3.17 & 3.21 & 3.10 \\
\hline House and durable goods & 2.15 & 2.13 & 2.17 & 2.02 & 2.02 & 2.02 \\
\hline Services and rent & 11.26 & 9.11 & 14.86 & 11.07 & 9.17 & 14.53 \\
\hline Taxes & 0.68 & 0.53 & 0.93 & 0.84 & 0.67 & 1.16 \\
\hline Recreation, entertainment, ceremony & 1.25 & 1.34 & 1.09 & 0.93 & 1.01 & 0.78 \\
\hline
\end{tabular}

Source: Author's computation, based on GTAP-E, Indonesian Input Output and Susenas 2005 and 2009. 
Table A.7. $\mathrm{CO}_{2}$ emissions $(\mathrm{kg})$ per expenditure category

\begin{tabular}{|c|c|c|c|c|}
\hline & 2005 & 2009 & $\begin{array}{r}\text { Growth } \\
\text { (nominal, \%) }\end{array}$ & $\begin{array}{r}\text { Growth } \\
\text { (real, \%) }\end{array}$ \\
\hline Cereal & 41.84 & 75.91 & 81.45 & 31.49 \\
\hline Vegetable and fruit & 107.54 & 194.38 & 80.75 & 30.98 \\
\hline Oil and fat & 20.55 & 35.51 & 72.84 & 25.24 \\
\hline Beverage & 163.86 & 308.16 & 88.06 & 36.28 \\
\hline Egg, fish, meat, dairy & 181.92 & 332.71 & 82.89 & 32.53 \\
\hline Tobacco & 67.59 & 120.25 & 77.91 & 28.92 \\
\hline Fuel and light & $1,688.51$ & $2,768.80$ & 63.98 & 18.82 \\
\hline Telecommunication & 29.84 & 57.70 & 93.38 & 40.13 \\
\hline Transportation & 183.07 & 400.84 & 118.95 & 58.66 \\
\hline Health & 13.08 & 28.84 & 120.45 & 59.75 \\
\hline Education & 22.97 & 47.47 & 106.63 & 49.74 \\
\hline Toiletry & 18.64 & 29.02 & 55.66 & 12.8 \\
\hline Clothes & 46.45 & 81.68 & 75.84 & 27.42 \\
\hline House and durable goods & 126.65 & 202.95 & 60.25 & 16.12 \\
\hline Services and rent & 84.79 & 151.85 & 79.09 & 29.77 \\
\hline Taxes & 3.68 & 7.85 & 113.01 & 54.35 \\
\hline Recreation, entertainment, ceremony & 46.47 & 63.88 & 37.44 & -0.4 \\
\hline
\end{tabular}

Source: Author's computation, based on GTAP-E, Indonesian Input Output and Susenas 2005 and 2009. 
Table A.8. Emission share to total emission vs. expenditure share to total expenditure, by quintile

\begin{tabular}{|c|c|c|c|c|c|c|c|c|c|c|c|c|}
\hline & \multicolumn{4}{|c|}{ Overall household } & \multicolumn{4}{|c|}{$\mathbf{I}$} & \multicolumn{4}{|c|}{ II } \\
\hline & \multicolumn{2}{|c|}{ s CO2 } & \multicolumn{2}{|c|}{ s EXP } & \multicolumn{2}{|c|}{ s CO2 } & \multicolumn{2}{|c|}{ s EXP } & \multicolumn{2}{|c|}{ s CO2 } & \multicolumn{2}{|c|}{ s EXP } \\
\hline & 2005 & 2009 & 2005 & 2009 & 2005 & 2009 & 2005 & 2009 & 2005 & 2009 & 2005 & 2009 \\
\hline Cereal & 0.025 & 0.023 & 0.162 & 0.155 & 0.044 & 0.032 & 0.261 & 0.210 & 0.030 & 0.027 & 0.198 & 0.181 \\
\hline Vegetable and fruit & 0.050 & 0.049 & 0.092 & 0.089 & 0.059 & 0.054 & 0.101 & 0.102 & 0.054 & 0.052 & 0.100 & 0.095 \\
\hline Oil and fat & 0.011 & 0.010 & 0.031 & 0.028 & 0.016 & 0.013 & 0.040 & 0.037 & 0.013 & 0.011 & 0.036 & 0.031 \\
\hline Beverage & 0.065 & 0.068 & 0.150 & 0.145 & 0.058 & 0.062 & 0.134 & 0.144 & 0.062 & 0.065 & 0.147 & 0.144 \\
\hline Egg, fish, meat, dairy & 0.076 & 0.073 & 0.132 & 0.124 & 0.076 & 0.065 & 0.116 & 0.112 & 0.077 & 0.072 & 0.130 & 0.122 \\
\hline Tobacco & 0.032 & 0.031 & 0.083 & 0.077 & 0.034 & 0.027 & 0.078 & 0.069 & 0.036 & 0.033 & 0.090 & 0.083 \\
\hline Fuel and light & 0.573 & 0.559 & 0.066 & 0.061 & 0.586 & 0.613 & 0.063 & 0.070 & 0.591 & 0.576 & 0.067 & 0.063 \\
\hline Telecommunication & 0.006 & 0.009 & 0.015 & 0.021 & 0.001 & 0.004 & 0.001 & 0.009 & 0.002 & 0.007 & 0.004 & 0.015 \\
\hline Transportation & 0.050 & 0.070 & 0.035 & 0.045 & 0.028 & 0.043 & 0.017 & 0.028 & 0.038 & 0.061 & 0.026 & 0.039 \\
\hline Health & 0.005 & 0.006 & 0.017 & 0.021 & 0.004 & 0.005 & 0.013 & 0.018 & 0.004 & 0.005 & 0.015 & 0.018 \\
\hline Education & 0.007 & 0.009 & 0.026 & 0.028 & 0.008 & 0.006 & 0.026 & 0.018 & 0.007 & 0.008 & 0.023 & 0.025 \\
\hline Toiletry & 0.008 & 0.007 & 0.029 & 0.025 & 0.009 & 0.007 & 0.030 & 0.028 & 0.008 & 0.007 & 0.030 & 0.026 \\
\hline Clothes & 0.019 & 0.018 & 0.034 & 0.032 & 0.021 & 0.017 & 0.034 & 0.030 & 0.020 & 0.019 & 0.035 & 0.032 \\
\hline House and durable & 0.028 & 0.027 & 0.021 & 0.020 & 0.017 & 0.016 & 0.011 & 0.011 & 0.020 & 0.019 & 0.014 & 0.014 \\
\hline Services and rent & 0.028 & 0.029 & 0.113 & 0.111 & 0.024 & 0.025 & 0.087 & 0.102 & 0.024 & 0.026 & 0.093 & 0.099 \\
\hline Taxes & 0.001 & 0.001 & 0.007 & 0.008 & 0.001 & 0.001 & 0.004 & 0.005 & 0.001 & 0.001 & 0.005 & 0.007 \\
\hline Recreation, entert. & 0.016 & 0.012 & 0.012 & 0.009 & 0.016 & 0.011 & 0.011 & 0.008 & 0.015 & 0.011 & 0.011 & 0.008 \\
\hline
\end{tabular}

\begin{tabular}{|c|c|c|c|c|c|c|c|c|c|c|c|c|}
\hline & \multicolumn{4}{|c|}{ III } & \multicolumn{4}{|c|}{ IV } & \multicolumn{4}{|c|}{$\bar{V}$} \\
\hline & \multicolumn{2}{|c|}{$\mathrm{s} \mathrm{CO2}$} & \multicolumn{2}{|c|}{ S EXP } & \multicolumn{2}{|c|}{ s CO2 } & \multicolumn{2}{|c|}{ S EXP } & \multicolumn{2}{|c|}{ s CO2 } & \multicolumn{2}{|c|}{ S EXP } \\
\hline & 2005 & 2009 & 2005 & 2009 & 2005 & 2009 & 2005 & 2009 & 2005 & 2009 & 2005 & 2009 \\
\hline Cereal & 0.023 & 0.023 & 0.159 & 0.155 & 0.017 & 0.019 & 0.122 & 0.131 & 0.010 & 0.015 & 0.072 & 0.098 \\
\hline Vegetable and fruit & 0.051 & 0.049 & 0.097 & 0.090 & 0.046 & 0.046 & 0.090 & 0.084 & 0.037 & 0.040 & 0.072 & 0.074 \\
\hline Oil and fat & 0.011 & 0.010 & 0.032 & 0.028 & 0.009 & 0.009 & 0.028 & 0.025 & 0.006 & 0.007 & 0.019 & 0.019 \\
\hline Beverage & 0.064 & 0.068 & 0.152 & 0.146 & 0.066 & 0.070 & 0.154 & 0.146 & 0.077 & 0.075 & 0.162 & 0.148 \\
\hline Egg, fish, meat, dairy & 0.079 & 0.075 & 0.140 & 0.127 & 0.079 & 0.077 & 0.145 & 0.131 & 0.069 & 0.076 & 0.129 & 0.127 \\
\hline Tobacco & 0.035 & 0.033 & 0.092 & 0.084 & 0.033 & 0.032 & 0.088 & 0.081 & 0.025 & 0.027 & 0.068 & 0.070 \\
\hline Fuel and light & 0.584 & 0.558 & 0.068 & 0.060 & 0.573 & 0.539 & 0.068 & 0.058 & 0.532 & 0.511 & 0.065 & 0.055 \\
\hline Telecommunication & 0.003 & 0.009 & 0.009 & 0.020 & 0.007 & 0.011 & 0.018 & 0.026 & 0.016 & 0.015 & 0.043 & 0.035 \\
\hline Transportation & 0.048 & 0.072 & 0.033 & 0.047 & 0.059 & 0.082 & 0.042 & 0.053 & 0.078 & 0.093 & 0.056 & 0.060 \\
\hline Health & 0.004 & 0.005 & 0.016 & 0.020 & 0.005 & 0.006 & 0.018 & 0.022 & 0.006 & 0.008 & 0.023 & 0.026 \\
\hline Education & 0.006 & 0.009 & 0.024 & 0.028 & 0.006 & 0.010 & 0.025 & 0.032 & 0.008 & 0.012 & 0.031 & 0.039 \\
\hline Toiletry & 0.007 & 0.007 & 0.030 & 0.024 & 0.007 & 0.006 & 0.029 & 0.024 & 0.007 & 0.006 & 0.028 & 0.023 \\
\hline Clothes & 0.019 & 0.019 & 0.035 & 0.032 & 0.018 & 0.019 & 0.034 & 0.033 & 0.017 & 0.018 & 0.032 & 0.032 \\
\hline House and durable & 0.024 & 0.024 & 0.017 & 0.018 & 0.030 & 0.030 & 0.023 & 0.023 & 0.052 & 0.045 & 0.043 & 0.035 \\
\hline Services and rent & 0.025 & 0.027 & 0.103 & 0.104 & 0.029 & 0.029 & 0.120 & 0.113 & 0.040 & 0.037 & 0.161 & 0.135 \\
\hline Taxes & 0.001 & 0.001 & 0.006 & 0.008 & 0.001 & 0.001 & 0.008 & 0.009 & 0.002 & 0.002 & 0.012 & 0.013 \\
\hline Recreation, entert. & 0.015 & 0.011 & 0.012 & 0.009 & 0.016 & 0.013 & 0.013 & 0.010 & 0.018 & 0.015 & 0.016 & 0.012 \\
\hline
\end{tabular}

Source: Author's computation, based on GTAP-E, Indonesian Input Output and Susenas 2005 and 2009. 
Table A.9. Province dummy

\begin{tabular}{|c|c|c|c|c|c|c|c|}
\hline Code & Province & I & II & III & IV & $\mathbf{V}$ & VI \\
\hline 12 & Sumatera Utara & 0.164 & 0.165 & 0.208 & -0.080 & -0.077 & -0.077 \\
\hline 13 & Sumatera Barat & 0.174 & 0.175 & 0.216 & -0.038 & -0.036 & -0.035 \\
\hline 14 & Riau & 0.175 & 0.175 & 0.297 & -0.046 & -0.047 & -0.048 \\
\hline 15 & Jambi & 0.193 & 0.193 & 0.180 & 0.016 & 0.013 & 0.012 \\
\hline 16 & Sumatera Selatan & 0.179 & 0.179 & 0.171 & -0.028 & -0.029 & -0.030 \\
\hline 17 & Bengkulu & 0.178 & 0.178 & 0.134 & 0.010 & 0.009 & 0.009 \\
\hline 18 & Lampung & 0.287 & 0.286 & 0.221 & -0.011 & -0.014 & -0.015 \\
\hline 19 & Bangka-Belitung & 0.186 & 0.185 & 0.296 & -0.018 & -0.020 & -0.020 \\
\hline 21 & Kepulauan Riau & 0.229 & 0.229 & 0.381 & -0.066 & -0.067 & -0.068 \\
\hline 31 & DKI Jakarta & 0.258 & 0.257 & 0.648 & -0.191 & -0.193 & -0.194 \\
\hline 32 & Jawa Barat & 0.311 & 0.310 & 0.270 & -0.011 & -0.013 & -0.013 \\
\hline 33 & Jawa Tengah & 0.403 & 0.402 & 0.274 & 0.023 & 0.020 & 0.022 \\
\hline 34 & DI Yogyakarta & 0.305 & 0.306 & 0.157 & 0.056 & 0.059 & 0.064 \\
\hline 35 & Jawa Timur & 0.383 & 0.382 & 0.229 & 0.041 & 0.038 & 0.039 \\
\hline 36 & Banten & 0.253 & 0.253 & 0.376 & -0.090 & -0.091 & -0.090 \\
\hline 51 & Bali & 0.354 & 0.354 & 0.405 & -0.024 & -0.024 & -0.023 \\
\hline 52 & Nusa Tenggara Barat & 0.152 & 0.152 & 0.044 & 0.023 & 0.022 & 0.019 \\
\hline 53 & Nusa Tenggara Timur & 0.000 & 0.001 & -0.104 & -0.036 & -0.035 & -0.033 \\
\hline 61 & Kalimantan Barat & 0.066 & 0.066 & 0.090 & -0.022 & -0.022 & -0.023 \\
\hline 62 & Kalimantan Tengah & 0.062 & 0.062 & 0.028 & 0.035 & 0.034 & 0.032 \\
\hline 63 & Kalimantan Selatan & 0.176 & 0.175 & 0.109 & 0.063 & 0.061 & 0.060 \\
\hline 64 & Kalimantan Timur & 0.199 & 0.198 & 0.348 & -0.069 & -0.070 & -0.070 \\
\hline 71 & Sulawesi Utara & 0.131 & 0.131 & 0.066 & 0.019 & 0.016 & 0.018 \\
\hline 72 & Sulawesi Tengah & 0.124 & 0.124 & 0.077 & 0.002 & 0.001 & 0.001 \\
\hline 73 & Sulawesi Selatan & 0.193 & 0.193 & 0.164 & -0.017 & -0.018 & -0.017 \\
\hline 74 & Sulawesi Tenggara & 0.222 & 0.222 & 0.223 & -0.049 & -0.047 & -0.047 \\
\hline 75 & Gorontalo & 0.077 & 0.076 & 0.046 & 0.007 & 0.003 & 0.002 \\
\hline 76 & Sulawesi Barat & 0.215 & 0.216 & 0.194 & -0.019 & -0.017 & -0.018 \\
\hline 81 & Maluku & 0.021 & 0.021 & 0.092 & -0.103 & -0.103 & -0.100 \\
\hline 82 & Maluku Utara & -0.013 & -0.013 & 0.081 & -0.083 & -0.083 & -0.082 \\
\hline 91 & Papua & -0.006 & -0.005 & -0.000 & -0.000 & 0.002 & -0.001 \\
\hline 94 & Papua Barat & 0.030 & 0.030 & 0.002 & 0.052 & 0.051 & 0.047 \\
\hline
\end{tabular}

Source: Author's estimation, based on GTAP-E, Indonesian Input Output and Susenas 2005 and 2009. Note: Nanggroe Aceh Darussalam (province code 11) as benchmark. 
Table A.10a. Quantile regression (excluding expenditure square)

\begin{tabular}{|c|c|c|c|c|c|c|}
\hline & \multicolumn{2}{|c|}{ OLS } & \multicolumn{2}{|c|}{$Q(0.1)$} & \multicolumn{2}{|c|}{$Q(0.25)$} \\
\hline & coef & se & coef & se & coef & se \\
\hline $\ln \exp$ & $0.957 * * *$ & 0.001 & $1.035 * * *$ & 0.002 & $0.999 * * *$ & 0.001 \\
\hline hhsize & $0.046 * * *$ & 0.002 & $0.070 * * *$ & 0.004 & $0.065 * * *$ & 0.003 \\
\hline hhsizesq & $-0.011 * * *$ & 0.000 & $-0.014 * * *$ & 0.001 & $-0.014 * * *$ & 0.001 \\
\hline hhsizecub & $0.001 * * *$ & 0.000 & $0.001 * * *$ & 0.000 & $0.001 * * *$ & 0.000 \\
\hline age & $0.020 * * *$ & 0.001 & $0.022 * * *$ & 0.001 & $0.022 * * *$ & 0.001 \\
\hline agesq & $-2.91 \mathrm{E}-04$ & 0.000 & $-0.000 * * *$ & 0.000 & $-3.39 \mathrm{E}-04$ & 0.000 \\
\hline agecub & $1.50 \mathrm{E}-06$ & 0.000 & $1.74 \mathrm{E}-06$ & 0.000 & $1.80 \mathrm{E}-06$ & 0.000 \\
\hline Urbanity & $0.173 * * *$ & 0.001 & $0.209 * * *$ & 0.002 & $0.206 * * *$ & 0.001 \\
\hline Married HH-head & $0.051 * * *$ & 0.002 & $0.047 * * *$ & 0.004 & $0.052 * * *$ & 0.003 \\
\hline Female HH-head & $0.051 * * *$ & 0.002 & $0.052 * * *$ & 0.004 & $0.053 * * *$ & 0.003 \\
\hline Elementary school & $0.023 * * *$ & 0.002 & $0.048 * * *$ & 0.003 & $0.032 * * *$ & 0.002 \\
\hline Secondary school & $0.024 * * *$ & 0.002 & $0.056 * * *$ & 0.004 & $0.035 * * *$ & 0.003 \\
\hline High school & $0.051 * * *$ & 0.002 & $0.085 * * *$ & 0.004 & $0.065 * * *$ & 0.003 \\
\hline At least college & $0.064 * * *$ & 0.003 & $0.084 * * *$ & 0.005 & $0.074 * * *$ & 0.004 \\
\hline Survey year 2009 & $0.065 * * *$ & 0.001 & $0.053 * * *$ & 0.002 & $0.050 * * *$ & 0.001 \\
\hline _cons & $-8.323 * * *$ & 0.018 & $-10.154 * * *$ & 0.033 & $-9.318 * * *$ & 0.025 \\
\hline \#Obs & \multicolumn{2}{|c|}{549,659} & \multicolumn{2}{|c|}{549,659} & \multicolumn{2}{|c|}{549,659} \\
\hline (pseudo) $\mathrm{R}^{2}$ & \multicolumn{2}{|c|}{0.806} & \multicolumn{2}{|c|}{0.553} & \multicolumn{2}{|c|}{0.557} \\
\hline
\end{tabular}

\begin{tabular}{|c|c|c|c|c|c|c|}
\hline & \multicolumn{2}{|c|}{$Q(0.50)$} & \multicolumn{2}{|c|}{$Q(0.75)$} & \multicolumn{2}{|c|}{$Q(0.90)$} \\
\hline & coef & se & coef & se & coef & se \\
\hline $\operatorname{lnexp}$ & $0.954 * * *$ & 0.001 & $0.914 * * *$ & 0.001 & $0.886 * * *$ & 0.001 \\
\hline hhsize & $0.050 * * *$ & 0.003 & $0.031 * * *$ & 0.003 & $0.016 * * *$ & 0.003 \\
\hline hhsizesq & $-0.012 * * *$ & 0.001 & $-0.008 * * *$ & 0.001 & $-0.006 * * *$ & 0.001 \\
\hline hhsizecub & $0.001 * * *$ & 0.000 & 4.46E-04 & 0.000 & $3.51 \mathrm{E}-04$ & 0.000 \\
\hline age & $0.021 * * *$ & 0.001 & $0.017 * * *$ & 0.001 & $0.013 * * *$ & 0.001 \\
\hline agesq & $-3.22 \mathrm{E}-04$ & 0.000 & $-2.49 \mathrm{E}-04$ & 0.000 & $-1.83 \mathrm{E}-04$ & 0.000 \\
\hline agecub & $1.70 \mathrm{E}-06$ & 0.000 & $1.26 \mathrm{E}-06$ & 0.000 & 8.60E-07 & 0.000 \\
\hline Urbanity & $0.177 * * *$ & 0.001 & $0.143 * * *$ & 0.001 & $0.121 * * *$ & 0.002 \\
\hline Married HH-head & $0.052 * * *$ & 0.003 & $0.045^{* * *}$ & 0.003 & $0.034 * * *$ & 0.003 \\
\hline Female HH-head & $0.050 * * *$ & 0.003 & $0.046 * * *$ & 0.003 & $0.035 * * *$ & 0.003 \\
\hline Elementary school & $0.018 * * *$ & 0.002 & $0.011 * * *$ & 0.002 & 0.001 & 0.003 \\
\hline Secondary school & $0.019 * * *$ & 0.003 & $0.010 * * *$ & 0.003 & -0.002 & 0.003 \\
\hline High school & $0.047 * * *$ & 0.003 & $0.036 * * *$ & 0.003 & $0.023 * * *$ & 0.003 \\
\hline At least college & $0.065 * * *$ & 0.003 & $0.057 * * *$ & 0.003 & $0.041 * * *$ & 0.004 \\
\hline Survey year 2009 & $0.048 * * *$ & 0.001 & $0.058 * * *$ & 0.001 & $0.075 * * *$ & 0.002 \\
\hline _cons & $-8.281 * * *$ & 0.022 & $-7.286 * * *$ & 0.022 & $-6.532 * * *$ & 0.028 \\
\hline \#Obs & \multicolumn{2}{|c|}{549,659} & \multicolumn{2}{|c|}{549,659} & \multicolumn{2}{|c|}{549,659} \\
\hline (pseudo) $\mathrm{R}^{2}$ & \multicolumn{2}{|c|}{0.564} & \multicolumn{2}{|c|}{0.573} & \multicolumn{2}{|c|}{0.576} \\
\hline
\end{tabular}

Source: Author's estimation based on GTAP-E, Indonesian Input Output and Susenas 2005 and 2009 . $* * *, * * *)$ indicates significance at the ten (five, one) percent level 
Table A.10b. Quantile regression (excluding expenditure square)

\begin{tabular}{|c|c|c|c|c|c|c|}
\hline & \multicolumn{2}{|c|}{ OLS } & \multicolumn{2}{|c|}{$\mathrm{Q}(0.1)$} & \multicolumn{2}{|c|}{$Q(0.25)$} \\
\hline & coef & se & coef & se & coef & se \\
\hline $\ln \exp$ & $0.959 * * *$ & 0.001 & $1.039 * * *$ & 0.002 & $1.001 * * *$ & 0.001 \\
\hline hhsize & $-0.014 * * *$ & 0.000 & $-0.011 * * *$ & 0.001 & $-0.013 * * *$ & 0.000 \\
\hline Age & $0.003 * * *$ & 0.000 & $0.003 * * *$ & 0.000 & $0.003 * * *$ & 0.000 \\
\hline Urbanity & $0.172 * * *$ & 0.001 & $0.206 * * *$ & 0.002 & $0.205 * * *$ & 0.002 \\
\hline Married HH-head & $0.075 * * *$ & 0.002 & $0.082 * * *$ & 0.004 & $0.084 * * *$ & 0.003 \\
\hline Female HH-head & $0.059 * * *$ & 0.002 & $0.063 * * *$ & 0.004 & $0.062 * * *$ & 0.003 \\
\hline Elementary school & $0.029 * * *$ & 0.002 & $0.054 * * *$ & 0.003 & $0.039 * * *$ & 0.002 \\
\hline Secondary school & $0.029 * * *$ & 0.002 & $0.062 * * *$ & 0.004 & $0.042 * * *$ & 0.003 \\
\hline High school & $0.057 * * *$ & 0.002 & $0.092 * * *$ & 0.004 & $0.072 * * *$ & 0.003 \\
\hline At least college & $0.068 * * *$ & 0.003 & $0.085 * * *$ & 0.005 & $0.077 * * *$ & 0.004 \\
\hline Survey year 2009 & $0.065 * * *$ & 0.001 & $0.054 * * *$ & 0.002 & $0.050 * * *$ & 0.001 \\
\hline _cons & $-7.996 * * *$ & 0.014 & $-9.796 * * *$ & 0.024 & $-8.929 * * *$ & 0.019 \\
\hline \#Obs & \multicolumn{2}{|c|}{549,659} & \multicolumn{2}{|c|}{549,659} & \multicolumn{2}{|c|}{549,659} \\
\hline (pseudo) R2 & \multicolumn{2}{|c|}{0.805} & \multicolumn{2}{|c|}{0.552} & \multicolumn{2}{|c|}{0.556} \\
\hline & \multicolumn{2}{|c|}{$Q(0.50)$} & $Q(0.75)$ & \multicolumn{3}{|c|}{$\mathrm{Q}(0.90)$} \\
\hline & coef & se & coef & se & coef & se \\
\hline $\operatorname{lnexp}$ & $0.955 * * *$ & 0.001 & $0.915 * * *$ & 0.001 & $0.886 * * *$ & 0.001 \\
\hline hhsize & $-0.013 * * *$ & 0.000 & $-0.013 * * *$ & 0.000 & $-0.012 * * *$ & 0.000 \\
\hline Age & $0.003 * * *$ & 0.000 & $0.002 * * *$ & 0.000 & $0.002 * * *$ & 0.000 \\
\hline Urbanity & $0.177 * * *$ & 0.001 & $0.142 * * *$ & 0.001 & $0.120 * * *$ & 0.002 \\
\hline Married HH-head & $0.078 * * *$ & 0.002 & $0.063 * * *$ & 0.003 & $0.046 * * *$ & 0.003 \\
\hline Female HH-head & $0.058 * * *$ & 0.003 & $0.052 * * *$ & 0.003 & $0.040 * * *$ & 0.003 \\
\hline Elementary school & $0.025 * * *$ & 0.002 & $0.017 * * *$ & 0.002 & $0.005 *$ & 0.003 \\
\hline Secondary school & $0.026 * * *$ & 0.003 & $0.016 * * *$ & 0.003 & 0.002 & 0.003 \\
\hline High school & $0.055 * * *$ & 0.003 & $0.043 * * *$ & 0.003 & $0.027 * * *$ & 0.003 \\
\hline At least college & $0.071 * * *$ & 0.003 & $0.063 * * *$ & 0.003 & $0.046 * * *$ & 0.004 \\
\hline Survey year 2009 & $0.047 * * *$ & 0.001 & $0.056 * * *$ & 0.001 & $0.074 * * *$ & 0.002 \\
\hline _cons & $-7.913 * * *$ & 0.016 & $-6.996 * * *$ & 0.016 & $-6.305 * * *$ & 0.021 \\
\hline \#Obs & \multirow{2}{*}{\multicolumn{2}{|c|}{$\begin{array}{c}549,659 \\
0.563\end{array}$}} & \multicolumn{2}{|c|}{549,659} & \multicolumn{2}{|c|}{549,659} \\
\hline (pseudo) $\mathrm{R}^{2}$ & & & \multicolumn{2}{|c|}{0.572} & \multicolumn{2}{|c|}{0.575} \\
\hline
\end{tabular}

Source: Author's estimation based on GTAP-E, Indonesian Input Output and Susenas 2005 and 2009. Note: $* * *, * *)$ indicates significance at the ten (five, one) percent level. 
Table A.11. Kaya Identity (expenditure deflated)

a. Data

\begin{tabular}{lcrrrrr}
\hline & \multicolumn{2}{c}{$\mathbf{C O}_{\mathbf{2}}(\mathbf{k g})$} & \multicolumn{2}{c}{ HH size (person) } & \multicolumn{2}{c}{ Expenditure (Rp) } \\
\cline { 2 - 7 } & $\mathbf{2 0 0 5}$ & $\mathbf{2 0 0 9}$ & $\mathbf{2 0 0 5}$ & $\mathbf{2 0 0 9}$ & $\mathbf{2 0 0 5}$ & $\mathbf{2 0 0 9}$ \\
\hline Q1 & 1280 & 1,663 & 5.04 & 5.24 & $4,263,872$ & $6,774,874$ \\
Q2 & 1782 & 2,425 & 4.35 & 4.46 & $6,803,753$ & $10,144,928$ \\
Q3 & 2271 & 3,084 & 4.00 & 3.95 & $9,130,943$ & $12,898,551$ \\
Q4 & 3042 & 3,973 & 3.71 & 3.47 & $12,600,000$ & $16,594,203$ \\
Q5 & 5861 & 6,637 & 3.31 & 2.68 & $26,600,000$ & $27,898,551$ \\
\hline All Obs & 2847 & 3,556 & 4.08 & 3.96 & $11,900,000$ & $14,855,072$ \\
\hline
\end{tabular}

\section{b. Factors of Kaya equation}

\begin{tabular}{lccrrrrrr}
\hline & \multicolumn{2}{c}{$\mathbf{C O}_{\mathbf{2}}(\mathbf{k g})$} & \multicolumn{2}{c}{ HH size (person) } & \multicolumn{2}{c}{ Per capita expenditure } & \multicolumn{2}{c}{ CO2 intensity (g/Rp) } \\
\cline { 2 - 9 } & $\mathbf{2 0 0 5}$ & $\mathbf{2 0 0 9}$ & $\mathbf{2 0 0 5}$ & $\mathbf{2 0 0 9}$ & $\mathbf{2 0 0 5}$ & $\mathbf{2 0 0 9}$ & $\mathbf{2 0 0 5}$ & $\mathbf{2 0 0 9}$ \\
\hline Q1 & 1,280 & 1,663 & 5.04 & 5.24 & 846,681 & $1,292,854$ & 0.3 & 0.25 \\
Q2 & 1,782 & 2,425 & 4.35 & 4.46 & $1,563,965$ & $2,272,167$ & 0.26 & 0.24 \\
Q3 & 2,271 & 3,084 & 4.00 & 3.95 & $2,283,311$ & $3,265,409$ & 0.25 & 0.24 \\
Q4 & 3,042 & 3,973 & 3.71 & 3.47 & $3,400,690$ & $4,781,893$ & 0.24 & 0.24 \\
Q5 & 5,861 & 6,637 & 3.31 & 2.68 & $8,039,117$ & $10,416,367$ & 0.22 & 0.24 \\
\hline All HH & 2,847 & 3,556 & 4.08 & 3.96 & $2,916,770$ & $3,750,554$ & 0.24 & 0.24 \\
\hline
\end{tabular}

c. Decomposition - change in $\mathrm{kg} \mathrm{CO}_{2}$ emissions attributable to each factor, 2005 to 2009

\begin{tabular}{lccccc}
\hline & $\begin{array}{c}\mathbf{C O}_{2} \text { change } \\
(\mathbf{k g})\end{array}$ & $\begin{array}{c}\text { Population } \\
\text { effect }\end{array}$ & $\begin{array}{c}\text { Expenditure } \\
\text { (income) effect }\end{array}$ & $\begin{array}{c}\text { Carbon } \\
\text { intensity effect }\end{array}$ & $\begin{array}{c}\text { Check (sum should } \\
\text { equal CO }\end{array}$ change) \\
\hline Q1 & 383 & 58 & 619 & -294 & 383 \\
Q2 & 643 & 54 & 780 & -191 & 643 \\
Q3 & 813 & -33 & 951 & -104 & 813 \\
Q4 & 930 & -228 & 1189 & -30 & 930 \\
Q5 & 775 & -1319 & 1617 & 478 & 775 \\
\hline All HH & 709 & -94 & 802 & 2 & 709 \\
\hline
\end{tabular}

d. Decomposition - change in $\mathrm{CO}_{2}$ emissions attributable to each factor, 2005 to 2009

\begin{tabular}{lccccc}
\hline & $\begin{array}{c}\mathbf{C O}_{2} \\
\text { change }\end{array}$ & $\begin{array}{c}\text { Population } \\
\text { effect }\end{array}$ & $\begin{array}{c}\text { Expenditure } \\
\text { (income) effect }\end{array}$ & $\begin{array}{c}\text { Carbon } \\
\text { intensity effect }\end{array}$ & $\begin{array}{c}\text { Check (sum should } \\
\text { equal CO }\end{array}$ change) \\
\hline Q1 & 29.90 & 4.50 & 48.40 & -23.00 & 29.90 \\
Q2 & 36.10 & 3.00 & 43.70 & -10.70 & 36.10 \\
Q3 & 35.80 & -1.40 & 41.90 & -4.60 & 35.80 \\
Q4 & 30.60 & -7.50 & 39.10 & -1.00 & 30.60 \\
Q5 & 13.20 & -22.50 & 27.60 & 8.10 & 13.20 \\
\hline All HH & 24.90 & -3.30 & 28.20 & 0.10 & 24.90 \\
\hline
\end{tabular}

Source: Author's computation based on GTAP-E, Indonesian Input Output and Susenas 2005 and 2009.

Source: Author's estimation based on GTAP-E, Indonesian Input Output and Susenas 2005 and 2009. Note: expenditure in 2009 is deflated $(2005=1)$ 
Table A.12. Expenditure elasticites to $\mathrm{CO}_{2}$ emission shares, pooled estimation

\begin{tabular}{|c|c|c|c|c|c|c|}
\hline Share of $\mathrm{CO}_{2}$ emission & $\mathbf{I}$ & II & III & IV & $\mathbf{V}$ & Overall \\
\hline Cereal & -0.010 & -0.011 & -0.010 & -0.008 & -0.005 & -0.009 \\
\hline Vegetable and fruit & -0.004 & -0.006 & -0.007 & -0.009 & -0.009 & -0.007 \\
\hline Oil and fat & -0.003 & -0.004 & -0.004 & -0.004 & -0.003 & -0.003 \\
\hline Beverage & 0.003 & 0.004 & 0.001 & 0.003 & -0.009 & 0.001 \\
\hline Egg, fish, meat, dairy & 0.016 & 0.025 & 0.020 & 0.013 & -0.006 & 0.011 \\
\hline Tobacco & 0.016 & 0.010 & 0.006 & -0.001 & -0.006 & 0.004 \\
\hline Fuel and light & -0.061 & -0.083 & -0.084 & -0.090 & -0.076 & -0.082 \\
\hline Telecommunication & 0.004 & 0.005 & 0.007 & 0.009 & 0.006 & 0.007 \\
\hline Transportation & 0.029 & 0.034 & 0.032 & 0.033 & 0.017 & 0.031 \\
\hline Health & 0.000 & 0.001 & 0.002 & 0.003 & 0.005 & 0.002 \\
\hline Education & 0.003 & 0.002 & 0.002 & 0.002 & 0.001 & 0.003 \\
\hline Toiletry & -0.001 & -0.001 & -0.001 & -0.001 & -0.001 & -0.001 \\
\hline Clothes & 0.004 & 0.002 & 0.001 & 0.001 & -0.001 & 0.002 \\
\hline House and durable goods & 0.008 & 0.015 & 0.022 & 0.034 & 0.051 & 0.029 \\
\hline Services and rent & -0.004 & 0.002 & 0.005 & 0.008 & 0.021 & 0.007 \\
\hline Taxes & 0.000 & 0.001 & 0.001 & 0.001 & 0.001 & 0.001 \\
\hline Recreation, ceremony & 0.001 & 0.004 & 0.007 & 0.006 & 0.010 & 0.006 \\
\hline No. of observations & & & & & & 549,659 \\
\hline
\end{tabular}


Table A.13. Expenditure elasticites to $\mathrm{CO}_{2}$ emission shares, 2005 and 2009 estimation

\begin{tabular}{lrrrrrr}
\hline \multirow{2}{*}{ Share of CO2 emission } & \multicolumn{2}{c}{ I } & \multicolumn{2}{c}{ II } & \multicolumn{2}{c}{ III } \\
\cline { 2 - 7 } & \multicolumn{1}{c}{$\mathbf{2 0 0 5}$} & $\mathbf{2 0 0 9}$ & $\mathbf{2 0 0 5}$ & $\mathbf{2 0 0 9}$ & $\mathbf{2 0 0 5}$ & $\mathbf{2 0 0 9}$ \\
\hline Cereal & -0.0298 & -0.0036 & -0.0113 & -0.0114 & -0.0089 & -0.0138 \\
Vegetable and fruit & -0.0086 & -0.0030 & -0.0073 & -0.0049 & -0.0079 & -0.0072 \\
Oil and fat & -0.0065 & -0.0017 & -0.0043 & -0.0030 & -0.0047 & -0.0038 \\
Beverage & 0.0099 & -0.0007 & -0.0014 & 0.0057 & -0.0075 & 0.0056 \\
Egg, fish, meat, dairy & 0.0087 & 0.0184 & 0.0096 & 0.0221 & 0.0128 & 0.0146 \\
Tobacco & 0.0088 & 0.0202 & 0.0138 & 0.0144 & 0.0116 & 0.0080 \\
Fuel and light & -0.0026 & -0.0911 & -0.0459 & -0.1007 & -0.0548 & -0.0956 \\
Telecommunication & 0.0006 & 0.0050 & 0.0010 & 0.0070 & 0.0024 & 0.0076 \\
Transportation & 0.0198 & 0.0349 & 0.0270 & 0.0445 & 0.0301 & 0.0467 \\
Health & 0.0001 & -0.0002 & -0.0006 & 0.0002 & 0.0000 & 0.0008 \\
Education & -0.0011 & 0.0061 & 0.0039 & 0.0056 & 0.0034 & 0.0061 \\
Toiletry & -0.0018 & -0.0006 & -0.0008 & -0.0011 & -0.0006 & -0.0012 \\
Clothes & 0.0021 & 0.0057 & 0.0036 & 0.0054 & 0.0027 & 0.0024 \\
House and durable goods & 0.0076 & 0.0078 & 0.0140 & 0.0104 & 0.0156 & 0.0184 \\
Services and rent & -0.0083 & -0.0019 & -0.0046 & -0.0005 & -0.0040 & 0.0019 \\
Taxes & -0.0002 & 0.0003 & 0.0004 & 0.0005 & 0.0003 & 0.0007 \\
Recreation, ceremony & -0.0009 & 0.0028 & 0.0011 & 0.0029 & 0.0074 & 0.0057 \\
\hline
\end{tabular}

\begin{tabular}{lrrrr}
\hline \multirow{2}{*}{ Share of CO emission } & \multicolumn{2}{c}{ IV } & \multicolumn{2}{c}{ V } \\
\cline { 2 - 5 } & \multicolumn{1}{c}{$\mathbf{2 0 0 5}$} & $\mathbf{2 0 0 9}$ & $\mathbf{2 0 0 5}$ & $\mathbf{2 0 0 9}$ \\
\hline Cereal & -0.0090 & -0.0135 & -0.0046 & -0.0084 \\
Vegetable and fruit & -0.0064 & -0.0088 & -0.0079 & -0.0094 \\
Oil and fat & -0.0041 & -0.0041 & -0.0025 & -0.0028 \\
Beverage & -0.0130 & 0.0001 & -0.0102 & -0.0079 \\
Egg, fish, meat, dairy & 0.0075 & 0.0073 & -0.0145 & -0.0017 \\
Tobacco & 0.0068 & 0.0005 & -0.0052 & -0.0072 \\
Fuel and light & -0.0565 & -0.0857 & -0.0690 & -0.0776 \\
Telecommunication & 0.0051 & 0.0083 & 0.0062 & 0.0059 \\
Transportation & 0.0314 & 0.0375 & 0.0144 & 0.0195 \\
Health & 0.0010 & 0.0021 & 0.0043 & 0.0047 \\
Education & 0.0011 & 0.0055 & -0.0024 & 0.0037 \\
Toiletry & -0.0009 & -0.0012 & -0.0010 & -0.0006 \\
Clothes & 0.0016 & 0.0022 & -0.0010 & -0.0008 \\
House and durable goods & 0.0285 & 0.0320 & 0.0565 & 0.0487 \\
Services and rent & -0.0009 & 0.0064 & 0.0215 & 0.0216 \\
Taxes & 0.0004 & 0.0010 & 0.0014 & 0.0016 \\
Recreation, ceremony & 0.0055 & 0.0072 & 0.0129 & 0.0083 \\
\hline sCO2 ${ }_{i j}=\beta_{0}+\beta_{1_{i j}} \ln E X P_{i}+\beta_{2_{i j}} X_{i}+\varepsilon_{i j}$ & & &
\end{tabular}

Source: Author's estimation based on GTAP-E, Indonesian Input Output and Susenas 2005 and 2009. Note: all estimated coefficients are significant at one percent level 
Table A.14. Expenditure elasticities to expenditure shares

\begin{tabular}{lrrrrrr}
\hline \multirow{2}{*}{ Share of expenditure } & \multicolumn{2}{c}{ Overall } & \multicolumn{2}{c}{ Rural } & \multicolumn{2}{c}{ Urban } \\
\cline { 2 - 7 } & $\mathbf{2 0 0 5}$ & $\mathbf{2 0 0 9}$ & $\mathbf{2 0 0 5}$ & $\mathbf{2 0 0 9}$ & $\mathbf{2 0 0 5}$ & $\mathbf{2 0 0 9}$ \\
\hline Cereal & -0.0856 & -0.0539 & -0.1016 & -0.0600 & -0.0665 & -0.0456 \\
Vegetable and fruit & -0.0173 & -0.0205 & -0.0126 & -0.0198 & -0.0231 & -0.0215 \\
Oil and fat & -0.0118 & -0.0101 & -0.0126 & -0.0110 & -0.0109 & -0.0088 \\
Beverage & 0.0016 & -0.0145 & 0.0089 & -0.0104 & -0.006 & -0.0203 \\
Egg, fish, meat, dairy & 0.0102 & 0.0154 & 0.0239 & 0.0194 & -0.0056 & 0.0102 \\
Tobacco & 0.0075 & 0.0083 & 0.0163 & 0.0184 & -0.0024 & -0.0048 \\
Fuel and light & -0.0094 & -0.0165 & -0.0085 & -0.0176 & -0.0111 & -0.0151 \\
Telecommunication & 0.0172 & 0.0152 & 0.0102 & 0.0138 & 0.0243 & 0.0170 \\
Transportation & 0.0193 & 0.0197 & 0.0207 & 0.0221 & 0.0177 & 0.0163 \\
Health & 0.0065 & 0.0049 & 0.0068 & 0.0037 & 0.0064 & 0.0064 \\
Education & -0.0026 & 0.0143 & 0.0001 & 0.0130 & -0.0064 & 0.0160 \\
Toiletry & -0.0043 & -0.0044 & -0.0041 & -0.0049 & -0.0046 & -0.0038 \\
Clothes & 0.0004 & 0.0025 & 0.0019 & 0.0035 & -0.0014 & 0.0013 \\
House and durable goods & 0.0298 & 0.0204 & 0.0328 & 0.0216 & 0.0267 & 0.0189 \\
Services and rent & 0.0248 & 0.0097 & 0.0070 & -0.0010 & 0.0448 & 0.0236 \\
Taxes & 0.0043 & 0.0049 & 0.0031 & 0.0038 & 0.0056 & 0.0062 \\
Recreation, entertainment, & 0.0069 & 0.0046 & 0.0077 & 0.0052 & 0.0059 & 0.0038 \\
\hline
\end{tabular}

Source: Author's estimation based on GTAP-E, Indonesian Input Output and Susenas 2005 and 2009. Note: all estimated coefficients are significant at one percent level 
Table A.15. Expenditure elasticities to expenditure shares: by quintiles

\begin{tabular}{lrrrrrr}
\hline \multirow{2}{*}{ Share of expenditure } & \multicolumn{2}{c}{ I } & \multicolumn{2}{c}{ II } & \multicolumn{2}{c}{ III } \\
\cline { 2 - 7 } & $\mathbf{2 0 0 5}$ & $\mathbf{2 0 0 9}$ & $\mathbf{2 0 0 5}$ & $\mathbf{2 0 0 9}$ & $\mathbf{2 0 0 5}$ & $\mathbf{2 0 0 9}$ \\
\hline Cereal & -0.0827 & -0.0108 & -0.1188 & -0.0523 & -0.1097 & -0.0778 \\
Vegetable and fruit & -0.0082 & -0.0243 & -0.0142 & -0.0236 & -0.0179 & -0.0274 \\
Oil and fat & -0.0110 & -0.0101 & -0.0140 & -0.0100 & -0.0134 & -0.0129 \\
Beverage & 0.0180 & -0.0215 & 0.0199 & 0.0060 & 0.0051 & -0.0169 \\
Egg, fish, meat, dairy & 0.0310 & 0.0157 & 0.0403 & 0.0084 & 0.0430 & 0.0244 \\
Tobacco & 0.0311 & 0.0515 & 0.0350 & 0.0287 & 0.0236 & 0.0176 \\
Fuel and light & -0.0056 & -0.0261 & -0.0096 & -0.0234 & -0.0097 & -0.0118 \\
Telecommunication & 0.0023 & 0.0116 & 0.0094 & 0.0166 & 0.0170 & 0.0187 \\
Transportation & 0.0127 & 0.0200 & 0.0248 & 0.0344 & 0.0240 & 0.0298 \\
Health & 0.0028 & -0.0025 & 0.0055 & 0.0025 & 0.0057 & 0.0065 \\
Education & 0.0007 & 0.0183 & -0.0042 & 0.0197 & -0.0088 & 0.0278 \\
Toiletry & -0.0032 & -0.0059 & -0.0052 & -0.0067 & -0.0046 & -0.0043 \\
Clothes & 0.0067 & 0.0073 & 0.0042 & 0.0048 & -0.0013 & 0.0115 \\
House and durable goods & 0.0083 & 0.0040 & 0.0125 & 0.0049 & 0.0177 & 0.0093 \\
Services and rent & -0.0058 & -0.0312 & 0.0048 & -0.0155 & 0.0105 & -0.0006 \\
Taxes & 0.0002 & 0.0020 & 0.0024 & 0.0046 & 0.0051 & -0.0007 \\
Recreation, ceremony & 0.0034 & 0.0020 & 0.0028 & 0.0008 & 0.0049 & 0.0066 \\
\hline
\end{tabular}

\begin{tabular}{lrrrr}
\hline \multirow{2}{*}{ Share of expenditure } & \multicolumn{2}{c}{ IV } & \multicolumn{2}{c}{ V } \\
\cline { 2 - 5 } & $\mathbf{2 0 0 5}$ & $\mathbf{2 0 0 9}$ & $\mathbf{2 0 0 5}$ & $\mathbf{2 0 0 9}$ \\
\hline Cereal & -0.1007 & -0.0666 & -0.0478 & -0.0439 \\
Vegetable and fruit & -0.0126 & -0.0100 & -0.0220 & -0.0223 \\
Oil and fat & -0.0116 & -0.0087 & -0.0085 & -0.0089 \\
Beverage & 0.0008 & -0.0270 & -0.0171 & -0.0214 \\
Egg, fish, meat, dairy & 0.0048 & 0.0189 & -0.0365 & -0.0219 \\
Tobacco & -0.0076 & -0.0029 & -0.0244 & -0.0313 \\
Fuel and light & -0.0065 & -0.0077 & -0.0112 & -0.0109 \\
Telecommunication & 0.0294 & 0.0183 & 0.0140 & 0.0101 \\
Transportation & 0.0246 & 0.0150 & 0.0087 & 0.0078 \\
Health & 0.0114 & 0.0081 & 0.0093 & 0.0142 \\
Education & -0.0041 & 0.0161 & -0.0003 & 0.0102 \\
Toiletry & -0.0029 & -0.0030 & -0.0033 & -0.0028 \\
Clothes & 0.0040 & 0.0065 & -0.0037 & -0.0046 \\
House and durable goods & 0.0317 & 0.0348 & 0.0538 & 0.0458 \\
Services and rent & 0.0233 & -0.0056 & 0.0678 & 0.0615 \\
Taxes & 0.0046 & 0.0042 & 0.0084 & 0.0098 \\
Recreation, ceremony & 0.0072 & 0.0098 & 0.0124 & 0.0087 \\
\hline Source: Author's estimation
\end{tabular}

Source: Author's estimation based on GTAP-E, Indonesian Input Output and Susenas 2005 and 2009. Note: all estimated coefficients are significant at one percent level. 
Appendix B (Chapter 2) 
Table B.1. Descriptive analysis: 2005 and 2009

\begin{tabular}{|c|c|c|c|c|c|c|}
\hline 2005 & Q1 & Q2 & Q3 & Q4 & Q5 & Overall \\
\hline Total household expenditure (Rp 000) & 6,433 & 8,519 & 10,500 & 13,600 & 26,700 & 13,100 \\
\hline Per capita expenditure $(\operatorname{Rp} 000)$ & 1,130 & 1,677 & 2,215 & 3,058 & 6,495 & 2,915 \\
\hline $\mathrm{CO}_{2}$ emission $(\mathrm{kg})$ & 1,323 & 1,875 & 2,413 & 3,283 & 6,669 & 3,113 \\
\hline Per capita $\mathrm{CO}_{2}$ emission $(\mathrm{kg})$ & 237 & 375 & 516 & 741 & 1,621 & 698 \\
\hline Household size (persons) & 5.76 & 5.09 & 4.73 & 4.45 & 4.16 & 4.84 \\
\hline No of observation & 210,420 & 210,419 & 210,416 & 210,420 & 210,416 & $1,052,091$ \\
\hline 2009 & Q1 & $\mathbf{Q 2}$ & Q3 & Q4 & Q5 & Overall \\
\hline Total HH expenditure (Rp 000), deflated & 6,685 & 10,072 & 12,826 & 16,739 & 29,348 & 15,145 \\
\hline Per capita expenditure (Rp 000), deflated & 1,123 & 1,935 & 2,750 & 3,995 & 8,986 & 3,751 \\
\hline $\mathrm{CO}_{2}$ emission $(\mathrm{kg})$ & 1,614 & 2,370 & 3,037 & 3,989 & 7,011 & 3,604 \\
\hline Per capita $\mathrm{CO}_{2}$ emission $(\mathrm{kg})$ & 277 & 462 & 655 & 957 & 2,139 & 898 \\
\hline Household size (persons) & 6.06 & 5.22 & 4.68 & 4.20 & 3.48 & 4.73 \\
\hline No of observation & 231,119 & 231,116 & 231,105 & 231,113 & 231,113 & $1,155,566$ \\
\hline
\end{tabular}

Source: Author's estimation based on GTAP-E, IO 2005 and Susenas 2005 and 2009. Note: the computations are based on per capita level analysis. The $\mathrm{CO}_{2}$ emissions are scaled up to national account expenditure. Quintile classification is based on the household per capita expenditure distribution. Quintile 1 refers to the poorest quintile. Expenditure in 2009 is deflated $(2005=100)$. 
Table B.2. Inequality measures of per capita emission and per capita expenditure, by subgroup (household characteristics) indices

\begin{tabular}{|c|c|c|c|c|c|c|c|c|}
\hline & \multicolumn{4}{|c|}{ Per capita emission } & \multicolumn{4}{|c|}{ Per capita expenditure } \\
\hline & \multicolumn{2}{|c|}{$\begin{array}{l}\text { (unconditional) } \\
\text { Gini Coefficient }\end{array}$} & \multicolumn{2}{|c|}{ Theil Index } & \multicolumn{2}{|c|}{$\begin{array}{l}\text { (unconditional) } \\
\text { Gini Coefficient }\end{array}$} & \multicolumn{2}{|c|}{ Theil Index } \\
\hline & 2005 & 2009 & 2005 & 2009 & 2005 & 2009 & 2005 & 2009 \\
\hline $\begin{array}{l}\text { Affluence } \\
\text { Q1 } \\
\text { Q2 } \\
\text { Q3 } \\
\text { Q4 } \\
\text { Q5 } \\
\text { Within group }(\%) \\
\text { Between group }(\%)\end{array}$ & $\begin{array}{l}0.262 \\
0.214 \\
0.203 \\
0.196 \\
0.317\end{array}$ & $\begin{array}{l}0.260 \\
0.206 \\
0.194 \\
0.188 \\
0.313\end{array}$ & $\begin{array}{l}0.117 \\
0.075 \\
0.068 \\
0.064 \\
0.169 \\
0.098(31 \%) \\
0.220(69 \%) \\
\end{array}$ & $\begin{array}{l}0.115 \\
0.069 \\
0.061 \\
0.058 \\
0.161 \\
0.093(28 \%) \\
0.245(72 \%) \\
\end{array}$ & $\begin{array}{l}0.109 \\
0.048 \\
0.047 \\
0.063 \\
0.259\end{array}$ & $\begin{array}{l}0.155 \\
0.063 \\
0.057 \\
0.070 \\
0.267\end{array}$ & $\begin{array}{l}0.023 \\
0.003 \\
0.003 \\
0.006 \\
0.118 \\
0.031(14 \%) \\
0.185(86 \%) \\
\end{array}$ & $\begin{array}{l}0.047 \\
0.006 \\
0.005 \\
0.007 \\
0.119 \\
0.037(13 \%) \\
0.249(87 \%) \\
\end{array}$ \\
\hline $\begin{array}{l}\text { Location } \\
\text { Rural } \\
\text { Urban } \\
\text { Within group (\%) } \\
\text { Between group (\%) }\end{array}$ & $\begin{array}{l}0.372 \\
0.397\end{array}$ & $\begin{array}{l}0.406 \\
0.425\end{array}$ & $\begin{array}{l}0.236 \\
0.267 \\
0.248(78 \%) \\
0.071(22 \%) \\
\end{array}$ & $\begin{array}{l}0.283 \\
0.309 \\
0.292(86 \%) \\
0.046(14 \%)\end{array}$ & $\begin{array}{l}0.294 \\
0.370\end{array}$ & $\begin{array}{l}0.372 \\
0.417\end{array}$ & $\begin{array}{l}0.142 \\
0.226 \\
0.174(81 \%) \\
0.042(19 \%)\end{array}$ & $\begin{array}{l}0.233 \\
0.294 \\
0.254(88 \%) \\
0.032(12 \%) \\
\end{array}$ \\
\hline $\begin{array}{l}\text { Education } \\
\text { did not grad } \\
\text { elementary } \\
\text { secondary } \\
\text { high school } \\
\text { at least college } \\
\text { Within group }(\%) \\
\text { Between group }(\%)\end{array}$ & $\begin{array}{l}0.405 \\
0.398 \\
0.405 \\
0.405 \\
0.426\end{array}$ & $\begin{array}{l}0.435 \\
0.427 \\
0.427 \\
0.439 \\
0.472\end{array}$ & $\begin{array}{l}0.281 \\
0.271 \\
0.280 \\
0.285 \\
0.318 \\
0.279(90 \%) \\
0.040(10 \%) \\
\end{array}$ & $\begin{array}{l}0.327 \\
0.314 \\
0.315 \\
0.335 \\
0.390 \\
0.325(71 \%) \\
0.013(29 \%)\end{array}$ & $\begin{array}{l}0.329 \\
0.320 \\
0.336 \\
0.357 \\
0.409\end{array}$ & $\begin{array}{l}0.400 \\
0.393 \\
0.396 \\
0.416 \\
0.456\end{array}$ & $\begin{array}{l}0.177 \\
0.169 \\
0.186 \\
0.210 \\
0.281 \\
0.185(86 \%) \\
0.031(14 \%)\end{array}$ & $\begin{array}{l}0.269 \\
0.261 \\
0.265 \\
0.294 \\
0.356 \\
0.275(96 \%) \\
0.011(4 \%) \\
\end{array}$ \\
\hline $\begin{array}{l}\text { Household membe } \\
1 \\
2 \\
3 \\
4 \\
5 \\
6 \\
7+ \\
\text { Within group }(\%) \\
\text { Between group }(\%)\end{array}$ & $\begin{array}{l}0.427 \\
0.417 \\
0.392 \\
0.405 \\
0.420 \\
0.424 \\
0.442\end{array}$ & $\begin{array}{l}0.394 \\
0.381 \\
0.378 \\
0.381 \\
0.387 \\
0.394 \\
0.404\end{array}$ & $\begin{array}{l}0.319 \\
0.297 \\
0.260 \\
0.278 \\
0.302 \\
0.306 \\
0.334 \\
0.279(90 \%) \\
0.040(10 \%)\end{array}$ & $\begin{array}{l}0.264 \\
0.245 \\
0.241 \\
0.245 \\
0.255 \\
0.264 \\
0.278 \\
0.254(75 \%) \\
0.083(25 \%)\end{array}$ & $\begin{array}{l}0.404 \\
0.365 \\
0.331 \\
0.338 \\
0.350 \\
0.348 \\
0.355\end{array}$ & $\begin{array}{l}0.369 \\
0.351 \\
0.347 \\
0.348 \\
0.350 \\
0.354 \\
0.357\end{array}$ & $\begin{array}{l}0.272 \\
0.219 \\
0.179 \\
0.187 \\
0.203 \\
0.199 \\
0.208 \\
0.197(91 \%) \\
0.019(19 \%)\end{array}$ & $\begin{array}{l}0.231 \\
0.206 \\
0.202 \\
0.203 \\
0.206 \\
0.211 \\
0.215 \\
0.207(72 \%) \\
0.079(28 \%)\end{array}$ \\
\hline $\begin{array}{l}\text { Gender of househo } \\
\text { Male } \\
\text { Female } \\
\text { Within group }(\%) \\
\text { Between group }(\%)\end{array}$ & $\begin{array}{r}\text {-head } \\
0.428 \\
0.432\end{array}$ & $\begin{array}{l}0.438 \\
0.445\end{array}$ & $\begin{array}{l}0.315 \\
0.322 \\
0.318(99 \%) \\
7.0 \mathrm{E}-05(1 \%) \\
\end{array}$ & $\begin{array}{l}0.332 \\
0.342 \\
0.337(99 \%) \\
2.2 \mathrm{E}-04(1 \%) \\
\end{array}$ & $\begin{array}{l}0.360 \\
0.364\end{array}$ & $\begin{array}{l}0.281 \\
0.291\end{array}$ & $\begin{array}{l}0.213 \\
0.218 \\
0.216(99 \%) \\
1.0 \mathrm{E}-05(1 \%) \\
\end{array}$ & $\begin{array}{l}0.408 \\
0.415 \\
0.286(99 \%) \\
1.8 E-04(1 \%) \\
\end{array}$ \\
\hline $\begin{array}{l}\text { Age } \\
<30 \\
30-44 \\
45-64 \\
65+ \\
\text { Within group }(\%) \\
\text { Between group }(\%)\end{array}$ & $\begin{array}{l}0.425 \\
0.428 \\
0.443 \\
0.415\end{array}$ & $\begin{array}{l}0.432 \\
0.433 \\
0.448 \\
0.471\end{array}$ & $\begin{array}{l}0.311 \\
0.316 \\
0.339 \\
0.296 \\
0.316(99 \%) \\
0.003(1 \%)\end{array}$ & $\begin{array}{l}0.323 \\
0.323 \\
0.348 \\
0.390 \\
0.331(98 \%) \\
0.007(2 \%)\end{array}$ & $\begin{array}{l}0.356 \\
0.366 \\
0.375 \\
0.351\end{array}$ & $\begin{array}{l}0.398 \\
0.403 \\
0.422 \\
0.455\end{array}$ & $\begin{array}{l}0.208 \\
0.220 \\
0.233 \\
0.203 \\
0.214(91 \%) \\
0.002(9 \%)\end{array}$ & $\begin{array}{l}0.269 \\
0.275 \\
0.303 \\
0.356 \\
0.280(98 \%) \\
0.006(2 \%)\end{array}$ \\
\hline Overall & 0.430 & 0.442 & 0.318 & 0.338 & 0.362 & 0.411 & 0.216 & 0.286 \\
\hline
\end{tabular}

Source: Author's estimation based on GTAP-E, IO 2005, and Susenas 2005 and 2009. 


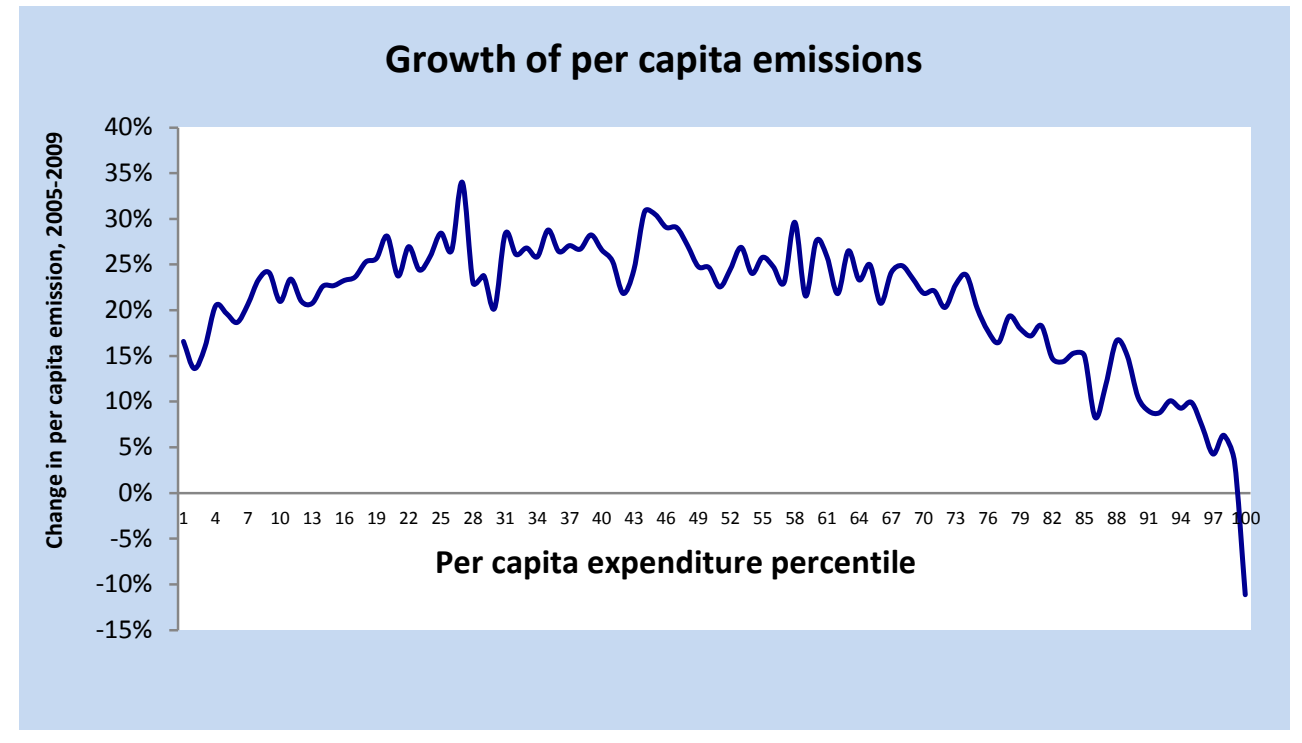

Figure B.1. Emission growth incidence curve

Source: Author's computation 
Appendix C (Chapter 3) 
per capita CO2 emissions (In)

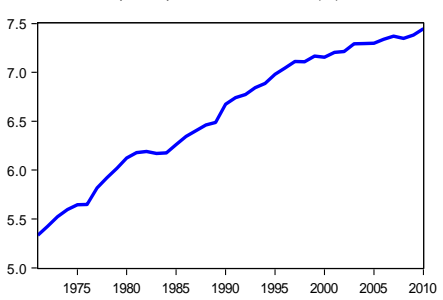

rban population (In)

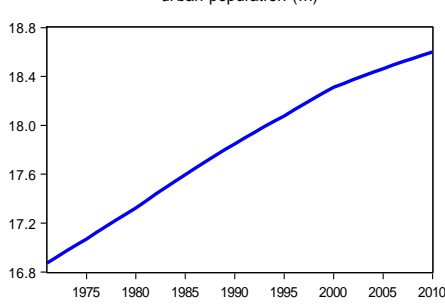

per capita energy use (In)

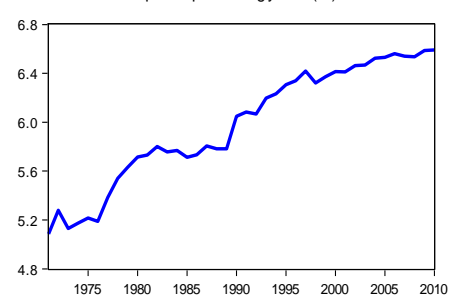

percapita GDP, real (In)

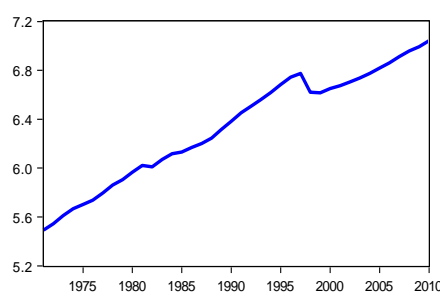

Figure C.1. Data

Source: WDI (2013), BPS (2013)

Table C.1. Data description

\begin{tabular}{ll}
\hline Variable & Measure \\
\hline LNCO2CP & Per capita $\mathrm{CO}_{2}$ emission, in $\mathrm{kg} \mathrm{CO}_{2}$ per capita $(\ln )$ \\
LNYCP & Per capita real GDP, in constant 2000 US $\$(\ln )$ \\
LNECP & Per capita energy use, kg of oil equivalent per capita $(\mathrm{ln})$ \\
LNU & Urban population $(\mathrm{ln})$ \\
LNK & Gross fixed capital formation, local currency $(\ln )$ \\
\hline
\end{tabular}




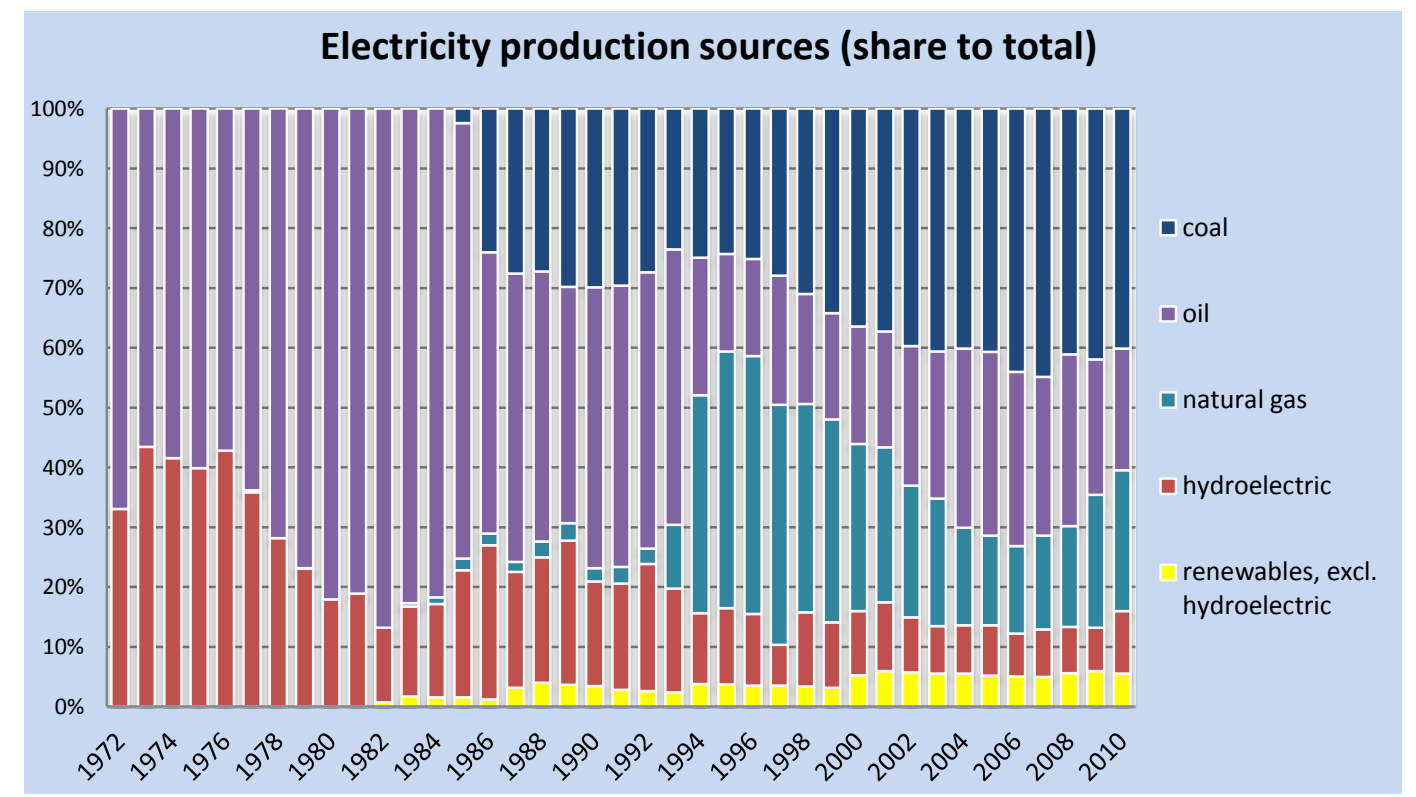

Figure C.2. Electricity production sources 
Table C.2. Engel-Granger estimates

\begin{tabular}{lrrrr}
\hline Dependent Variable: LNCO2CP & & \\
\hline & Coefficient & Std. Error & t-Statistic & Prob. \\
\hline LNECP & 0.679850 & 0.110600 & 6.146941 & 0.0000 \\
LNYCP & 0.712252 & 0.117429 & 6.065386 & 0.0000 \\
C & -1.997799 & 0.152235 & -13.12308 & 0.0000 \\
\hline $\mathrm{R}^{2}$ & 0.991925 & Mean dependent var & 6.584764 \\
Adjusted $\mathrm{R}^{2}$ & 0.991488 & S.D. dependent var & 0.649683 \\
\hline
\end{tabular}

Source: Author's estimation.

\section{Table C.3. ADF test of residuals}

\begin{tabular}{lllr}
\hline \multirow{2}{*}{ Augmented Dickey-Fuller test statistic } & & t-Statistic & Prob. \\
\cline { 3 - 4 } & & $\mathbf{- 3 . 0 6 4 8 3 0}$ & $\mathbf{0 . 0 3 7 7}$ \\
\hline Test critical values: & 1\% level & -3.610453 \\
& $5 \%$ level & -2.938987 \\
& $10 \%$ level & -2.607932 & \\
\hline
\end{tabular}

Source: Author's estimation. Note: Residuals from Table C.2. Exogenous: Constant. Null hypothesis is that the residual has a unit root. Lag Length: 0 (based on SIC, maximum lag = 9)

Augmented Dickey-Fuller Test Equation

Dependent Variable: D(Residuals Table C.2)

\begin{tabular}{lrrrr}
\hline Variable & Coefficient & Std. Error & t-Statistic & \multicolumn{1}{c}{ Prob. } \\
\hline Residuals Table C.2(-1) & -0.409951 & 0.133760 & -3.064830 & 0.0041 \\
C & 0.000204 & 0.007725 & 0.026444 & 0.9790 \\
\hline R-squared & 0.202469 & & & \\
Adjusted R-squared & 0.180914 & & & \\
S.E. of regression & 0.048231 & & & \\
Prob(F-statistic) & 0.004052 & & & \\
\hline
\end{tabular}

Table C.4. Engel-Granger short-run estimates ${ }^{36}$

\begin{tabular}{lrrrr}
\hline \multicolumn{1}{l}{ Dependent Variable: D(LNCO2CP) } & & & \\
\hline Variable & Coefficient & Std. Error & t-Statistic & Prob. \\
\hline ECT(-1) & -0.253578 & 0.104878 & -2.417827 & 0.021 \\
D(LNECP) & 0.374931 & 0.082779 & 4.529315 & 0.0001 \\
D(LNYCP) & 0.216801 & 0.166448 & 1.302519 & 0.2012 \\
$\mathrm{C}$ & 0.031450 & 0.008620 & 3.648487 & 0.0009 \\
\hline $\mathrm{R}^{2}$ & 0.452251 & & Sum squared resid & 0.04517 \\
Adjusted $\mathrm{R}^{2}$ & 0.405302 & & F-statistic & 9.632646 \\
S.E. of regression & 0.035925 & & Prob(F-statistic) & 0.000089 \\
\hline
\end{tabular}

Source: Author's estimation. Note: ECT(-1) is lagged of residuals from Table C.2.

36 The model passes all diagnostic tests (normality, serial correlation, and heteroskedasticity 
Table C.5. VECM Estimates

\begin{tabular}{lrrr}
\hline $\begin{array}{l}\text { Short-run } \\
\text { Estimates }\end{array}$ & & & \\
\hline Error Correction: & D(LNCO2CP) & D(LNECP) & D(LNYCP) \\
\hline CointEq1 & -0.212939 & -0.047260 & -0.081293 \\
& $(0.04869)$ & $(0.08498)$ & $(0.04420)$ \\
& {$[-4.37378]$} & {$[-0.55614]$} & {$[-1.83929]$} \\
& & & \\
D(LNCO2CP(-1)) & 0.045064 & 0.397083 & 0.114930 \\
& $(0.18556)$ & $(0.32388)$ & $(0.16845)$ \\
& {$[0.24286]$} & {$[1.22601]$} & {$[0.68227]$} \\
D(LNECP(-1)) & 0.028818 & -0.319227 & -0.006377 \\
& $(0.11288)$ & $(0.19703)$ & $(0.10248)$ \\
& {$[0.25529]$} & {$[-1.62018]$} & {$[-0.06223]$} \\
D(LNYCP(-1)) & -0.064884 & 0.280332 & 0.246254 \\
& $(0.21950)$ & $(0.38313)$ & $(0.19927)$ \\
& {$[-0.29560]$} & {$[0.73168]$} & {$[1.23579]$} \\
\hline
\end{tabular}

\begin{tabular}{lrrr}
\hline \multicolumn{4}{l}{ Long run coefficient (Cointegrating equation (CointEq1) } \\
\hline LNCO2CP(-1) & LNECP(-1) & LNYCP(-1) & C \\
1.000000 & -0.064256 & -1.179065 & 1.028018 \\
& $(0.35680)$ & $(0.37789)$ & $(0.49308)$ \\
& {$[-0.18009]$} & {$[-3.12014]$} & {$[2.08489]$} \\
\hline
\end{tabular}

Source: Author's estimation Note: sample (adjusted): 1973 2010. Standard errors in ( ) and tstatistics in [] 
Table C.6a. DOLS: Dependent Variable: LNECP

\begin{tabular}{lrrrc}
\hline Variable & Coefficient & \multicolumn{1}{c}{ Std. Error } & \multicolumn{1}{c}{ t-Statistic } & \multicolumn{1}{c}{ Prob. } \\
\hline C & 2.405715 & 0.390858 & 6.154956 & 0.000000 \\
LNCO2CP & 0.628015 & 0.153234 & 4.098397 & 0.000500 \\
LNYCP & -0.052977 & 0.203446 & -0.260401 & 0.797000 \\
D(LNCO2CP) & -0.020073 & 0.195019 & -0.102927 & 0.919000 \\
D(LNCO2CP(-1)) & -0.014191 & 0.168668 & -0.084135 & 0.933700 \\
D(LNCO2CP(-2)) & -0.031098 & 0.182472 & -0.170425 & 0.866200 \\
D(LNCO2CP(1)) & 0.101980 & 0.242244 & 0.420980 & 0.677900 \\
D(LNCO2CP(2)) & 0.073143 & 0.260620 & 0.280651 & 0.781600 \\
D(LNYCP) & 0.213008 & 0.221363 & 0.962256 & 0.346400 \\
D(LNYCP(-1)) & 0.224483 & 0.112815 & 1.989821 & 0.059200 \\
D(LNYCP(-2)) & -0.083195 & 0.190633 & -0.436415 & 0.666800 \\
D(LNYCP(1)) & -0.010232 & 0.110346 & -0.092728 & 0.927000 \\
D(LNYCP(2)) & -0.054710 & 0.107635 & -0.508295 & 0.616300 \\
\hline R $^{2}$ & 0.986905 & & F-statistic & 138.1715 \\
Adjusted R & 0.979763 & & Prob(F-stat) & 0.000000 \\
\hline Source: Author's
\end{tabular}

Source: Author's estimation

Table C.6b. DOLS: Dependent Variable: LNYCP

\begin{tabular}{lrrrc}
\hline Variable & Coefficient & Std. Error & t-Statistic & Prob. \\
\hline C & 0.736960 & 0.729926 & 1.009637 & 0.323600 \\
LNCO2CP & 0.339954 & 0.307771 & 1.104570 & 0.281300 \\
LNECP & 0.543182 & 0.448280 & 1.211701 & 0.238500 \\
D(LNCO2CP) & 0.430340 & 0.424374 & 1.014058 & 0.321600 \\
D(LNCO2CP(-1)) & 0.686992 & 0.446857 & 1.537387 & 0.138500 \\
D(LNCO2CP(-2)) & 0.288925 & 0.329378 & 0.877182 & 0.389900 \\
D(LNCO2CP(1)) & 0.875615 & 0.364071 & 2.405064 & 0.025000 \\
D(LNCO2CP(2)) & 0.924711 & 0.321747 & 2.874030 & 0.008800 \\
D(LNECP) & -0.499881 & 0.319438 & -1.564875 & 0.131900 \\
D(LNECP(-1)) & -0.470964 & 0.298399 & -1.578301 & 0.128800 \\
D(LNECP(-2)) & -0.139007 & 0.201865 & -0.688616 & 0.498300 \\
D(LNECP(1)) & -0.186648 & 0.193648 & -0.963852 & 0.345600 \\
D(LNECP(2)) & -0.236333 & 0.155522 & -1.519609 & 0.142900 \\
\hline R $^{2}$ & 0.987592 & & F-statistic & 145.9220 \\
Adjusted R & 0.980824 & & Prob(F-stat) & 0.000000 \\
\hline Sour & & & &
\end{tabular}

Source: Author's estimation 
Table C.7. DOLS estimation (without energy use)

\begin{tabular}{lccrr}
\hline & \multicolumn{2}{c}{$\begin{array}{c}\text { Dependent Variable: } \\
\text { LNCO2CP }\end{array}$} & \multicolumn{2}{c}{$\begin{array}{c}\text { Dependent Variable: } \\
\text { LNYCP }\end{array}$} \\
\cline { 2 - 5 } Variable & Coefficient & Std. Error & Coefficient & Std. Error \\
\hline LNCO2CP & & & 0.702921 & 0.026794 \\
LNYCP & 1.419081 & 0.044247 & & \\
D(LNCO2CP) & & & -0.120042 & 0.178584 \\
D(LNCO2CP(-1)) & & & 0.083999 & 0.198087 \\
D(LNCO2CP(-2)) & & & 0.033320 & 0.165857 \\
D(LNCO2CP(1)) & & & 0.368303 & 0.129736 \\
D(LNCO2CP(2)) & & & 0.351898 & 0.155573 \\
D(LNYCP) & -0.825987 & 0.146722 & & \\
D(LNYCP(-1)) & -0.725341 & 0.132864 & & \\
D(LNYCP(-2)) & -0.565653 & 0.170011 & & \\
D(LNYCP(1)) & 0.273623 & 0.133415 & & \\
D(LNYCP(2)) & 0.199060 & 0.202879 & & \\
C & -2.339396 & 0.287559 & 1.668240 & 0.1852 \\
\hline R $^{2}$ & 0.989079 & & 0.983007 & \\
Adjusted R & 0.986739 & & 0.979366 & \\
\hline
\end{tabular}

Error correction term and long-run Granger causality

\begin{tabular}{lrrrr}
\hline & \multicolumn{2}{c}{$\begin{array}{c}\text { Dependent Variable: } \\
\text { D(LNCO2CP) }\end{array}$} & \multicolumn{2}{c}{$\begin{array}{c}\text { Dependent Variable: } \\
\text { D(LNYCP) }\end{array}$} \\
\cline { 2 - 5 } Variable & Coefficient & Std. Error & Coefficient & Std. Error \\
\hline C & 0.022777 & 0.011553 & 0.022953 & 0.008619 \\
D(LNCO2CP(-1)) & 0.243703 & 0.164494 & -0.004338 & 0.086125 \\
D(LNCO2CP(-2)) & 0.120785 & 0.087678 & -0.107175 & 0.092144 \\
D(LNYCP(-1)) & 0.039806 & 0.133660 & 0.413820 & 0.150556 \\
D(LNYCP(-2)) & 0.187066 & 0.096042 & 0.133591 & 0.118531 \\
ECT(-1) & -0.368924 & 0.131873 & -0.324250 & 0.257653 \\
\hline R $^{2}$ & 0.250666 & & 0.197433 & \\
Adjusted R & 0.121471 & & 0.059059 & \\
\hline Source: Authyyyyy
\end{tabular}

Source: Author's estimation 
Table C.8. DOLS estimation (without output)

\begin{tabular}{|c|c|c|c|c|}
\hline \multirow[b]{2}{*}{ Variable } & \multicolumn{2}{|c|}{$\begin{array}{c}\text { Dependent Variable: } \\
\text { LNCO2CP }\end{array}$} & \multicolumn{2}{|c|}{$\begin{array}{c}\text { Dependent Variable: } \\
\text { LNECP }\end{array}$} \\
\hline & Coefficient & Std. Error & Coefficient & Std. Error \\
\hline $\mathrm{LNCO} 2 \mathrm{CP}$ & & & 0.721377 & 0.034013 \\
\hline LNECP & 1.112404 & 0.009131 & & \\
\hline $\mathrm{D}(\mathrm{LNCO} 2 \mathrm{CP})$ & & & & \\
\hline $\mathrm{D}(\mathrm{LNCO} 2 \mathrm{CP}(-1))$ & & & 0.003441 & 0.287423 \\
\hline $\mathrm{D}(\mathrm{LNCO} 2 \mathrm{CP}(-2))$ & & & -0.065865 & 0.178829 \\
\hline $\mathrm{D}(\mathrm{LNCO} 2 \mathrm{CP}(1))$ & & & -0.370554 & 0.236548 \\
\hline $\mathrm{D}(\mathrm{LNCO} 2 \mathrm{CP}(2))$ & & & -0.382223 & 0.207391 \\
\hline $\mathrm{D}(\mathrm{LNECP})$ & 1.351536 & 0.279200 & & \\
\hline $\mathrm{D}(\operatorname{LNECP}(-1))$ & -0.33126 & 0.298066 & & \\
\hline $\mathrm{D}(\operatorname{LNECP}(-2))$ & -0.358924 & 0.239348 & & \\
\hline $\mathrm{D}(\operatorname{LNECP}(1))$ & 0.124845 & 0.309333 & & \\
\hline $\mathrm{D}(\operatorname{LNECP}(2))$ & -0.10153 & 0.346472 & & \\
\hline $\mathrm{R}^{2}$ & 0.965645 & & 0.983007 & \\
\hline Adjusted $\mathrm{R}^{2}$ & 0.959722 & & 0.979366 & \\
\hline
\end{tabular}

Source: Author's estimation

Error correction term and long-run Granger causality

\begin{tabular}{lrrrr}
\hline & \multicolumn{2}{c}{$\begin{array}{c}\text { Dependent Variable: } \\
\text { D(LNCO2CP) }\end{array}$} & \multicolumn{2}{c}{$\begin{array}{c}\text { Dependent Variable: } \\
\text { D(LNECP) }\end{array}$} \\
\cline { 2 - 5 } Variable & Coefficient & \multicolumn{1}{c}{ Std. Error } & Coefficient & Std. Error \\
\hline D(LNCO2CP(-1)) & 0.479643 & 0.170685 & 0.028467 & 0.017938 \\
D(LNCO2CP(-2)) & 0.395428 & 0.188688 & 0.221372 & 0.198225 \\
D(LNECP(-1)) & -0.127246 & 0.111857 & -0.021545 & 0.221538 \\
D(LNECP(-2)) & -0.052123 & 0.147050 & -0.028810 & 0.169856 \\
ECT(-1) & -0.071605 & 0.075035 & -0.417095 & 0.198052 \\
\hline R $^{2}$ & 0.250666 & & 0.197433 & \\
Adjusted R & 0.121471 & & 0.059059 & \\
\hline Source: Author's estimation & & &
\end{tabular}


Table C.9. Lag length of Toda-Yamamoto augmented-VAR

\begin{tabular}{lrrrr}
\hline Lag & LR & AIC & SC & HQ \\
\hline 0 & NA & -8.524277 & -8.306586 & -8.447531 \\
1 & 446.6905 & -21.58230 & $-20.27615^{*}$ & -21.12182 \\
2 & 46.84083 & -22.03252 & -19.63791 & -21.18831 \\
3 & $40.70280^{*}$ & $-22.61939^{*}$ & -19.13633 & $-21.39145^{*}$ \\
\hline
\end{tabular}

Source: Author's estimation. Note: Endogenous variables: LNCO2CP, LNYCP, LNECP, LNU, LNK. Exogenous variables: $\mathrm{C}$. * indicates lag order selected by the criterion.

Table C.10. Analysis of variance decomposition (numerical presentation)

\begin{tabular}{|c|c|c|c|c|c|c|}
\hline \multicolumn{2}{|c|}{$\begin{array}{l}\text { Variance } \\
\text { LNCO2CP: }\end{array}$} & \multicolumn{2}{|c|}{ Decomposition } & \multirow[b]{2}{*}{ LNECP } & \multirow[b]{2}{*}{ LNU } & \multirow[b]{2}{*}{ LNK } \\
\hline Period & S.E. & LNCO2CP & LNYCP & & & \\
\hline 1 & 0.032725 & 100.0000 & 0.000000 & 0.000000 & 0.000000 & 0.000000 \\
\hline 2 & 0.036624 & 89.89743 & 0.689134 & 6.881835 & 0.442338 & 2.089265 \\
\hline 3 & 0.040156 & 74.77979 & 0.573820 & 17.03446 & 5.745618 & 1.866313 \\
\hline 4 & 0.044152 & 71.47139 & 0.478967 & 18.50352 & 7.355042 & 2.191075 \\
\hline 5 & 0.049658 & 65.53069 & 4.947136 & 18.50419 & 7.067301 & 3.950678 \\
\hline 6 & 0.054211 & 57.58714 & 13.36376 & 16.68023 & 9.051847 & 3.317016 \\
\hline 7 & 0.061528 & 48.89557 & 21.10415 & 15.20023 & 11.74922 & 3.050824 \\
\hline 8 & 0.070919 & 44.15391 & 26.74514 & 16.70995 & 9.877544 & 2.513464 \\
\hline 9 & 0.077581 & 42.60191 & 28.37937 & 17.59227 & 9.046848 & 2.379594 \\
\hline 10 & 0.084605 & 42.58124 & 27.42638 & 15.75068 & 11.12938 & 3.112319 \\
\hline \multicolumn{7}{|c|}{ Variance Decomposition of LNECP: } \\
\hline Period & S.E. & LNCO2CP & LNYCP & LNECP & LNU & LNK \\
\hline 1 & 0.040066 & 64.08946 & 0.000000 & 35.91054 & 0.000000 & 0.000000 \\
\hline 2 & 0.053076 & 59.42729 & 2.697644 & 34.79542 & 2.674279 & 0.405365 \\
\hline 3 & 0.061032 & 47.27685 & 8.144295 & 26.33455 & 17.21666 & 1.027651 \\
\hline 4 & 0.068044 & 43.26789 & 9.852112 & 27.29378 & 16.14980 & 3.436422 \\
\hline 5 & 0.071621 & 43.56302 & 9.838986 & 26.88570 & 16.40728 & 3.305011 \\
\hline 6 & 0.073884 & 41.31406 & 10.61616 & 29.63355 & 15.26857 & 3.167661 \\
\hline 7 & 0.075873 & 38.57875 & 15.66925 & 25.33132 & 17.26757 & 3.153113 \\
\hline 8 & 0.077140 & 35.65724 & 19.04559 & 29.62800 & 13.20826 & 2.460910 \\
\hline 9 & 0.077576 & 40.21366 & 19.31490 & 25.55639 & 12.60389 & 2.311150 \\
\hline 10 & 0.078548 & 36.22091 & 23.06676 & 21.71330 & 15.86087 & 3.138168 \\
\hline \multicolumn{7}{|c|}{ Variance Decomposition of LNYCP: } \\
\hline Period & S.E. & LNCO2CP & LNYCP & LNECP & LNU & LNK \\
\hline 1 & 0.039950 & 5.130975 & 31.00192 & 63.86711 & 0.000000 & 0.000000 \\
\hline 2 & 0.041562 & 14.70885 & 29.17508 & 55.30094 & 0.573309 & 0.241823 \\
\hline 3 & 0.048297 & 24.56817 & 22.08082 & 48.75188 & 0.433652 & 4.165477 \\
\hline 4 & 0.050717 & 32.57878 & 18.87698 & 41.57754 & 1.694753 & 5.271944 \\
\hline 5 & 0.051716 & 33.61206 & 19.31362 & 37.80370 & 3.565372 & 5.705259 \\
\hline 6 & 0.053914 & 31.76306 & 20.25942 & 36.27781 & 6.038689 & 5.661023 \\
\hline 7 & 0.058490 & 30.12023 & 22.89932 & 34.45063 & 6.858771 & 5.671051 \\
\hline 8 & 0.066888 & 29.56179 & 24.11283 & 33.50684 & 7.308080 & 5.510457 \\
\hline 9 & 0.072046 & 29.30033 & 23.84351 & 34.01596 & 7.352171 & 5.488028 \\
\hline 10 & 0.084696 & 29.03051 & 23.25775 & 34.46849 & 7.887009 & 5.356240 \\
\hline
\end{tabular}

Source: Author's estimation Note: Cholesky Ordering: LNCO2CP LNECP LNYCP LNU LNK 
Table. C.11. Impulse response function (numerical presentation)

\begin{tabular}{|c|c|c|c|c|c|}
\hline \multicolumn{6}{|c|}{ Response of LNCO2CP: } \\
\hline Period & LNCO2CP & LNYCP & LNECP & LNU & LNK \\
\hline \multirow[t]{2}{*}{1} & 0.032725 & 0.000000 & 0.000000 & 0.000000 & 0.000000 \\
\hline & (0.00391) & $(0.00000)$ & $(0.00000)$ & $(0.00000)$ & $(0.00000)$ \\
\hline \multirow[t]{2}{*}{2} & 0.011614 & -0.00962 & -0.003 & -0.00244 & 0.005294 \\
\hline & $(0.00881)$ & $(0.00854)$ & $(0.00729)$ & $(0.00858)$ & $(0.00452)$ \\
\hline \multirow[t]{2}{*}{3} & 0.000121 & 0.011025 & 0.007799 & -0.00931 & 0.001439 \\
\hline & $(0.00773)$ & (0.00906) & $(0.00713)$ & $(0.00804)$ & $(0.00424)$ \\
\hline \multirow[t]{2}{*}{4} & -0.01369 & 0.007444 & 0.005540 & -0.00712 & -0.00355 \\
\hline & $(0.00943)$ & $(0.00961)$ & $(0.00743)$ & $(0.00791)$ & $(0.00439)$ \\
\hline \multirow[t]{2}{*}{5} & -0.01492 & 0.014089 & -0.00312 & 0.005558 & -0.0074 \\
\hline & $(0.01016)$ & (0.01070) & (0.00798) & $(0.00814)$ & $(0.00463)$ \\
\hline \multirow[t]{2}{*}{6} & -0.00874 & 0.004628 & -0.01683 & 0.009578 & -0.00025 \\
\hline & $(0.01115)$ & $(0.01160)$ & $(0.00853)$ & $(0.00885)$ & $(0.00515)$ \\
\hline \multirow[t]{2}{*}{7} & -0.0126 & 0.019096 & -0.01126 & 0.013371 & -0.00424 \\
\hline & $(0.01170)$ & $(0.01235)$ & $(0.00897)$ & $(0.00867)$ & $(0.00550)$ \\
\hline \multirow[t]{2}{*}{8} & -0.01923 & 0.026717 & -0.00987 & 0.007212 & -0.00331 \\
\hline & $(0.01276)$ & $(0.01263)$ & (0.00959) & $(0.01012)$ & $(0.00565)$ \\
\hline \multirow[t]{2}{*}{9} & -0.01853 & 0.023017 & -0.00718 & 0.006908 & -0.0041 \\
\hline & $(0.01344)$ & $(0.01384)$ & $(0.01051)$ & $(0.01180)$ & $(0.00622)$ \\
\hline \multirow[t]{2}{*}{10} & -0.022 & 0.015926 & -0.00837 & 0.015879 & -0.00892 \\
\hline & $(0.01464)$ & $(0.01523)$ & $(0.01090)$ & $(0.01144)$ & $(0.00582)$ \\
\hline \multicolumn{6}{|c|}{ Response of LNECP: } \\
\hline Period & LNCO2CP & LNYCP & LNECP & LNU & LNK \\
\hline \multirow[t]{2}{*}{1} & 0.031982 & 0.019643 & 0.013685 & 0.000000 & 0.000000 \\
\hline & $(0.00557)$ & $(0.00330)$ & $(0.00164)$ & $(0.00000)$ & $(0.00000)$ \\
\hline 2 & -0.00192 & -0.00824 & 0.002580 & -0.0068 & 0.002646 \\
\hline & $(0.01053)$ & (0.01037) & $(0.00890)$ & $(0.01046)$ & $(0.00548)$ \\
\hline 3 & 0.008732 & -0.00983 & 0.007745 & -0.01885 & 0.004119 \\
\hline & $(0.01035)$ & $(0.01118)$ & $(0.00902)$ & $(0.00940)$ & $(0.00532)$ \\
\hline 4 & 0.003183 & 0.003133 & 0.011890 & -0.00372 & -0.00803 \\
\hline & $(0.01158)$ & $(0.01195)$ & $(0.00974)$ & $(0.01065)$ & $(0.00578)$ \\
\hline 5 & -0.00723 & 0.001602 & 0.004919 & -0.00484 & $-6.24 \mathrm{E}-05$ \\
\hline & $(0.01080)$ & $(0.01202)$ & $(0.00864)$ & $(0.00925)$ & $(0.00589)$ \\
\hline 6 & 0.005979 & -0.00593 & -0.01235 & 0.002233 & 0.001918 \\
\hline & $(0.01058)$ & $(0.01185)$ & $(0.00797)$ & $(0.00798)$ & $(0.00555)$ \\
\hline 7 & -0.01091 & 0.006745 & -0.01368 & 0.012121 & -0.00397 \\
\hline & $(0.01053)$ & $(0.01269)$ & $(0.00850)$ & $(0.00819)$ & $(0.00587)$ \\
\hline 8 & -0.0166 & 0.027741 & -0.00234 & 0.000464 & -0.00149 \\
\hline & $(0.01207)$ & $(0.01308)$ & $(0.00850)$ & $(0.00951)$ & $(0.00630)$ \\
\hline 9 & -0.02218 & 0.007811 & -0.00951 & 0.007954 & -0.00314 \\
\hline & $(0.01251)$ & $(0.01447)$ & $(0.01030)$ & $(0.01160)$ & $(0.00705)$ \\
\hline 10 & -0.0226 & 0.027070 & -0.01226 & 0.021990 & -0.01025 \\
\hline & $(0.01440)$ & $(0.01600)$ & $(0.01106)$ & $(0.01187)$ & $(0.00655)$ \\
\hline & & & & & \\
\hline Period & LNCO2CP & LNYCP & LNECP & LNU & LNK \\
\hline 1 & -0.00908 & 0.039025 & 0.000000 & 0.000000 & 0.000000 \\
\hline & $(0.00668)$ & $(0.00466)$ & $(0.00000)$ & $(0.00000)$ & $(0.00000)$ \\
\hline 2 & -0.01822 & 0.029229 & -0.00158 & -0.00402 & -0.00261 \\
\hline & $(0.01173)$ & $(0.01088)$ & $(0.00888)$ & $(0.01047)$ & $(0.00549)$ \\
\hline 3 & -0.02238 & 0.013627 & 0.008545 & $-5.09 \mathrm{E}-05$ & -0.01218 \\
\hline & $(0.01096)$ & $(0.01267)$ & $(0.01017)$ & $(0.01214)$ & $(0.00615)$ \\
\hline 4 & -0.02436 & 0.012671 & $8.14 \mathrm{E}-05$ & 0.007894 & -0.00943 \\
\hline & $(0.01288)$ & (0.01294) & $(0.01014)$ & $(0.01159)$ & $(0.00565)$ \\
\hline 5 & -0.01469 & 0.009261 & -0.00671 & 0.010219 & -0.00697 \\
\hline & $(0.01384)$ & $(0.01347)$ & (0.00989) & $(0.01061)$ & $(0.00620)$ \\
\hline 6 & -0.00312 & 0.000871 & -0.01248 & 0.012114 & -0.00405 \\
\hline & $(0.01361)$ & $(0.01362)$ & $(0.00984)$ & $(0.00965)$ & $(0.00567)$ \\
\hline 7 & -0.00021 & 0.006937 & -0.01293 & 0.008075 & 0.004176 \\
\hline & $(0.01427)$ & (0.01409) & $(0.00928)$ & $(0.00904)$ & $(0.00539)$ \\
\hline 8 & -0.00502 & 0.003498 & -0.01072 & 0.006327 & 0.001199 \\
\hline & $(0.01393)$ & $(0.01357)$ & $(0.00870)$ & $(0.00833)$ & $(0.00557)$ \\
\hline 9 & -0.00205 & -0.00586 & -0.00435 & 0.002753 & -0.00154 \\
\hline & $(0.01316)$ & $(0.01302)$ & $(0.00812)$ & $(0.00769)$ & $(0.00540)$ \\
\hline 10 & 0.005275 & -0.00745 & -0.00492 & 0.006645 & 0.000446 \\
\hline & $(0.01228)$ & $(0.01264)$ & $(0.00776)$ & $(0.00708)$ & $(0.00515)$ \\
\hline
\end{tabular}

Source: Author's estimation. Note: Cholesky Ordering: LNCO2CP LNYCP LNECP LNU LNK. Standard Errors: Analytic 
Table C.12. $\mathrm{CO}_{2}$ emissions (in kilotons $\mathrm{CO}_{2}$ )

\begin{tabular}{|c|c|c|c|c|c|c|c|c|}
\hline \multirow{2}{*}{$\begin{array}{c}\text { Rank } \\
1\end{array}$} & \multicolumn{2}{|c|}{1990} & \multicolumn{2}{|c|}{1995} & \multicolumn{2}{|l|}{2000} & \multicolumn{2}{|l|}{2005} \\
\hline & USA & $4,990,000$ & USA & $5,260,000$ & USA & $5,870,000$ & USA & $5,940,000$ \\
\hline 2 & China & $2,510,000$ & China & $3,520,000$ & China & $3,560,000$ & China & $5,850,000$ \\
\hline 3 & Russian Fed. & $2,440,000$ & Russian Fed. & $1,750,000$ & Russian Fed. & $1,660,000$ & Russian Fed. & $1,720,000$ \\
\hline 4 & Japan & $1,160,000$ & Japan & $1,250,000$ & Japan & $1,280,000$ & Japan & $1,320,000$ \\
\hline 5 & Germany & $1,020,000$ & Germany & 920,000 & India & $1,060,000$ & India & $1,290,000$ \\
\hline 6 & Ukraine & 770,000 & India & 870,000 & Germany & 870,000 & Germany & 850,000 \\
\hline 7 & India & 660,000 & UK & 560,000 & UK & 550,000 & Canada & 570,000 \\
\hline 8 & UK & 590,000 & Canada & 480,000 & Canada & 550,000 & UK & 550,000 \\
\hline 9 & Canada & 450,000 & Ukraine & 450,000 & Italy & 460,000 & South Korea & 500,000 \\
\hline 10 & Italy & 430,000 & Italy & 440,000 & South Korea & 450,000 & Italy & 480,000 \\
\hline 11 & France & 390,000 & South Korea & 400,000 & France & 410,000 & Iran & 450,000 \\
\hline 12 & Poland & 310,000 & France & 390,000 & Mexico & 380,000 & Mexico & 420,000 \\
\hline 13 & Mexico & 310,000 & Mexico & 330,000 & Australia & 360,000 & France & 410,000 \\
\hline 14 & Australia & 270,000 & Poland & 320,000 & Ukraine & 350,000 & Australia & 410,000 \\
\hline 15 & South Africa & 270,000 & Australia & 300,000 & Brazil & 350,000 & Brazil & 370,000 \\
\hline 16 & Kazakhstan & 255,684 & South Africa & 290,000 & Iran & 340,000 & South Africa & 360,000 \\
\hline 17 & South Korea & 250,000 & Iran & 280,000 & South Africa & 310,000 & Spain & 360,000 \\
\hline 18 & Spain & 230,000 & Brazil & 270,000 & Spain & 310,000 & Indonesia & $\underline{360,000}$ \\
\hline 19 & Brazil & 220,000 & Spain & 250,000 & Poland & 290,000 & Ukraine & 340,000 \\
\hline 20 & Iran & 210,000 & Saudi Arabia & 210,000 & Indonesia & 290,000 & Saudi Arabia & 320,000 \\
\hline 21 & Romania & 184,706 & Indonesia & 210,000 & $\overline{\text { Saudi Arabia }}$ & $\overline{260,000}$ & Poland & 310,000 \\
\hline 22 & Saudi Arabia & 170,000 & Kazakhstan & 181,119 & Taiwan & 230,000 & Taiwan & 270,000 \\
\hline 23 & Czech Republic & 167,460 & Turkey & 177,111 & Turkey & 225,794 & Turkey & 246,134 \\
\hline 24 & Netherlands & 160,000 & Netherlands & 170,000 & Netherlands & 170,000 & Kazakhstan & 191,703 \\
\hline \multirow[t]{2}{*}{25} & Indonesia & 160,000 & Taiwan & 170,000 & Argentina & 148,882 & Netherlands & 180,000 \\
\hline & World Total & $22,060,863$ & & $22,957,340$ & & $24,586,832$ & & $28,438,699$ \\
\hline
\end{tabular}

\begin{tabular}{clrlrlr}
\hline Rank & & $\mathbf{2 0 0 9}$ & & \multicolumn{3}{c}{$\mathbf{2 0 1 0}$} \\
\hline 1 & China & $8,270,000$ & China & $8,900,000$ & China & $9,700,000$ \\
2 & USA & $5,330,000$ & USA & $5,530,000$ & USA & $5,420,000$ \\
3 & India & $1,750,000$ & India & $1,860,000$ & India & $1,970,000$ \\
4 & Russian Fed. & $1,740,000$ & Russian Fed. & $1,780,000$ & Russian Fed. & $1,830,000$ \\
5 & Japan & $1,180,000$ & Japan & $1,260,000$ & Japan & $1,240,000$ \\
6 & Germany & 800,000 & Germany & 840,000 & Germany & 810,000 \\
7 & South Korea & 540,000 & South Korea & 590,000 & South Korea & 610,000 \\
8 & Canada & 530,000 & Canada & 540,000 & Canada & 560,000 \\
9 & UK & 490,000 & UK & 500,000 & Indonesia & $\underline{\mathbf{4 9 0 , 0 0 0}}$ \\
10 & Mexico & 440,000 & Indonesia & $\mathbf{4 9 0 , 0 0 0}$ & UK & 470,000 \\
11 & Australia & 440,000 & Mexico & 440,000 & Saudi Arabia & 460,000 \\
12 & Indonesia & $\mathbf{4 4 0 , 0 0 0}$ & Brazil & 440,000 & Mexico & 450,000 \\
13 & Italy & 410,000 & Saudi Arabia & 430,000 & Brazil & 450,000 \\
14 & Saudi Arabia & 400,000 & Italy & 420,000 & Australia & 430,000 \\
15 & Brazil & 390,000 & Australia & 400,000 & Italy & 410,000 \\
16 & France & 380,000 & Iran & 400,000 & Iran & 410,000 \\
17 & Iran & 380,000 & France & 380,000 & France & 360,000 \\
18 & South Africa & 350,000 & South Africa & 360,000 & South Africa & 360,000 \\
19 & Poland & 310,000 & Poland & 340,000 & Poland & 350,000 \\
20 & Spain & 300,000 & Ukraine & 300,000 & Ukraine & 320,000 \\
21 & Ukraine & 280,000 & Spain & 290,000 & Spain & 300,000 \\
22 & Taiwan & 260,000 & Taiwan & 270,000 & Turkey & 278,866 \\
23 & Turkey & 255,869 & Turkey & 264,492 & Taiwan & 270,000 \\
24 & Kazakhstan & 204,601 & Kazakhstan & 211,496 & Kazakhstan & 222,991 \\
25 & Egypt & 190,836 & Egypt & 204,467 & Egypt & 208,865 \\
\hline & World Total & $30,728,861$ & & $32,377,875$ & & $33,376,327$ \\
\hline & & & &
\end{tabular}

Source: European Commission, Emission Database for Global Atmospheric Research (EDGAR), release version 4.2. Accessible at: http://edgar.jrc.ec.europa.eu/overview.php?v=CO2ts19902011\&sort=des2. Note: $\mathrm{CO}_{2}$ emissions are based on fossil fuel consumption and cement production. Emissions from land use, land use change, and forestry are not included. 


\section{Bibliography}

Akbostanci, E., S. Turut-Asik, and G.I. Tunc (2009). The relationship between income and environment in Turkey: Is there an environmental Kuznets curve? Energy Policy, 37 (3) (2009), pp. 861-867.

Albert, J.R., and A.P. Ramos (2010). Examining recent trends in poverty, inequality, and vulnerability. PIDS Policy Notes, 2010 (03).

Alcantara, V., and J. A. Duro (2004). Inequality of energy intensities across OECD countries: a Note. Energy Policy 32 (11) (July): 1257-1260.

Ang, B.W. (2005). The LMDI approach to decomposition analysis: a practical guide, Energy Policy 32:1131-1139.

Badan Pusat Statistik (BPS) (2010). Census 2010. Indonesian Central Bureau of Statistics, 2010.

Baek, J.Y., S. Cho, and W.W. Koo (2008). The environmental consequences of globalization: a country-specific time series analysis. Agribusiness and Applied Economics Report No. 631, June 2008.

Baiocchi, G., J. Minx, and K. Hubacek (2010). The impact of social factors and consumer behavior on carbon dioxide emissions in the United Kingdom. Journal of Industrial Ecology, 14 (1): 50-72.

Banerjee, A.V., and E. Duflo (2008). What is middle class about the middle classes around the world? The Journal of Economic Perspectives: a Journal of the American Economic Association, 22(2): 3.

Bernard, J-T., M. Gavin, L. Khalaf, and M. Voia (2011). The Environmental Kuznets Curve: tipping points, uncertainty and weak identification. CREATE Working paper, December 2011.

Bin, S., and H. Dowlatabadi (2005). Consumer lifestyle approach to US energy use and the related $\mathrm{CO}_{2}$ emissions. Energy Policy, 33(2): 197-208.

Blinder, A.S. (2009). Wage discrimination: Reduced form and structural estimates. Journal of Human Resource, VIII 4.

Boyce, J.K. (1994). Inequality as a cause of environmental degradation. Ecological Economics, 11 (1994): 169-178

Cameron, A.C., and P.K. Trivedi (2010). Microeconometrics using Stata, Revised Edition. Stata Press. 
Cantore, N., and E. Padilla (2010). Equality and $\mathrm{CO}_{2}$ emissions distribution in climate change integrated assessment modelling. Energy, 35 (1) (January): 298313.

Carbon Dioxide Information Analysis Center (CDIAC) (2012). Ranking of the world's countries by 2009 per capita fossil fuel $\mathrm{CO}_{2}$ emission rates. Available at http://cdiac.ornl.gov/trends/emis/top2009.cap.

Carbon Dioxide Information Analysis Center (CDIAC) (2013). Global carbon project, full global carbon budget (1959-2011). Available at http://cdiac.ornl.gov/trends/emis/meth_reg.html

Choi, E., A. Heshmati, Y. Cho (2010). An empirical study of the relationships between $\mathrm{CO}_{2}$ emissions, economic growth and openness. IZA Discussion Paper, No. 5304, November 2010.

Clarke-Sather, A., J. Qu, Q. Wang, J. Zeng, and Y. Li (2011). Carbon Inequality at the Sub-national Scale: A Case Study of Provincial-level Inequality in CO2 Emissions in China 1997-2007. Energy Policy, 39 (9) (September): 5420-5428.

Coondoo, D., and S. Dinda (2002). Causality between income and emission: a country group-specific econometric analysis. Ecological Economics, 40 (2002) 351367.

Deaton, A. (1997). The analysis of household surveys: a microeconometric approach to development policy, World Bank Publications.

Deaton, A. and J. Muellbauer (1980). Economics and Consumer Behavior, Cambridge University Press.

Dickey, D.A., and W.A. Fuller (1979). Distribution of the estimators for autoregressive time series with a unit root. Journal of the American Statistical Association, 74 (366a) (1979): 427-431.

Dinda, S., and D. Coondoo (2006). Income and emission: A panel data-based cointegration analysis. Ecological Economics, 57 (2006): 167- 181.

Druckman, A., and T. Jackson (2009). The carbon footprint of UK households 1990-2004: a socio-economically disaggregated, quasi-multi-regional inputoutput model. Ecological Economics, 68 (7) (May 15): 2066-2077.

Duro, J.A. (2012). On the automatic application of inequality indexes in the analysis of the international distribution of environmental indicators. Ecological Economics, 76 (April): 1-7. 
Duro, J.A., and E. Padilla (2006). International inequalities in per capita $\mathrm{CO}_{2}$ emissions: a decomposition methodology by Kaya Factors.” Energy Economics, 28 (2) (March): 170-187.

Duro, J.A., and J. Teixidó-Figueras (2013). Ecological footprint inequality across countries: the role of environment intensity, income and interaction effects. Ecological Economics, 93 (September): 34-41.

EDGAR (2011). Emission Database for Global Atmospheric Research (EDGAR), release version 4.2. http://edgar.jrc.ec.europa.eu/overview.php?v=CO2ts1990$2011 \&$ sort $=$ des 2

Enders, W. (2009). Applied econometric time series, $3^{\text {rd }}$ edition. United Kingdom, Wiley.

Engle, R.F., and C.W.J. Granger (1987). Cointegration and error correction: representation, estimation, and testing, Econometrica, 55: 251276.

Estudillo, J. P. (1997). Income inequality in the Philippines, 1961-91. The Developing Economies, 35 (1): 68-95.

Galeotti, M., M. Manera, and A. Lanza. (2009). On the robustness of robustness checks of the Environmental Kuznets Curve hypothesis. Environmental and Resource Economics 42 (4) (April 1): 551-574.

Geweke, J. (1984). Inference and causality in economic time series models. In: Z. Griliches and M. D. Intriligator (eds.) Handbook of Econometrics. Elsevier Science Publishers, Amsterdam, 1101-1144.

Girod, B., and P. de Haan (2009). GHG reduction potential of changes in consumption patterns and higher quality levels: Evidence from Swiss household consumption survey. Energy Policy, 37 (12), 5650-5661.

Golley, J., and X. Meng (2012). Income inequality and carbon dioxide emissions: The Case of Chinese Urban Households. Energy Economics, 34 (6) (November): 1864-1872.

Granger, C.W.J. (1969). Investigating causal relations by econometric models and cross-spectral methods. Econometrica, 37: 424-438.

Granger, C.W.J. (1986). Developments in the study of cointegrated economic variables, Oxford Bulletin of Economics and Statistics, 48: 213-228.

Granger, C.W.J. (1988). Some recent developments in a concept of causality. Journal of Econometrics, 39 (1-2): 199-211. 
Groot, L. (2010). Carbon Lorenz Curves. Resource and Energy Economics, 32 (1) (January): 45-64.

Grossman, G.M., and A.B. Krueger (1995). Economic growth and the environment. The Quarterly Journal of Economics, 110 (2) (May, 1995): 353377.

Grunewald, N. (2013). Growth, carbon dioxide emissions, climate and wellbeing. Dissertation at Wirtschaftswissenschaftlichen Fakultät, University of Göttingen.

Hedenus, F., and C. Azar (2005). Estimates of trends in global income and resource inequalities. Ecological Economics, 55 (3) (November 15): 351-364.

Heerink, N., A. Mulato, and E. Bulte (2001). Income inequality and the environment: aggregation bias in environmental Kuznets curves, Ecological Economics, 38: 359-367.

Heil, M.T., and Q.T. Wodon (1997). Inequality in $\mathrm{CO}_{2}$ emissions between poor and rich countries. The Journal of Environment and Development, 6 (4) (December 1): 426-452.

Heil, M. T., and Q.T. Wodon (1999). Future inequality in carbon dioxide emissions and the projected impact of abatement proposals. World Bank Publications, 1999: 2084.

Hendry, D.F. (1986). Econometric modeling with cointegrated variables: an overview. Oxford Bulletin of Economics and Statistics, 48: 201-212.

Hertwich, E.G., and G.P. Peters (2009). Carbon footprint of nations: a global, trade-linked analysis. Environmental Science and Technology, 43(16): 64146420 .

Hossain, S.M. (2011). Panel estimation for $\mathrm{CO}_{2}$ emissions, energy consumption, economic growth, trade openness and urbanisation of newly industrialized countries. Energy Policy, 39 (2011): 6991-6999.

Huff, K., R. McDougall, and T. Walmsley (2000). Contributing input-output tables to the GTAP data base. GTAP Technical Paper, 1 (4.2), January 2000.

Jalil, A. and M. Feridun (2010). The impact of growth, energy and financial development on the environment in China: A cointegration analysis. Energy Economics, 33 (2010): 284-291.

International Energy Agency (IEA) (2013). $\mathrm{CO}_{2}$ Emissions from Fuel Combustion. http://www.iea.org/publications/freepublications/publication/co2emissionsfromfuelco mbustionhighlights2013.pdf 
Jalil, A. and S. F. Mahmud (2009). Environment Kuznets Curve for $\mathrm{CO}_{2}$ emissions: A cointegration analysis for China. Energy Policy, 37 (2009) 51675172 .

Jann, B. (2008). The Blinder-Oaxaca decomposition for linear regression models. The Stata Journal, 8(4): 453-479

Johansen, S. and K. Juselius (1990). Maximum likelihood estimation and inference on cointegration - with applications to the demand for money. Oxford Bulletin of Economics and Statistics, 52(2) (May 1990): 169-210.

Johansen, S., and K. Juselius (1992). Testing structural hypotheses in a multivariate cointegration analysis of the PPP and the UIP for UK. Journal of Econometrics, 53(1-3) (July-September 1992): 211-244.

Kakwani, N.C., A. Wagstaff, and E. van Doorslaer (1997). Socioeconomic inequalities in health: measurement, computation and statistical inference. Journal of Econometrics, 77(1): 87-104.

Kaya, Y. (1990). Impact of carbon dioxide emission control on GNP growth: Interpretation of proposed scenarios. IPCC Energy and Industry SubgroupResponse Strategies Working Group, 1990.

Kenny, T., and N.F. Gray (2009). A preliminary survey of household and personal carbon dioxide emissions in Ireland. Environment InterTotal expenditure, 35: 259-272.

Kerkhof, N.S., and H. Moll (2009). Relating the environmental impact of consumption to household expenditures: An input-output analysis. Ecological Economics, 68(4): 1160-1170.

Kok, R., R.M.J. Benders, and H.C. Moll (2006). Measuring the environmental load of household consumption using some methods based on input-output energy analysis: A comparison of methods and a discussion of results. Energy Policy, 34(17): 2744-2761.

Kraft, J., and A. Kraft (1978). Note and comments: on the relationship between energy and GNP. The Journal of Energy and Development, 3: 401-403.

Lee, H-L. (2008). An emissions database for integrated assessment of climate change policy using GTAP. Center for Global Trade Analysis, 2008.

Lenzen, M. (1998a). Energy and greenhouse gas cost of living for Australia during 1993/94. Energy, 23(6) (June): 497-516. 
Lenzen, M. (1998b). Primary energy and greenhouse gases embodied in Australian final consumption: an input-output analysis. Energy Policy, 26(6): 495-506.

Lenzen, M., L.-L. Pade, and J. Munksgaard (2004). $\mathrm{CO}_{2}$ multipliers in multiregion Input-Output models. Economic Systems Research, 16: 391-412.

Lenzen, M., M. Wier, C. Cohen, H. Hayami, S. Pachauri, and R. Schaeffer (2006). A comparative multivariate analysis of household energy requirements in Australia, Brazil, Denmark, India and Japan. Energy, 31 (2-3) (February): 181207.

Leontief, W. (1970). Environmental repercussions and the economic structure: An Input-Output approach. The Review of Economics and Statistics, 52(3): 262-271.

Lerman, R. I., and S. Yitzhaki (1985). Income inequality effects by income source: A new approach and applications to the United States. The Review of Economics and Statistics, 67 (1) (February 1): 151-156.

Levy, A., K. Chowdhury, and J. Livermore (2009). International emission inequality: abatement on a per capita basis with rewards. Department of Economics, University of Wollongong Working Paper, (2009): 09-15, 20p.

Li, J., and Y. Wang (2010). Income, lifestyle and household carbon footprints (carbon-income relationship), a micro-level analysis on China's urban and rural household surveys, Environmental Economics, 1 (2010): Issue 2.

Lopez-Feldman, A. (2006). Decomposing inequality and obtaining marginal effects. The Stata Journal, 6 (1): 106-111.

Martinez-Zarzoso, I., and A. Bengochea-Morancho (2004). Pooled mean group estimation of an environmental Kuznets curve for $\mathrm{CO}_{2}$. Economics Letters, 82(1) (January): 121-126.

Martinez-Zarzoso, I., and A. Maruotti (2011). The impact of urbanization on $\mathrm{CO}_{2}$ emissions: Evidence from developing countries. Ecological Economics, 70(7) (May): 1344-1353.

Masih, R., and A.M.M. Masih (1996). Stock-Watson dynamic OLS (DOLS) and error-correction modeling approaches to estimating long- and short-run elasticities in a demand function: new evidence and methodological implications from an application to the demand for coal in Mainland China. Energy Economics, 18 (1996): 315-334.

Ministry of Energy and Mineral Resources (2012). Media Komunikasi Kementrian Energi and Sumber Daya Mineral (Indonesian Ministry of Energy and Mineral Resources). ESDMMag, 2012(1). 
Ministry of Finance (2013). Data Pokok APBN 2007-2013, Kementerian Keuangan Republik Indonesia, 2013.

Ministry of National Planning (Bappenas) (2011). Master plan for acceleration and expansion of Indonesia's economic development (MP3EI).

Minx, J.C., T. Wiedmann, R. Wood, G.P. Peters, M. Lenzen, A. Owen, K. Scott, J. Barrett, K. Hubacek, G. Baiocchi, A. Paul, E. Dawkins, J. Briggs, D. Guan, S. Suh, and F. Ackerman. (2009). Input-output analysis and carbon footprinting: an overview of applications. Economic Systems Research, 21(3) (September): 187216.

Mishra, S.C. (2009). Economic inequality in Indonesia: trend causes and policy responses. Strategic Asia, March 2009.

Murthy, N., M. Panda, and J. Parikh (1997). Economic development, poverty reduction and carbon emissions in India. Energy Economics, 19(3): 327-354.

Myers, N., and J. Kent, J. (2003). New consumers: The influence of affluence on the environment. Proc. Natl. Acad. Sciences USA ,100 (8): 4963-4968.

Narayan, P. K., I. Nielsen, and R. Smyth (2008). Panel data, cointegration, causality and Wagner's law: Empirical evidence from Chinese provinces. China Economic Review, 19(2): 297-307.

Nasir, M., and F.U. Rehman (2011). Environmental Kuznets Curve for carbon emissions in Pakistan: An empirical investigation. Energy Policy, 39 (2011): 1857-1864.

Newey, W.K. and K.D. West (1987). A simple, positive semi-definite hcteroscedasticity and autocorrelation consistent covariance matrix. Econometrica, 55: 703-708.

Oaxaca, R. (1973). Male-female wage differentials in urban labor markets. International Economic Review, 14(3) (October 1973): 693-709.

Pachauri, S. (2004). An analysis of cross-sectional variations in total household energy requirements in India using micro survey data. Energy Policy, 32 (2004): $1723-1735$.

Pachauri, S., and D. Spreng (2002). Direct and indirect energy requirements of households in India. Energy policy, 30(6): 511-523.

Pachauri, S., and L. Jiang (2008). The household energy transition in India and China. Energy Policy, 36 (2008): 4022-4035. 
Padilla, E., and A. Serrano (2006). Inequality in $\mathrm{CO}_{2}$ emissions across countries and its relationship with income inequality: A distributive approach. Energy Policy, 34(14) (September): 1762-1772.

Padilla, E., and J.A. Duro. (2013). Explanatory factors of $\mathrm{CO}_{2}$ per capita emission inequality in the European Union. Energy Policy, 62 (November 2013): 13201328

Pao H-T., and C-M. Tsai (2010). $\mathrm{CO}_{2}$ emissions, energy consumption and economic growth in BRIC countries. Energy Policy, 38: 7850-7860.

Parikh, J., M. Panda, and N. S. Murthy. (1997). Consumption patterns by income groups and carbon dioxide implications for India: 1990-2010. International Journal of Global Energy, 9 (4-6): 237-255.

PEACE (2007). Indonesia and Climate Charge: Current Status and Policies. http://siteresources.worldbank.org/INTINDONESIA/Resources/Environment/Cli mateChange_Full_EN.pdf

Peters, G.P., J.C. Minx, C.L. Weber, and O. Edenhofer (2011). Growth in emission transfers via international trade from 1990 to 2008. Proceedings of the National Academy of Sciences, 108: 8903-8908.

Phillips, P.C.B., and P. Perron, 1988, Testing for a unit root in time series regression. Biometrika, 75 (2): 335-346.

Ravallion, M., and S. Chen (2003). Measuring pro-poor growth. Economics Letters, 78(1) (January): 93-99.

Ray, D. (1998). Development Economics. Princeton, NJ: Princeton University Press.

Rees, W. E. (1992). Ecological footprints and appropriated carrying capacity: What urban economics leaves out. Environment and Urbanization, 4(2) (October 1): 121-130.

Saboori, B. and A. Soleymani (2011). Environmental Kuznets curve in Indonesia, the role of energy consumption and foreign trade. MPRA Paper, (June 2011): 31534.

Saboori, B., J.B. Sulaiman, and M. Saidatulakmal (2012). An empirical analysis of the Environmental Kuznets Curve for $\mathrm{CO}_{2}$ emissions in Indonesia: the role of energy consumption and foreign trade. International Journal of Economics and Finance, 4(2), February 2012.

Saikkonen, P. (1991). Asymptotically efficient estimation of cointegrating regressions, Econometrica Theory, 7: 1-21. 
Schäfer, A. (2005). Structural change in energy use. Energy Policy, 33 (2005): 429-437.

Selden, T. M., and D. Song (1994). Environmental quality and development: is there a Kuznets curve for air pollution emissions? Journal of Environmental Economics and Management, 27 (1994): 147-162.

Shafik, N. (1994). Economic development and environmental quality: an econometric analysis. Oxford Economic Papers, 46 (October 1994): 757-773.

Shahbaz, M., Q.M.A. Hye, and A.K. Tiwari (2013). Economic growth, energy consumption, financial development, international trade and $\mathrm{CO}_{2}$ emissions in Indonesia. MPRA Paper, 43272.

Soytas, U., R. Sari, and B.T. Ewing (2007). Energy consumption, income, and carbon emissions in the United States. Ecological Economics, 62 (2007): 482-489.

Stark, O., J. E. Taylor, and S. Yitzhaki (1986). Remittances and inequality. Economic Journal, 96: 722-740.

Stern, D. I. (2004). The rise and fall of the Environmental Kuznets Curve. World Development, 32 (8) (August): 1419-1439.

Stock, J. H., and M. Watson (1988). Testing for common trends. Journal of the American Statistical Association, 83: 1097-1107.

Stock, J. H., and M. Watson (1993). A simple estimator of cointegrating vectors in higher order integrated systems. Econometrica, 61: 783-820.

Suh, S. 2009. Handbook of Input-Output economics in industrial Ecology. Springer. USA.

Thomas, R.L. (1993). Introductory Econometrics: Theory and Applications, Longman, London.

Tiwari, A.K. (2011). Energy consumption, $\mathrm{CO}_{2}$ emission, and economic growth: evidence from India. Journal of International Business and Economy, 12(1) (2011): 85-122.

Toda, H.Y., and T. Yamamoto (1995). Statistical inference in vector autoregressions with possibly integrated processes). Journal of Econometrics 66 (1995): 225-250.

Torras, M., and J.K. Boyce (1998). Income, inequality, and pollution: a reassessment of the environmental Kuznets Curve. Ecological Economics, 25 (1998): 147-160. 
Tukker, A., and B. Jansen (2006). Environment impacts of products - a detailed review of studies. Journal of Industrial Ecology, 10: 159-182

U.S. Energy Information Administration (EIA) (2012). International Energy Outlook, 2011.

UNFCCC (2010). United Nations Framework Convention on Climate Change, available at http://unfccc.int/2860.php.

Wackernagel, M., and W.E. Rees (1996). Our Ecological Footprint. Reducing Human Impact on Earth. New Society Press.

Weber, C. L. and H.S. Matthews (2008). Quantifying the global and distributional aspects of American household carbon footprint. Ecological Economics, 66(2-3): 379-391.

Weidema, B. P., M. Thrane, P. Christensen, J. Schmidt, and S. Løkke (2008). Carbon Footprint. Journal of Industrial Ecology, 12 (1): 3-6.

Wiedmann, T., and J. Minx (2007). A definition of carbon footprint. Ecological Economics Research Trends, 1: 1-11.

Wier, M., M. Lenzen, J. Munksgaard, and S. Smed (2001). Effects of household consumption patterns on $\mathrm{CO}_{2}$ requirements. Economic Systems Research, 13: 259-274.

World Bank (2013). CO $\mathrm{CO}_{2}$ Emissions (metric Tons Per Capita). Available at http://data.worldbank.org/indicator/EN.ATM.CO2E.PC

Yusuf, A.A. (2006). On the re-assessment of inequality in Indonesia: household survey or national account? MPRA Paper, No 1728, February 2007.

Zaman, K. (2010). Trade liberalisation, financial development and economic growth: evidence from Pakistan (1980-2009). Journal of International Academic Research, 10 (2010): No.2.

Zhang, X-P., and X-M. Cheng (2009). Energy consumption, carbon emissions, and economic growth in China. Ecological Economics, 68 (2009): 2706-2712. 